\title{
Early Detection and Establishment Assessment of Aquatic Invasive Species
}

Robinson, Chloe V.

How to cite:

Robinson, Chloe V. (2018) Early Detection and Establishment Assessment of Aquatic Invasive Species. Doctoral thesis, Swansea University.

http://cronfa.swan.ac.uk/Record/cronfa47968

Use policy:

This item is brought to you by Swansea University. Any person downloading material is agreeing to abide by the terms of the repository licence: copies of full text items may be used or reproduced in any format or medium, without prior permission for personal research or study, educational or non-commercial purposes only. The copyright for any work remains with the original author unless otherwise specified. The full-text must not be sold in any format or medium without the formal permission of the copyright holder. Permission for multiple reproductions should be obtained from the original author.

Authors are personally responsible for adhering to copyright and publisher restrictions when uploading content to the repository.

Please link to the metadata record in the Swansea University repository, Cronfa (link given in the citation reference above.)

http://www.swansea.ac.uk/library/researchsupport/ris-support/ 


\title{
Early Detection and Establishment Assessment of Aquatic Invasive Species
}

\author{
Submitted by
}

Chloe Victoria Robinson

To Swansea University as a thesis for the degree of Doctor of Philosophy in Biological Sciences, September 2018

(Chloe V Robinson) 


\begin{abstract}
Aquatic invasive species are drivers of ecological change through directly competing with native counterparts, causing alterations in community structure and acting as vectors for the introduction of novel pathogens. A combination of human-mediated introductions and accidental releases from aquaculture facilities has enabled highly invasive species, including the American signal crayfish (Pacifastacus leniusculus), Chinese mitten crab (Eriocheir sinensis) and topmouth gudgeon (Pseudorasbora parva) to become established in Great Britain. I assessed the factors which could have facilitated their establishment success and dispersal, including genetic diversity. Novel tools such as environmental DNA and citizen science have been proven effective for detecting and monitoring aquatic invasive species. Yet, the motivation for participation and continued data collection in citizen science initiatives are not clear. I have determined that multiple introductions from different source populations are likely to have contributed to the invasion success of signal crayfish in Great Britain. Secondly, I have developed and employed a quantitative PCR environmental DNA multiplex which has enabled simultaneous detection of non-native pathogens (crayfish plague) alongside native and invasive crayfish species, providing information on the coexistence of native and invasive crayfish in absence of crayfish plague. Application of this assay in water and sediment samples has also highlighted the relative impacts of river barriers on mitten crab and signal crayfish dispersal and demonstrated that similar DNA results can be achieved by utilising both types of samples. I also developed a species-specific DNA assay for topmouth gudgeon which detected its presence despite lack of visual confirmation, emphasising the greater sensitivity of environmental DNA tools. Finally, I designed and launched a citizen science initiative in an attempt to assess distribution and pathogen status of signal crayfish, which highlighted the complexity of ensuring participation for successful invasive species initiatives.
\end{abstract}




\section{Declarations and Statements}

I, Chloe Victoria Robinson, certify that this work has not previously been accepted in substance for any degree and is not being concurrently submitted in candidature for any degree.

Signed

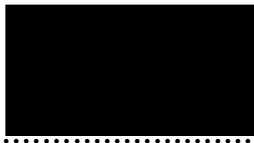

(candidate)

Date

$$
27.11 .2018
$$

This thesis is the result of my own investigations, except where otherwise stated. Other sources are acknowledged by footnotes giving explicit references. A bibliography is appended.

Signed

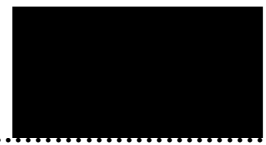
(candidate)

$$
27.11 .2018
$$

Date

I hereby give consent for my thesis, if accepted, to be available for photocopying and for inter-library loan, and for the title and summary to be made available to outside organisations.

Signed

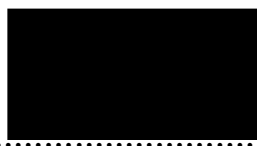
(candidate)

$$
27.11 .2018
$$

Date 
The following people and institutions contributed to the publication of work undertaken as part of this thesis:

\begin{tabular}{|c|c|}
\hline Candidate & Chloe Victoria Robinson (Biosciences) \\
\hline Author 1 & $\begin{array}{l}\text { Carlos Garcia de Leaniz (Swansea } \\
\text { University) }\end{array}$ \\
\hline Author 2 & $\begin{array}{l}\text { Tamsyn Uren Webster (Swansea } \\
\text { University) }\end{array}$ \\
\hline Author 3 & Joanne Cable (Cardiff University) \\
\hline Author 4 & Joanna James (Environment Agency) \\
\hline Author 5 & $\begin{array}{l}\text { Pablo Orozco-terWengel (Cardiff } \\
\text { University) }\end{array}$ \\
\hline Author 6 & Matteo Rolla (Swansea University) \\
\hline Author 7 & Sofia Consuegra (Swansea University) \\
\hline
\end{tabular}

\section{Author details and their roles:}

Paper 1: Genetic diversity and parasite-mediated facilitation of establishment in invasive North American signal crayfish (Pacifastacus leniusculus)

Located in Chapter 1

Candidate contributed to project design, performed genetic analyses and wrote the paper.

Author 1 contributed statistical analyses

Author 3 contributed samples and information

Author 4 contributed samples and information

Author 5 contributed advice for genetic analyses

Author 7 contributed help to design study, advised on genetic analyses and assisted in writing the paper with candidate and author 1 
Paper 2: Simultaneous detection of invasive signal crayfish, endangered white-clawed crayfish and the crayfish plague pathogen using environmental DNA

Located in Chapter 2

Candidate contributed to project design, performed genetic analyses and wrote the paper.

Author 2 contributed to genetic analyses

Author 3 contributed samples and information

Author 4 contributed samples and information

Author 7 contributed help to design study and assisted in writing the paper with candidate and authors 2,3 and 4

Paper 3: Development of a novel eDNA-HRM assay for monitoring the eradication of the highly invasive topmouth gudgeon (Pseudorasbora parva)

Located in Chapter 4

Candidate contributed to project design, performed genetic analyses and wrote the paper.

Author 1 contributed statistical analyses

Author 6 contributed sample collection and advised on the manuscript

Author 7 contributed help to design the study and assisted in writing the paper with candidate and author 1

We the undersigned agree with the above stated "proportion of work undertaken" for each of the above published peer-reviewed manuscripts contributing to this thesis:

Signed Candidate

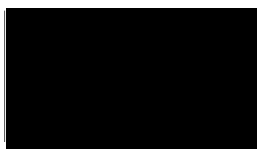

Author 1 
Author 2

Author 3

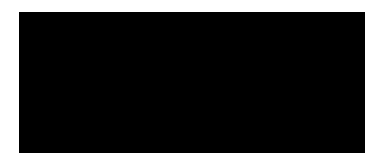

Author 4

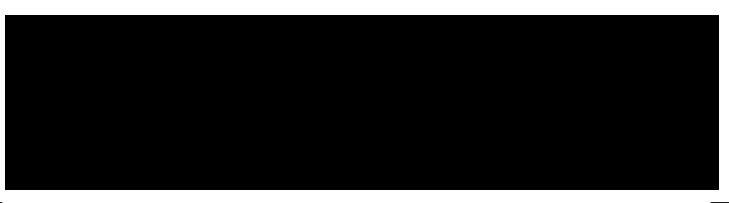

Author 5

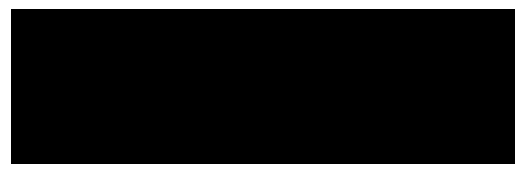

Author 6

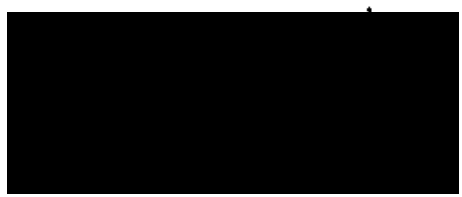

Author 7

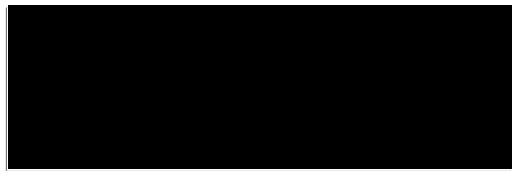




\section{Table of Contents}

Title Page

Abstract

Statements and Declarations $\quad$ iii

Table of Contents vii

Acknowledgements $\quad$ ix

List of Figures and Tables $\quad$ xi

List of Abbreviations xxii

GENERAL INTRODUCTION 1

1.1 Introduction and establishment of aquatic invasive species 2

1.2 Study species 3

1.3 River connectivity and invasive species dispersal 7

1.4 Detection and monitoring techniques for aquatic invasive species 8

1.4.1 Traditional methods of monitoring 9

1.4.2 Application of eDNA for AIS detection 9

1.4.2.1 Metabarcoding versus single-species detection $\quad 10$

1.4.2.2 High-resolution melt curve analysis 11

1.5 Public engagement and citizen science for invasive species research 12

1.6 Aims and objectives of this $\mathrm{PhD} \quad 13$

CHAPTER 1: 16

Genetic diversity and parasite-mediated facilitation of establishment in invasive North American signal crayfish (Pacifastacus leniusculus)

CHAPTER 2:

Simultaneous detection of invasive signal crayfish, endangered whiteclawed crayfish and the crayfish plague pathogen using environmental DNA.

CHAPTER 3:

Effect of artificial barriers on the distribution of the invasive signal crayfish and Chinese mitten crab.

CHAPTER 4:

Development of a novel eDNA assay for monitoring the eradication of the highly invasive topmouth gudgeon (Pseudorasbora parva). 
When citizen science projects fail: lack of engagement with novel invasive species citizen science initiative

$\begin{array}{lr}\text { GENERAL DISCUSSION } & 120\end{array}$

22. CONCLUSIONS

23. SUPPORTING INFORMATION 126

24. ETHICS STATEMENTS AND PERMITS 200

25. GLOSSARY 207

26. REFERENCES 210 


\section{Acknowledgements}

For a $\mathrm{PhD}$ to be a success,

There are multiple factors to address.

For a $\mathrm{PhD}$ cannot be done alone,

Many hands make light work it has been shown.

Kind people have made this thesis a thing,

With data, knowledge and samples they bring.

Provide me with hope and help ease my way,

And to you all a huge thank you I say.

Collecting eDNA has been key,

In making data for my $\mathrm{PhD}$.

I thank Stephen and Louis for their time,

With Wye sampling, despite lack of sunshine.

Haydn and Emma I also do thank,

For helping me trap by the riverbank.

Thank you Peter and Ben for your hard work,

Hours spent in rivers doing fieldwork.

To Derek and Tony I thank you too,

For help getting samples of great value.

Guillermo, thank you for help overseas,

Crayfish tail clips arrived here with ease.

Providing DNA for lab trials,

I thank Jennifer for many vials.

Oliver, Adam and Stephanie too,

For sending tissue, I really thank you.

Thank you Lyn Byrne and Mark for sending me,

Crab samples and water from River Dee.

To Chris and Gereint I appreciate,

Sending fish to me by a certain date.

Tristan, thank you for knowledge of the Dee,

And Kathy for help with my species plea.

I thank Kerry and Emma from EA,

For information needed for field day.

I thank the NRN-LCEE,

For providing money through Sêr Cymru.

For the contribution, I thank HEFCW,

For investing in this $\mathrm{PhD}$ too.

It is time to thank my lab partners in crime, For your help and friendship throughout this climb.

You are all special and I wish you well,

I can say to most this isn't farewell.

A special thanks to Tamsyn, you are great, You have been my lab rock and a good mate.

Thank you for advice and guiding my way, 
And for help with strawberry DNA.

To my friends and family, I love you,

You made me smile on days that were blue.

$\mathrm{PhDs}$ are tough on the ones you love,

Yet you helped pull me through and rise above.

To my supervisors: you inspire me,

And push me to be the best I can be.

You help my mind grow and give me confidence,

And reground me when I cannot see sense.

At last I thank my Fiancée Jessie,

You were there even when things got messy.

Your patience and love has helped get me through,

From the bottom of my heart I thank you.

Thank you very much to everyone who has helped me throughout this thesis:

Jennifer Nightingale (Bristol Zoo)

Oliver Brown (Cynrig)

Dr. Adam Petrusek (Prague University)

Derek Whitehead (Medway Valley Countryside Partnership)

Chris Lloyd

Gereint Mortimer (Afan Valley Angling Club)

Dr. Guillermo R. Giannico (Oregon State University)

Stephanie Bradbeer (Leeds University)

Dr. Stephen Marsh-Smith (Wye and Usk Foundation)

Louis Macdonald-Ames (Wye and Usk Foundation)

Haydn Probert (Wye and Usk Foundation)

Emma Keenan (Natural Resources Wales)

Tony Rees and members of Merthyr Tydfil Angling Club

Dr. Peter Jones (AMBER)

Dr. Ben Rushbrook (Hampshire and Isle of Wight Wildlife Trust)

Mark Hudson and Lyn Byrne (North Wales Wildlife Trust)

Dr. Tristan Hatton-Ellis (Natural Resources Wales)

Kathy Friend (Environment Agency)

Dr. Kerry Walsh (Environment Agency)

Emma McSwann (Environment Agency)

Dr. Tamsyn Uren Webster (Swansea University)

Professor Sofia Consuegra (Swansea University)

Professor Carlos Garcia de Leaniz (Swansea University)

Professor Jo Cable (Cardiff University)

Friends

Family

Jessica

Welsh Government and Higher Education Funding Council for Wales (HEFCW) through the Sêr Cymru National Research Network for Low Carbon Energy and Environment (NRN-LCEE). 


\section{List of Figures and Tables}

Table 1. Sample site information for all nine populations of Pacifastacus leniusculus sampled in Great Britain, including site name, latitude and longitude, site type and origin, catchment, crayfish plague infection status and number of crayfish collected per site.

Table 2. Summary statistics for each population of Pacifastacus leniusculus. $\mathrm{N}=$ number of individuals, $N_{\mathrm{A}}=$ mean number of alleles, $N_{\mathrm{EF}}=$ mean number of effective alleles, $N_{\mathrm{e}}=$ effective population size, $N_{\mathrm{PA}}=$ mean number of private alleles, $H_{\mathrm{O}}=$ mean observed heterozygosity, $H_{\mathrm{E}}=$ mean expected heterozygosity, $H_{\mathrm{L}}=$ mean homozygosity by locus, $F_{\mathrm{IS}}=$ mean fixation index.

Table 3. Pairwise $F_{\text {ST }}$ values (below diagonal) and significance (above diagonal) for nine populations of invasive Pacifastacus leniusculus sampled in Great Britain.

Table 4. Results of Analysis of Molecular Variance (AMOVA) for all nine populations of invasive Pacifastacus leniusculus, presenting the different sources of variation (among populations, among individuals, within individuals), degrees of freedom (d.f.), sum of squared differences (SSD), variance components, percentage variation and $P$ value for each source.

Table 5. Location and environmental data for eDNA sampling sites in the River Wye for July 2015 and October 2016 (in italics); River Taff (May 2015); River Medway (July 2016) and the River Itchen (October 2017), including waterbody type, GPS coordinates, shade cover (0-3), temperature $\left({ }^{\circ} \mathrm{C}\right)$, flow rate $(\mathrm{m} / \mathrm{s})$ and total number of samples collected per site minus negative controls (three samples in duplicate (6) or triplicate (9)).

Table 6. Summary of average values from qPCR outputs for both Pacifastacus leniusculus and Austropotamobius pallipes. Average melt temperature $\left({ }^{\circ} \mathrm{C}\right.$; Avg. tm); Average melt peak height (Avg. peak height); Average start melt temperature $\left({ }^{\circ} \mathrm{C}\right.$; Avg. start melt); Average end melt temperature $\left({ }^{\circ} \mathrm{C}\right.$; Avg. end melt) of resultant qPCR products with standard deviation. Values were obtained for each individual over at least three separate runs, each consisting of three replicates and negative control blanks. 
Table 7. Location of crayfish traps in corresponding waterbodies in the Wye catchment and number of crayfish caught per trap.

Table 8. Melt data from SsoFast ${ }^{\mathrm{TM}}$ EvaGreen ${ }^{\circledR}$ eDNA qPCR amplifications for the Taff catchment.

Table 9. Site information for eDNA sample collection in the River Medway (M), River Stour (S) and River Dee (D) including site name, GPS coordinates of site, temperature $\left({ }^{\circ} \mathrm{C}\right)$, flow rate $(\mathrm{m} / \mathrm{s})$, shade level $(0-3)$, sediment collection status (yes/no), bank consistency (concrete vs. mud/clay) and bank angle in relation to waterbody (left and right in relation to downstream direction of water flow).

Table 10. Catchment location, number of known river obstructions within area sampled, month/year of sample collection, number of sites sampled in 2016, total number of eDNA water and eDNA sediment samples collected from the River Medway, River Dee and River Stour.

Table 11. Positive amplifications for signal crayfish (SC) and mitten crab 85 (MC) in eDNA water (W) and sediment (S) samples across all sites for all three catchments (Medway, Dee and Stour) sampled in 2016. '+ positive amplification for target species in at least two out of three replicates in qPCR, '-' no amplifications for target species.

Table 12. Site information for the four ponds (1-4) and two reservoirs (5-6) sampled for presence of Pseudorasbora parva in South Wales during August 2017 and October 2018.

Table 13. Mean $\mathrm{Ct}$ values of positive amplifications for Pseudorasbora 102 parva in $750 \mathrm{~mL}$ and $15 \mathrm{~mL}$ water samples, amplified with designed Pparva16S primers from all four ponds (Morolwg Pond, MP; Ashpits Pond, AP; Turbine Pond, TP and Dyfatty Pond, DP) at each sampling point (1 - 10) in optimised SsoFast ${ }^{\mathrm{TM}}$ EvaGreen ${ }^{\circledR}$ qPCR assay.

Table 14. Positive amplifications for Pseudorasbora parva in filtered 750 $\mathrm{mL}$ water samples amplified with designed Pparva16S primers, $750 \mathrm{~mL}$ water samples amplified in end-point PCR with Davison et al. (2017) primers and positives amplifications in $15 \mathrm{~mL}$ water samples amplified with designed Pparva16S primers from all four ponds (Morolwg Pond, MP; Ashpits Pond, 
AP; Turbine Pond, TP and Dyfatty Pond, DP) at each sampling point (1 - 10) in optimised SsoFast ${ }^{\mathrm{TM}}$ EvaGreen ${ }^{\circledR}$ qPCR assay.

Table 15. Summary of successful citizen science initiatives which include members of the public collecting biological monitoring data for a variety of aquatic and terrestrial species. Summaries of protocols used, number of sites sampled (where known), total number of volunteers engaged, the platform for data compiling and study reference are detailed below.

Table S1. Information on the microsatellites used in analysis (Froufe et al. 2015), including multiplexes used, primer sequences, fluorescent dyes, concentration of primer in PCR reaction $(\mu \mathrm{m})$ and allele size range covered by each microsatellite (bp).

Table S2. Pairwise $F_{\mathrm{ST}}$ values (below diagonal) and significance (above diagonal) for all populations of Pacifastacus leniusculus sampled with 'null' microsatellites (Scop1, Scop9, Scop31 and LPL45) removed.

Table S3. Genetic diversity values of nine Pacifastacus leniusculus populations for nine microsatellite loci. $\mathrm{N}_{\mathrm{A}}$ Number of alleles; $\mathrm{N}_{\mathrm{E}}$ Number of effective alleles; $\mathrm{H}_{\mathrm{O}}$ Observed heterozygosity; $\mathrm{H}_{\mathrm{E}}$ Expected heterozygosity; HW P-values for deviation of Hardy-Weinberg equilibrium; FIS Fixation index (positive value indicates homozygosity excess); N Number of samples. Significant values of deviation of HW after Bonferroni correction $(\mathrm{P}<0.000617)$ are indicated in bold

Table S4. Results of $\mathrm{ABC}$ analyses for estimated posterior parameters. Means, medians, modes and quantiles are displayed. $\mathrm{N} 1=$ Effective population size $\left(N_{\mathrm{e}}\right)$ of Sirhowy; N2 $=N_{\mathrm{e}}$ of Lugg; N3 $=N_{\mathrm{e}}$ of Dderw; N4 = $N_{\mathrm{e}}$ of pooled populations (Lea, Mochdre and Gavenny); N5 $=N_{\mathrm{e}}$ of Bachowey; N6 $=N_{\mathrm{e}}$ of Pant-y-Llyn; $\mathrm{t}=$ time of divergence in generations; Â $\mu$ mic_1 $=$ mean mutation rate; pmic_1 $=$ number of repeat motifs added/removed from microsatellites in each mutation step and snimic_1 = single insertion nucleotide rate.

Table S5. Posterior probabilities for all three scenarios estimated with a maximum of $1 \%$ of simulated data sets. $n=$ number of simulated datasets closest to the observed using the logistic approach. 
Table S6. StructureSelector output table using the Puechmaille Method to infer the true K (4) from the British Pacifastacus leniusculus populations analysed using four alternative statistics (MedMed, MedMean, MaxMed and MaxMean).

Table S7. StructureSelector output table using the Puechmaille Method to 136 infer the true K (5) from the all Pacifastacus leniusculus populations analysed using four alternative statistics (MedMed, MedMean, MaxMed and MaxMean).

Table S8. Melt peak data from SYBR ${ }^{\mathrm{TM}}$ Green and SsoFast ${ }^{\mathrm{TM}}$ EvaGreen ${ }^{\circledR}$ dilution series for Pacifastacus leniusculus (s_pool) and Austropotamobius pallipes ( $\mathrm{n} \_$pool).

Table S9. Melt curve data from SsoFast ${ }^{\mathrm{TM}}$ EvaGreen ${ }^{\circledR}$ mixed DNA ratios of 148 crayfish species (Pacifastacus leniusculus and Austropotamobius pallipes) qPCR amplifications.

Table S10. Melt peak data from HOT FIREPol ${ }^{\circledR}$ EvaGreen $^{\circledR}$ eDNA qPCR 150 amplifications from the Medway and Itchen catchments, at sites where both Pacifastacus leniusculus and Austropotamobius pallipes DNA was detected in the same site.

Table S11. Melt peak data from SsoFast ${ }^{\mathrm{TM}}$ EvaGreen ${ }^{\circledR}$ eDNA qPCR 152 amplifications from the River Itchen at for samples positive for Pacifastacus leniusculus and Austropotamobius pallipes DNA.

Table S12. Information on location of known major barriers present within the upstream to downstream sampling area of the River Medway, River Dee and River Stour, including type of and GPS of obstruction, distance to nearest upstream and downstream barriers $(\mathrm{km})$ based on information provided by Environment Agency and Natural Resources Wales (EA, 2017).

Table S13. Upstream and downstream proximity of each sampling in relation to the nearest known river obstruction in the River Medway and River Dee. Table S14. Melt peak data from SsoFast ${ }^{\mathrm{TM}}$ EvaGreen ${ }^{\circledR}$ dilution series for Pacifastacus leniusculus (SC_pool), Austropotamobius pallipes (NC_pool) and Eriocheir sinensis (MC_pool). 
Table S15. Melt peak data from SsoFast ${ }^{\mathrm{TM}}$ EvaGreen ${ }^{\circledR}$ dilution series for

Pacifastacus leniusculus (SC), Austropotamobius pallipes (NC) and Eriocheir sinensis (MC) mixed proportions

Table S16. Melt peak data from SsoFast ${ }^{\mathrm{TM}}$ EvaGreen ${ }^{\circledR}$ dilution series for 160 Pacifastacus leniusculus (SC), and Eriocheir sinensis (MC) mixed proportions.

Table S17. Summary of number of sites which had water and sediment samples collected, number of positive sites for both water and sediment samples for each species (signal crayfish (SC) and mitten crab (MC)) and total number of positive sites for each sample type.

Table S18. Melt peak data from SsoFast ${ }^{\mathrm{TM}}$ EvaGreen ${ }^{\circledR}$ water field samples in the River Medway positive for Pacifastacus leniusculus (SC), and Eriocheir sinensis (MC) DNA.

Table S19. Melt peak data from SsoFast ${ }^{\mathrm{TM}}$ EvaGreen ${ }^{\circledR}$ sediment field samples in the River Medway positive for Pacifastacus leniusculus (SC), and Eriocheir sinensis (MC) DNA.

Table S20. Melt peak data from SsoFast ${ }^{\mathrm{TM}}$ EvaGreen ${ }^{\circledR}$ water field samples 169 in the River Stour positive for Pacifastacus leniusculus (SC), and Eriocheir sinensis (MC) DNA.

Table S21. Melt peak data from SsoFast ${ }^{\mathrm{TM}}$ EvaGreen ${ }^{\circledR}$ sediment field samples in the River Stour positive for Pacifastacus leniusculus (SC), and Eriocheir sinensis (MC) DNA.

Table S22. Melt peak data from SsoFast ${ }^{\mathrm{TM}}$ EvaGreen ${ }^{\circledR}$ water field samples 171 in the River Dee positive for Pacifastacus leniusculus (SC), and Eriocheir sinensis (MC) DNA.

Table S23. Melt peak data from SsoFast ${ }^{\mathrm{TM}}$ EvaGreen ${ }^{\circledR}$ sediment field samples in the River Dee positive for Pacifastacus leniusculus (SC), and Eriocheir sinensis (MC) DNA.

Table S24. Amplification data from SsoFast ${ }^{\mathrm{TM}}$ EvaGreen ${ }^{\circledR}$ dilution series for Pseudorasbora parva DNA pool.

Table S25. Melt curve data from SsoFast ${ }^{\mathrm{TM}}$ EvaGreen ${ }^{\circledR} \quad$ qPCR 177 amplifications of positive $750 \mathrm{~mL}$ field samples from Morolwg Pond, MP; 
Ashpits Pond, AP; Turbine Pond, TP and Dyfatty Pond, DP at each sampling point (P) for Pseudorasbora parva.

Table S26. Melt curve data from SsoFast ${ }^{\mathrm{TM}}$ EvaGreen ${ }^{\circledR}$ qPCR 181 amplifications of $15 \mathrm{~mL}$ field samples from Morolwg Pond, MP; Ashpits Pond, AP; Turbine Pond, TP and Dyfatty Pond, DP at each sampling point (P) for Pseudorasbora parva.

Table S27. Probability of detection (binomial proportions, 95 CI) of 185 topmouth gudgeon (Pseudorasbora parva) at different spatial scales using a traditional PCR method and the novel qPCR assay with different volumes of water.

Figure 1. Map of UK sampling sites for Pacifastacus leniusculus, infection status and the three highly significant breaks in genetic continuity generated by BARRIER in relation to sample sites (1=Sirhowy, 2=Lugg, 3=Dderw, 4=Lea, 5=Bachowey, 6=Mochdre, 7=Gavenny, 8= Pant-y-Llyn).

$\begin{array}{llll}\text { Figure } & \text { 2. STRUCTURE for }\end{array}$ 26

UK Pacifastacus leniusculus populations at $\mathrm{K}=4$ clusters (A); each bar represents an individual crayfish, the different colours represent different clusters and therefore indicate the proportion of each crayfish attributed to each cluster. Infection status is stated above the output and corresponding population names stated below for each population. b) STRUCTURE analysis for all nine $P$. leniusculus populations at $\mathrm{K}=5$ clusters (B).

Figure 3. Three scenarios of signal crayfish colonisation tested using Approximate Bayesian Computation analysis (ABC) (A): Simultaneous divergence (Scenario 1), simultaneous divergence of Sirhowy, Pool 1, Lugg, Bachowey and Dderw, followed by divergence of Pant-y-Llyn from Bachowey (Scenario 2) and simultaneous divergence of Sirhowy, Pool 1, Lugg, Bachowey and Dderw, followed by admixture of pool 1 with Bachowey to produce Pant-y-Llyn (Scenario 3). Reliability of scenarios displayed through posterior probabilities as the logistic regressions (B). Principal component analysis (PCA) showing the fit of posterior distributions for scenario $1(\mathrm{C})$. 
Figure 4. Homozygosity by locus $\left(H_{\mathrm{L}}\right)$ values for each of the crayfish populations with known infection status.

Figure 5. A) eDNA sampling sites for catchments sampled (Wye, Taff, $44-$ Itchen and Medway) with known presence of Pacifastacus leniusculus 46 individuals (red circle), Austropotamobius pallipes (green circle) or without information regarding crayfish status (blue circle); B) Location of the rivers Wye and Taff eDNA sampling sites in Wales. Wye sites 1 and 2 (Sgithwen Brook) were confirmed for crayfish species Austropotamobius pallipes; sites 3 (Bachowey), 4 (Bachowey) and 6 (Duhonw) were confirmed for crayfish species Pacifastacus leniusculus and site 5 (Edw) had unknown crayfish status. Taff sites T1 to T7 all had unknown crayfish presence status; C) Locations of the River Medway and River Itchen eDNA sampling sites. There were 11 sites in total (M1 to M11); M1, M2 - M6 were classified as positive for Pacifastacus leniusculus presence whereas M3, M8 - M11 have an unknown crayfish species status. In the Itchen, there were 18 sites in total (I1 to I18); I1 - I11 classified as positive for Austropotamobius pallipes presence and I12 - 18 classified as positive for Pacifastacus leniusculus presence. Each point represents a locality where between three and nine water samples were collected. (Austropotamobius pallipes photograph OChloe Robinson; Pacifastacus leniusculus photograph (CRhidian Thomas).

Figure 6. Average eDNA concentration across all ex-situ samples for the three time points $(\mathrm{T} 0=$ time of crayfish removal; $\mathrm{T} 1=24 \mathrm{hrs}$ post crayfish removal; $\mathrm{T} 2=48 \mathrm{hrs}$ post crayfish removal.

Figure 7. Melt peaks from SsoFast ${ }^{\mathrm{TM}}$ EvaGreen ${ }^{\circledR}$ mixed DNA ratios of crayfish species (Pacifastacus leniusculus and Austropotamobius pallipes) qPCR amplifications (A). 10:90 Pacifastacus leniusculus: Austropotamobius pallipes to 90:10 Pacifastacus leniusculus: Austropotamobius pallipes

Figure 8. qPCR product melt peak output for multiplex amplification of DNA using optimised HOT FIREPol® ${ }^{\circledR}$ EvaGreen ${ }^{\circledR}$ from three different Pacifastacus leniusculus individuals and Aphanomyces astaci DNA in the same qPCR reaction (Pool 1-3), displaying the diagnostic double melt peaks at $75.9 \pm 0.2{ }^{\circ} \mathrm{C}$ for Pacifastacus leniusculus and $82.9{ }^{\circ} \mathrm{C}$ for Aphanomyces 
astaci. Control PL = Pacifastacus leniusculus control for HOT FIREPol qPCR $(73.9 \pm 0.2)$.

Figure 9. Melt peak profile for SsoFast ${ }^{\mathrm{TM}}$ EvaGreen ${ }^{\circledR}$ eDNA qPCR 58 amplifications of positive amplifications for both Pacifastacus leniusculus in the River Taff. The three largest sets of peaks correspond to positive control tissue (one sample in triplicate) for both Pacifastacus leniusculus $\left(74.9^{\circ} \mathrm{C}\right)$, Austropotamobius pallipes $\left(75.9{ }^{\circ} \mathrm{C}\right)$ and Aphanomyces astaci $\left(82.9{ }^{\circ} \mathrm{C}\right)$. Subsequent peaks represent eDNA field sample melt peaks from nine samples (in triplicate) for invasive Pacifastacus leniusculus. Non-template control has no melt profile (flat line).

Figure 10. Melt peaks from SsoFast ${ }^{\mathrm{TM}}$ EvaGreen ${ }^{\circledR}$ eDNA qPCR amplifications for the Medway catchment site 5 (A) and Itchen catchment at site $8(B)$.

Figure 11. eDNA sampling sites for River Medway and River Stour. Signal 76 crayfish DNA was confirmed at sites 1 (Tonbridge Castle), 5 (Horse Farm), 7 (Green Lane), 8 (Teston Bridge), 10 (Asda), and 11 (Leybourne Lakes); mitten crab DNA was confirmed at site 7,10 and 11 in the Medway and in the Stour, both signal crayfish and mitten crabs were detected at site 7, 10 and 11. At each point, three water samples and between zero and three sediment samples were collected in 2016.

Figure 12. eDNA sampling sites for River Dee. Signal crayfish DNA was confirmed at sites 1 (NRW Bala), 7 (Sutton Green) and 8 (Caldecott); mitten crab DNA was confirmed at site 7, 8 and 9 (Holt). At each point, six water samples and three sediment samples were collected in 2016.

Figure 13. Melt peaks from SsoFast ${ }^{\mathrm{TM}}$ EvaGreen ${ }^{\circledR}$ dilution series for Pacifastacus leniusculus, Austropotamobius pallipes and Eriocheir sinensis DNA pools, displaying lack of cross-over between product melt peaks.

Figure 14. Melt peaks from SsoFast ${ }^{\mathrm{TM}}$ EvaGreen ${ }^{\circledR}$ mixed proportions for 82 Pacifastacus leniusculus, Austropotamobius pallipes and Eriocheir sinensis DNA ratios 2:2:2, 1:2:2, 2:1:2, 2:2:1 and positive control pools for each species. Diagnostic ' $S$ ' shape start to melt curve is present for all combinations of mixed DNA. 
Figure 15. Melt peaks from SsoFast ${ }^{\mathrm{TM}}$ EvaGreen ${ }^{\circledR}$ mixed proportions for Pacifastacus leniusculus, and Eriocheir sinensis DNA ratios 9:1 to 1:9 $\mu \mathrm{L}$ signal crayfish: mitten crab DNA and positive control pools for each species. Figure 16. Melt peaks from SsoFast ${ }^{\mathrm{TM}}$ EvaGreen ${ }^{\circledR}$ water field samples in 84 the River Dee positive for Pacifastacus leniusculus, and Eriocheir sinensis DNA.

Figure 17. Location of study ponds. A) Location of the Millennium Coastal 96 Park within relation to Wales (red rectangle). B) Four ponds sampled for Pseudorasbora parva eDNA Millennium Coastal Park in Llanelli. At each pond (Morolwg Pond, MP; Ashpits Pond, AP; Turbine Pond, TP and Dyfatty Pond, DP) both ten $250 \mathrm{~mL}$ water samples were collected in triplicate (750 $\mathrm{mL}$ total per sampling point) and one $15 \mathrm{~mL}$ water sample were collected at each sampling point. Ordnance Survey (GB), Using: EDINA Digimap Ordnance Survey Service, <http://digimap.edina.ac.uk/>, Created: July 2017. Figure 18. Melt curves from SsoFast ${ }^{\mathrm{TM}}$ EvaGreen ${ }^{\circledR}$ qPCR from positive 107 field samples from pond (Morolwg Pond, MP; Ashpits Pond, AP; Turbine Pond, TP and Dyfatty Pond, DP) for Pseudorasbora parva.

Figure 19. Agarose gel from end-point PCR using Davison et al., 2017 108 primers on field eDNA samples in triplicate for Pseudorasbora parva. A) Field samples (x) with positive samples displaying a band at $350 \mathrm{bp}$ (200 bp ladder). B) Positive control tissue from topmouth gudgeon and negative controls.

Figure 20. Probability of top mouth gudgeon (Pseudorasbora parva) DNA 108 detection with deviation for each pond (Morolwg Pond, MP (P1); Ashpits Pond, AP (P2); Turbine Pond, TP (P3) and Dyfatty Pond, DP (P4)) for each amplification method (end point-PCR, qPCR with $750 \mathrm{~mL}$ water and $\mathrm{qPCR}$ with $15 \mathrm{~mL}$ water).

Figure S1. STRUCTURE analysis for Pacifastacus leniusculus populations with 'null' microsatellites (Scop1, Scop9, Scop31 and LPL45) removed at K $=5$ clusters; each bar represents an individual crayfish, the different colours represent different clusters and therefore indicate the proportion of each 
crayfish attributable to each cluster. Infection status is stated above the output and corresponding population names stated below for each population.

Figure S2. Most likely $\mathrm{K}$ for all British populations studied (excluding Oregon), determined using MedMedK, MedMeanK, MaxMedK and MaxMeanK statistics in StructureSelector.

Figure S3. Most likely K for all nine populations studied (including Oregon) determined using MedMedK, MedMeanK, MaxMedK and MaxMeanK statistics in StructureSelector.

Figure S4. Output from BARRIER, highlighting the main breaks in genetic continuity (red lines); the green line corresponds to the Delaunay triangulation between populations (red dots) and Voronoï tessellation used to calculate position of the barriers (blue line). Populations: 1=Sirhowy, 2=Lugg, 3=Dderw, 4=Lea, 5=Bachowey, 6=Mochdre, 7=Gavenny, 8=Panty-Llyn. Barriers: $\mathrm{a}=$ isolates population $3, \mathrm{~b}=$ isolates population $1, \mathrm{c}=$ between population 2 and 5 .

Figure S5. Principal component analysis (PCA) showing the fit of posterior distributions for all three scenarios tested, displaying 10000 prior plots per scenario.

Figure. S6. Alignment of DNA fragments from eDNA samples for both Pacifastacus leniusculus and Austropotamobius pallipes and ApalPlen16S forward (A) and reverse (B) primers against reference sequences. Seq_A.pal = positive in-situ Austropotamobius pallipes eDNA fragment; Seq_P. len = positive in-situ Pacifastacus leniusculus eDNA fragment.

Figure. S7. Melt peaks from SYBR ${ }^{\mathrm{TM}}$ Green dilution series (A) and from SsoFast ${ }^{\mathrm{TM}}$ EvaGreen ${ }^{\circledR}$ dilution series (B) for Pacifastacus leniusculus and Austropotamobius pallipes DNA pools.

Figure S8. Efficiency outputs from SYBR ${ }^{\mathrm{TM}}$ Green dilution series for Pacifastacus leniusculus (A) and Austropotamobius pallipes (B); efficiency outputs from SsoFast ${ }^{\mathrm{TM}}$ EvaGreen ${ }^{\circledR}$ dilution series for (B) for Pacifastacus leniusculus (C) and Austropotamobius pallipes (D).

Figure S9. Melt peaks from SsoFast ${ }^{\mathrm{TM}}$ EvaGreen ${ }^{\circledR}$ ex-situ Pacifastacus 145 leniusculus eDNA qPCR amplifications. 
Figure S10. Efficiency curve from SsoFast ${ }^{\mathrm{TM}}$ EvaGreen ${ }^{\circledR}$ dilution series for Pseudorasbora parva DNA pool, starting at $5 \mathrm{ng} / \mu \mathrm{l}$ DNA concentration to 5 X $10^{-7} \mathrm{ng} / \mu \mathrm{l}$.

Figure S11. Gel electrophoresis output for end-point PCR 10-fold dilution series with COI primers (Davison et al., 2017; A) and designed Pparva16S primers (B).

Figure S12. Cover page for crayfish count kit.

Figure S13. Contents page for crayfish count kit.

Figure S14. Sampling protocol detailing instructions for field sampling and handling of samples.

Figure S15. Recording sheet for marking dark spots on crayfish found, complete with protocol and guide.

Figure S16. Key identification features for signal crayfish, including claw colour, size and general coloration and appearance of dorsal carapace (@NNSS).

Figure S17. Key identification features of the underside of signal crayfish and white-clawed crayfish to assist with ID of species found and to avoid endangered white-clawed crayfish being sampled.

Figure S18. Recording sheet for signal crayfish sightings including example recording (in red).

Figure S19. Guide for use of Aquainvaders smartphone app, including stepby-step guide on submitting recordings and screenshots to help assist with navigating the app.

Figure S20. Guide for use of Aquainvaders website, including step-by-step guide on submitting recordings and screenshots to help assist with navigating the website.

Figure S21. Participation sheet to be filled out by individuals which have collected samples to gauge the age range, education level, fishing frequency and interest towards future citizen science projects.

Figure S22. Short phrase 'Swab. Record. Post' with pictures on back page of Crayfish Count kit. 


\section{List of Abbreviations}

$\mu l$

AIS

bp

COI

DNA

eDNA

GCN

HRM

HPLC

L

LOD

LOQ

MC

$\mathrm{mL}$

NRW

PCR

qPCR

SC

tm

TMG

UV

WCC

WT
Microlitres

Aquatic invasive species

Base pair

Cytochrome c oxidase unit 1

Deoxyribonucleic acid

Environmental DNA

Great crested newt

High-resolution melt

High performance liquid chromatography

Litre

Limit of detection

Limit of quantification

Mitten crab

Millilitres

Natural Resources Wales

Polymerase Chain Reaction

Quantitative PCR

Signal crayfish

Melt temperature

Topmouth gudgeon

Ultra violet

White-clawed crayfish

Wildlife Trust 


\section{GENERAL INTRODUCTION}




\section{GENERAL INTRODUCTION}

1.1. Introduction and establishment of aquatic invasive species

Aquatic invasive species (hereafter AIS) are known to generate global ecological change in aquatic ecosystems, and as a result management and eradication of AIS has taken top priority in conservation and monitoring programmes (Havel et al. 2015; Lennox et al. 2015). Introductions of AIS within the last century have been attributed to aquaculture practice regarding cultivation of commercially important species in countries outside of native ranges (Arismendi et al. 2009; Dittel and Epifanio 2009; Savini et al. 2010). Farmed species can be liberated from aquaculture facilities via two pathways: intentional stocking and unintentional escape. Accidental releases following handling or live transportation, escapees from damaged containment structures (i.e. damage through bad weather or predators or wear and tear) and introduction through ballast water or shipping activities to and from aquaculture facilities are common causes of introduction (Arismendi et al. 2009; Gallardo and Aldridge 2013). Regulations have been established to limit further release of AIS from aquaculture facilities following previous ill-consideration regarding aquaculture as a vector for the introduction of farmed species (Copp et al. 2016; EU 2014; Minchin 2007; Ruesink et al. 2005).

To predict whether a species will become invasive, the following factors need to be assessed: number of individuals at release event and frequency of events (propagule pressure), ecological compatibility and adaptive potential of species, and also amount of genetic variation in invading individuals (Allendorf and Lundquist 2003; Kolar and Lodge 2001; Lee 2002; Szücs et al. 2017). Larger numbers of individuals being introduced combined with multiple introductions can reduce the impact of founder effects and aid in successful establishment (Allendorf and Lundquist 2003; Fischer et al. 2017; Prentis et al. 2008). The extent of dispersal after establishment can vary amongst different AIS species due to differences in ecology, variations in local environmental conditions and degree of anthropogenic activity around release sites (Bubb et al. 2005; McMahon 2002; Pinder et al. 2005; Van Leeuwen et al. 2013). Human-mediated dispersal and anthropogenic activities can facilitate numerous introductions in addition to natural dispersal (Banks et al. 2015; Brancatelli and Zalba 2018; Uller and Leimu 2011). Man-made structures, including urban settlements and 
weirs can also influence both the number of introduction events and rate of advancement from source populations (Crowl et al. 2008; Johnson et al. 2008; Pratt et al. 2009; Rahel 2013; Taylor et al. 2018). Species which persist and disperse in the local environment after introduction often have adverse effects on native flora and fauna which can result in native species decline, including competitive exclusion, habitat transformation and/or transmission of disease (De Silva et al. 2009; Didham et al. 2005; Vilà et al. 2010).

In addition to successful establishment and proliferation of AIS, there is often the potential for non-native pathogens to be co-introduced with AIS (Prenter et al. 2004; Vilcinskas 2015). These pathogens have the potential to be transmitted to and have detrimental impacts on native counterparts, which can result in disease outbreaks in native populations, referred to as 'spill-over' (Lymbery et al. 2014; Prenter et al. 2004). There are several examples where pathogens have facilitated the invasion process for a number of invasive species (Strauss et al. 2012); the most relevant for AIS being the co-introduction of crayfish plague oomycete Aphanomyces astaci with American signal crayfish (Pacifastacus leniusculus), which is considered to have increased invasion success of signal crayfish through selective removal of native European crayfish species, white-clawed crayfish (Austropotamobius pallipes) and noble crayfish (Astacus astacus; Edgerton et al. 2004). Invasive hosts which benefit from coinvasion with pathogens are often not adversely affected by or have a higher tolerance to the pathogen in comparison to native counterparts (Lymbery et al. 2014), which is true in the case of the asymptomatic signal crayfish carrier and A. astaci pathogen (Edgerton et al. 2004). Co-invasion with pathogens clearly facilitates the establishment success of invasive species in a majority of cases, however the ecology and competitive ability of both invasive species and native counterparts need to be assessed to determine the overall contribution of pathogens towards invasion success (Strauss et al. 2012).

\subsection{Study species}

Three study species were used in this thesis: North American signal crayfish, Chinese mitten crab (Eriocheir sinensis) and topmouth gudgeon (Pseudorasbora parva). These species were chosen because their introduction has been heavily influenced by 
aquaculture and fisheries activities in the UK (Lodge et al. 2000; Winfield et al. 2011; Brodin and Drotz 2014).

Freshwater crayfish, predominantly from North America, have been cultivated in aquaculture facilities across Europe since 1970 to supply the Scandinavian food market (Holdich et al. 2004; Lodge et al. 2000). Non-native crayfish species are highly plastic in their life cycle, can occupy numerous niches within freshwater food webs and have a higher fecundity than native European crayfish, which overall renders nonnative crayfish highly invasive and likely to pose a threat to novel aquatic ecosystems (Gherardi et al. 2011). Introductions of 20 non-native crayfish species have been reported in the last 100 years, most of these introductions being a result of deliberate stockings and accidental releases from asciculture (crayfish aquaculture) facilities and private outdoor ponds (Hobbs et al. 1989; Lodge et al. 2000). Signal crayfish are notably one of the most successful and invasive introduced crayfish species due to their aggressive behaviour, large body size and role as a pathogen vector (Alderman and Wickins 1996; Holdich et al. 2014; Lodge et al. 2000; Peay 2009; Pintor et al. 2008). In addition, signal crayfish are fast-growing and highly fecund, producing an excess of 400 eggs in comparison to the slow-growth and low fecundity ( $<100$ eggs; (Rhodes and Holdich 1982)) of white-clawed crayfish (Guan and Wiles 1999; Holdich et al. 2014) and also display high levels of abiotic tolerance, which allows for continued existence and further colonisations (Bubb et al. 2006; Holdich et al. 2014; Lodge et al. 2000). Due to the presence of signal crayfish, populations of both noble and white-clawed crayfish have been extirpated in a large majority of previously occupied lentic and lotic sites across Europe and specifically in Great Britain, whiteclawed crayfish populations have been reduced by $90 \%$ (Holdich et al. 2014; Holdich et al. 2009; Schrimpf et al. 2012). These population declines of European crayfish are considered to be a direct result of competition with invasive crayfish for resources and shelter, localised alterations and degradation of habitat through invasive crayfish action (Holdich et al. 2014) and crayfish plague infection which is often $100 \%$ lethal for native crayfish (Bubb et al. 2006; Dunn et al. 2012; Griffiths et al. 2004; Lodge et al. 2000; Peay 2009). Displacement by signal crayfish and high mortality rates associated with transmission of crayfish plague has resulted in white-clawed crayfish being IUCN classified as 'endangered' (IUCN 2017). 
Crayfish plague exists in three forms during its life cycle: mycelium, zoospore and cyst (Oidtmann et al. 2002). Zoospores are the infectious stage of the oomycete and are released from the mycelium, found in the cuticle of the crayfish. Zoospores are typically released into the local environment when a crayfish either succumbs to the infection (as is the case for native white-clawed crayfish) or when the infected host crayfish moults (Oidtmann et al. 2002). The longevity of zoospores in the local environment is limited, however these spores undergo encapsulation to from cysts which persist for up to 14 days in temperatures between zero and $10{ }^{\circ} \mathrm{C}$. It is expected that spores will persist longer in more favourable conditions (around $20{ }^{\circ} \mathrm{C}$; DiéguezUribeondo et al. 1995; Unestam 1966; Wittwer et al. 2018). The ability of A.astaci to transition between zoospores and cysts (repeated encapsulation), results in a higher likelihood of the species finding a host and also enables spores to survive translocation on damp surfaces (e.g. fish nets, clothing, crayfish; Oidtmann et al. 2002; Wittwer et al. 2018). A combination of physical dispersal of infected signal crayfish and humanmediated translocation of infected water, equipment and crayfish has resulted in widespread prevalence of $A$. astaci across the UK (Wittwer et al. 2018).

Despite previous attempts to eradicate signal crayfish using a variety of different control methods (trapping, natural biocides and synthetic biocides), there is no effective control measure in place to prevent further spread of signal crayfish (Holdich et al. 2014). In Great Britain, trapping has been successful on a local scale at reducing population sizes short-term, however trapping is known to be size-bias for signal crayfish and long-term impact of trapping on signal crayfish populations is difficult to assess (Freeman et al. 2010).

An increasingly abundant invasive crustacean species in Great Britain is the Chinese mitten crab (Eriocheir sinensis (NBN 2015)). First detected in Europe in the 1910s and Great Britain in 1935, mitten crabs have the ability to disperse considerable distances upstream in rivers from initial area of invasion (Gilbey et al. 2008; Herborg et al. 2007). The two main vectors for dispersal of mitten crabs are mariculture and ballast water; the latter considered to be the most influential over long-range dispersal (Brodin and Drotz 2014; Gollasch 2010). Transport of mitten crab larvae in freight ballast has contributed to recordings of the species around the coastlines of Great Britain and Ireland. Repeated influxes of new individuals to existing sites of 
occupancy could be providing new genetic material and thus enhancing the success of mitten crabs as an invasive species (Herborg et al. 2005; Herborg et al. 2003; Lewis et al. 2016). Due to the catadromous nature of his species, juveniles are known to migrate up to $15 \mathrm{~km}$ a day upstream into freshwater to mature (two to five years), before migrating downstream to estuaries to spawn (Brodin and Drotz 2014; Dittel and Epifanio 2009; Gilbey et al. 2008).

Mitten crabs are known to overlap both in habitat preference and feeding ecology to signal crayfish and similarly, mitten crabs are known to cause significant structural damage to banks and levees through extensive burrowing (Dittel and Epifanio 2009; Gilbey et al. 2008; Herborg et al. 2005). In addition to competitive interactions with both native crab Carcinus maenus (Gilbey et al. 2008) and existing crayfish species within the same catchment, mitten crabs are also a known carrier of the crayfish plague pathogen A. astaci (Schrimpf et al. 2014; Tilmans et al. 2014). It is only recently that it has been fully proven that mitten crabs are capable of transmitting A. astaci, which has critical consequences for dispersal of the pathogen into upper reaches of river catchments, especially in rivers where native crayfish are also present (Schrimpf et al. 2014; Svoboda et al. 2014; Tilmans et al. 2014).

The last study species for this thesis is the invasive topmouth gudgeon (Pseudorasbora parva), which is another prolific AIS which was introduced accidently into UK aquaculture facilities through contaminated fish imports (Winfield et al. 2011). Topmouth gudgeon established through repeated escape events into local lentic systems and has subsequently caused declines in native fish populations (Beyer 2004; Britton et al. 2007; Gozlan 2017; Laverty et al. 2017). This species displays broad environmental plasticity, matures early and spawns in large sequential batches, which ultimately favours successful invasion into novel environments (Beyer et al. 2007; Britton et al. 2008; Pinder et al. 2005). In environments with established topmouth gudgeon, the rapid reproductive rate and r-selected strategy of this species negatively impacts on native fish through intraspecific competition for resources (Britton et al. 2007). Topmouth gudgeon is also a asymptomatic vector for several fish pathogens, including the Ichthyosporea eukaryotic parasite Sphaerothecum destruens (Spikmans et al. 2013) which has caused declines of numerous European native fish species (Gozlan et al. 2005), the eel nematode parasite Anguillicola crassus, the 
trematode Clinostomum complanatum and the Pike Fry Rhabdovirus (PFR; (Britton et al. 2007). Across Great Britain, topmouth gudgeon had been reported in 25 locations by 2005 (Pinder et al. 2005), seven of which were enclosed waterbodies and the remaining sites had a direct connection to major catchments and were considered to be highly invasive populations (Britton et al. 2010; Britton et al. 2007). By 2014, 17 out of the 25 known sites have been eradicated, with five sites remaining across England and a further three in Wales (Brazier 2015).

\subsection{River connectivity and invasive species dispersal}

Man-made structures and natural barriers can limit the upstream migration of native vertebrate and invertebrate species (Blanchet et al. 2009; Coleman et al. 2018; Kerby et al. 2005; O'Hanley et al. 2013). Presence of river obstacles cause modification of local regimes and habitat degradation, which often results in removal of native species (Casimiro et al. 2017; Marvier et al. 2004). This change in native species presence and assemblage and the ecosystem modification associated with fragmentation of river systems often facilitates the establishment of AIS in comparison to fully connected habitats (Johansson et al. 2018; Lee et al. 2018; Trombulak and Frissell 2000). Installations of barriers such as dams in previously connected river systems have created novel impoundments and the presence of impoundments is a strong indicator of the presence of established populations of invasive species, with AIS being 7.8 times more likely to occur in impoundments than in natural lakes (Johnson et al. 2008). Impoundments are considered to act as invasion 'hubs', by both increasing the likelihood of initial invasion and the facilitation of subsequent spread of AIS into natural lentic systems (Casimiro et al. 2017; Johnson et al. 2008). In addition, waterfalls have been reported to hinder the expansion of both vertebrate and invertebrate AIS to headwater environments (Fagan 2002; Fausch et al. 2009; Taylor et al. 2018). Invasive brown trout (Salmo trutta) in New Zealand were effectively prevented from progressing upstream to natal waters of common river galaxias (Galaxias vulgaris) due to the presence of large waterfalls (Lintermans 2000; Townsend and Crowl 1991).

Physical river barriers are known to influence the upstream movement of aquatic invasive species such as sea lamprey (Petromyzon marinus (Pratt et al. 2009)) and 
silver carp (Hypophthalmichthys molitrix (Dettmers et al. 2005)), limiting the extent of upstream colonisation (Rosewarne et al. 2013; Vanschoenwinkel et al. 2008). The effect of river obstacles on AIS which are not limited to movement through water (i.e. invasive crayfish) is rarely considered and thus not well understood (Rosewarne et al. 2013; Vanschoenwinkel et al. 2008). Red swamp crayfish (Procambarus clarkii), signal crayfish and mitten crabs are known to exhibit overland dispersal to find more suitable, accessible habitats if faced with unfavourable conditions and/or barriers (Fialho et al. 2016; Kerby et al. 2005; Ramalho and Anastácio 2015; Rosewarne et al. 2013). The ability of such AIS to actively navigate around barriers by leaving the aquatic environment and moving overland has facilitated their upstream range expansion in fragmented river systems (Banha and Anastácio 2014; Marques et al. 2015). Previously, the extent of upstream movement of signal crayfish has been analysed through radiotracking (Bubb et al. 2004), however it is difficult to assess the influence of barriers independently on upstream dispersal due to the combined effect of factors such as flow rate, river level and temperature on movement (Cowart et al. 2018; Frings et al. 2012).

\subsection{Detection and monitoring techniques for aquatic invasive species}

Knowledge of the current distribution and projected future dispersal of species is vital for implementing conservation strategies, particularly when addressing threatened, endangered or invasive species (Dejean et al. 2012). Detection of AIS is often only possible when populations have already become established, spread from original source and begun influencing the local environment (Vander Zanden et al. 2010; Zaiko et al. 2014). Often with AIS, juveniles have a patchy distribution, are difficult to identify by assessing morphological features, and therefore species are easily missed by monitoring programmes (Pochon et al. 2013; Trebitz et al. 2017). Current methods used to detect and monitor aquatic species are can be unreliable due as they can only provide reliable estimates of species presence and absence (Darling and Mahon 2011; Jerde et al. 2011; Price and Peterson 2010; Rödel and Ernst 2004). Populations of established AIS can undergo dramatic localised population crashes (Simberloff and Gibbons 2004) and boom and bust cycles (Britton et al. 2008; Kirjavainen and Westman 1999), which results in species being undetectable using traditional monitoring methods despite previously existing in higher numbers (Hayes et al. 2005; 
Price and Peterson 2010; Rout et al. 2009; Vander Zanden et al. 2010). Topmouth gudgeon, for example, is known to undergo boom and bust cycles in novel environments, most likely caused by a combination of biotic and abiotic factors, including habitat suitability and temperature fluctuations and predation pressure (Britton et al. 2008; Britton et al. 2007; Copp et al. 2007). Additionally, signal crayfish may experience cyclical fluctuations in population abundance across some of its range (Kirjavainen and Westman 1999).

\subsubsection{Traditional methods of monitoring}

Employing traditional sampling methods such as trapping, as part of AIS monitoring management strategies can often result in lack of detection despite the species being present (false negative; Darling and Mahon 2011). In particular, trapping during the initial stages of invasion or during bust cycles may result in false negatives, resulting in lack of detection for a long period, allowing sufficient time for populations to increase in numbers and potentially spread further (Davies and Britton 2015; Gherardi et al. 2011). Mechanical removal of signal crayfish is effective for reducing population size but not for elimination, due mainly to bias size-selection of traps resulting in large males being removed exclusively (Bills and Marking 2011; Hein et al. 2006; Hein et al. 2007). Management efforts for removal of topmouth gudgeon has consisted of eradication attempts using the chemical piscicide Rotenone (Allen et al. 2006; Britton et al. 2008), which is known to be effective at removing topmouth gudgeon within standing water environments (Ling 2003). Biocides can be developed and targeted towards a specific group of animals (i.e. avermectins and crayfish; (Turner and Schaeffer 1989)), however many compounds are still indiscriminate and are often detrimental to native fauna (Freeman et al. 2010; Lemmens et al. 2014; Ling 2003). This non-selective nature of chemical eradication can result in nonviability of this method for eradicating invasive species in specific locations, particularly if the predicted loss of native biodiversity is too great or if eradication would result in loss of threatened, rare or protected species (Britton et al. 2011a; Ling 2003). Lack of successful detection of AIS in early stages of invasion more than often results in the species being difficult to eradicate (Freire et al. 2014). Early detection of AIS is necessary to deliver more effective management actions regarding eradication and control of invasive species (Lodge et al. 2016) and as such is becoming 
fundamental for the management and control of aquatic invasive species (Vander Zanden et al. 2010).

\subsubsection{Application of eDNA for AIS detection}

Environmental DNA (eDNA), i.e. DNA molecules released from sources including faeces, skin, urine, blood or secretions of organisms, is proving increasingly useful for detecting low abundance and hard to identify species, including many AIS (Biggs et al. 2015; Dejean et al. 2011; Smart et al. 2016). Endangered fauna, including freshwater mussels (Charise et al. 2018) and salmonids (Laramie et al. 2015) have been successfully identified using eDNA, as well as AIS at the early stages of their introduction (Bohmann et al. 2014; Dejean et al. 2012). Despite being a relatively new tool, the use of eDNA is proving to be reliable at detecting a variety of species and is being widely utilised for species management and conservation (Biggs et al. 2015; Laramie et al. 2015; Spear et al. 2015; Thomsen and Willerslev 2015; Walker et al. 2017). Detection rates using eDNA can differ among aquatic species, which can be attributed to abundance variation and/or differences in eDNA shedding rates; highest shedding rates are amongst fish species (Barnes and Turner 2015; Klymus et al. 2015; Sassoubre et al. 2016), whereas invertebrate species such as crayfish have a much reduced rate of eDNA shedding (Sansom and Sassoubre 2017). Successful detection of target species can also depend on the sample source collected; eDNA has been successful detected in both aqueous samples and in aquatic sediment, with some studies suggesting DNA concentration is higher in sediments versus surface water (Pietramellara et al. 2009; Rees et al. 2014; Turner et al. 2015) depending on factors such as seasonality (Buxton et al. 2018), localised hydrological flow rates (Shogren et al. 2017) and target species ecology (Klymus et al. 2015; Roussel et al. 2015). Numerous successful eDNA assays have been refined to increase sensitivity of the tool (Goldberg et al. 2016; Walker et al. 2017; Wilson et al. 2016) and application of digital droplet PCR (ddPCR) has enabled limiting factors to be overcome, such as PCR inhibition (Doi et al. 2015).

\subsubsection{Metabarcoding versus single-species detection}

Environmental DNA can be analysed using two main approaches: metabarcoding and single-species detection (Klymus et al. 2017; Taberlet et al. 2018). Metabarcoding has 
the advantage of high species coverage (Taberlet et al. 2012b), whereas the targeted approach can offer greater sensitivity (Furlan et al. 2016; Smart et al. 2016). In addition, multiple target species can be detected at once by using a multiplex approach, pooling specific primers for each species (Davy et al. 2015; Wozney and Wilson 2017). Species-specific approaches have been previously used in conventional PCR for detection of AIS (Davison et al. 2017; Jackson et al. 2017) whereas quantitative PCR (qPCR) is now more commonly used to target particular species in eDNA samples (e.g. (Carlsson et al. 2017; Ficetola et al. 2008; Hutchins et al. 2017; Thomsen et al. 2012). Moreover, $\mathrm{qPCR}$ is widely used to detect infectious agents in environmental samples (Guy et al. 2003; Huver et al. 2014), and can be particularly useful for the early detection of novel aquatic pathogens (Ganoza et al. 2006; Strand et al. 2014; Wittwer et al. 2018).

\subsubsection{High-resolution melt curve analyses}

High Resolution Melt (HRM) curve analysis is a qPCR-based approach which facilitates identification of small variations in nucleic acid sequences by differences in the melting temperature of double stranded DNA products depending on fragment length and sequence composition (Wittwer 2009). Analysis of HRM peaks has been widely used for SNP genotyping as a fast method to discriminate species (BehrensChapuis et al. 2018; Yang et al. 2009), including natives and invasives (Ramón-Laca et al. 2014). In comparison to fluorogenic probe qPCR assays such as TaqMan ${ }^{\mathrm{TM}}$, which relies on specificity of labelled probes, HRM analysis allows for real-time assessment of qPCR product formation rather than relying solely on amplification curves (Reed et al. 2007). Due to the diagnostic nature of HRM analyses, it is easier to distinguish non-specific amplifications from amplifications of target species DNA (Martinou et al. 2010; Vossen et al. 2009) resulting in fewer false positives, which is particularly important for use as an eDNA monitoring tool (Ficetola et al. 2016; Rees et al. 2014). The qPCR-HRM approach has not extensively been adopted for analysing detection of target species in eDNA samples, despite having potential to be an effective method for rapid species identification (Cowart et al. 2018).

As traditional methods for detecting aquatic invasive species are often ineffective, there is the increasing need to develop non-invasive conservation and management 
tools in the form of reliable, diagnostic eDNA assays. qPCR-HRM assays can provide information on presence and absence of target AIS, which can be achieved in a single reaction tube if employing the multiplex approach (Davy et al. 2015; Wozney and Wilson 2017; Robinson et al. 2018). Despite the inability to determine the source location and exact quantity of eDNA detected using qPCR-HRM assays, presence and absence data can be compared against records of known locations for target species, and can suggest evidence of population expansion and novel invasions (Bohmann et al. 2014; Dejean et al. 2012). Ultimately, the application of eDNA qPCR-HRM assays can inform management strategies, referring to both identification of ark sites for endangered native species and priority locations for eradication of AIS (Thomsen and Willerslev, 2015; Goldberg et al. 2016).

\subsection{Public engagement and citizen science for invasive species research}

An increasingly valuable component of biological monitoring programmes is the input, in terms of volunteer hours and sample collection, from members of the public as part of citizen science initiatives (Conrad and Hilchey 2011; Dickinson et al. 2012). Citizen science projects have gained momentum over the last 40 years, with access to the internet enhancing collection of biological information since the late 1990s (Dickinson and Bonney 2012). For public engagement with monitoring projects, protocols and methods of sample collection should be easily accessible and scientifically robust to ensure full public involvement and enable high-quality samples to be obtained (Devictor et al. 2010; Silvertown 2009) Recently, citizen science initiatives have been employed for a number of eDNA-based monitoring projects for a range of species including the rare great crested newt (Triturus cristatus, hereafter GCN; (Biggs et al. 2015) and the invasive pygmy mussel (Xenostrobus secures; Miralles et al. 2016)).

For eDNA-based citizen science, the success in terms of public involvement and viability of samples collected (i.e. no contamination) in the GCN programme was relatively high, as results from 25 out of 26 volunteer survey sites matched with results from professional team members from the same sites (Biggs et al. 2015). When developing a citizen science programme, many factors including target audience, project duration and frequency of data collection (i.e. one-off event or ongoing) need 
to be considered to achieve the highest levels of engagement and reliable data (Devictor et al. 2010; Tulloch et al. 2013). However, some programmes are unsuccessful and members of the public fail to engage largely through mistrust by the public and concern of data usage, despite appropriate training, protocols and support being in place (Conrad and Hilchey 2011; Tulloch et al. 2013).

\subsection{Aims and objectives of this $\mathrm{PhD}$}

Current methods for detection of aquatic invasive species are often costly, labourintensive and largely ineffective. The main objective of this $\mathrm{PhD}$ is developing methodologies to enable detection and monitoring of target aquatic invasive species (American signal crayfish, Chinese mitten crab and topmouth gudgeon). Implementing methodologies, including novel molecular techniques (high-resolution melt eDNA assays) designed for use by members of the public in citizen science initiatives, this thesis aims to improve the detection and enable a greater understanding of establishment success of target aquatic invasive species. Environmental DNA assays for early detection of aquatic invasive species have been widely developed for a variety of invasive fish and amphibian species, however there is limited research regarding assays for invasive invertebrates and simultaneous detection of multiple species using a multiplex assay. This $\mathrm{PhD}$ aimed to 1) to use microsatellites to assess genetic diversity and structuring of signal crayfish in relation to crayfish plague infection status; 2) develop conservation tools in the form of numerous novel high-resolution melt eDNA assays, including a multiplex assay, to investigate potential areas of coexistence between native and invasive species in relation to presence/absence of invasive pathogens and assess the effect of river fragmentation on target AIS; and 3) design a novel citizen science project, aimed at monitoring distribution of signal crayfish and associated pathogen A. astaci, and compare success with previous similar initiatives.

The main objectives for each chapter are detailed as follows:

The aim of Chapter 1 was to investigate the population genetic diversity and level of population structuring of crayfish plague infected and uninfected signal crayfish populations in locations across England and Wales. A secondary aim was to assess 
whether there is a link between individual genetic diversity and individual crayfish plague infection level in order to investigate whether crayfish plague has facilitated establishment of signal crayfish. In this work, I used a previously designed panel of microsatellites and previous infection data on individual crayfish to analyse genetic diversity and model the relationship of homozygosity and crayfish plague infection.

Robinson, C.V., Garcia de Leaniz, C., James, J., Cable, J., Consuegra, S., 2018. Genetic diversity and parasite-mediated facilitation of establishment in invasive North American signal crayfish (Pacifastacus leniusculus). Ecology and Evolution; DOI:10.1002/ece3.4235.

The aim of Chapter 2 was to develop an eDNA multiplex assay to enable detection of signal crayfish, white-clawed crayfish and crayfish plague simultaneously, in order to investigate detection rates and locations of potential coexistence between crayfish species in three river catchments (River Wye, River Taff and River Itchen). To undertake this work, I designed and optimised a high-resolution melt qPCR multiplex assay and validated positive detections of target species through cloning. Sample collection methodology involving small water volumes was selected to aid ease of collection by members of the public (citizen science).

Robinson, C.V., Uren Webster, T.M., Cable, J., James, J., Consuegra, S., 2018. Simultaneous detection of invasive signal crayfish, endangered white-clawed crayfish and the crayfish plague pathogen using environmental DNA. Biological Conservation 222, 241-252.

The aim of Chapter 3 was to determine the influence of barriers on the distribution of both signal crayfish and mitten crabs in two river catchments (River Medway and River Dee). I employed the previously designed eDNA assay to assess detection rates of both target species in both water and sediment eDNA samples in order to determine whether barriers restrict the movement of target species both up and downstream.

Robinson, C.V., Garcia de Leaniz, C., Consuegra, S. Effect of stream fragmentation on the distribution of the invasive signal crayfish and Chinese mitten crab. (Manuscript in preparation).

The aim of Chapter 4 was to determine the success of previous eradication attempts of topmouth gudgeon through development of a novel eDNA qPCR assay. For this 
work, I developed and optimised a species-specific assay for topmouth gudgeon and determined presence/absence of target species in four ponds in South Wales. Sensitivity of the assay was determined through assessing positive detections in two differing water volumes (15 mL vs $750 \mathrm{~mL})$.

Robinson, C.V., Garcia de Leaniz, C. Rolla, M., Consuegra, S. Development of a novel eDNA assay for monitoring the eradication of the highly invasive topmouth gudgeon (Pseudorasbora parva). (Biological Invasions; in review).

The aim of Chapter 5 was to design and implement a novel invasive species citizen science programme (Crayfish Count) to investigate the distribution of signal crayfish and crayfish plague infection levels. A secondary aim of this chapter was to assess the success of the project and identify strengths, weaknesses and improvements. 


\section{CHAPTER 1}

\section{Genetic diversity and parasite-mediated facilitation of establishment in invasive North American signal crayfish

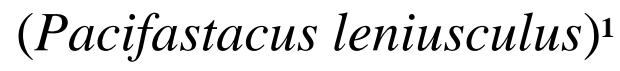

Pages $16-34$

Supporting information (pages $126-141$ )

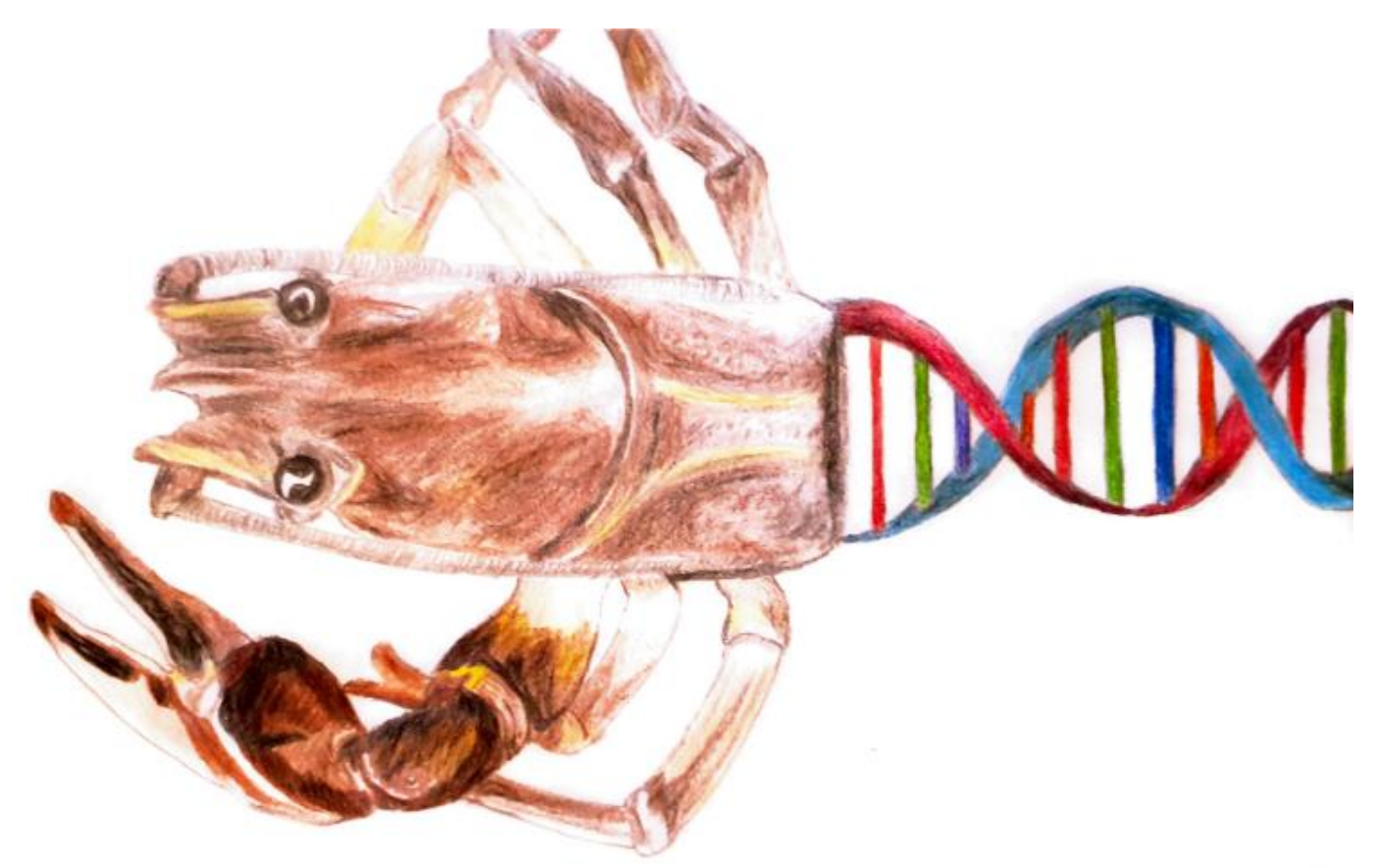

\footnotetext{
${ }^{1}$ This chapter is based on manuscript 'Robinson, C.V., Garcia de Leaniz, C., James, J., Cable, J., Consuegra, S., 2018. Genetic diversity and parasite-mediated facilitation of establishment in invasive North American signal crayfish (Pacifastacus leniusculus). Ecology and Evolution; DOI:10.1002/ece3.4235.'
} 


\section{CHAPTER 1: INTRODUCTION}

Crayfish species have been introduced throughout Europe since the 1890, with signal crayfish being introduced across many countries including Great Britain (Petrusek et al. 2017). It is thought that the spread of signal crayfish (Pacifastacus leniusculus) has been facilitated by human-mediated dispersal and proximity of previous crayfish farms to river catchments (Crowl et al. 2008). Despite the current widespread distribution of this invasive species and previous research regarding haplotype diversity across Europe (Petrusek et al. 2017), it is unclear how many introductions have taken place, from which source introduced signal crayfish have originated from and the genetic fitness of current populations across Great Britain. It is expected that newly introduced populations of signal crayfish will lose genetic diversity due to founder effects (Dlugosch and Parker 2008), although multiple introductions from different source populations can facilitate an increase in genetic diversity and the likelihood of establishing (Allendorf and Lundquist 2003; Prentis et al. 2008). However, some crayfish species have succeeded in the absence of numerous introduction events; despite a large bottleneck following a single introduction event of 90 spiny-cheek crayfish (Orconectes limosus) individuals in 1890, this species have achieved high invasion success and is currently widespread across Europe (Filipová et al. 2011).

It is currently unclear as to how available genetic diversity and presence of invasive crayfish plague pathogen Aphanomyces astaci has enabled signal crayfish to become a successful invasive species in Great Britain, and therefore I aimed to assess the relative roles of the crayfish plague and multiple introductions in the establishment and dispersal of invasive crayfish in Great Britain. To do this, I compared the genetic diversity, effective population size and potential origin of seven signal crayfish populations with different plague infection status.

\section{METHODS}

3.1. Study sites and sample collection

American signal crayfish were collected using baited crayfish traps (checked every 24 hours) and hand netting (James et al. 2017), from five sites in Wales (Sirhowy, Dderw, Bachowey, Mochdre and Gavenny) and two sites in England (Lugg and Lea) between May - September 2014 and one site (Pant-y-Llyn) in 2016 (Figure 1; Table 1). In 
addition, 30 crayfish were collected from a native population with unknown infection status in Oregon (US) as a reference for genetic diversity. The crayfish plague pathogen had not been detected at sites 1 (Sirhowy), 2 (Lugg) and 3 (Dderw), but had been isolated from crayfish at the remaining sites (James et al. 2017). Crayfish were collected under NRW Permits NT/CW065-C-652/5706/01 and NT/CW081-B797/3888/02. 
Table 1. Sample site information for all nine populations of Pacifastacus leniusculus sampled in Great Brita longitude, site type and origin, catchment, crayfish plague infection status and number of crayfish collected $\mathrm{p}$

\begin{tabular}{|c|c|c|c|c|c|}
\hline $\begin{array}{l}\text { Site } \\
\text { No. }\end{array}$ & $\begin{array}{l}\text { Site name } \\
\text { (Country) }\end{array}$ & Latitude & Longitude & $\begin{array}{c}\text { Site Type } \\
\text { (Origin) } \\
\end{array}$ & Catchment \\
\hline 1 & Sirhowy (GB) & 51.61628 & -3.138935 & Stream (Natural) & Usk \\
\hline 2 & Lugg (GB) & 52.10007 & -2.420102 & River (Natural) & Wye \\
\hline 3 & Dderw (GB) & 52.01450 & -3.152826 & $\begin{array}{c}\text { Pond } \\
\text { (Manmade) }\end{array}$ & Wye \\
\hline 4 & Lea (GB) & 51.47595 & -0.043186 & River (Natural) & Thames \\
\hline 5 & Bachowey (GB) & 52.06341 & -3.135126 & River (Natural) & Wye \\
\hline 6 & Mochdre (GB) & 52.30137 & -3.520527 & Stream (Natural) & Wye \\
\hline 7 & Gavenny (GB) & 51.82175 & -3.012968 & River (Natural) & Usk \\
\hline 8 & Pant-y-Llyn (GB) & 52.10932 & -3.405192 & $\begin{array}{c}\text { Pond } \\
\text { (Manmade) }\end{array}$ & Wye \\
\hline 9 & Oregon (USA) & 44.55362 & -123.2539 & Stream (Natural) & Willamette \\
\hline
\end{tabular}




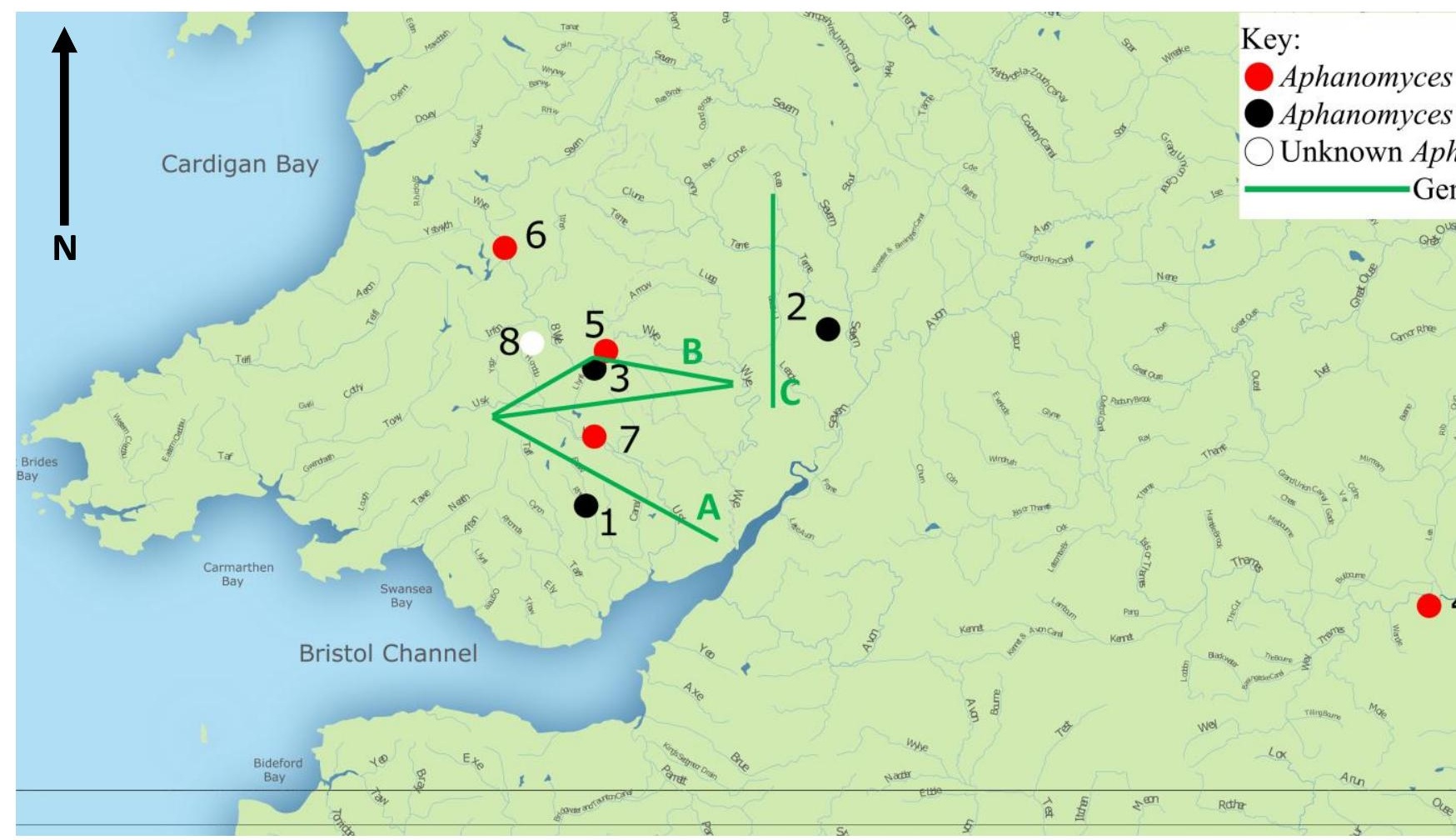

Figure 1. Map of UK sampling sites for Pacifastacus leniusculus, infection status and the three highly sigI generated by BARRIER in relation to sample sites ( $1=$ Sirhowy, $2=$ Lugg, 3=Dderw, 4=Lea, 5=Bachowey, Llyn). 


\subsection{DNA extraction and amplification}

Total genomic DNA was extracted from each crayfish from a section of tail fan, soft abdominal cuticle and walking leg tissue using the DNeasy tissue kit (QIAGEN, Sussex, UK) following the manufacturer's instructions (James et al. 2017). A total of 214 crayfish were analysed using 9 microsatellites (Table 1), in three separate multiplex reactions (Azuma et al. 2011; Froufe et al. 2015). Extracted DNA was analysed for quantity and quality using a Nanodrop 2000 (Thermo Fisher Scientific Inc., USA) and approximately $8 \mu \mathrm{g}$ were used for amplification using the QIAGEN Multiplex PCR kit, following the QIAGEN multiplex reaction protocol (QIAGEN, Sussex, UK) in a total volume of $12 \mu \mathrm{L}$. Each reaction consisted of the concentrations of primers detailed in (Froufe et al. 2015) (Table S1), with the exception of Scop31 (forward and reverse), which was re-optimised at $1 \mu \mathrm{M}$.

Amplification conditions consisted of a single-cycle initial activation step of $15 \mathrm{~min}$ at $95^{\circ} \mathrm{C}$ followed by a touchdown PCR of eight cycles with a $30 \mathrm{~s}$ denaturation step at $94^{\circ} \mathrm{C}$, a $90 \mathrm{~s}$ annealing step starting at $64^{\circ} \mathrm{C}$ and descending in 2-cycle steps of $2^{\circ} \mathrm{C}$ $\left(64,62,60,58\right.$ and $\left.56^{\circ} \mathrm{C}\right)$ and $90 \mathrm{~s}$ of extension at $72^{\circ} \mathrm{C}$. Twenty-four additional cycles of PCR were then run as above at an annealing temperature of $56^{\circ} \mathrm{C}$ followed by a single final extension cycle of $30 \mathrm{~min}$ at $60^{\circ} \mathrm{C}$. Microsatellites were resolved on an Applied Biosystems ABI3130xl Genetic Analyser (Applied Biosystems, Sussex, UK), and fragment length was determined using the GeneScan 500-LIZ size standard and scored using GeneMapper v45.0 (Applied Biosystems, Sussex, UK).

\subsection{Genetic analyses}

MICRO-CHECKER v2.2.3 (Van Oosterhout et al. 2004) was used to assess presence of null alleles, large allele drop-outs and scoring errors due to stuttering. GENALEX v6.5 (Peakall and Smouse 2006) was used to estimate effective number of alleles ( $\left.N_{\mathrm{EF}}\right)$ and the populations' expected $\left(H_{\mathrm{E}}\right)$ and observed heterozygosities $\left(H_{\mathrm{O}}\right)$ respectively. Deviations from Hardy-Weinberg equilibrium and tests for linkage disequilibrium were investigated using GENEPOP online v4.0.10 (Rousset 2008). Pairwise $F_{\text {ST }}$ values and heterozygosity per locus were calculated using FSTAT v1.2 (Goudet 1995). Analysis of Molecular Variance (AMOVA) among populations, among individuals and within individuals was calculated in ARLEQUIN v3.1 (Excoffier et al. 2005). Homozygosity by locus $\left(H_{\mathrm{L}}\right)$, which weighs the 
contribution of each locus to the homozygosity index depending on their allelic variability, was estimated for each individual in Cernicalin v1.0 (Aparicio et al. 2006). Effective population size was estimated using $\mathrm{N}_{\mathrm{e}}$ Estimator v2.01 (Do et al. 2013) for samples with a minimum of 19 individuals using the Linkage Disequilibrium method with allele frequencies larger than 0.02 . For $H_{\mathrm{L}}$ analyses, both the Oregon and Pant-yLlyn populations were excluded, as crayfish plague infection status and therefore PCR forming units (PFU) values for these individuals were unknown.

STRUCTURE v2.3.4 (Pritchard et al. 2000), was used to estimate the most likely number of genetic clusters in the data. The analysis was run under the admixture ancestry model, computing the proportion of the genome of each individual originating from each cluster (K). The number of clusters tested ranged from $K=1$ to 9, with 20 repetitions for each $\mathrm{K}$ value, and 60,000 MCMC steps discarding the first 10,000 as burn-in (Pritchard et al. 2000). The best fitting $\mathrm{K}$ value was estimated using StructureSelector ( $\mathrm{Li}$ and Liu 2017), which utilises four alternative statistics (MEDMEDK, MEDMEAK, MAXMEDK and MAXMEAK) to produce more accurate results for populations with uneven sample size.

BARRIER v2.2 (Manni et al. 2004) was used to detect discontinuities in allelic frequencies between British crayfish populations based on genetic distance and geographical distance values using the Monmonier's maximum difference algorithm (Monmonier 1973). Initially one data matrix containing pairwise $F_{\text {ST }}$ values was imported in BARRIER to detect genetic barriers across all populations. Eight data matrices were then imported into BARRIER containing pairwise $F_{\text {ST }}$ values per locus to assess the number of loci supporting each barrier and test for barrier robustness' (Manni et al. 2004).

The most likely scenario of colonisation for UK populations was estimated using and Approximate Bayesian Computation approach implemented in the software DIYABC v2.1.0 (Cornuet et al. 2014). For this analysis the Lea, Mochdre and Gavenny populations were grouped into one genetic group (pool 1) based on $F_{\text {ST }}$ values and similarity of genetic clusters from the STRUCTURE analysis and the remaining populations were analysed as separate populations. Three scenarios of colonisation were tested (Figure 3): Scenario 1 - simultaneous divergence (null hypothesis), 
Scenario 2 - simultaneous divergence of Sirhowy, pool 1, Lugg, Bachowey and Dderw followed by divergence of Pant-y-Llyn from Bachowey, Scenario 3 - simultaneous divergence of Sirhowy, pool 1, Lugg, Bachowey and Dderw followed by admixture of pool 1 with Bachowey to produce the Pant-y-Llyn population. Default settings were used for mutation rates (generalised stepwise mutation model (Estoup et al. 2002) with a uniform prior distribution of mean mutation rate between $10^{-4}$ and $10^{-3}$, priors were set uniformly distributed, prior distribution of individual locus mutation rates were set between $10^{-5}$ and $10^{-2}$ following a Gamma distribution with mean determined by the mean mutation rate across loci. Effective population sizes were set between 10 and 2,500 for all populations. A total of $1,000,000$ simulations per scenario $(1,2,3)$ were generated from the parameters prior distributions. Mean gene diversity across loci and mean $\mathrm{M}$ index diversity across loci (one sample summary statistics) were calculated for each population. Pre-evaluation of each scenario was carried out by generating Principal Component Analysis (PCA) plots based on summary statistics using 30,000 (1\%) simulated data sets and the posterior distribution of the parameters was estimated using the logit function (Cornuet et al. 2014). For model checking, I performed a PCA using new simulated datasets $(1,000,000$ per scenario) drawn from the posterior distribution of parameters, which are also represented on the PCA. Two sample summary statistics were used in model checking (mean number of alleles, mean genic diversity, mean size variance, $F_{\mathrm{ST}}$, classification index, shared allele distance and $(\mathrm{d} \mu)^{2}$ distance) to assess whether the observed data was included within the distribution of the predictive posterior parameters of the simulated data. Confidence in each scenario was obtained from the highest posterior probability using logistic regression, estimated by comparing the summary statistics from simulated and observed results, and from calculating type I and type II errors using 1000 simulated datasets (Cornuet et al. 2014).

Population heterozygosity and effective population size were compared between infected and non-infected populations using a Welch t-test for unequal variances. I also modelled infection status (yes/no) and plague intensity (measured as density of plaqueforming units, PFU) in individual crayfish using population of origin as a random factor and individual homozygosity $\left(H_{\mathrm{L}}\right)$ as a predictor with either a binomial logit link 
(infection status) or a gaussian link (plague intensity, measured as $\log (\mathrm{PFU}+0.5)$ with the lme4 package in $\mathrm{R}$, version 3.3.2.

\section{RESULTS}

4.1. Host genetic diversity and population structuring

MICRO-CHECKER results indicated that four microsatellites had significant evidence of null alleles $(P=0.001)$, however results of repeated analyses $\left(F_{\mathrm{ST}}\right.$, STRUCTURE) removing the affected microsatellites showed no obvious deviations from the results including all nine microsatellites (Table S2; Figure S1), therefore I carried out all subsequent analyses with all of them (van Oosterhout et al. 2004). The nine microsatellite loci displayed moderate to high levels of polymorphism $\left(H_{\mathrm{E}}\right.$ between 0.5 and 0.7 ) across all the sites. All populations displayed a degree of deviation from Hardy-Weinberg Equilibrium (HWE) across various loci due to lower than expected $H_{\mathrm{E}}$. Out of 81 Chi-Square tests conducted (one per locus) 37 showed a significant deviation from HWE (Table S3) after sequential Bonferroni correction. The across loci population tests of HWE showed that all populations deviated significantly from HWE, displaying a deficiency of heterozygosity $(P<0.0001)$. Tests for linkage disequilibrium (LD) for each locus pair across all populations (Fisher's method) revealed only three significant associations out of 36 pairwise comparisons after Bonferroni corrections, these were between LPL26 and LPL40, LPL6 and LPL45 and LPL26 and Scop9.

Across all populations, the mean number of alleles ranged from 4.11 to 8.56 , with the Gavenny site having the highest mean number of alleles and the Sirhowy site the lowest across all populations sampled (Table 2). The mean expected heterozygosity $\left(H_{\mathrm{E}}\right)$ across all populations ranged from 0.46 to 0.69 respectively. The mean effective number of alleles ranged from 2.25 in the Dderw site to 5.45 in the Gavenny site and for Lea the mean was 4.55. Across all loci, there was no significant difference in number of effective alleles $\left(N_{\mathrm{EF}}\right)$ between populations (One-way ANOVA, $\mathrm{F}_{8,72}=$ $1.496, P=0.1739)$. Effective population size $\left(N_{\mathrm{e} ;}\right)$ ranged between 12.9 (Sirhowy) and 90.4 (Gavenny; Table 2) and, probably due to small sample size, confidence intervals were relatively large (3.9 to 28.6 ).

The STRUCTURE and StructureSelector analyses indicated that $K=4$ (Figure 2; Figure S2; Table S6) is the most likely number of clusters in the dataset for British 
populations only and $\mathrm{K}=5$ (Figure S3; Table S7) for the British populations plus Oregon (Figures 2A and 2B).

Table 2. Summary statistics for each population of Pacifastacus leniusculus. $\mathrm{N}=$ number of individuals, $N_{\mathrm{A}}=$ mean number of alleles, $N_{\mathrm{EF}}=$ mean number of effective alleles, $N_{\mathrm{e}}=$ effective population size, $N_{\mathrm{PA}}=$ mean number of private alleles, $H_{\mathrm{O}}=$ mean observed heterozygosity, $H_{\mathrm{E}}=$ mean expected heterozygosity, $H_{\mathrm{L}}=$ mean homozygosity by locus, $F_{\mathrm{IS}}=$ mean fixation index.

\begin{tabular}{|c|c|c|c|c|c|c|c|c|c|c|}
\hline Population & & $N$ & $N_{A}$ & NEF & $\mathrm{Ne}$ & $N_{P A}$ & $\mathrm{Ho}_{\mathrm{O}}$ & $\boldsymbol{H}_{\mathrm{E}}$ & $H_{\mathrm{L}}$ & $F_{\text {IS }}$ \\
\hline \multirow[t]{2}{*}{ Sirhowy } & Mean & 30 & 4.222 & 2.460 & 12.300 & 0.000 & 0.397 & 0.569 & 0.607 & 0.309 \\
\hline & $\mathrm{SE} \pm$ & & 0.795 & 0.195 & 8.000 & 0.000 & 0.076 & 0.041 & 0.030 & 0.121 \\
\hline \multirow[t]{2}{*}{ Lugg } & Mean & 30 & 5.667 & 3.703 & 26.400 & 0.111 & 0.364 & 0.541 & 0.564 & 0.381 \\
\hline & $\mathrm{SE} \pm$ & & 1.280 & 0.890 & 17.000 & 0.111 & 0.112 & 0.117 & 0.032 & 0.105 \\
\hline \multirow[t]{2}{*}{ Dderw } & Mean & 30 & 4.111 & 2.248 & 19.900 & 0.111 & 0.273 & 0.464 & 0.676 & 0.349 \\
\hline & $\mathrm{SE} \pm$ & & 0.790 & 0.301 & 11.200 & 0.111 & 0.079 & 0.090 & 0.030 & 0.116 \\
\hline \multirow[t]{2}{*}{ Lea } & Mean & 37 & 7.778 & 4.552 & 76.500 & 0.444 & 0.426 & 0.628 & 0.516 & 0.328 \\
\hline & $\mathrm{SE} \pm$ & & 1.392 & 1.054 & 47.000 & 0.242 & 0.099 & 0.092 & 0.022 & 0.103 \\
\hline \multirow[t]{2}{*}{ Bachowey } & Mean & 19 & 5.000 & 3.090 & 29.900 & 0.222 & 0.398 & 0.577 & 0.552 & 0.307 \\
\hline & $\mathrm{SE} \pm$ & & 0.772 & 0.527 & 14.600 & 0.147 & 0.080 & 0.079 & 0.036 & 0.087 \\
\hline \multirow[t]{2}{*}{ Mochdre } & Mean & 19 & 6.778 & 4.108 & 42.800 & 0.111 & 0.427 & 0.653 & 0.525 & 0.367 \\
\hline & $\mathrm{SE} \pm$ & & 1.222 & 0.773 & 22.100 & 0.111 & 0.104 & 0.072 & 0.040 & 0.117 \\
\hline \multirow[t]{2}{*}{ Gavenny } & Mean & 30 & 8.556 & 5.445 & 90.400 & 0.389 & 0.441 & 0.687 & 0.519 & 0.350 \\
\hline & $\mathrm{SE} \pm$ & & 1.730 & 1.430 & 49.500 & 0.564 & 0.073 & 0.073 & 0.035 & 0.081 \\
\hline \multirow[t]{2}{*}{ Pant-y-Llyn } & Mean & 32 & 5.444 & 3.449 & 14.200 & 0.556 & 0.350 & 0.574 & 0.594 & 0.428 \\
\hline & $\mathrm{SE} \pm$ & & 1.029 & 0.729 & 10.000 & 0.338 & 0.089 & 0.089 & 0.037 & 0.104 \\
\hline \multirow[t]{2}{*}{ Oregon } & Mean & 19 & 7.222 & 4.191 & 32.600 & 1.556 & 0.374 & 0.588 & 0.502 & 0.404 \\
\hline & $\mathrm{SE} \pm$ & & 1.623 & 8.972 & 18.700 & 0.580 & 0.118 & 0.103 & 0.050 & 0.137 \\
\hline
\end{tabular}




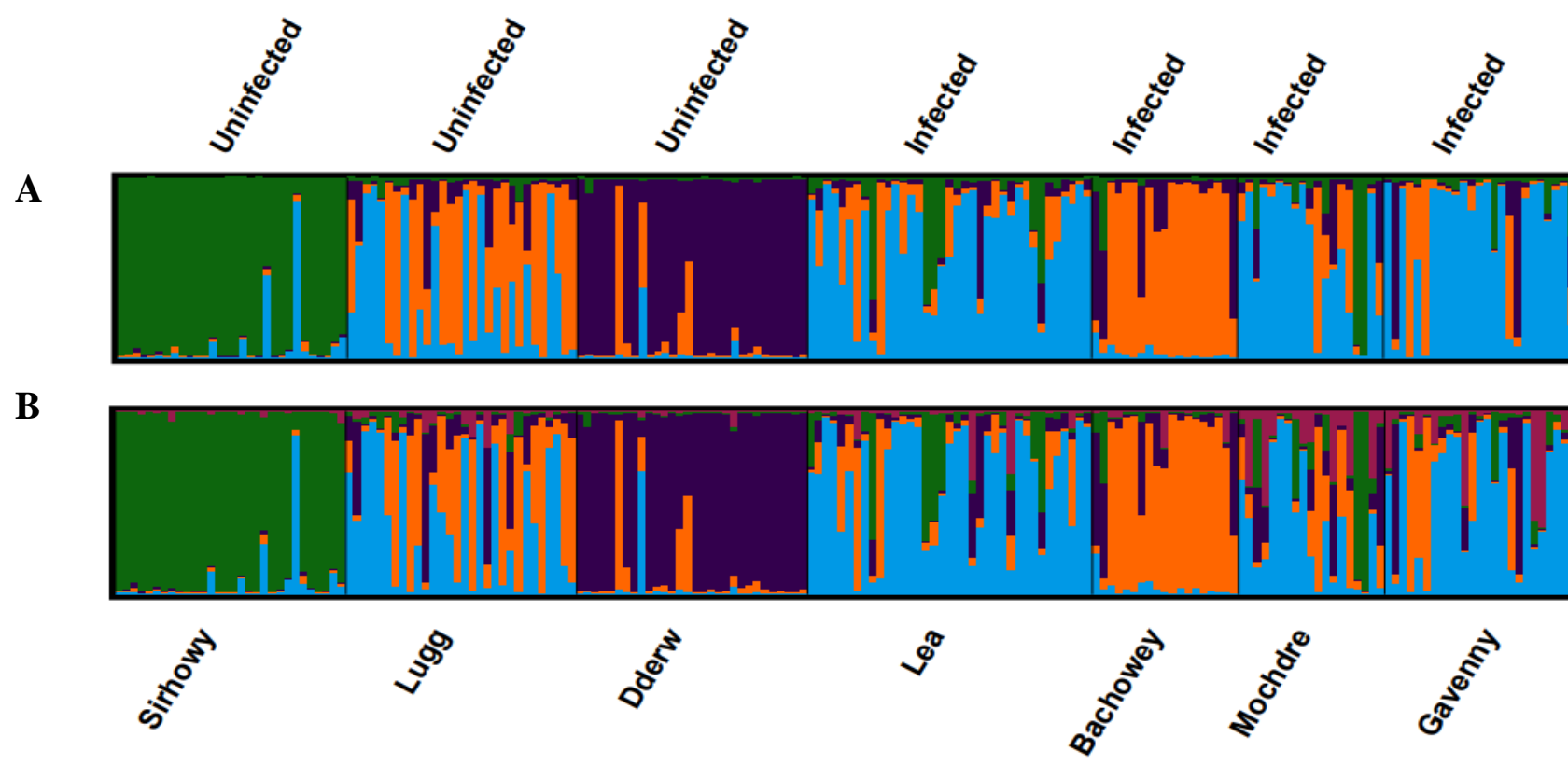

Figure 2. STRUCTURE analysis for UK Pacifastacus leniusculus populations at $K=4$ clusters (A); each $b$ the different colours represent different clusters and therefore indicate the proportion of each crayfish attribut stated above the output and corresponding population names stated below for each population. b) STRU crayfish populations at $\mathrm{K}=5$ clusters $(\mathrm{B})$. 
Pairwise population $F_{\mathrm{ST}}$ values were highly significant (after Bonferroni correction, $P<0.00138$ ), with the exception of the Mochdre and Gavenny sites, and the Mochdre and Lea sites (Table 3). Among the UK populations, the Dderw displayed the highest divergence, with the highest pairwise $F_{\mathrm{ST}}$ observed between the Dderw and Sirhowy populations $\left(F_{\mathrm{ST}}=0.294, P<0.001\right)$. The AMOVA results for all sites indicated that variation among populations accounted for $15 \%$ of the genetic differentiation, while variance among individuals within populations accounted for $31 \%$ and the remaining $54 \%$ was due to intra-individual variation (Table 4). Most populations displayed a relatively high degree of admixture (average Q value 69\%), apart from Sirhowy and Dderw (average Q value of 91\%). Geographically distant populations (e.g. Lea and Mochdre) displayed high levels of genetic similarity despite distance, which was reflected in lack of IBD in the Mantel test for UK populations (y $\left.=0.0009 \mathrm{x}+17.053, \mathrm{R}^{2}=0.0003, P>0.05\right)$.

Analysis of the most likely scenario of colonization suggested the simultaneous divergence of populations (Scenario 1), based on logistic regression and PCA results (Figure 3; Figure S5). Observed summary statistics did not deviate significantly from simulated statistics and scaled posteriors aligned well with priors (Table S4; Table S5). According to this scenario, six main colonisation events could have taken place; (1) Sirhowy; (2) Dderw; (3) Bachowey; (4) pool 1 (Lea, Mochdre and Gavenny), (5) Lugg, (6) Pant-y-Llyn.

Populations with the lowest degree of admixture (Sirhowy, Bachowey and Dderw) did not have a significantly lower heterozygosity $\left(H_{\mathrm{E}}=0.527\right)$ compared to populations which were more admixed (Lugg, Lea, Mochdre, Gavenny, Pant-y-Llyn; average $H_{\mathrm{E}}=$ 0.617; $\mathrm{df}=4.4$; Welch t-test; $P=0.098$ ). Results from BARRIER suggested that the most likely number of discontinuities in genetic connectivity was due to three barriers (Figure S4), the strongest division occurring between Sirhowy and all the other sites (Barrier a; Figure 1). The next largest discontinuity was observed between Dderw and surrounding populations (Barrier b; Figure 1), while the third barrier separated Lugg from the Welsh populations (Barrier c; Figure 1; site 2). All barriers were supported by seven out of nine loci. 
Table 3. Pairwise $F_{\mathrm{ST}}$ values (below diagonal) and significance (above diagonal) for nine pop leniusculus sampled in Great Britain.

\begin{tabular}{ccccccccc}
\hline & Sirhowy & Lugg & Dderw & Lea & Bachowey & Mochdre & Gavenny & P \\
\hline Sirhowy & 0.000 & $*$ & $*$ & $*$ & $*$ & $*$ & $*$ \\
Lugg & 0.206 & 0.000 & $*$ & $*$ & $*$ & $*$ & $*$ \\
Dderw & 0.294 & 0.138 & 0.000 & $*$ & $*$ & $*$ & $*$ \\
Lea & 0.162 & 0.041 & 0.139 & 0.000 & $*$ & NS & $*$ \\
Bachowey & 0.195 & 0.085 & 0.145 & 0.056 & 0.000 & $*$ & $*$ \\
Mochdre & 0.150 & 0.053 & 0.148 & 0.026 & 0.050 & 0.000 & NS \\
Gavenny & 0.155 & 0.056 & 0.129 & 0.029 & 0.063 & 0.017 & 0.000 \\
Pant-y-Llyn & 0.199 & 0.064 & 0.100 & 0.037 & 0.017 & 0.052 & 0.052 \\
Oregon & 0.334 & 0.337 & 0.410 & 0.273 & 0.312 & 0.253 & 0.258 \\
\hline
\end{tabular}

Significance values for each pairwise comparison adjusted by sequential Bonferroni corrections. $* P<0.00138$ 
Table 4. Results of Analysis of Molecular Variance (AMOVA) for all nine populations of invasive Paci different sources of variation (among populations, among individuals, within individuals), degrees of freedo (SSD), variance components, percentage variation and $P$ value for each source.

\begin{tabular}{ccccc}
\hline $\begin{array}{c}\text { Source of } \\
\text { Variance }\end{array}$ & d.f. & SSD & $\begin{array}{c}\text { Variance } \\
\text { Components }\end{array}$ & $\begin{array}{c}\text { Percentage } \\
\text { Variation }\end{array}$ \\
\hline $\begin{array}{c}\text { Among } \\
\text { Populations }\end{array}$ & 8 & 235.163 & 0.475 & 14.892 \\
$\begin{array}{c}\text { Among } \\
\text { Individuals } \\
\quad \text { Within }\end{array}$ & 236 & 876.566 & 1.001 & 31.400 \\
Individuals & 245 & 419.500 & 1.712 & 53.708 \\
\hline
\end{tabular}


A

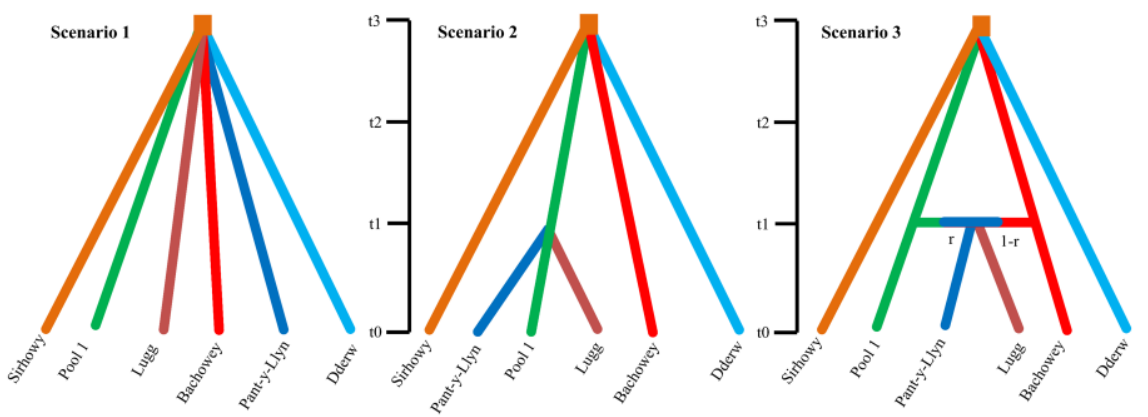

B

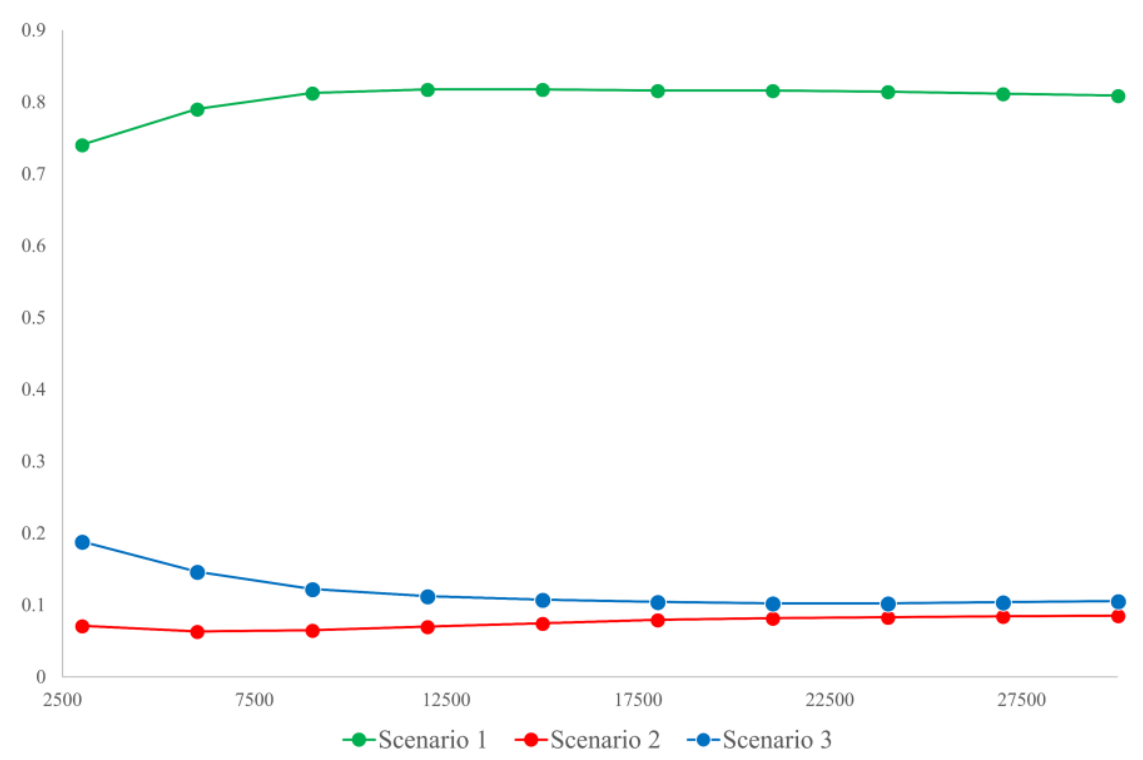

C

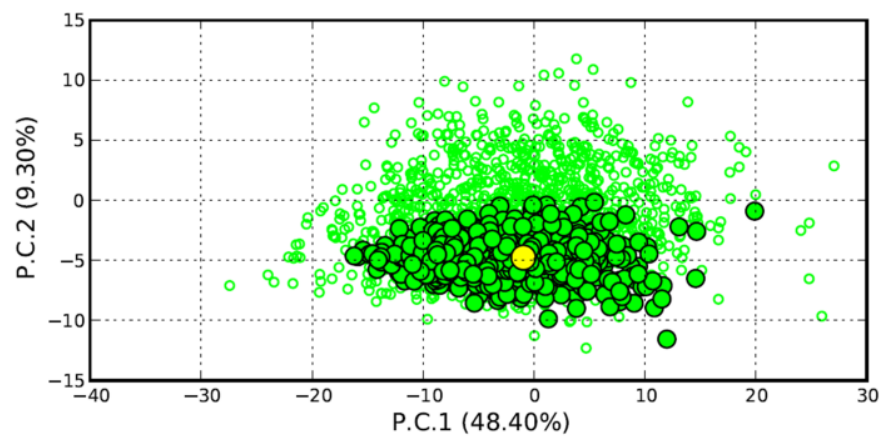

\begin{tabular}{ll} 
Scenario 1 prior \\
8 & Scenario 1 posterior \\
\hline
\end{tabular}

$8 \begin{aligned} & \text { Scenario } 1 \text { posterior } \\ & \text { Observed data set }\end{aligned}$

Figure 3. Three scenarios of signal crayfish colonisation tested using Approximate Bayesian Computation analysis (ABC) (A): Simultaneous divergence (Scenario 1), simultaneous divergence of Sirhowy, Pool 1, Lugg, Bachowey and Dderw, followed 
by divergence of Pant-y-Llyn from Bachowey (Scenario 2) and simultaneous divergence of Sirhowy, Pool 1, Lugg, Bachowey and Dderw, followed by admixture of pool 1 with Bachowey to produce Pant-y-Llyn (Scenario 3). Reliability of scenarios displayed through posterior probabilities as the logistic regressions (B). Principal component analysis (PCA) showing the fit of posterior distributions for scenario 1 (C).

4.2. Aphanomyces astaci infection levels and population genetic diversity Infected crayfish populations had a significantly higher mean expected heterozygosity than uninfected ones $\left(H_{\mathrm{E}}\right.$ infected $=0.64, \mathrm{SE}=0.02 ; H_{\mathrm{E}}$ uninfected $=0.52, \mathrm{SE}=0.02$; Welch two sample t-test $=3.509, \mathrm{df}=4.5, P=0.019$ ), while their effective population size did not differ significantly between them (average $N_{\mathrm{e}}$ infected $=59.90 \mathrm{SE}=24.48$; average $N_{\mathrm{e}}$ uninfected $=19.73 \mathrm{SE}=5.51 ;$ Welch two sample t-test $=2.36, \mathrm{df}=$ $3.4, P=0.06)$.

Mean $H_{\mathrm{L}}$ for each population ranged from 0.50 to 0.68 ( 0 being heterozygous and 1 being completely homozygous). Crayfish populations differed significantly in individual homozygosity (Figure $4 ; F_{6,187}=3.71, P=0.002$ ), with infected populations having a significantly lower homozygosity by locus. Crayfish populations also differed significantly in plague infection loads $\left(F_{6,187}=38.27, P<0.001\right)$, but homozygosity did not explain the probability that an individual would be infected $(z=$ $1.337, P=0.181)$ or the intensity of infection $\left(t_{186.94}=0.874, P=0.383\right)$ when controlling for population of origin. 


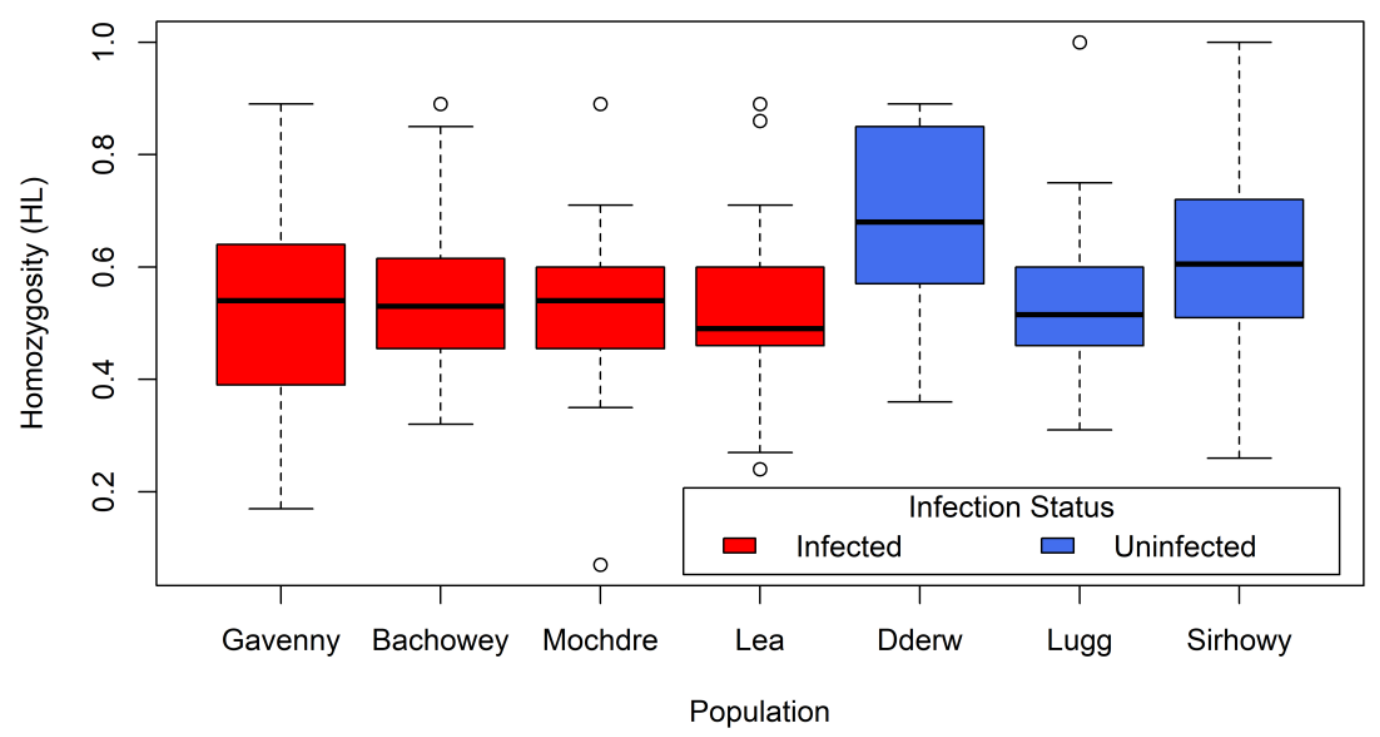

Figure 4. Homozygosity by locus $\left(H_{\mathrm{L}}\right)$ values for each of the crayfish populations with known infection status.

\section{DISCUSSION}

Signal crayfish represents an ideal species to test the roles of genetic diversity and pathogens as novel weapons on invasion success, as the species is highly invasive throughout most of Europe, and Great Britain in particular. Its success has been attributed to preadaptation, aggressive behaviour, niche plasticity, and the presence of the highly infectious A. astaci (Becking et al. 2015; Holdich et al. 2014; Hudina et al. 2011; James et al. 2014a). Admixture between lineages could have also facilitated the establishment of this species, allowing populations to overcome founder effects and loss of genetic diversity (Kolbe et al. 2004; Rius and Darling 2014), particularly when combined with high propagule pressure (Consuegra et al. 2011), but this had not been considered before. In Britain, the species has continued to spread despite management and control measures (Holdich et al. 2014). 
The invasive signal crayfish populations I studied had small effective population sizes and low to moderate genetic diversity, despite having been established for more than 25 years (c. 25 generations), which is similar to what is observed in other invasive crayfish species populations, (e.g. the red swamp crayfish (Procambarus clarkii) in China (Yue et al. 2010), Mexico and Costa Rica (Belfiore and May 2000; NBN 2009; Torres and Álvarez 2012). It is possible that the low levels of heterozygosity observed are the result of recurrent translocations of small numbers of signal crayfish which may have resulted in founder effects (Gouin et al. 2006). None of the populations were in Hardy-Weinberg equilibrium and all had lower than expected heterozygosity, which is consistent with founder effects. In addition, lack of isolation by distance and strong population structuring could be the result of multiple introductions from different sources (Le Roux and Wieczorek 2008; Roman and Darling 2007) or of small founder sizes followed by genetic drift and isolation. Eradication efforts over the last 10 years, such as the removal of c56,000 crayfish in the Bachowey (Abdelkrim et al. 2007; WUF 2012), could have also contributed to decreasing genetic diversity and increasing population structuring, but the documentation of these events is too scarce to draw any conclusions.

Evidence of four main genetic clusters in the introduced signal crayfish populations, the strong differentiation $\left(F_{\mathrm{ST}}\right)$ values and the most likely colonisation scenario support the assumption that current crayfish populations in Britain are not genetically homogenous, a phenomenon common in invasive species originating from different origins (Zalewski et al. 2010). The most likely colonisation scenario for signal crayfish in the sites sampled in Britain suggested that populations most likely originated from six source populations with varying levels of genetic diversity, although some caution is warranted in the interpretation of the results due to the deviations from HardyWeinberg equilibrium. The observed spatial pattern of infected crayfish populations is best explained by considering numerous founder events and further colonisation helped by human-mediated dispersal. This corresponds well to the diversity of mitochondrial DNA previously observed for this species in Europe (including six different haplotypes in the British Isles), which lacks a geographical pattern and has been attributed to different introductions and secondary human-mediated 
translocations (Petrusek et al. 2017), and would explain why some infected populations (Lea, Mochdre and Gavenny) have a common genetic background, similar to what has been observed in the Czech Republic (Kozubíková et al. 2008). Infected crayfish populations had higher heterozygosity than uninfected populations which, if representative of whole genome heterozygosity, could represent higher fitness (Forstmeier et al. 2012; Reed and Frankham 2003). The presence of infected and uninfected signal crayfish in close proximity (i.e. Dderw and Bachowey) could be a consequence of physical barriers and is important in relation to the conservation of endangered native crayfish populations, as invasive signal crayfish and native European crayfish can coexist in the absence of plague (Bubb et al. 2005; DiéguezUribeondo 2006; Filipová et al. 2013). Native crayfish tend to inhabit refugia in the headwaters of numerous catchments within Britain, some of which have tested positive for A. astaci downstream (Bubb et al. 2005; Filipová et al. 2013).

In summary, it is likely that human-mediated dispersal has contributed to the numerous colonisation events from a minimum of four genetic origins and further facilitated population expansion and succession of signal crayfish. Populations with $A$. astaci displayed higher heterozygosity, which could potentially be an indication of fitness benefits or a consequence of the absence of competition with native crayfish, however, physical and/or environmental barriers to dispersal may have additionally contributed to differences in A. astaci infection levels between populations as opposed to the varying genetic diversity of individual crayfish. Despite this species' invasion success, low effective population size and levels of genetic diversity observed suggest that populations are either still establishing in Great Britain and have not yet overcome the effects of founder effects or have suffered a decrease in local genetic diversity as a result of invasive crayfish removal programmes. The success of local management programmes is difficult to assess, as crayfish populations are very difficult to eradicate by mechanical means (Freeman et al. 2010), and negative density dependence can improve the body condition of survivors (Moorhouse and Macdonald 2010). However, my study suggests that genetic monitoring before and after physical removal of crayfish can provide measures of genetic diversity and effective population size that could be used to assess the population consequences of removal actions. 


\section{CHAPTER 2}

Simultaneous detection of invasive signal crayfish, endangered white-clawed crayfish and the crayfish plague pathogen using environmental DNA ${ }^{2}$

Pages $35-66$

Supporting information (pages $142-153$ )

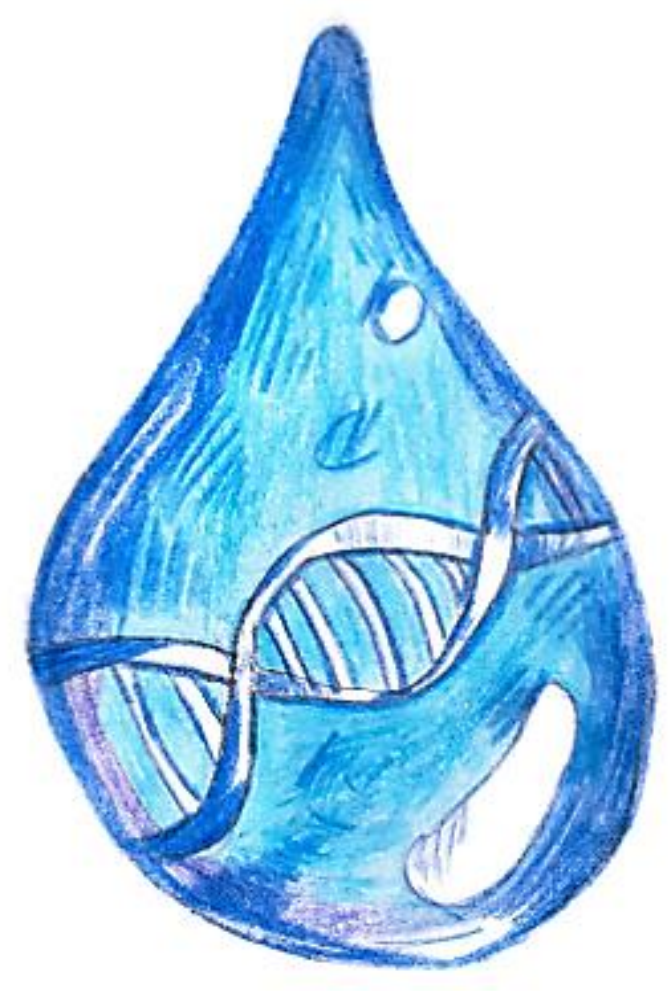

${ }^{2}$ This chapter is based on manuscript 'Robinson, C.V., Uren Webster, T.M., Cable, J., James, J., Consuegra, S., 2018. Simultaneous detection of invasive signal crayfish, endangered white-clawed crayfish and the crayfish plague pathogen using environmental DNA. Biological Conservation 222, 241-252.' 


\section{CHAPTER 2: INTRODUCTION}

Monitoring programs targeting the highly invasive signal crayfish (Pacifastacus leniusculus) have recently shifted focus to the use of non-invasive tools including eDNA. Numerous species-specific qPCR assays have been designed and implemented mainly in closed systems across a range of countries (Scandinavia (Agersnap et al. 2017); North America (Larson et al. 2017); France (Mauvisseau et al. 2018) and UK (Harper et al. 2018)). A majority of assays have been designed using the TaqMan ${ }^{\circledR}$ approach, relying on specific probes to confirm positive detection of target species; however one study (Mauvisseau et al. 2018) has highlighted the greater sensitivity and reproducibility using SYBR ${ }^{\mathrm{TM}}$ Green $\mathrm{qPCR}$ for field samples due to lack of inhibition compared to TaqMan ${ }^{\circledR}$ assays. The additional high-resolution melt curve analysis step added to SYBR ${ }^{\mathrm{TM}}$ Green $\mathrm{qPCR}$ protocols decrease the likelihood of false positives from non-specific amplification and allow for a faster, more reliable and diagnostic result for both single and/or multiple species per reaction (Liu et al. 2018).

An important factor to consider for signal crayfish invasion is the combined influence of both the crayfish and the crayfish plague oomycete (Aphanomyces astaci) on the local environment. It is difficult to disentangle the effects of these two factors and therefore detection of both the crayfish host and A. astaci together is needed to gain information regarding the infection status of any newly invading individuals (Peiró et al. 2016). By using a novel approach to simultaneously identify both AIS and their major associated pathogens, I analysed the distribution of the highly invasive signal crayfish, the native crayfish and the crayfish plague pathogen in areas where the presence of the signal crayfish is severely impacting the native populations, to identify potential areas of coexistence and refugia for the native species. I expected to find coexisting populations of both species more likely in locations where the crayfish plague has been historically and continually absent.

\section{METHODS}

7.1. Assay validation 
In order to validate the eDNA assay in a controlled environment and assess short-term degradation rates, a pilot experiment was conducted by placing individual signal crayfish in three isolated tanks, each with $2 \mathrm{~L}$ of water. After 24 hours, they were removed and two $15 \mathrm{~mL}$ water samples were taken from each tank. The sampling was repeated 24 and 48 hours after removal. Two ultrapure water blanks and four tank blanks (with no crayfish in) were also taken as controls during each sampling period. Immediately after collection, a standard method of preserving and extracting eDNA was applied by the addition of $33 \mathrm{~mL}$ of absolute ethanol and $1.5 \mathrm{~mL}$ of $3 \mathrm{M}$ sodium acetate to samples and subsequent storage at $-20^{\circ} \mathrm{C}$ for a minimum of 24 hours before DNA extraction (Ficetola et al. 2008). To recover precipitated DNA, samples were centrifuged to create a DNA pellet. The supernatant was discarded and the remaining pellet was air-dried before being subjected to DNA extraction. Extraction blanks consisting of ultrapure water in place of sampled water and tank blanks were used to test for any cross-contamination of the samples. Similarly, nine $15 \mathrm{~mL}$ water samples were taken, along with a system blank, at a local hatchery containing a population of white-clawed crayfish, to test detection levels of native crayfish in aqueous eDNA samples.

\subsection{Study populations and eDNA sample collection}

I sampled six locations in the River Wye catchment and seven additional sites in the River Taff catchment, both in Wales, UK (Figure 5A-C), as well as 18 sites from the River Itchen (Southern England) and 11 from the River Medway (South-East England; Figure 5C; Table 5), all of them introduced c.1970. Records of the introduction of signal crayfish in Europe are very limited, but some evidence suggests that between 1976 and 1978 around 150,000 juvenile signal crayfish were introduced into Britain and other European countries from a hatchery in Simontorp, Sweden, which originally imported them from Lake Tahoe in California and Nevada, USA, in 1969 (Holdich and Lowery 1988). After the Simontorp introductions, crayfish began to be imported directly from different American hatcheries (Holdich and Lowery 1988), suggesting that the current populations could have different origins, and potentially initial infection status. 
Welsh locations were selected based upon data from CrayBase (James et al. 2014a); two of the locations supported white-clawed crayfish populations, with no evidence of signal crayfish presence, three locations only had populations of signal crayfish and the remaining eight locations could potentially have both Signal crayfish and whiteclawed crayfish or neither species, but their status was uncertain as these had not been previously monitored. Two out of the three signal crayfish confirmed sites were known to contain A. astaci infected crayfish (James et al. 2017).

In the river Medway, signal crayfish was thought to inhabit the upper catchment but the crayfish status downstream was unknown, while in the river Itchen white-clawed crayfish was assumed to be present throughout most of the upper catchment and signal crayfish had been recorded in few sites both upstream and downstream of whiteclawed crayfish presence (Rushbrook 2014); Table 5). The infection status of both the Medway and Itchen crayfish populations was unknown.

Each site was subdivided into three sampling sites (upstream, midstream and downstream), separated where possible by ca. $500 \mathrm{~m}$, to increase the area sampled. Between three and nine $15 \mathrm{~mL}$ water samples were taken from each sampling site simultaneously. All samples were collected ca. $1 \mathrm{~m}$ beneath the surface for ponds and in shallow areas of low flow streams and preserved as for the ex-situ experiment. Negative controls consisting of ultrapure water in place of river/pond water were taken before and after sampling, at each sampling site. Temperature, weather conditions, amount of shade cover, flow rate and $\mathrm{pH}$ were measured at each site (Table 5). Footwear was washed with Virkon ${ }^{\mathrm{TM}}$ and equipment disinfected with bleach between samplings to prevent the possible spread of $A$. astaci spores and DNA contamination between sites. All Wye sites which indicated presence of either crayfish species based on initial qPCR results were re-sampled the following year to assess reproducibility of positive amplifications at the sites (Table 5). To estimate the current presence of both host species, 25 standard TRAPPY ${ }^{\mathrm{TM}}$ crayfish traps (500 x 200 × 57 mm; NRW Permit Reference: NT/CW081-B-797/3888/02) were set following standard guidelines for trapping crayfish (DEFRA 2015). Traps were baited with halibut pellets and set at all 
of the eDNA sample sites and left for 24-48 hour, and 24 hour checks were conducted. Three $15 \mathrm{~mL}$ water samples were taken downstream of traps (or around the trap for still water bodies) which had successfully trapped crayfish, as a control of crayfish eDNA detectability in the river. Crayfish were collected and euthanised by freezing at $-20{ }^{\circ} \mathrm{C}$ (Cooper 2011).

Positive controls for eDNA screening consisted of 15 tissue samples from signal crayfish individuals (pooled tail fan and soft cuticle) from three different source populations (Gavenny, Bachowey and Mochdre), part of a previous study within close proximity to eDNA sampling sites within the Bachowey and Duhonw catchments (James et al. 2017), and 12 white-clawed crayfish individuals (first carapace moults and mortalities preserved in $100 \%$ ethanol) from two different locations in the UK (Cynrig Hatchery, Brecon and Bristol Zoo). 
Table 5. Location and environmental data for eDNA sampling sites in the River Wye for July 2015 Taff (May 2015); River Medway (July 2016) and the River Itchen (October 2017), including wate cover $(0-3)$, temperature $\left({ }^{\circ} \mathrm{C}\right)$, flow rate $(\mathrm{m} / \mathrm{s})$ and total number of samples collected per site minus duplicate (6) or triplicate (9)).

\begin{tabular}{|c|c|c|c|c|c|c|c|}
\hline Date & Waterbody & $\begin{array}{c}\text { Crayfish } \\
\text { Status } \\
\end{array}$ & $\begin{array}{l}\text { Site } \\
\text { No. }\end{array}$ & $\begin{array}{c}\text { Waterbody } \\
\text { Type }\end{array}$ & $\begin{array}{c}\text { GPS } \\
\text { Coordinates } \\
\end{array}$ & $\begin{array}{l}\text { Shade } \\
\text { Cover }\end{array}$ & $\begin{array}{c}\text { Temperatu } \\
\left({ }^{\circ} \mathrm{C}\right)\end{array}$ \\
\hline \multirow{2}{*}{$10 / 07 / 2015$} & & & & & SO 11152 & & \\
\hline & Sgithwen & Native & 1 & Stream & 41419 & 3 & 15 \\
\hline \multirow{2}{*}{$14 / 10 / 2016$} & & & & & SO 11152 & & \\
\hline & Sgithwen & Native & 1 & Stream & 41419 & 2 & 8.5 \\
\hline \multirow{2}{*}{ 10/07/2015 } & & & & & SO 10819 & & \\
\hline & Sgithwen & Native & 2 & Stream & $\begin{array}{c}41423 \\
\text { SO } 10819\end{array}$ & 3 & 14 \\
\hline $14 / 10 / 2016$ & Sgithwen & Native & 2 & Stream & $\begin{array}{c}41423 \\
S 010623\end{array}$ & 2 & 9 \\
\hline $10 / 07 / 2015$ & Bachowey & Signal & $3 \mathrm{~A}$ & Stream & $\begin{array}{c}\text { SO } 10623 \\
42814\end{array}$ & 2 & 14 \\
\hline $10 / 07 / 2015$ & Bachowey & Signal & $3 B$ & Stream & $\begin{array}{c}\text { SO } 13821 \\
45723 \\
\text { SO } 13821\end{array}$ & 1 & 15 \\
\hline $14 / 10 / 2016$ & Bachowey & Signal & $3 B$ & Stream & $\begin{array}{c}45723 \\
\text { SO } 18504\end{array}$ & 0 & 9 \\
\hline 10/07/2015 & Bachowey & Signal & $3 \mathrm{C}$ & Pond & $\begin{array}{c}47170 \\
\text { SO } 18504\end{array}$ & 0 & 23 \\
\hline $14 / 10 / 2016$ & Bachowey & Signal & $3 C$ & Pond & $\begin{array}{c}47170 \\
\text { SO } 18562\end{array}$ & 0 & 8.5 \\
\hline 10/07/2015 & Bachowey & Signal & 4 & Stream & 47118 & 1 & 15 \\
\hline
\end{tabular}




\begin{tabular}{|c|c|c|c|c|c|c|c|}
\hline $14 / 10 / 2016$ & Bachowey & Signal & 4 & Stream & $\begin{array}{c}\text { SO } 18562 \\
47118 \\
\text { SO } 08471\end{array}$ & 1 & 8 \\
\hline $15 / 07 / 2015$ & Edw & Unknown & $5 \mathrm{~A}$ & Stream & $\begin{array}{c}47124 \\
\text { SO } 11226\end{array}$ & 2 & 16 \\
\hline $15 / 07 / 2015$ & Edw & Unknown & $5 B$ & Stream & $\begin{array}{c}48715 \\
\text { SO } 12409\end{array}$ & 2 & 15 \\
\hline $15 / 07 / 2015$ & Edw & Unknown & $5 \mathrm{C}$ & Stream & $\begin{array}{c}52102 \\
\text { SO } 03831\end{array}$ & 2 & 16 \\
\hline $15 / 07 / 2015$ & Duhonw & Signal & $6 \mathrm{~A}$ & Stream & $\begin{array}{c}48780 \\
\text { SO } 02837\end{array}$ & 2 & 15 \\
\hline $15 / 07 / 2015$ & Duhonw & Signal & $6 \mathrm{~B}$ & Stream & $\begin{array}{c}47179 \\
\text { SO } 03891\end{array}$ & 3 & 14 \\
\hline $01 / 05 / 2016$ & Duhonw & Signal & $6 \mathrm{C}$ & Pond & $\begin{array}{c}46490 \\
\text { SO } 07192\end{array}$ & 0 & 23 \\
\hline $01 / 05 / 2016$ & Taff & Unknown & $\mathrm{T} 1$ & Pond & $\begin{array}{c}08525 \\
\text { SO } 07195\end{array}$ & 0 & 10 \\
\hline $01 / 0 د / 2010$ & Taff & Unknown & $\mathrm{T} 2$ & Pond & $\begin{array}{c}08318 \\
\text { SO } 03963\end{array}$ & 0 & 12 \\
\hline 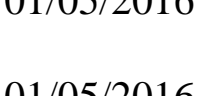 & Taff & Unknown & $\mathrm{T} 3$ & Lake & $\begin{array}{c}07262 \\
\text { SO } 03719\end{array}$ & 1 & 13 \\
\hline $01 / 05 / 2016$ & Taff & Unknown & $\mathrm{T} 4$ & Stream & $\begin{array}{c}07681 \\
\text { SO } 03756\end{array}$ & 0 & 11 \\
\hline $01 / 05 / \angle 010$ & Taff & Unknown & T5 & Stream & $\begin{array}{c}07480 \\
\text { SO } 00849\end{array}$ & 2 & 10 \\
\hline $01 / 05 / 2016$ & Taff & Unknown & T6 & Lake & $\begin{array}{c}11346 \\
\text { SO } 01560\end{array}$ & 0 & 13 \\
\hline $01 / 05 / 2016$ & Taff & Unknown & T6 & Stream & 10665 & 2 & 11 \\
\hline
\end{tabular}




\begin{tabular}{|c|c|c|c|c|c|c|c|}
\hline $27 / 07 / 16$ & Medway & Signal & 1 & River & $\begin{array}{c}\text { TQ } 59089 \\
46489 \\
\text { TO } 67472\end{array}$ & 0 & 17 \\
\hline $27 / 07 / 16$ & Medway & Signal & 2 & Stream & $\begin{array}{c}48254 \\
\text { TQ } 60810\end{array}$ & 0 & 15 \\
\hline 7/07/16 & Medway & Unknown & 3 & Pond & $\begin{array}{c}51347 \\
\text { TQ } 68987\end{array}$ & 2 & 17 \\
\hline $1 / 07 / 16$ & Medway & Signal & 4 & River & $\begin{array}{c}49924 \\
\text { TQ } 72866\end{array}$ & 1 & 18 \\
\hline (1/0/710 & Medway & Signal & 5 & River & $\begin{array}{c}48687 \\
\text { TQ } 77297\end{array}$ & 1 & 16 \\
\hline . & Medway & Signal & 6 & Stream & $\begin{array}{c}46511 \\
\text { TQ } 72843\end{array}$ & 3 & 14 \\
\hline 1/07/10 & Medway & Signal & 7 & Stream & $\begin{array}{c}45680 \\
\text { TQ } 70880\end{array}$ & 1 & 13 \\
\hline $2 / 107100$ & Medway & Unknown & 8 & River & $\begin{array}{c}53290 \\
\text { TQ } 73478\end{array}$ & 1 & 15 \\
\hline $2 / 10 / 110$ & Medway & Unknown & 9 & River & $\begin{array}{c}53564 \\
\text { TQ } 75665\end{array}$ & 0 & 16 \\
\hline 27/07/16 & Medway & Unknown & 10 & River & $\begin{array}{c}55630 \\
\text { TQ } 70192\end{array}$ & 0 & 17 \\
\hline & Medway & Unknown & 11 & Lake & 59812 & 2 & 19 \\
\hline 12.10 .17 & $\begin{array}{l}\text { Itchen } \\
\text { Itchen }\end{array}$ & $\begin{array}{l}\text { Native } \\
\text { Native }\end{array}$ & 1 & Stream & N/A & 2 & $\begin{array}{l}12 \\
13\end{array}$ \\
\hline $\begin{array}{l}12.10 .17 \\
12.10 .17\end{array}$ & $\begin{array}{l}\text { Itchen } \\
\text { Itchen }\end{array}$ & $\begin{array}{l}\text { Native } \\
\text { Native }\end{array}$ & $\begin{array}{l}2 \\
3\end{array}$ & $\begin{array}{l}\text { Stream } \\
\text { Stream }\end{array}$ & $\begin{array}{l}\text { N/A } \\
\text { N/A }\end{array}$ & $\begin{array}{l}2 \\
0\end{array}$ & 12 \\
\hline 12.10 .17 & Itchen & Native & 4 & River & N/A & 1 & 12 \\
\hline 12.10 .17 & Itchen & Native & 5 & River & N/A & 1 & 12 \\
\hline 12.10 .17 & Itchen & Native & 6 & Stream & N/A & 0 & 12 \\
\hline 12.10 .17 & Itchen & Native & 7 & Stream & N/A & 2 & 13 \\
\hline
\end{tabular}




\begin{tabular}{llllllll}
12.10 .17 & Itchen & Native & 8 & Stream & N/A & 0 & 12 \\
12.10 .17 & Itchen & Native & 9 & Stream & N/A & 1 & 13 \\
12.10 .17 & Itchen & Native & 10 & River & N/A & 3 & 13 \\
12.10 .17 & Itchen & Native & 11 & River & N/A & 2 & 12 \\
12.10 .17 & Itchen & Signal & 12 & River & N/A & 2 & 12 \\
12.10 .17 & Itchen & Signal & 13 & River & N/A & 1 & 12 \\
12.10 .17 & Itchen & Signal & 14 & River & N/A & 3 & 12 \\
12.10 .17 & Itchen & Signal & 15 & River & N/A & 2 & 12 \\
12.10 .17 & Itchen & Native & 16 & River & N/A & 3 & 12 \\
12.10 .17 & Itchen & Signal & 17 & River & N/A & 3 & 12 \\
12.10 .17 & Itchen & Signal & 18 & River & N/A & 3 & 12 \\
\hline
\end{tabular}




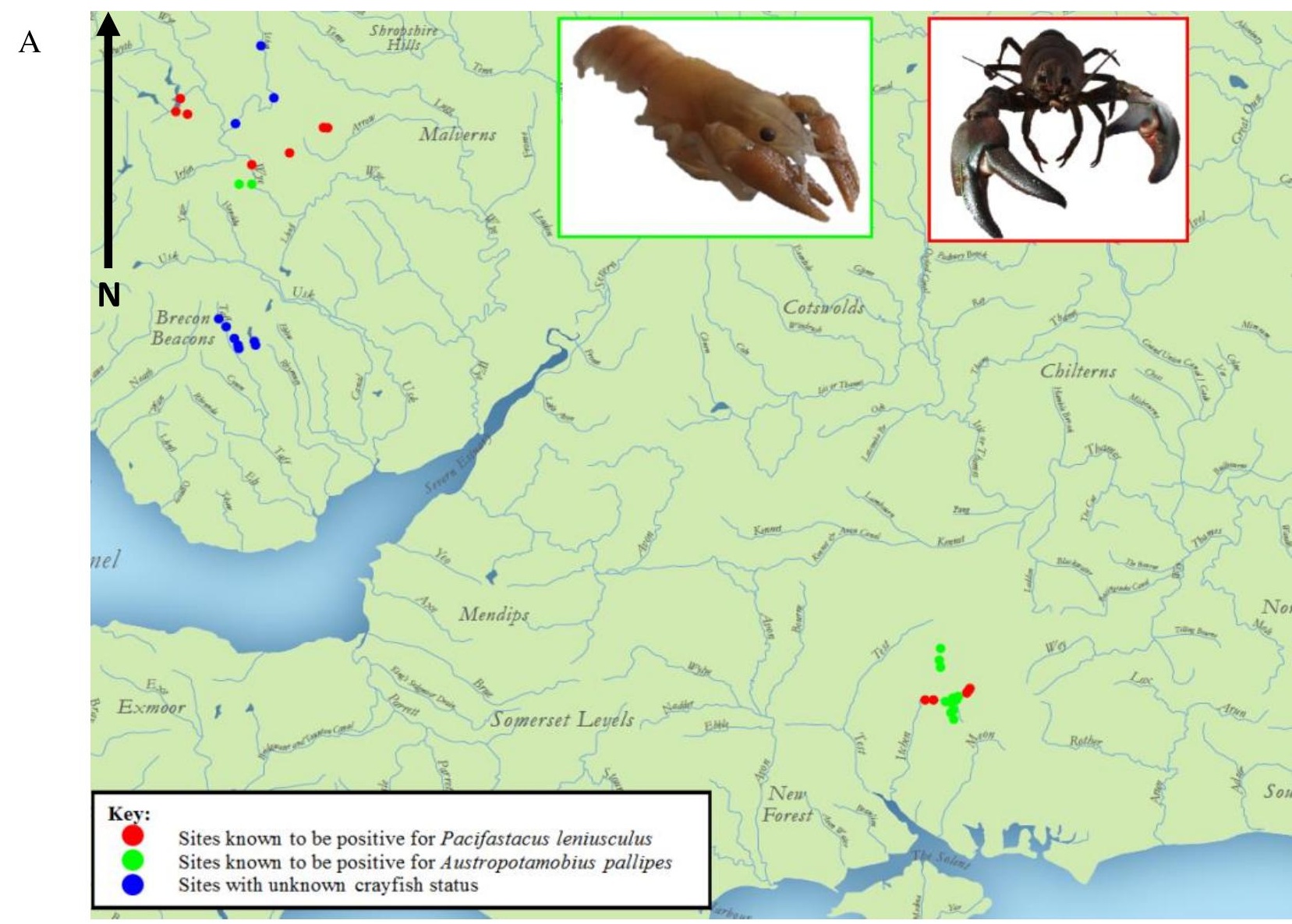




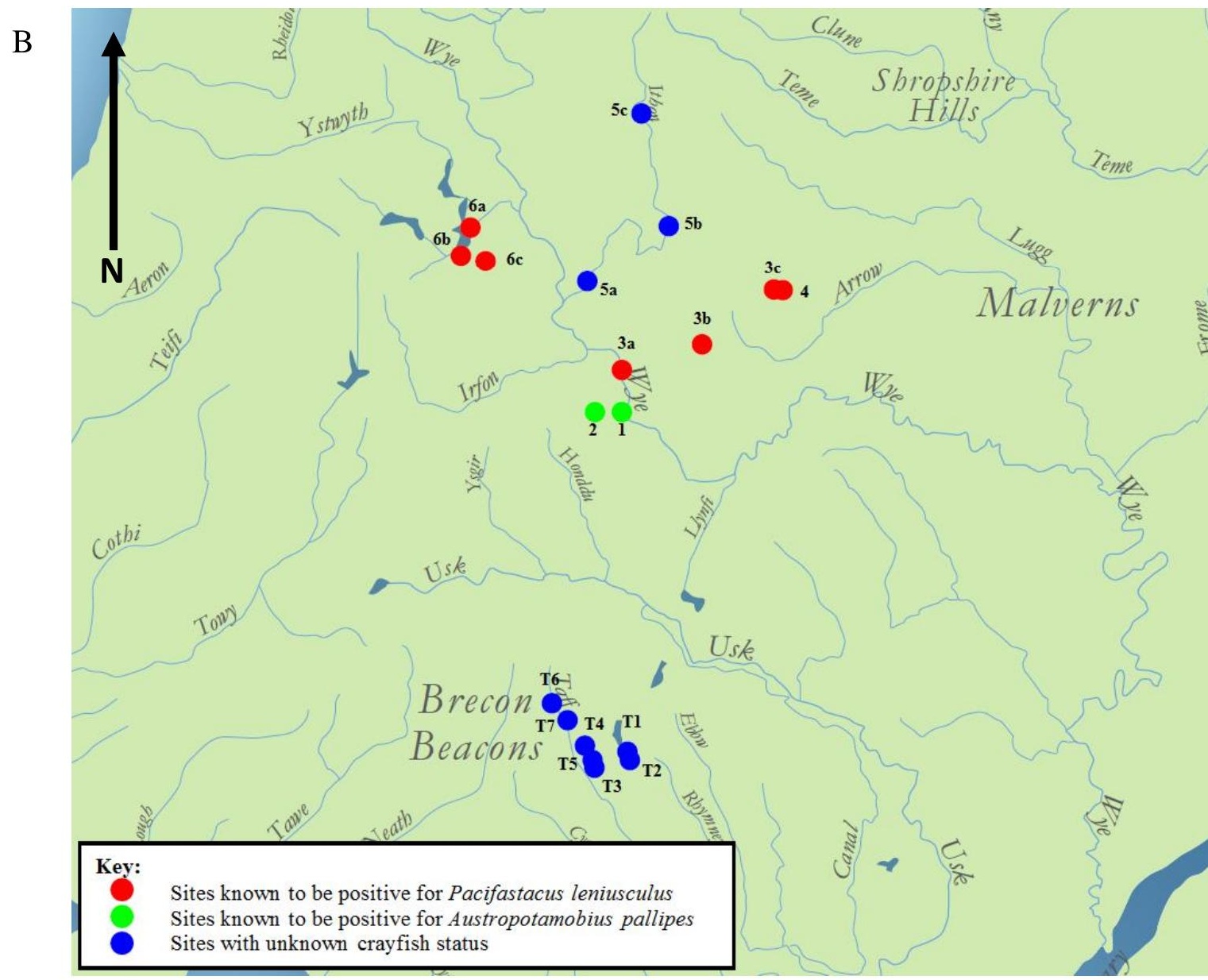




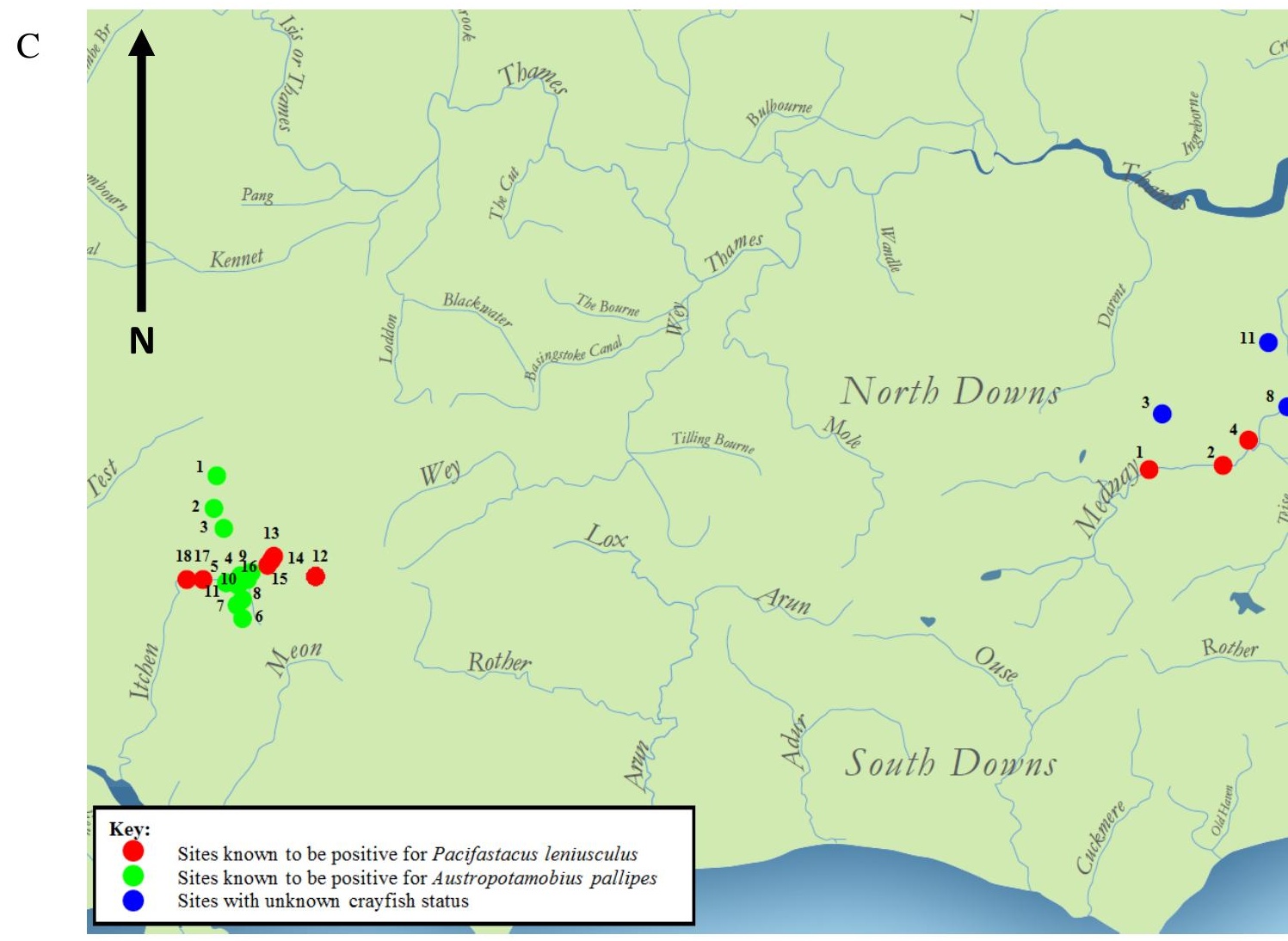

Figure 5. A) eDNA sampling sites for catchments sampled (Wye, Taff, Itchen and Medway) w leniusculus individuals (red circle), Austropotamobius pallipes (green circle) or without information $\mathrm{r}$ B) Location of the rivers Wye and Taff eDNA sampling sites in Wales. Wye sites 1 and 2 (Sgithwen 
species Austropotamobius pallipes; sites 3 (Bachowey), 4 (Bachowey) and 6 (Duhonw) were confirn leniusculus and site 5 (Edw) had unknown crayfish status. Taff sites T1 to T7 all had unknown cray the River Medway and River Itchen eDNA sampling sites. There were 11 sites in total (M1 to M1 positive for Pacifastacus leniusculus presence whereas M3, M8 - M11 have an unknown crayfish sp 18 sites in total (I1 to I18); I1 - I11 classified as positive for Austropotamobius pallipes presence a Pacifastacus leniusculus presence. Each point represents a locality where between three and (Austropotamobius pallipes photograph @Chloe Robinson; Pacifastacus leniusculus photograph @R 


\section{3. qPCR primer design}

Crayfish specific primers were designed using Primer3 software, tested in silico using Beacon Primer Designer (ver. 2.1, PREMIER Biosoft), and checked for crossamplification using NCBI Primer-BLAST (Ye et al. 2006). The primer pair was designed to be complementary to both the signal crayfish and native white-clawed crayfish (ApalPlen16SF: 5'-AGTTACTTTAGGGATAACAGCGT-3' and ApalPlen16SR: 5'-CTTTTAATTCAACATCGAGGTCG-3'), to allow the amplification of an 83bp fragment of the 16S mtDNA gene (Figure S6). The primers were assessed in vitro using positive control tissue (crayfish tail fan clips and moults) from 15 different signal and white-clawed crayfish individuals. DNA was extracted using Qiagen ${ }^{\circledR}$ DNeasy Blood and Tissue Kit (Qiagen, UK), eluted in $100 \mu 1$, and amplified in end-point PCR using the following ApalPlen16S protocol: $95{ }^{\circ} \mathrm{C}$ for 3 min, followed by 40 cycles of $95^{\circ} \mathrm{C}$ for $30 \mathrm{~s}, 61.5^{\circ} \mathrm{C}$ for $30 \mathrm{~s}$ and $72{ }^{\circ} \mathrm{C}$ for $45 \mathrm{~s}$ with a final elongation step of $72{ }^{\circ} \mathrm{C}$ for $10 \mathrm{~min}$. All amplified PCR products were checked for the correct amplicon size using a 2\% agarose gel electrophoresis. Primers were also tested on tissue samples from a second invasive crayfish species established in the UK, the virile crayfish (Orconectes cf. virilis), and against a related species commonly found in the same environment, the freshwater shrimp (Gammarus sp.) to check for non-specific amplification.

DNA from the ex-situ eDNA samples for signal crayfish and white-clawed crayfish were extracted using Qiagen ${ }^{\circledR}$ DNeasy Blood and Tissue Kit (Qiagen, UK), eluted in $100 \mu 1$, and amplified with ApalPlen16S primers. PCR products were run in a $2 \%$ agarose gel to check for correct amplicon size against positive controls (extracted crayfish tail clip), purified and analysed using Sanger Sequencing on an ABI Prism 277 DNA sequencer. Resulting sequences were aligned using BioEdit v. 5.0.9 (using the ClustalW program) and inputted to BLAST (Ye et al. 2006) to confirm the species identity.

\section{4. qPCR optimisation}

Specific in vitro testing of RT-qPCR-HRM analysis was performed for both signal crayfish and white-clawed crayfish samples to ensure that each species could be 
identified based on their specific differential PCR product melt temperatures. Annealing temperature for ApalPlen16S primers was optimised at $61.5{ }^{\circ} \mathrm{C}$ and resulting efficiency values at this temperature for both species were 92.0 and $93.8 \%$ for signal crayfish and white-clawed crayfish, respectively. For optimisation, the ApalPlen16S-qPCR cycling protocol began with 15 min of denaturation at $95{ }^{\circ} \mathrm{C}$, followed by 40 cycles of $95^{\circ} \mathrm{C}$ for $10 \mathrm{~s}$ and $61.5^{\circ} \mathrm{C}$ for $30 \mathrm{~s}$. A HRM step was applied to the end of RT-qPCR reactions, ranging from $55{ }^{\circ} \mathrm{C}$ to $95{ }^{\circ} \mathrm{C}$ in $0.1{ }^{\circ} \mathrm{C}$ increments to assess the consistency of amplicon melt temperature (tm) for both crayfish species. Limit of detection (LOD) and limit of quantification (LOQ) were determined through running a dilution series ranging from $5 \mathrm{ng} / \mu \mathrm{l}$ to $5 \times 10^{-7} \mathrm{ng} / \mu \mathrm{l}$, using DNA pools for both species. HRM analysis was conducted on a minimum of 12 and a maximum of 15 individuals from several signal crayfish and white-clawed crayfish populations to account for any potential intraspecific variation in qPCR product tm (Table 6). qPCRHRM analysis was undertaken comparing two master mixes, SYBR® Green (Bio-Rad, UK) and SsoFast ${ }^{\mathrm{TM}}$ EvaGreen ${ }^{\circledR}$ (Bio-Rad, UK), assessing consistency and reproducibility of both with relation to melt curve profiles (Table 6). To assess ability to detect both crayfish species in the same reaction, equal volumes of signal crayfish and white-clawed crayfish DNA were pooled together from ten different individuals of both species at various concentration ratios (ranging from 50:50 to 10:90).

Once the in vitro testing was complete for positive controls, further testing was undertaken for the eDNA samples collected in the assay validation study to ensure that the primers would amplify environmental DNA samples and to assess the minimum levels of detection of eDNA samples.

\subsection{Multiplex optimisation}

For the A. astaci multiplex assay, optimisation of primer quantity and concentration was undertaken by combining the two sets of primers (ApalPlen16S and AphAstITS; (Vrålstad et al. 2009) at starting concentrations between $1 \mu \mathrm{M}$ and $20 \mu \mathrm{M}$. Equal concentrations of each set of primers at $5 \mu \mathrm{M}$ produced the most efficient coamplification for both sets of primers, with poor amplifications resulting in 
concentrations from 1 to $4 \mu \mathrm{M}$ and above $6 \mu \mathrm{M}$ starting concentration. Uninfected crayfish DNA controls were obtained through extraction of a tail fan clip from noninfected individuals and $A$. astaci-positive samples were obtained from a previous study by Cardiff University (James et al. 2017), where an infected crayfish tail fan clip, melanised soft cuticle and walking leg tissue were pooled together and DNA extracted for A. astaci screening.

The final optimised multiplex qPCR reactions were carried out in a final volume of 10 $\mu 1$, which contained $2 \mu 15 \times$ HOT FIREPol ${ }^{\circledR}$ EvaGreen ${ }^{\circledR}$ qPCR Mix Plus ROX (Soils Biodyne, Estonia), $0.4 \mu 1$ of primer mix $(5 \mu \mathrm{M}), 1 \mu \mathrm{l}$ template DNA at $5 \mathrm{ng} / \mu \mathrm{l}$ and 6.6 $\mu 1$ of ultrapure water. The amplification was carried out using a Bio-Rad CFX96 Touch Real-Time PCR Detection System (Bio-Rad, UK). The PCR protocol was as follows: once cycle of initial activation at $95{ }^{\circ} \mathrm{C}$ for $12 \mathrm{~min}$, followed by 40 cycles of $95{ }^{\circ} \mathrm{C}$ for $15 \mathrm{~s}, 61.5^{\circ} \mathrm{C}$ for $20 \mathrm{~s}$ and $72{ }^{\circ} \mathrm{C}$ for $20 \mathrm{~s}$. After the PCR reaction, a melt curve program was set, which ran from $65{ }^{\circ} \mathrm{C}$ to $95^{\circ} \mathrm{C}$ by raising $1{ }^{\circ} \mathrm{C}$ for $10 \mathrm{~s}$ each step. The resulting curve was then used to assess the presence/absence of $A$. astaci and target crayfish species DNA based on the species-specific melting temperatures of the DNA product (A. astaci $=82.9^{\circ} \mathrm{C}$; signal crayfish $=75.9 \pm 0.2^{\circ} \mathrm{C}$ and white-clawed crayfish $=76.6$ $\pm 0.2^{\circ} \mathrm{C}$ ) which were identified during optimization of the multiplex assay.

\section{6. eDNA in situ analyses}

eDNA extraction from 407 field samples (Table 5) was performed using Qiagen ${ }^{\circledR}$ DNeasy Blood and Tissue Kit (Qiagen, UK), following the manufacturer's instructions, apart from a reduction in the elution volume from a single elution step of $200 \mu 1$ to two elution steps of $50 \mu 1$ to maximise DNA yield. DNA extractions took place in a dedicated eDNA area within an extraction cabinet, equipped with a UV light and a flow-through air system to minimise chances of contamination. Extractions were conducted wearing eDNA-dedicated laboratory coat, face mask and gloves. Samples were amplified in triplicate in a Bio-Rad CFX96 Touch Real-Time PCR Detection System (Bio-Rad, UK), in $10 \mu 1$ reactions consisting of $5 \mu 1$ SsoFast $^{\text {TM }}$ EvaGreen ${ }^{\circledR}$ Supermix (Bio-Rad, UK), $0.25 \mu$ l each ApalPlen16SF and ApalPlen16SR, $3.5 \mu 1$ 
HPLC water and $2 \mu 1$ extracted DNA. Amplifications were carried out in triplicate using standard ApalPlen16s-qPCR protocol as described above and only samples which amplified consistently in at least two replicates at the target DNA product tm (either $73.9 \pm 0.2$ or $74.8 \pm 0.2{ }^{\circ} \mathrm{C}$ ), with a melt rate above $200-\mathrm{d}(\mathrm{RFU}) / \mathrm{dT}$ were considered to be a positive result. qPCR reactions were carried out in a separate room to eDNA extractions under a PCR hood with laminar flow. Two positive controls per species were added to each plate once all the eDNA samples were loaded and sealed to prevent false positives in the eDNA samples. Two amplification negative controls consisting of HPLC water and two extraction negative controls were also added in the same well location on each plate test for contamination in eDNA samples.

A subset of positive field samples, along with a positive control for each crayfish species were re-amplified using end-point PCR, purified and cloned into pDrive plasmid cloning vector (Qiagen PCR Plus Cloning Kit, Qiagen, UK). Three to nine clones per sample were sequenced using T7 and SP6 primers on an ABI Prism 377 sequencer.

\section{RESULTS}

\subsection{Assay validation and detection rates}

Reference DNA was successfully extracted and amplified in triplicate from signal crayfish and white-clawed crayfish positive controls (tail clips and moults/carcasses) and species confirmed by Sanger Sequencing of the 83bp fragment of the 16S mtDNA. DNA from signal crayfish was detected in all water samples taken at different time points from the $e x$-situ study. eDNA concentrations marginally decreased overtime but remained detectable (Figure 6). DNA from native crayfish was also amplified in all nine water samples from the reference hatchery. No amplification bands were present in any of the negative controls (tank, extraction and amplification). 


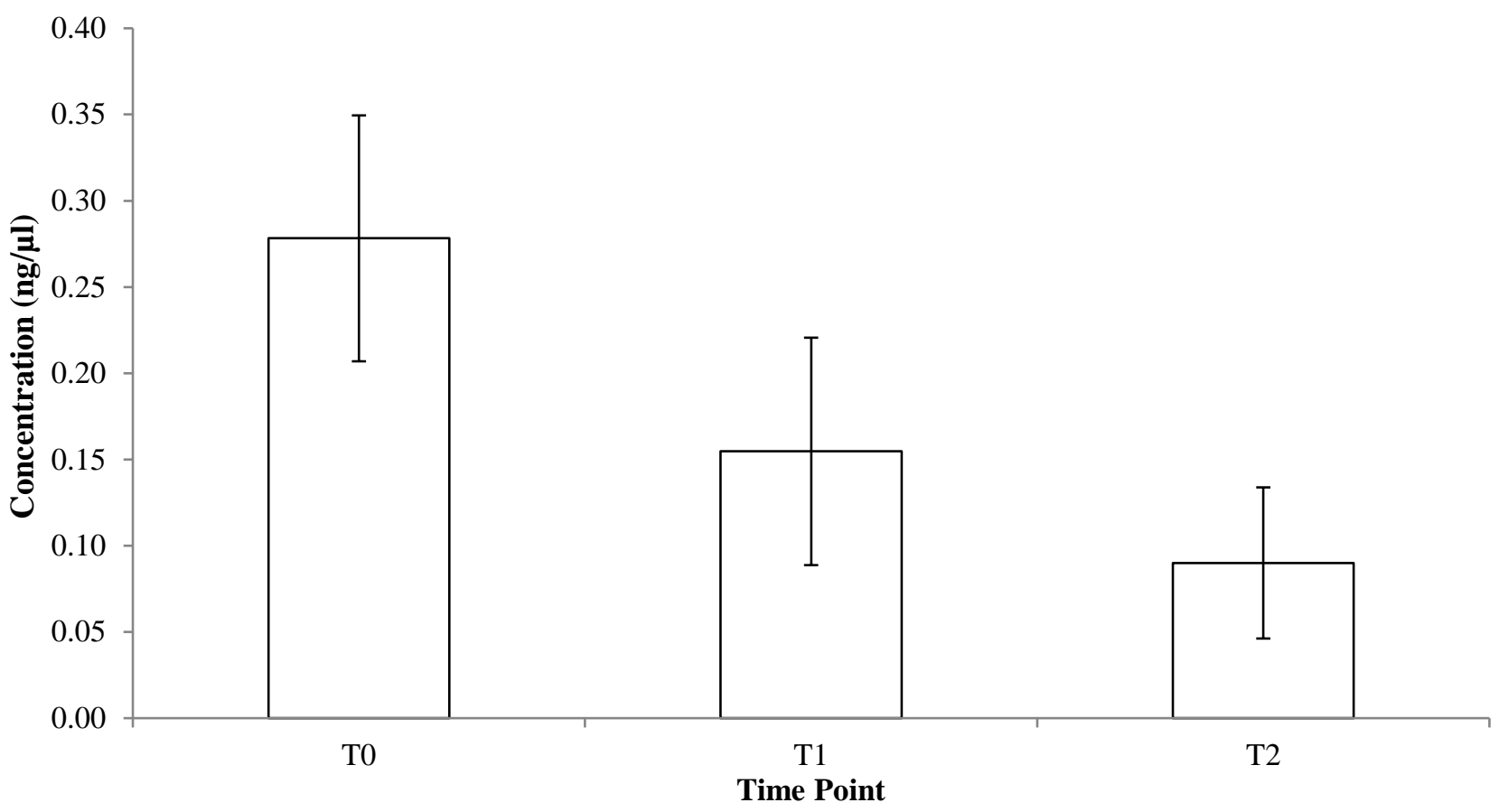

Figure 6. Average eDNA concentration across all ex-situ samples for the three time points $(\mathrm{T} 0=$ time of crayfish removal; $\mathrm{T} 1=24 \mathrm{hrs}$ post crayfish removal; $\mathrm{T} 2=48 \mathrm{hrs}$ post crayfish removal.

\subsection{Crayfish detection limits}

The results of the qPCR optimisation indicated that the limit of detection (LOD) of both signal crayfish and white-clawed crayfish DNA was $0.005 \mathrm{ng} / \mu \mathrm{l}$, after a 10-fold dilution series. The detection threshold for amplification of positive control DNA used for optimisation from both species was between 16 and 28 cycles, and the melting temperatures $(\mathrm{tm})$ of the DNA products were consistent for both signal crayfish and white-clawed crayfish, with no overlap between the two species (Table 6; Figure S7). SsoFast ${ }^{\mathrm{TM}}$ EvaGreen ${ }^{\circledR}$ multiplex master mix performed more consistently than the SYBR ${ }^{\circledR}$ Green master mix, with a lower standard deviation for average tm, average peak height, average start melt temperature and average end melt temperature (Table 6; Table S8; Figure S8). Results of the qPCR analysis of mixed proportions of signal crayfish and white-clawed crayfish DNA confirmed that it is possible to discriminate 
between positive amplifications of eDNA for single crayfish species vs. mixed crayfish species (signal crayfish and white-clawed crayfish). Diagnostic peaks in early product melt temperatures were present for all amplifications containing 90:10 to 50:50 ratios of signal crayfish: white-clawed crayfish DNA (Table S9; Figure 7).

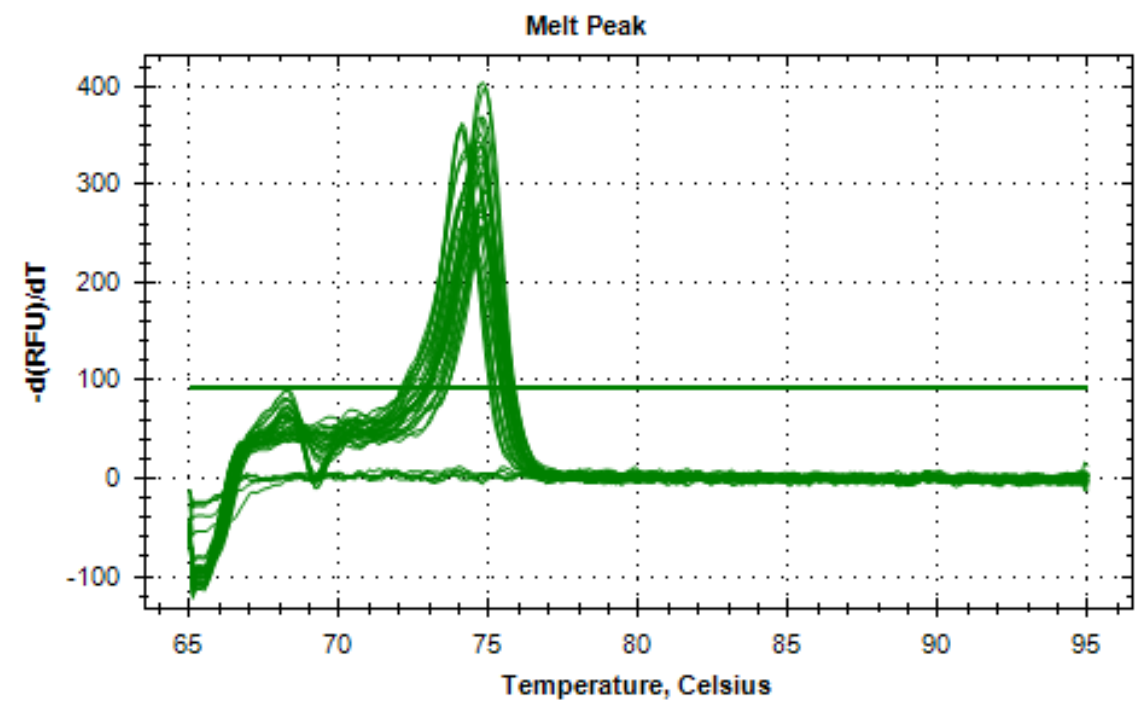

Figure 7. Melt peaks from SsoFast ${ }^{\mathrm{TM}}$ EvaGreen ${ }^{\circledR}$ mixed DNA ratios of crayfish species (Pacifastacus leniusculus and Austropotamobius pallipes) qPCR amplifications (A). 10:90 Pacifastacus leniusculus: Austropotamobius pallipes to 90:10 Pacifastacus leniusculus: Austropotamobius pallipes. 
Table 6. Summary of average values from qPCR outputs for both Pacifastacus leniusculus and Austropotamobius pallipes. Average melt temperature $\left({ }^{\circ} \mathrm{C}\right.$; Avg. tm); Average melt peak height (Avg. peak height); Average start melt temperature $\left({ }^{\circ} \mathrm{C}\right.$; Avg. start melt); Average end melt temperature $\left({ }^{\circ} \mathrm{C}\right.$; Avg. end melt) of resultant qPCR products with standard deviation. Values were obtained for each individual over at least three separate runs, each consisting of three replicates and negative control blanks.

\begin{tabular}{|c|c|c|c|c|c|}
\hline $\begin{array}{c}\text { Species/Master } \\
\text { Mix }\end{array}$ & $\begin{array}{c}\text { Sample } \\
\text { size } \\
(\mathbf{N})\end{array}$ & $\begin{array}{l}\text { Avg. tm } \\
\left({ }^{\circ} \mathrm{C}\right)( \pm \mathrm{SD})\end{array}$ & $\begin{array}{c}\text { Avg. peak } \\
\text { height }( \pm S D)\end{array}$ & $\begin{array}{l}\text { Avg. } \\
\text { start } \\
\text { melt } \\
\left({ }^{\circ} \mathrm{C}\right) \\
( \pm \text { SD })\end{array}$ & $\begin{array}{c}\text { Avg. end } \\
\text { melt }\left({ }^{\circ} \mathrm{C}\right) \\
( \pm \mathrm{SD})\end{array}$ \\
\hline
\end{tabular}

$\begin{array}{llllll}\text { Pacifastacus } & & & & & \\ \text { leniusculus / } & 15 & 72.7(0.2) & 376.3(40.8) & 69.5 & 75.5(0.3) \\ \text { SYBR } ® \text { Green } & & & & (0.4) & \end{array}$

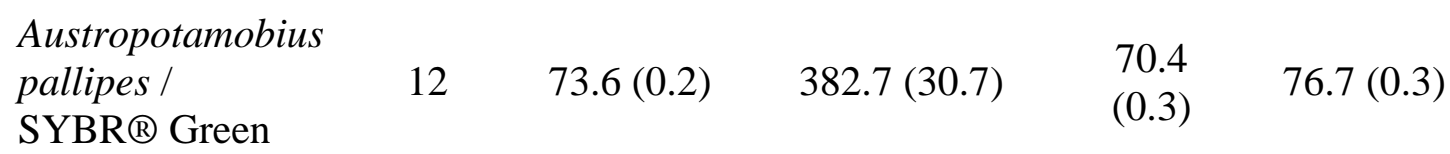

Pacifastacus

leniusculus /

SsoFast ${ }^{\mathrm{TM}}$

$15 \quad 73.9(0.2) \quad 397.6(36.4) \quad \begin{array}{lll}71.1 & (0.2) & 76.6(0.2)\end{array}$

EvaGreen®

$\begin{array}{llllll}\begin{array}{l}\text { Austropotamobius } \\ \text { pallipes / }\end{array} & & & & & \\ \text { SsoFast } & & & & & \\ \text { Eva } & 12 & 74.8(0.2) & 449.1(21.6) & (0.3) & 77.2(0.2) \\ \text { EvaGreen }{ }^{\circledR} & & & & & \end{array}$

\subsection{Simultaneous detection of crayfish and Aphanomyces astaci}

The multiplex assay for simultaneous crayfish and $A$. astaci detection resulted in two products with an average tm of $75.9 \pm 0.2{ }^{\circ} \mathrm{C}$ for signal crayfish (or $76.6 \pm 0.2{ }^{\circ} \mathrm{C}$ for white-clawed crayfish; four individuals) and $82.9^{\circ} \mathrm{C}$ for $A$. astaci. DNA controls from four A. astaci-infected signal crayfish individuals (pool 1 - pool 3) were successfully 
amplified with two products of the corresponding temperatures. Amplification of uninfected signal crayfish DNA resulted in a single product with tm of $75.9 \pm 0.2^{\circ} \mathrm{C}$ (Figure 8).

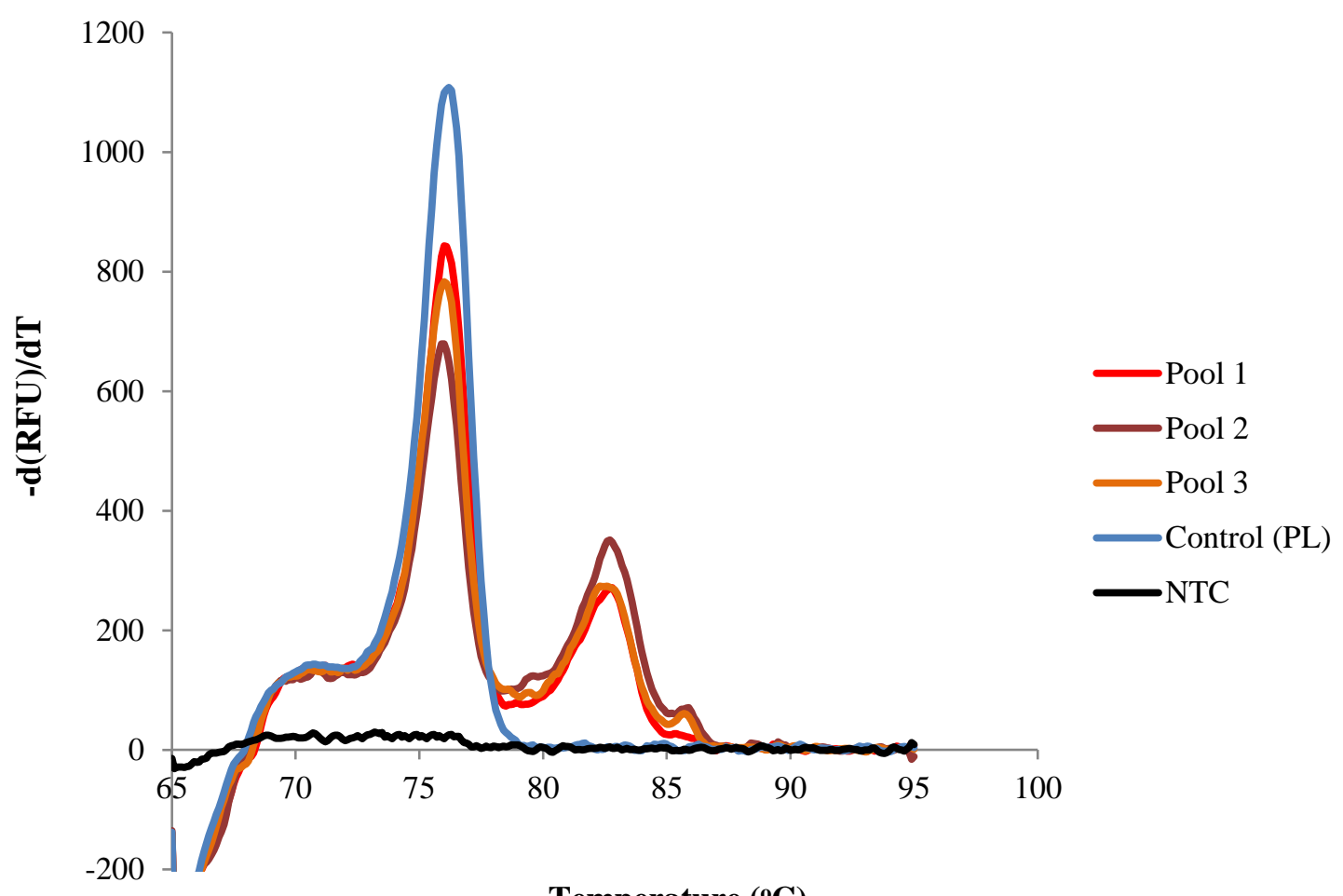

Temperature $\left({ }^{\circ} \mathrm{C}\right)$

Figure 8. qPCR product melt peak output for multiplex amplification of DNA using optimised HOT FIREPol ${ }^{\circledR}$ EvaGreen ${ }^{\circledR}$ from three different Pacifastacus leniusculus individuals and Aphanomyces astaci DNA in the same qPCR reaction (Pool 1-3), displaying the diagnostic double melt peaks at $75.9 \pm 0.2{ }^{\circ} \mathrm{C}$ for Pacifastacus leniusculus and $82.9{ }^{\circ} \mathrm{C}$ for Aphanomyces astaci. Control PL = Pacifastacus leniusculus control for HOT FIREPol qPCR (73.9 \pm 0.2$)$.

\subsection{Crayfish species distribution and infection status}

For Welsh sites, crayfish trapping confirmed the presence of signal crayfish (11 caught across 3 different sites; Table 7) in positive sites, whereas no white-clawed crayfish were caught, despite visual confirmation of the species upon collecting traps. Signal crayfish eDNA was successfully detected around each of the three traps in the 
reservoir. qPCR detected signal crayfish eDNA at all three confirmed sites for the species and white-clawed crayfish eDNA was detected within the confirmed tributary for the species. Additionally, signal crayfish eDNA was detected in one of the unknown crayfish status sites in the river Taff whereas there was no positive detection of white-clawed crayfish in any of the other the sites with unknown presence of the species (Figure 9, Table 8). For the River Itchen, white-clawed crayfish were successfully detected in the headwater stream (I1) at a site where they have been visually confirmed and similarly signal crayfish were detected in a majority of sites known to be positive for signal crayfish (Table S10 and S11). There was also evidence of potential range expansion for signal crayfish, as DNA from this species was successfully detected at sites previously considered to be exclusively white-clawed crayfish sites (I5, I7, I10).

In both the Medway and Itchen there was evidence of signal crayfish and white-clawed crayfish coexisting in two sampling sites, based upon the unique melt profiles produced in qPCR (Figure 10). One site in the Medway was positive for both crayfish species (diagnostic sigmoidal melt at start of melt curve) and one site in the Itchen was also positive for both species (Figure 10). Both signal crayfish and white-clawed crayfish were also detected in the Medway and Itchen in separate areas (white-clawed crayfish: Medway (2 sites), Itchen (4 sites); signal crayfish: Medway (3 sites), Itchen (9 sites). 
Table 7. Location of crayfish traps in corresponding waterbodies in the Wye catchment and number

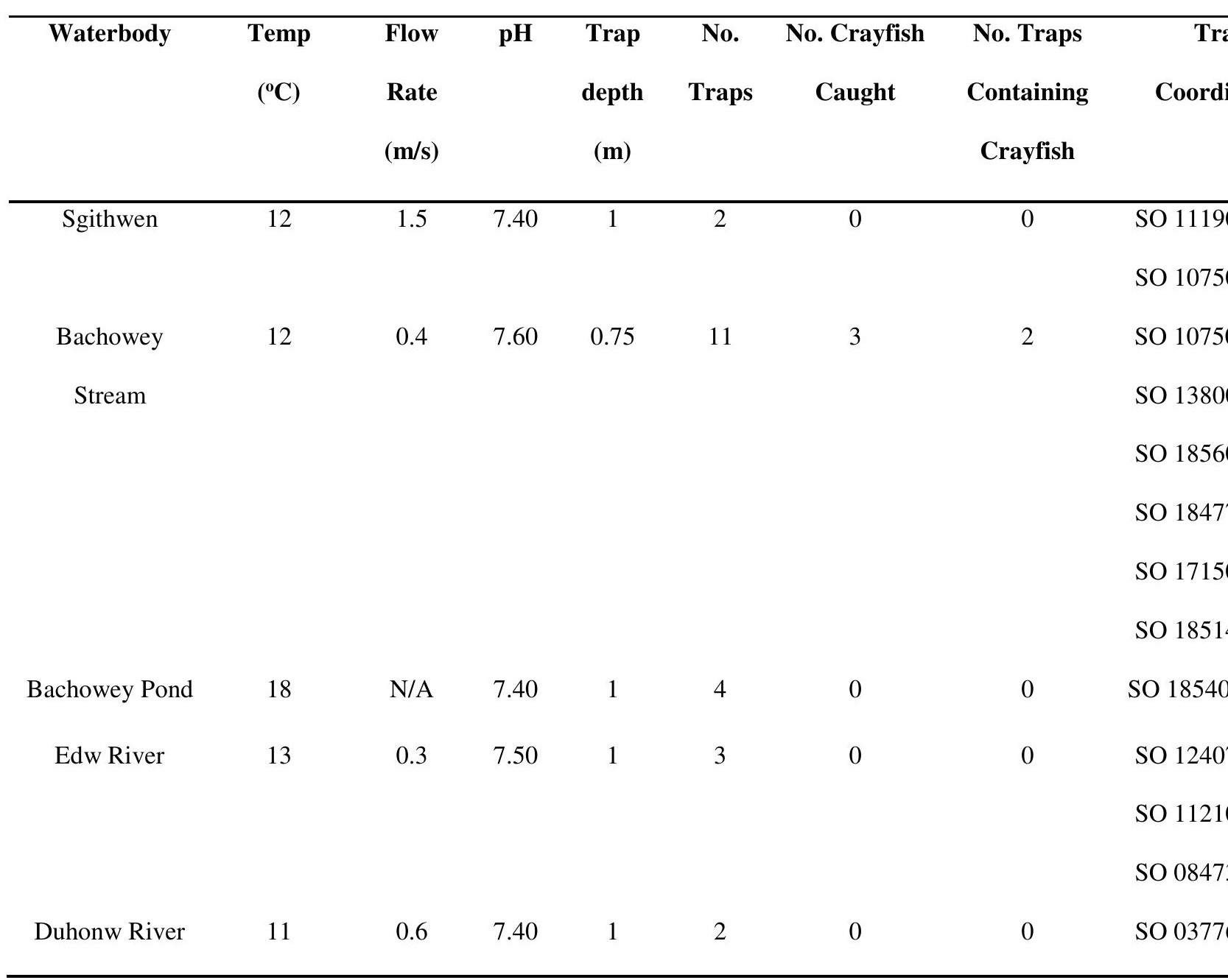




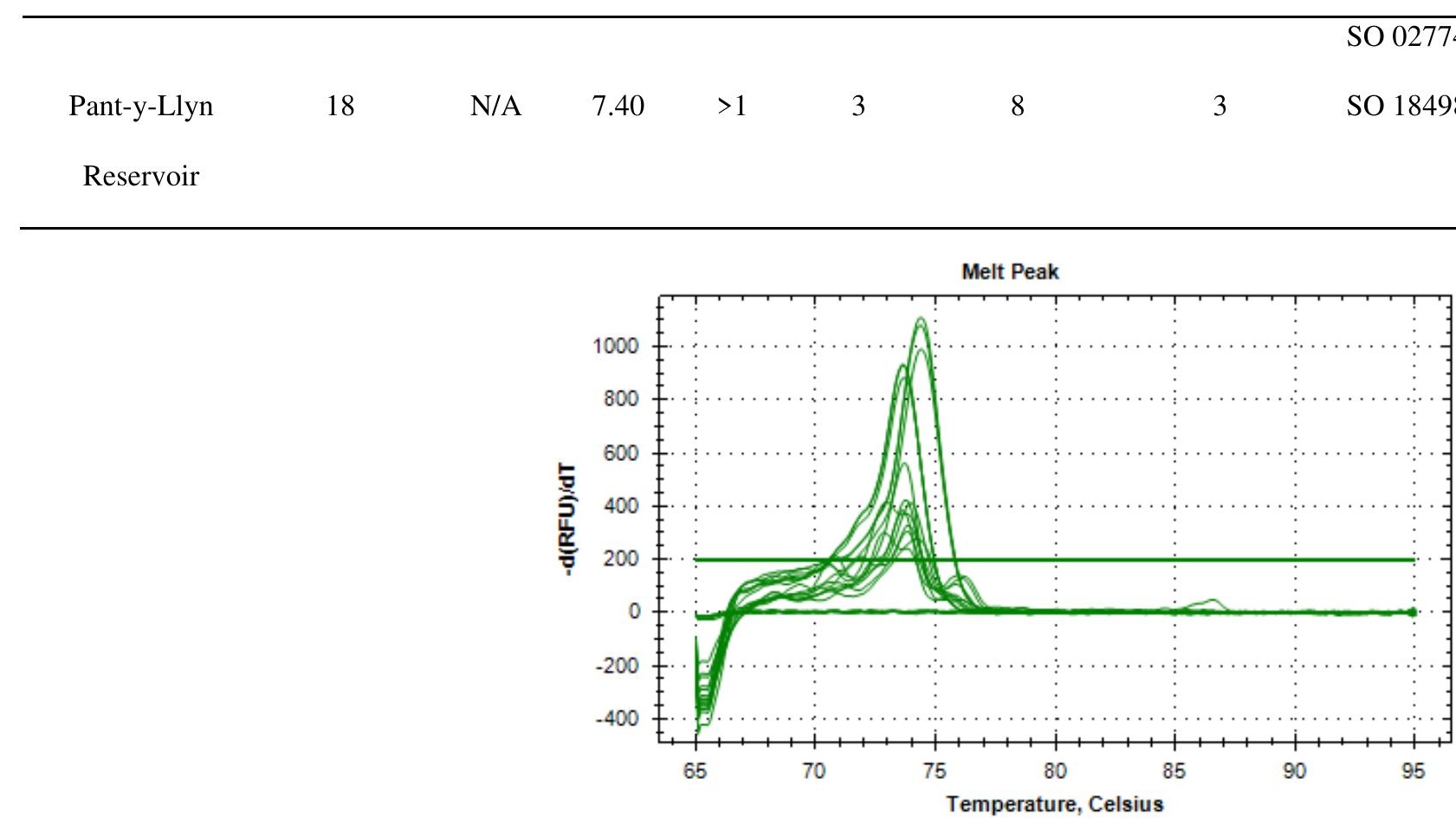

Figure 9. Melt peak profile for SsoFast ${ }^{\mathrm{TM}}$ EvaGreen ${ }^{\circledR}$ eDNA qPCR amplifications of positive leniusculus in the River Taff. The three largest sets of peaks correspond to positive control tissu Pacifastacus leniusculus $\left(74.9^{\circ} \mathrm{C}\right)$, Austropotamobius pallipes $\left(75.9^{\circ} \mathrm{C}\right)$ and Aphanomyces astaci $(8$ eDNA field sample melt peaks from nine samples (in triplicate) for invasive Pacifastacus leniuscul profile (flat line). 

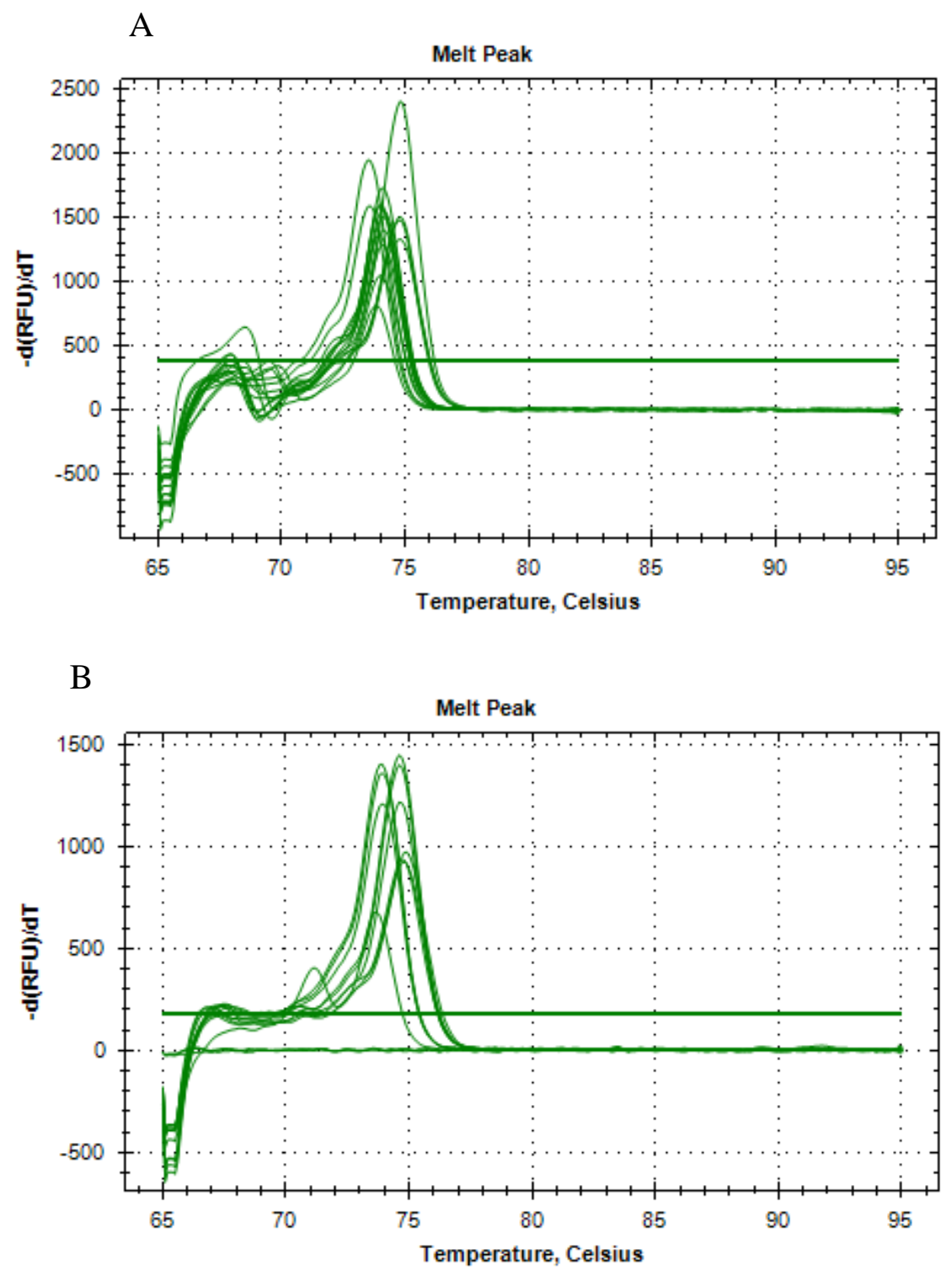

Figure 10. Melt peaks from SsoFast ${ }^{\mathrm{TM}}$ EvaGreen ${ }^{\circledR}$ eDNA qPCR amplifications for the Medway catchment site 5 (A) and Itchen catchment at site 8 (B).

A. astaci was confirmed in all sites in the river Bachowey, resulting in two products with melt peaks at $75.9 \pm 0.2$ and $82.9^{\circ} \mathrm{C}$ for the signal crayfish and plague agent respectively. All other sites positive for signal crayfish and white-clawed crayfish were negative for A. astaci, which was not detected in the rivers Medway or Itchen, despite the coexistence of both crayfish species.

A subset of five positive amplifications was selected (one for white-clawed crayfish and four for signal crayfish) to confirm species identity by cloning and sequencing. 
Out of 36 successfully transformed clones for the field samples of signal crayfish (nine for each sample), between two and nine clone sequences per sample matched $100 \%$ with signal crayfish on BLAST (Ye et al. 2006); remaining clones were a product of non-specific amplification. For white-clawed crayfish field samples, two out of 3 clones from the positive field sample matched $100 \%$ for white-clawed crayfish. All six positive control clones matched $100 \%$ with respective crayfish species (signal crayfish/white-clawed crayfish).

Table 8. Melt data from SsoFast ${ }^{\mathrm{TM}}$ EvaGreen ${ }^{\circledR}$ eDNA qPCR amplifications for the Taff catchment.

\begin{tabular}{|c|c|c|c|}
\hline Mastermix & Catchment & Sample ID & Melt Temperature $\left({ }^{\circ} \mathrm{C}\right)$ \\
\hline SssoFast $^{\mathrm{TM}}$ EvaGreen ${ }^{\circledR}$ & Taff & $5 B$ & 73.80 \\
\hline SssoFast $^{\mathrm{TM}}$ EvaGreen ${ }^{\circledR}$ & Taff & $5 B$ & 73.80 \\
\hline SssoFast $^{\mathrm{TM}}$ EvaGreen ${ }^{\circledR}$ & Taff & $5 B$ & 73.80 \\
\hline SssoFast $^{\mathrm{TM}}$ EvaGreen ${ }^{\circledR}$ & Taff & $5 B$ & 74.00 \\
\hline SssoFast $^{\mathrm{TM}}$ EvaGreen ${ }^{\circledR}$ & Taff & $5 \mathrm{C}$ & 73.80 \\
\hline SsoFast $^{\mathrm{TM}}$ EvaGreen ${ }^{\circledR}$ & Taff & $5 \mathrm{C}$ & 73.80 \\
\hline SssoFast $^{\mathrm{TM}}$ EvaGreen ${ }^{\circledR}$ & Taff & $5 \mathrm{C}$ & 73.90 \\
\hline SsoFast $^{\mathrm{TM}}$ EvaGreen ${ }^{\circledR}$ & Taff & $5 \mathrm{C}$ & 73.60 \\
\hline SssoFast $^{\mathrm{TM}}$ EvaGreen ${ }^{\circledR}$ & Taff & $5 \mathrm{D}$ & 74.00 \\
\hline SssoFast $^{\mathrm{TM}}$ EvaGreen ${ }^{\circledR}$ & Taff & $5 \mathrm{D}$ & 73.80 \\
\hline SsoFast $^{\mathrm{TM}}$ EvaGreen ${ }^{\circledR}$ & Taff & $5 \mathrm{D}$ & 73.70 \\
\hline SsoFast $^{\mathrm{TM}}$ EvaGreen ${ }^{\circledR}$ & Taff & PC_SC & 73.70 \\
\hline SssoFast $^{\mathrm{TM}}$ EvaGreen ${ }^{\circledR}$ & Taff & PC_SC & 73.70 \\
\hline SssoFast $^{\mathrm{TM}}$ EvaGreen ${ }^{\circledR}$ & Taff & PC_SC & 73.70 \\
\hline SssoFast $^{\mathrm{TM}}$ EvaGreen $®$ & Taff & PC_NC & 74.70 \\
\hline SsoFast $^{\mathrm{TM}}$ EvaGreen ${ }^{\circledR}$ & Taff & PC_NC & 74.70 \\
\hline SsoFast $^{\mathrm{TM}}$ EvaGreen ${ }^{\circledR}$ & Taff & PC_NC & 74.70 \\
\hline SsoFast ${ }^{\mathrm{TM}}$ EvaGreen ${ }^{\circledR}$ & Taff & MB & None \\
\hline SssoFast $^{\mathrm{TM}}$ EvaGreen ${ }^{\circledR}$ & Taff & $\mathrm{MB}$ & None \\
\hline
\end{tabular}




\begin{tabular}{|c|c|c|c|}
\hline SsoFast $^{\mathrm{TM}}$ EvaGreen ${ }^{\circledR}$ & Taff & $\mathrm{MB}$ & None \\
\hline SsoFast ${ }^{\mathrm{TM}}$ EvaGreen ${ }^{\circledR}$ & Taff & MB & None \\
\hline SsoFast $^{\mathrm{TM}}$ EvaGreen ${ }^{\circledR}$ & Taff & MB & None \\
\hline SsoFast $^{\mathrm{TM}}$ EvaGreen ${ }^{\circledR}$ & Taff & MB & None \\
\hline
\end{tabular}

Sample ID: PC_SC Signal crayfish positive DNA control, PC_NC Native crayfish positive DNA control, MB Amplification negative control

\section{DISCUSSION}

By using a novel multiplex approach, I could simultaneously detect the presence of the endangered white clawed crayfish and the highly invasive North American signal crayfish within a catchment that was free of crayfish plague. In contrast, I did not detect any native crayfish or coexistence of both species in tributaries where the pathogen was identified. A common impact of invasive species on native populations is the transmission of pathogens. Many non-native species not only introduce novel pathogens (Miaud et al. 2016) but also act as non-clinical carriers, facilitating their dispersal (Andreou et al. 2012). In this way, pathogens can act as biological weapons that allow invasive species to outcompete their native counterparts (Vilcinskas 2015), as in the case of the UK native crayfish, highly susceptible to the plague carried out, mostly asymptomatically, by the invasive signal crayfish (Andreou et al. 2012). As highlighted in the principles adopted by the Convention on Biological Diversity on invasive species, prevention and early detection should represent the priority responses to invasive species to allow for rapid response and more cost-effective removal when possible (Simberloff et al. 2013) and my study is the first one to combine eDNA and HRM for early detection of novel pathogens carried by non-native species, being particularly relevant for management and conservation in relation to aquatic biological invasions. My protocols followed the most updated guidelines for the use of eDNA for aquatic monitoring (Goldberg et al. 2016), ensuring the consistency of my results. I first validated this method with positive controls and by detecting both native and 
signal crayfish in sites where they had been previously observed as well as detecting A. astaci in a recognised infected river.

Only native or invasive crayfish (not both species coexisting) were expected in the Wye catchment, where some populations of signal crayfish are known to be carriers of the plague and have been established for a sufficient amount of time to entirely displace native white-clawed crayfish from most of the species' historical locations (Dunn et al. 2009; James et al. 2014b), and this was supported by our results. This multiplex approach successfully identified A. astaci in the Bachowey stream and signal crayfish in an associated pond less than $10 \mathrm{~m}$ from this stream, revealing the presence of infected crayfish further upstream than previously detected (James et al. 2017), despite previous intensive trapping of signal crayfish, which removed 36,000 individuals from the area between 2006 and 2008 (Wye \& Usk Foundation 2012). I also detected the endangered crayfish white-clawed crayfish in spite of its very low abundance in the Sgithwen, made apparent by lack of trapping success, highlighting the sensitivity of the method.

In the rivers Medway and Itchen, where invasions date back to the 1970s (NBN 2009), both signal crayfish and white-clawed crayfish had been previously reported but the crayfish plague status was unknown. I did not find $A$. astaci DNA in any samples from either catchment but found both the native and the invasive species coexisting in at least two sampling sites. This could be explained by the absence of plague, as A. astaci is often the main cause of white-clawed crayfish population declines (Haddaway et al. 2012). I detected both species in the Medway, which combined with the absence of crayfish plague DNA presence suggests this could be a location where both species' populations are stable (Bubb et al. 2005; Kozubíková et al. 2008). Populations of signal crayfish and white-clawed crayfish can coexist for a substantial length of time (c.25 years), as has been observed in other invasive-native crayfish population assemblages (Kozubíková et al. 2008; Peters and Lodge 2013; Schrimpf et al. 2012), providing that there is no introduction of A. astaci (Kozubíková et al. 2008; Schrimpf et al. 2012). However, due to competitive exclusion, it is unlikely that populations of both species will coexist indefinitely (Schrimpf et al. 2012; Westman et al. 2002), therefore areas 
where they overlap should be prioritised for management and control of the invasive species.

Detectability was variable among sampling seasons. There were more positive signal crayfish field samples from the sampling of Wye sites in October 2016 compared to the samples collected in July 2015 from the same sites, with three and one positive samples respectively. For white-clawed crayfish, the only positive field samples for the Welsh sites were from samples collected in October; however eDNA from both signal crayfish and white-clawed crayfish was successfully detected in the Medway samples in June.

Seasonal differences could be due to the influence of temperature on eDNA detection rates among aquatic species; with every $1.02{ }^{\circ} \mathrm{C}$ rise in temperature, species are 1.7 times less likely to be detected, especially if the populations are at very low abundance (Moyer et al. 2014), whereas time since DNA release seems to have less effect on detectability at constant temperature (Eichmiller et al. 2016; Moyer et al. 2014). As temperatures in the Wye catchment were around six degrees colder in the stream sites and up to 14 degrees colder in still water bodies in October compared to July, this could explain the differences in detection success among samplings in the Wye catchment (Eichmiller et al. 2016; Moyer et al. 2014). However, temperatures in the Medway were similar to those in the Wye in July suggesting that the differences in detectability between catchments could be due to differences in population size or to local environmental conditions increasing DNA degradation rates in the Wye (Barnes et al. 2014; Dougherty et al. 2016; Jane et al. 2015; Pilliod et al. 2014). In contrast, $A$. astaci sporulation occurs most efficiently at temperatures nearer $20^{\circ} \mathrm{C}$, which could result in more spores being present in the river system in the summer months in comparison to any other time of the year (Wittwer et al. 2018). Released zoospores can only survive up to three days without a host and encysted spores survive up to two weeks in water, particularly during summer months when average temperatures of flowing and enclosed waterbodies are above $18{ }^{\circ} \mathrm{C}$ (Diéguez-Uribeondo et al. 1995; Unestam 1966), meaning it is possible to achieve a relatively real-time picture of $A$. astaci prevalence in water samples (Wittwer et al. 2018). Lower abundance of A. astaci 
spores in colder temperatures could explain lack of detection of A. astaci in the October samples at the positive July sites in the Wye catchment (Strand et al. 2014), although detection levels could also have been affected by natural variation in population levels of plague infection (James et al. 2017). Considering this variability, seasonal samplings repeated over at least two years are advisable to reliably map the presence/absence of native and invasive crayfish and determine their infectious status.

In contrast to other essays developed for crayfish detection (Agersnap et al. 2017; Cai et al. 2017; Dougherty et al. 2016; Mauvisseau et al. 2018), my single, closed tube reaction, reduces not only the processing time and number of reactions but also the risk of contamination inherent to carry out a larger number of amplifications. HRM has already proved highly specific and useful for multiple species identification (Naue et al. 2014) and for the management of terrestrial invasive species (Ramón-Laca et al. 2014) but had never been applied to the detection of aquatic invasive species and their impacts using eDNA water sampling. Implementation of this multiplex assay provided three-fold biological information (invasive/native/pathogen) on target species', which allows to assess potential contributing factors to native crayfish decline (such as the presence of invasive crayfish and crayfish plague) with greater sensitivity, specificity and efficiency than trapping (Barnes and Turner 2015) or single-species assays, essential to inform effective conservation and management strategies (Thomsen and Willerslev 2015).

In addition to detecting multiple species in a single reaction, my method has also proved useful for monitoring target species in flowing water bodies. This is important for early detection of invasive crayfish which use rivers and streams as a means for dispersal (Bubb et al. 2004) and particularly for white-clawed crayfish whose detection was marginally better using eDNA (7\%) than trapping $(0 \%)$. In terms of sampling effort, eDNA tends to be more time effective than trapping (Smart et al. 2015). However, I failed to detect crayfish in the deep reservoir at Pant-Y-Llyn using eDNA, where trapping had revealed the presence of signal crayfish. Taxonomic groups such as fish and amphibians shed significantly more DNA into the environment compared to invertebrate species, especially those with a hardened exoskeleton such as the crayfish (Thomsen et al. 2012; Tréguier et al. 2014). This reduced release of 
extracellular DNA can lower the detectability of crayfish, resulting in an increased occurrence of false negatives (Ikeda et al. 2016), particularly when the concentration of DNA is low due to few individuals or large water volumes (Tréguier et al. 2014). The nature of the crayfish exoskeleton combined with the depth of the reservoir prevented samples being taken near the sediment where the crayfish reside could account for observed lack of detection at the Pant-y-Llyn site (Tréguier et al. 2014). Collection of sediment samples in addition to water could improve levels of detection of target species, because DNA from sediment can last longer and be more concentrated than in water (Turner et al. 2015).

Conservation efforts rely on efficient, standardised methods for collecting biological data, which advance beyond the limitations of traditional sampling methods (Thomsen and Willerslev, 2015). Ecosystem management and conservation strategies strive to protect biodiversity through preventing invasions from novel species (thus the need for early detection) and effectively monitoring rare native species to preserve hotspots and ark sites (Lodge et al. 2012). Environmental DNA has been directly used as a conservation tool to survey both invasive (e.g.(Takahara et al. 2013; Tréguier et al. 2014) and endangered native species (e.g. (Olson et al. 2012; Sigsgaard et al. 2015) and I have shown how an eDNA-based qPCR-HRM multiplex approach can identify invasive hosts and their pathogens as well as refugia for the native species. This was particularly important to identify areas of coexistence between aquatic native and invasive crayfish (e.g. at the early stages of invasion or where crayfish plague is absent; (Schrimpf et al. 2012), which could be prioritised for long-term conservation plans.

Incorporating this tool to monitoring programmes for conservation significantly reduces the costs of sample processing compared to species' targeted methods. This method can ultimately help in the early detection and prevention of dispersal of invasive hosts and pathogens in threatened freshwater ecosystems, as well as in determining suitable locations for the potential reintroduction of the native species to historic habitats. As genomic technology advances, environmental DNA assays should continue to provide additional information, including more accurate data on species abundance and biomass in both lotic and lentic systems (Bohmann et al. 2014; 
Rees et al. 2014) as well as development of additional multiplexes to simultaneously detect numerous target species of conservation interest. 


\section{CHAPTER 3}

\section{Effect of artificial barriers on the distribution of the invasive signal crayfish and Chinese mitten $\mathrm{crab}^{3}$}

Pages $67-91$

Supporting information (pages $154-174$ )

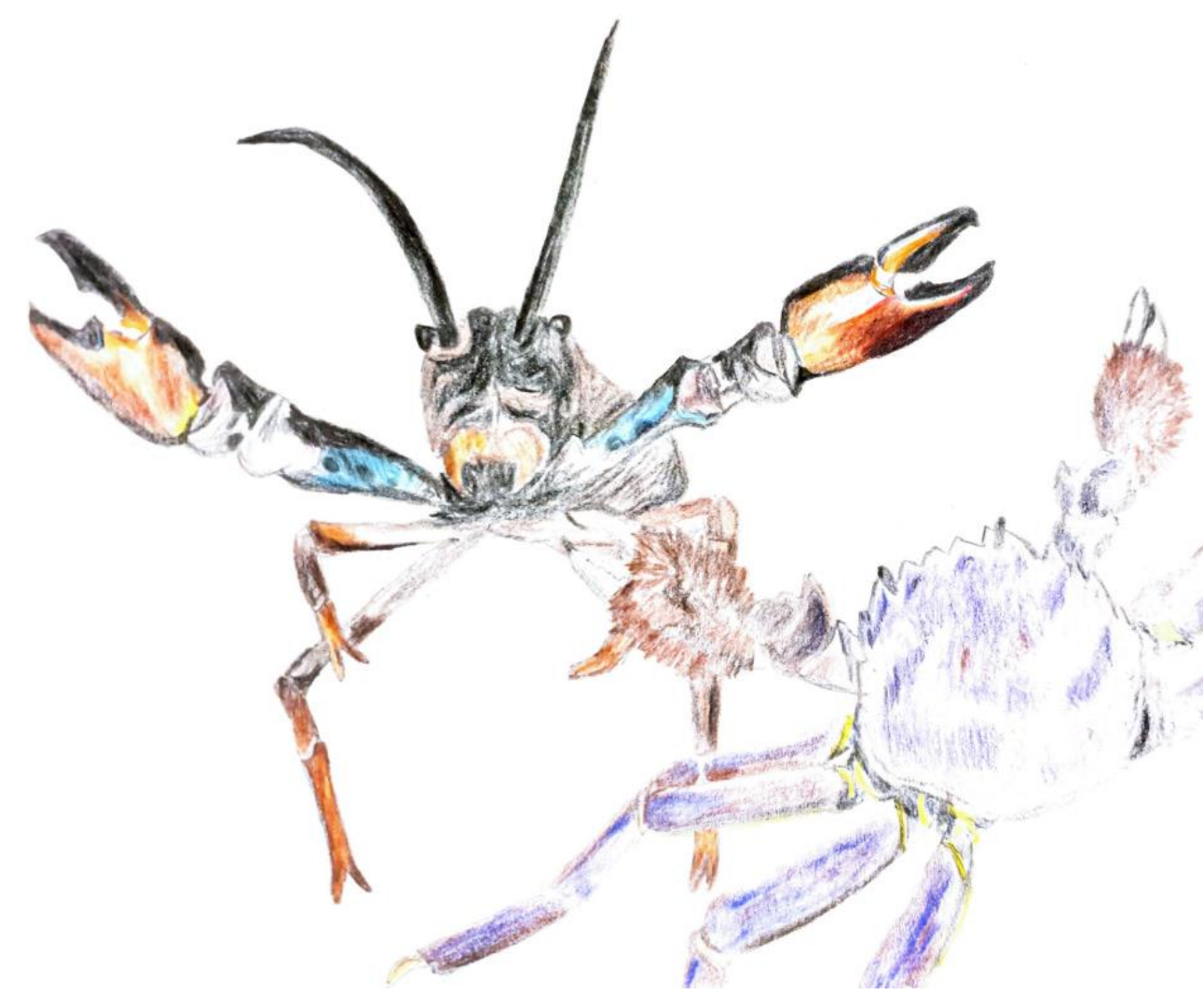

${ }^{3}$ This chapter is based on manuscript 'Robinson, C.V., Garcia de Leaniz, C, Consuegra, S. Effect of artificial barriers on the distribution of the invasive signal crayfish and Chinese mitten crab. (In review: Scientific Reports).' 


\section{CHAPTER 3: INTRODUCTION}

Signal crayfish and Chinese mitten crab are highly invasive species and both negatively impact on local ecosystems, primarily through competing with native counterparts for resources and causing physical damage to banks and levees through burrowing (Bubb et al. 2004; Dittel and Epifanio 2009). Both species have the potential to displace native white-clawed crayfish due to a combination of their aggressive competitive nature and their role as asymptomatic carriers of the crayfish plague pathogen (Aphanomyces astaci (Filipová et al. 2013; James et al. 2017). In some river catchments in Great Britain, signal crayfish and mitten crabs have been reported to coexist, particularly throughout the winter months (NBN 2009, 2015), and in highly modified and/or fragmented systems (CanalPlan 2015).

Impoundments can facilitate the establishment of aquatic invasive species (Johnson et al. 2001), however there is little research regarding the impact of barriers on the movement of AIS able to disperse overland such as signal crayfish and mitten crabs. eDNA methodology can facilitate the assessment of upstream movement of invasive crayfish species in relation to river barriers (Cowart et al. 2018), which is vital information for the designation of upstream ark sites for endangered native crayfish (Bubb et al. 2004; Frings et al. 2012; Kerby et al. 2005).

Over the last five years, an increasing number of biological monitoring research papers have consisted of the use of eDNA as a means to determine presence (Laramie et al. 2015; Takahara et al. 2013) and abundance of invasive species including crayfish (Doi et al. 2017; Mizumoto et al. 2018; Tillotson et al. 2018). In freshwater systems, the lotic nature of rivers results in downstream transport of eDNA from source individual(s), which often results in reduced detection rates and causes spatial issues when attempting to estimate species distribution (Deiner and Altermatt 2014; Thomsen et al. 2012), especially invertebrates with low DNA shedding rates, such as invasive crayfish and mitten crabs (Rice et al. 2018). 
Previous studies have been able to successfully detect invasive signal crayfish in river systems from eDNA water samples (Harper et al. 2018; Chapter 2), however there is limited literature regarding the use of aquatic sediment as a reliable environmental DNA sample option despite the likelihood of eDNA being more readily available in sediment due to the benthic nature of crayfish (Figiel and Bohn 2015; Geerts et al. 2018). Aquatic sediments have long been considered a viable source of DNA (Willerslev et al. 2003; Pietramellara et al. 2009), due in part to the adsorbing nature of materials found within sediments (e.g. Humic acid and clay minerals), which bind to DNA molecules (Levy-Booth et al. 2017; Pietramellara et al. 2009). Sedimentary DNA is derived from the release of extracellular DNA from organisms into the surrounding aquatic environment (i.e. faeces, skin cells), which sink and ultimately deposited into the surficial sediment (Leff et al. 1992). The persistence of DNA within sediments can vary greatly (e.g. 132 days (Turner et al. 2015) to $>4800$ years (GiguetCovex et al. 2014)), depending on the depth of deposition (Levy-Booth et al. 2017) and therefore the temporal reliability of eDNA detected within sediments can be problematic when attempting to asses current occupancy of target species in eDNA studies (Turner et al. 2015). However, in lotic systems where new sediment is deposited regularly, the surficial sediment $(0-15 \mathrm{~cm}$ surface layer) can provide information on species presence over a shorter temporal window (days to several years; Nielsen et al. 2007).

For this chapter, I aimed 1) to assess the relative effects of artificial barriers on both signal crayfish and mitten crabs through the use of eDNA in water and sediment and 2) investigate locations of shared site occupancy for both target species using eDNA.

\section{METHODS}

\subsection{Sample sites and eDNA collection}

Samples were collected at three river systems with differing levels of fragmentation: River Medway (14 barriers; Figure 11; Table S12), River Dee (four barriers; Figure 12; Table S12) and River Stour (no barriers; Figure 11) in July/October 2016 with the assistance of North Wales Wildlife Trust (Dee). The River Medway spans $113 \mathrm{~km}$ 
from West Sussex to Sheerness (Spencer et al. 2003). In comparison, the River Dee is considerably more connected than the Medway and runs $110 \mathrm{~km}$ from source at Dduallt to the Dee estuary (Gurnell et al. 1994). Thirdly, the River Stour, a highly connected river, begins at Lenham and runs $82.4 \mathrm{~km}$ to Pegwell Bay (de Vos et al. 2002). All three river systems are known to sustain populations of both signal crayfish and mitten crabs; signal crayfish generally occupies the upper to middle reaches and mitten crabs found to occupy the middle to lower reaches (NBN 2009, 2015). Sampling took place in the high-mid to lower catchment of each river (Figure 11 and Figure 12).

A total of 11 sites were sampled in the River Medway and River Dee, three sites were sampled in the River Stour (Table 9). Samples were collected at regular intervals (average distance of $7.8 \mathrm{~km}$ between each site) down all three rivers where possible and distance from each samples site to nearest barrier upstream and downstream was measured for the Medway and Dee (Table S13). Three water samples of $30 \mathrm{~mL}$ were taken at each site (one on either side of river near bank and one in central channel), at a minimum of $1 \mathrm{~m}$ depth (where possible) for all river systems. After collection, 30 $\mathrm{mL}$ samples were split into two $15 \mathrm{~mL}$ samples to create technical replicates, resulting in six samples per site and each $15 \mathrm{~mL}$ sample was added to $33 \mathrm{~mL}$ of absolute ethanol and $1.5 \mathrm{~mL} 5 \mathrm{M}$ sodium acetate in a $50 \mathrm{~mL}$ Falcon tube and tubes were subsequently placed on ice before being stored upright at $-20^{\circ} \mathrm{C}$ until DNA extraction. Negative controls consisting of ultrapure water in place of DNA were taken both before sampling and at the end of each sampling effort per site to test for any DNA carryover between sites resulting in false positives. In addition to water samples, two $5 \mathrm{~g}$ sediment samples were collected at each site where possible for all river systems. Due to lack of sediment cohesion at a majority of sites, a sterile $15 \mathrm{~mL}$ Falcon tube was used to collect $5 \mathrm{~mL}$ from the top $2 \mathrm{~cm}$ of sediment (Turner et al. 2015). I collected eDNA water samples prior to collecting sediment samples, to ensure DNA being collected was derived from the water and not from re-suspension of fragments from the sediment during collection (Turner et al. 2015). Sediment was stored on ice and then kept frozen at $-80^{\circ} \mathrm{C}$ until DNA extraction. Environmental conditions including temperature, flow rate, shade cover, bank consistency (concrete vs. mud/clay) and also bank angle 
(rounded up to nearest $5^{\circ}$ ) in relation to river/pond water were recorded for each site (Table 9). 
Table 9. Site information for eDNA sample collection in the River Medway (M), River Stour (S) an GPS coordinates of site, temperature $\left({ }^{\circ} \mathrm{C}\right)$, flow rate $(\mathrm{m} / \mathrm{s})$, shade level $(0-3)$, sediment collectio (concrete vs. mud/clay) and bank angle in relation to waterbody (left and right in relation to downstr

\begin{tabular}{|c|c|c|c|c|c|c|c|}
\hline Site & Site Name & Site Type & $\begin{array}{c}\text { River } \\
\text { System }\end{array}$ & GPS & Temp. $\left({ }^{\circ} \mathrm{C}\right)$ & Flow Rate $(\mathrm{m} / \mathrm{s})$ & $\begin{array}{l}\text { Shade } \\
(0-3)\end{array}$ \\
\hline \multirow{2}{*}{ M1 } & Tonbridge & River & Medway & TQ 59089 & 17 & 0.2 & 0 \\
\hline & Castle & & & 46489 & & & \\
\hline \multirow[t]{2}{*}{ M2 } & Tudeley & Stream & Medway & TQ 67472 & 15 & 0.3 & 0 \\
\hline & Brook & & & 48254 & & & \\
\hline \multirow[t]{2}{*}{ M3 } & Puttenden & Pond & Medway & TQ 60810 & 17 & N/A & 2 \\
\hline & Lake & & & 51347 & & & \\
\hline \multirow[t]{2}{*}{ M4 } & Canoe & River & Medway & TQ 68987 & 18 & 0.2 & 1 \\
\hline & Landing & & & 49924 & & & \\
\hline \multirow[t]{2}{*}{ M5 } & Horse & River & Medway & TQ 72866 & 16 & 0.25 & 1 \\
\hline & Farm & & & 48687 & & & \\
\hline \multirow[t]{2}{*}{ M6 } & Summerhi & Stream & Medway & TQ 77297 & 14 & 0.1 & 3 \\
\hline & 11 Road & & & 46511 & & & \\
\hline
\end{tabular}




\begin{tabular}{|c|c|c|c|c|c|c|c|}
\hline \multirow{2}{*}{ M7 } & Green & Stream & Medway & TQ 72843 & 13 & 0.2 & 1 \\
\hline & Lane & & & 45680 & & & \\
\hline \multirow[t]{2}{*}{ M8 } & Teston & River & Medway & TQ 70880 & 15 & 0.2 & 1 \\
\hline & Bridge & & & 53290 & & & \\
\hline \multirow[t]{2}{*}{ M9 } & Farleigh & River & Medway & TQ 73478 & 16 & 0.4 & 0 \\
\hline & Station & & & 53564 & & & \\
\hline M1 & Asda & River & Medway & TQ 75665 & 17 & 0.3 & 0 \\
\hline 0 & & & & 55630 & & & \\
\hline M1 & Leybourne & Lake & Medway & TQ 70192 & 19 & N/A & 2 \\
\hline 1 & Lakes & & & 59812 & & & \\
\hline \multirow[t]{2}{*}{ ST1 } & Gore & Stream & Stour & TR 26937 & 17 & 0.25 & 2 \\
\hline & Street & & & 63415 & & & \\
\hline \multirow[t]{3}{*}{$\mathrm{ST} 2$} & Grove & River & Stour & TR 23499 & 18 & 0.1 & 1 \\
\hline & Ferry & & & 63189 & & & \\
\hline & Road & & & & & & \\
\hline \multirow[t]{2}{*}{ ST3 } & Fordwich & River & Stour & TR 17922 & 17 & 0.5 & 1 \\
\hline & & & & 59782 & & & \\
\hline \multirow[t]{2}{*}{ D1 } & NRW Bala & River & Dee & SH 93341 & 15 & N/A & 0 \\
\hline & & & & 35505 & & & \\
\hline
\end{tabular}




\begin{tabular}{|c|c|c|c|c|c|c|c|}
\hline D2 & Cilan & River & Dee & SJ 02021 & 15 & N/A & 1 \\
\hline & & & & 37388 & & & \\
\hline D3 & Carrog & River & Dee & $\begin{array}{c}\text { SJ } 02080 \\
37443\end{array}$ & 16 & N/A & 0 \\
\hline D4 & $\begin{array}{c}\text { Llangollen } \\
\text { Serpents }\end{array}$ & River & Dee & $\begin{array}{c}\text { SJ } 20486 \\
43565\end{array}$ & 15 & N/A & 3 \\
\hline D5 & $\begin{array}{l}\text { Halton } \\
\text { Woods }\end{array}$ & River & Dee & $\begin{array}{c}\text { SJ } 29494 \\
40857\end{array}$ & 14 & N/A & 2 \\
\hline D6 & Eyton Hall & River & Dee & $\begin{array}{c}\text { SJ } 36286 \\
44256\end{array}$ & 13 & N/A & 1 \\
\hline D7 & $\begin{array}{l}\text { Sutton } \\
\text { Green }\end{array}$ & River & Dee & $\begin{array}{c}\text { SJ } 41383 \\
47928\end{array}$ & 13 & N/A & 0 \\
\hline D8 & Caldecott & River & Dee & $\begin{array}{c}\text { SJ } 42500 \\
51100\end{array}$ & 13 & N/A & 3 \\
\hline D9 & Holt & River & Dee & $\begin{array}{c}\text { SJ } 40307 \\
56900\end{array}$ & 14 & N/A & 3 \\
\hline D10 & Eccleston & River & Dee & $\begin{array}{c}\text { SJ } 41592 \\
62289\end{array}$ & 13 & N/A & 2 \\
\hline
\end{tabular}




\begin{tabular}{lllllllll}
\hline D11 & Chester & River & Dee & SJ 41701 & 14 & N/A & 0 & Y \\
& Meadows & & & & & & & \\
\end{tabular}

Table 10. Catchment location, number of known river obstructions within area sampled, month/year sampled in 2016, total number of eDNA water and eDNA sediment samples collected from the River

\begin{tabular}{cccccc}
\hline River System & Location & $\begin{array}{c}\text { Number of } \\
\text { Known River } \\
\text { Obstructions }\end{array}$ & Month/Year & $\begin{array}{c}\text { Number of } \\
\text { sites sampled }\end{array}$ & $\begin{array}{r}\text { Tota } \\
\text { eD }\end{array}$ \\
& SE England & 15 & July/2016 & 11 \\
Medway & N Wales & 4 & September/2016 & 11 \\
Stour & SE England & 0 & July/2016 & 3 \\
& & & TOTAL: & $\mathbf{2 5}$ \\
\hline
\end{tabular}

* Including field blanks 


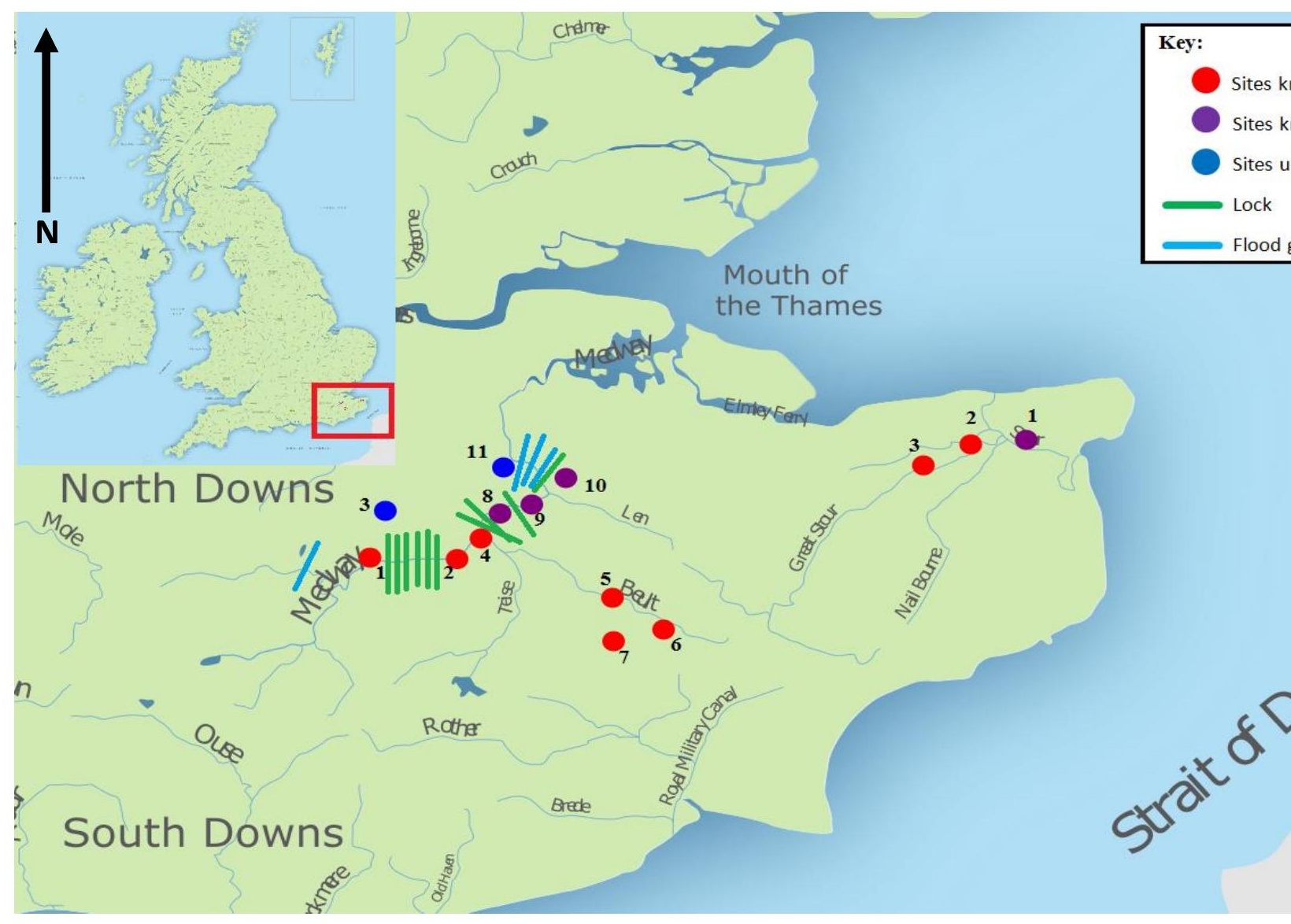

Figure 11. eDNA sampling sites for River Medway and River Stour. Signal crayfish DNA was confi (Horse Farm), 7 (Green Lane), 8 (Teston Bridge), 10 (Asda), and 11 (Leybourne Lakes); mitten crab 11 in the Medway and in the Stour, both signal crayfish and mitten crabs were detected at site 7, 1 samples and between zero and three sediment samples were collected in 2016. 


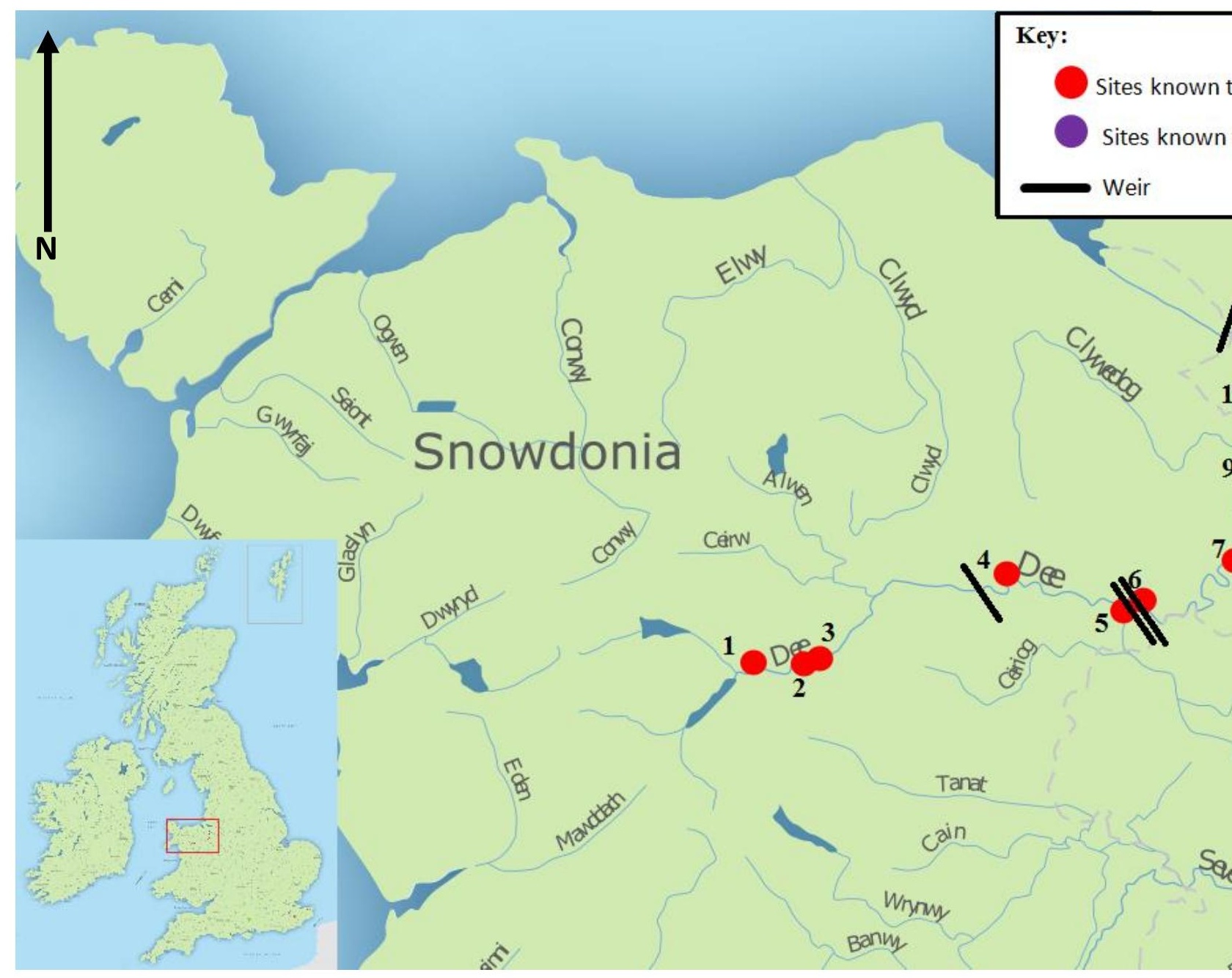

Figure 12. eDNA sampling sites for River Dee. Signal crayfish DNA was confirmed at sites 1 (N (Caldecott); mitten crab DNA was confirmed at site 7, 8 and 9 (Holt). At each point, six water samp collected in 2016. 
11.2. DNA extraction and qPCR optimisation

Primers for crayfish (Chapter 2) unintentionally also amplify mitten crab DNA (noncomplementary) and therefore were used to amplify a $83 \mathrm{bp}$ product of both target species. Primers were assessed in vitro for mitten crab using positive control tissue (leg muscle) from eight mitten crab individuals from three populations (Maidstone, Kent; Chester, Cheshire; Leeds, Yorkshire) to ensure primers continually amplify mitten crab DNA despite not being designed for the species. Mitten crab DNA was extracted using Qiagen ${ }^{\circledR}$ DNeasy Blood and Tissue Kit (Qiagen, UK), eluted in 200 $\mu 1$, and amplified in end-point PCR with the above primers using the following protocol: $95{ }^{\circ} \mathrm{C}$ for $3 \mathrm{~min}$, followed by 40 cycles of $95{ }^{\circ} \mathrm{C}$ for $30 \mathrm{~s}, 61^{\circ} \mathrm{C}$ for $30 \mathrm{~s}$ and $72{ }^{\circ} \mathrm{C}$ for $45 \mathrm{~s}$ with a final elongation step of $72{ }^{\circ} \mathrm{C}$ for $10 \mathrm{~min}$. All amplified PCR products were checked for the correct amplicon sizes using a 2\% agarose gel electrophoresis. To confirm the species identity, PCR products were analysed using Sanger Sequencing on an ABI Prism 277 DNA sequencer. Resulting sequences were aligned using BioEdit v. 5.0.9 (using the ClustalW program) and inputted to BLAST (Ye et al. 2006).

\subsection{Mitten crab qPCR-HRM optimisation}

For optimisation of crayfish primers for mitten crab DNA, specific in vitro testing of RT-qPCR-HRM analysis was performed using SsoFast EvaGreen ${ }^{\circledR}$ qPCR Supermix (BioRad, UK) in a Bio-Rad CFX96 Touch Real-Time PCR Detection System (BioRad, UK) beginning with 15 min of denaturation at $98{ }^{\circ} \mathrm{C}$, followed by 40 cycles of 95 ${ }^{\circ} \mathrm{C}$ for $15 \mathrm{~s}$ and $61.5{ }^{\circ} \mathrm{C}$ for $30 \mathrm{~s}$. A HRM step was applied at the end of RT-qPCR reactions, ranging from $65{ }^{\circ} \mathrm{C}$ to $95{ }^{\circ} \mathrm{C}$ in $0.1{ }^{\circ} \mathrm{C}$ increments to assess the consistency of amplicon melt temperature (tm). Resulting efficiency value for mitten crab DNA at pre-determined annealing temperature $\left(61.5^{\circ} \mathrm{C}\right)$ was $105.8 \%, \mathrm{R}^{2}=0.997$ (previously determined efficiency of $100.2 \%, \mathrm{R}^{2}=0.986$ for signal crayfish, and $107.9 \%$ Chapter 2). Limit of detection (LOD) and limit of quantification (LOQ) were determined for mitten crab through a dilution series ranging from $5 \mathrm{ng} / \mu \mathrm{l}$ to $5 \times 10^{-7} \mathrm{ng} / \mu \mathrm{l}$, using a mitten crab DNA pool. HRM analysis was conducted on seven individuals to account for any degree of intraspecific variation in $\mathrm{qPCR}$ product tm. Melt temperatures $(\mathrm{tm})$ 
generated from positive qPCR amplifications were compared to known speciesspecific product tms (signal crayfish: $73.8^{\circ} \mathrm{C} \pm 0.2$; mitten crab: $73.2^{\circ} \mathrm{C} \pm 0.2$ ) obtained through qPCR optimisation, to assess the presence/absence of all species in each qPCR reaction.

\subsection{Mixed target species qPCR-HRM optimisation}

For assessing the ability to detect target species in the same reaction, equal concentrations $(5 \mathrm{ng} / \mu \mathrm{l})$ of signal crayfish, native crayfish and mitten crab DNA were pooled together from seven different individuals of each species at various volume ratios (from 2:2:2, 1:2:2, 2:1:2 and 2:2:1 $\mu$ l signal crayfish: mitten crab: white-clawed crayfish). Further analysis of mixed proportions was conducted with only signal crayfish and mitten crab DNA, because native crayfish are known to be locally extinct in the catchments being sampled. Different volume ratios were combined for just the two invasive species (signal crayfish and mitten crabs from 1:9 $\mu$ l through all ratios to 9:1 $\mu$ l signal crayfish: mitten crab).

\section{5. eDNA in situ analyses}

DNA extraction from 177 separate field eDNA water samples (including negative controls) and 39 eDNA sediment samples (Table 10) was performed using Qiagen $\AA$ DNeasy PowerSoil Kit (Qiagen, UK), following the manufacturer's instructions, apart from a reduction in the elution volume from $60 \mu 1$ to $50 \mu 1$, to maximise DNA yield. Sediment samples were extracted in triplicate (78 in total). DNA extractions were undertaken in a dedicated eDNA area within an extraction cabinet, fully equipped with flow-through air system and UV light and to minimise contamination; additionally, dedicated eDNA laboratory coat and nitrile gloves were worn during the process.

Amplifications were undertaken in triplicate using the protocol previously described, with the final optimised qPCR reactions carried out in a final volume of $10 \mu$, containing $2 \mu \mathrm{l} \mathrm{SsoFast}{ }^{\mathrm{TM}}$ EvaGreen ${ }^{\circledR}$ (Bio-Rad, UK), $0.25 \mu$ l each primer $(10 \mu \mathrm{M})$, $1 \mu \mathrm{l}$ template DNA at $5 \mathrm{ng} / \mu \mathrm{l}$ and $3.5 \mu \mathrm{l}$ of ultrapure water. Melt curves generated from species-specific product tms (signal crayfish: $73.8^{\circ} \mathrm{C} \pm 0.2$; mitten crab: $73.2^{\circ} \mathrm{C}$ 
\pm 0.2 ; white-clawed crayfish: $74.8 \pm 0.2$ ) were analysed to assess the presence/absence of target species in field samples. Samples which had at least two out of three PCR replicates with corresponding target melt tm for either or both species, with a melt rate above $200-\mathrm{d}(\mathrm{RFU}) / \mathrm{dT}$ were considered positive. In addition, qPCR reactions were carried out at sites positive for both signal crayfish and mitten crabs to test for presence of crayfish plague causal agent $A$. astaci using $2 \mu 15$ x HOT FIREPol ${ }^{\circledR}$ EvaGreen $^{\circledR}$ qPCR Mix Plus ROX (Soils Biodyne, Estonia), $0.4 \mu \mathrm{l}$ of primer mix $(5 \mu \mathrm{M}), 1 \mu \mathrm{l}$ template DNA at $5 \mathrm{ng} / \mu \mathrm{l}$ and $6.6 \mu \mathrm{l}$ of ultrapure water (Robinson et al. 2018; Chapter 2). Resulting melt peaks for target species using the HOT FIREPol ${ }^{\circledR}$ EvaGreen $^{\circledR}$ qPCR Mix were $75.9 \pm 0.2^{\circ} \mathrm{C}$ (signal crayfish), $75.2 \pm 0.2^{\circ} \mathrm{C}$ (mitten crab) and $82.9^{\circ} \mathrm{C}(\mathrm{A}$. astaci) respectively.

qPCR amplifications were carried out in a separate room to eDNA extractions under a PCR hood with laminar flow. Each plate had the addition of both target species positive control DNA once all the eDNA samples were loaded and sealed to prevent false positive signals in the eDNA samples. Amplification negative controls consisting of HPLC water and extraction negative controls were also added in the same well location on each plate test for contamination in eDNA samples.

To confirm mitten crab presence in field samples, a subset of four positive amplifications were cloned and sequenced. Out of 21 successfully transformed clones (seven per sample), between five and seven sequences matched $100 \%$ with mitten crab on BLAST (Ye et al. 2006); non-specific amplification was observed in the remaining clones. In addition, all positive control clones (seven) for mitten crab matched $100 \%$ on BLAST.

\subsection{Statistical analysis}

I employed a generalized linear modelling approach in R v.3.4.3 (R Core Team, 2017) to model detection success (i.e. the proportion of samples that tested positive for signal crayfish and mitten crabs at each site) for both water and sediment eDNA samples as a function of the number of river barriers both upstream and downstream of each 
positive site and river identity (n: 2 rivers; Medway and Dee). A quasibinomial loglink was used to correct for overdispersion.

\section{RESULTS}

12.1. Mitten crab detection limits

Results from a 10-fold dilution series revealed that for mitten crabs, the limit of detection (LOD) was $0.005 \mathrm{ng} / \mu 1$ for the qPCR assay, which is the same LOD as the predetermined value for both signal crayfish and white-clawed crayfish (Chapter 2). No overlap in qPCR product melt temperature ( $\mathrm{tm}$ ) was observed between the three species (Figure 13; Table S14) and it was possible to detect presence of all three species in a single reaction based on the diagnostic melt curve shape produced when combining varying ratios of pooled DNA for both species, however melt curves reflected native crayfish temperature in all samples apart from the 2:2:1 $\mu \mathrm{L}$ (signal crayfish: mitten crab: white-clawed crayfish) ratio (Figure 14; Table S15).Results from mixed proportions of just signal crayfish and mitten crabs displayed signal crayfish melt temperatures $\left(73.9^{\circ} \mathrm{C}\right)$ from $9: 1$ to $7: 3 \mu \mathrm{L}$ signal crayfish: mitten crab ratios and from $6: 4$ to $1: 9 \mu \mathrm{L}$ ratios, the melt curves corresponded to mitten crabs melt tm only $\left(73.2^{\circ} \mathrm{C}\right.$; Figure 15; Table S16).

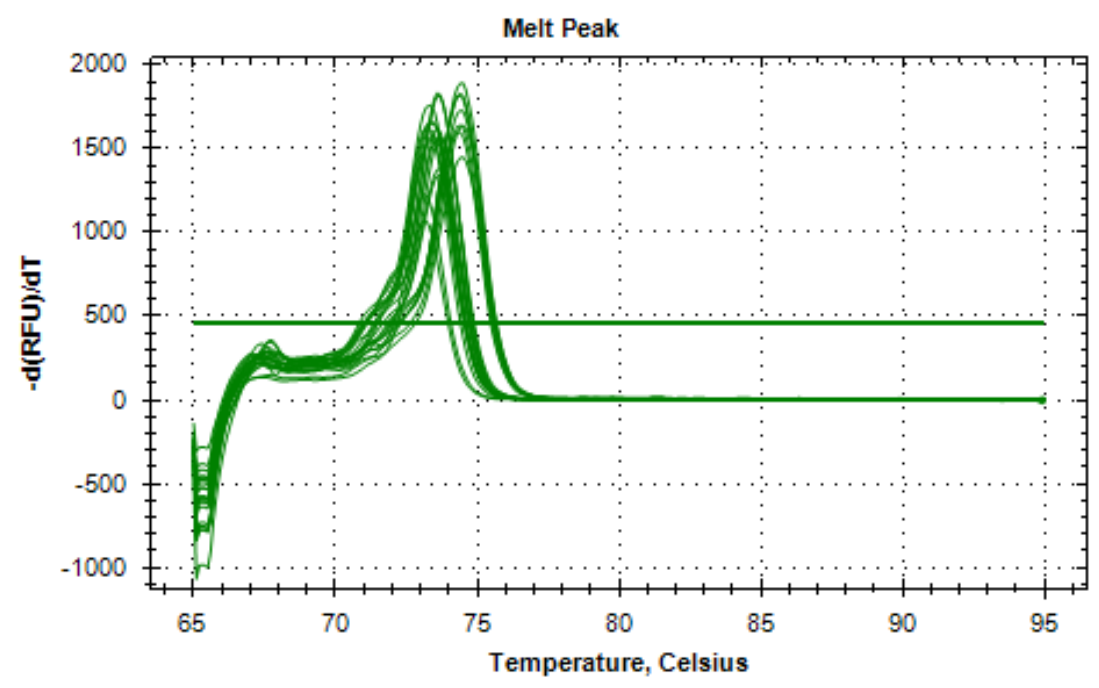

Figure 13. Melt peaks from SsoFast ${ }^{\mathrm{TM}}$ EvaGreen ${ }^{\circledR}$ dilution series for Pacifastacus leniusculus, Austropotamobius pallipes and Eriocheir sinensis DNA pools, displaying lack of cross-over between product melt peaks. 


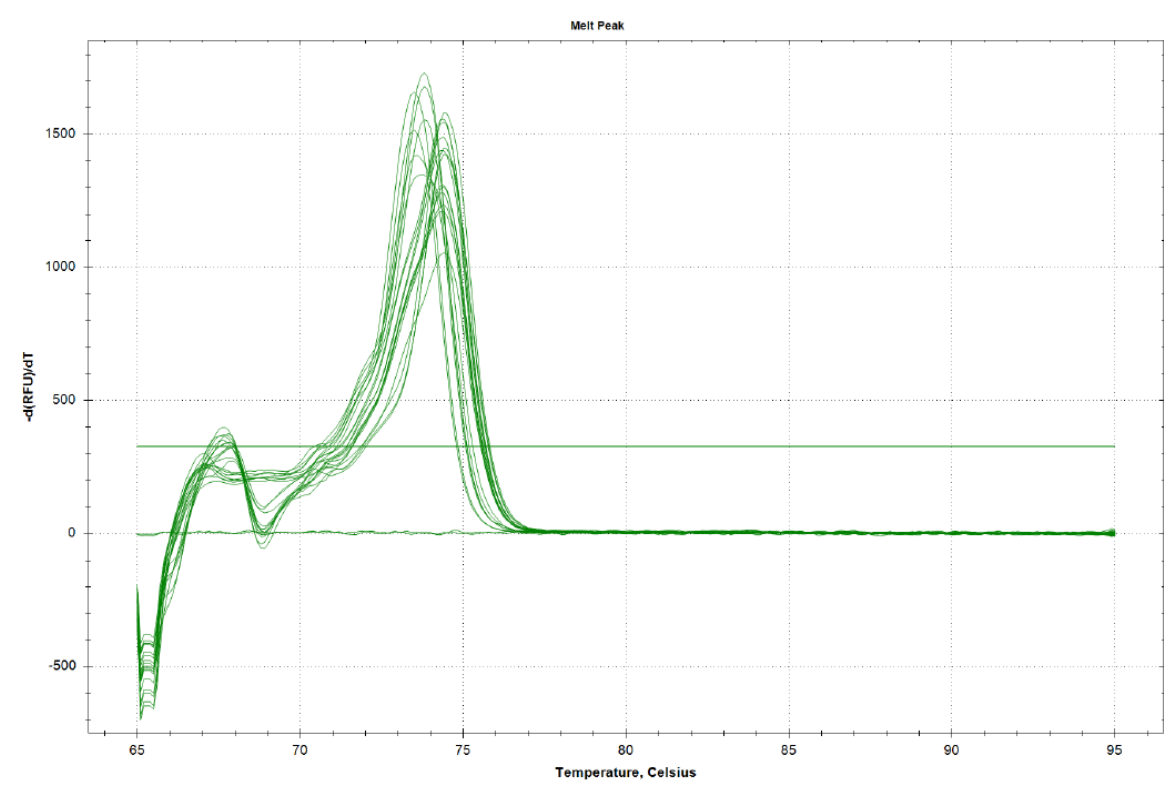

Figure 14. Melt peaks from SsoFast ${ }^{\mathrm{TM}}$ EvaGreen ${ }^{\circledR}$ mixed proportions for Pacifastacus leniusculus, Austropotamobius pallipes and Eriocheir sinensis DNA ratios 2:2:2, 1:2:2, 2:1:2, 2:2:1 and positive control pools for each species. Diagnostic ' $\mathrm{S}$ ' shape start to melt curve is present for all combinations of mixed DNA.

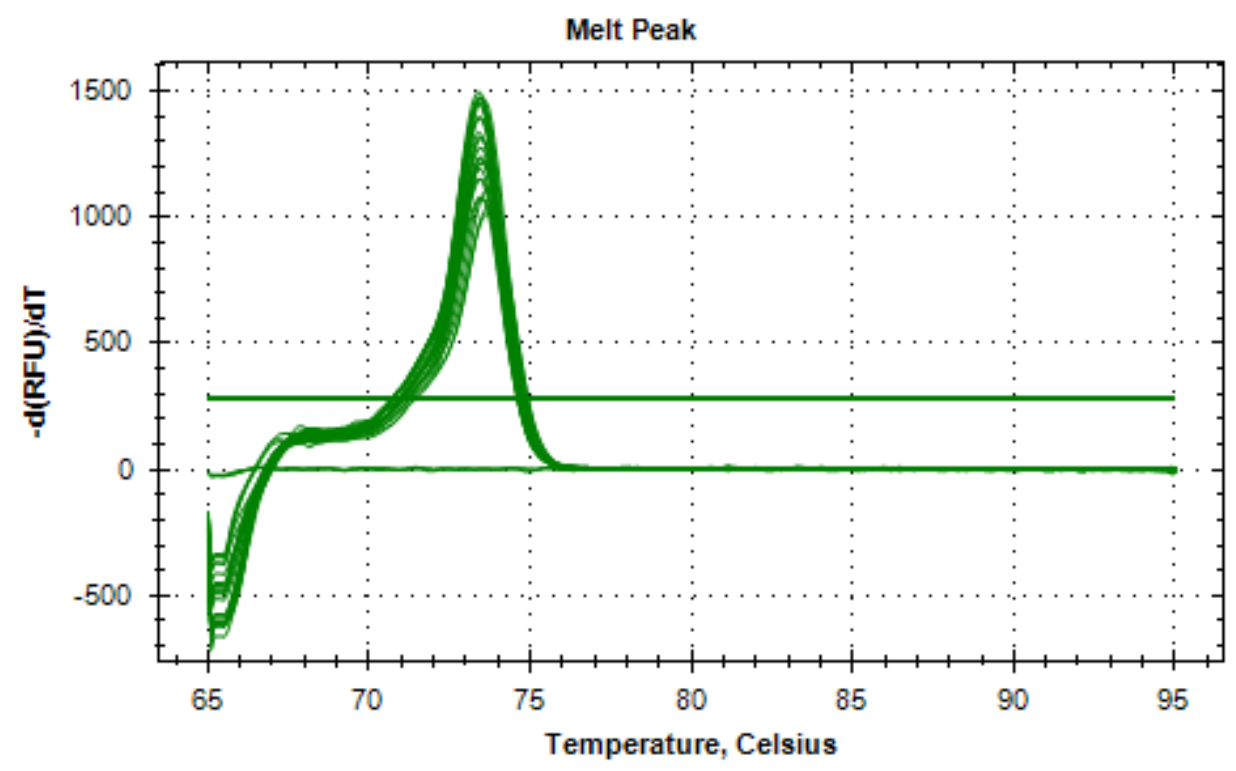

Figure 15. Melt peaks from SsoFast ${ }^{\mathrm{TM}}$ EvaGreen ${ }^{\circledR}$ mixed proportions for Pacifastacus leniusculus, and Eriocheir sinensis DNA ratios 9:1 to 1:9 $\mu \mathrm{L}$ signal crayfish: mitten crab DNA and positive control pools for each species. 
12.2. Detection success and spatial distribution

Signal crayfish DNA was detected in six out of the 11 sites sampled in the River Medway, whereas mitten crab DNA was only detected in three sites (Table 11; Table S17, Table S18 and S19). For all three catchments, both signal crayfish and mitten crab were detected within sections of the catchment where there had been visual confirmation of both species (NBN 2009, 2015). As expected, positive sites for signal crayfish were located in the upper reaches of the river area sampled (Table 11), however signal crayfish DNA was detected further downstream than previously reported in the Dee and Medway catchments (NBN 2009). Similarly, mitten crab DNA was detected further upstream than previously reported from visual surveys in the Medway and the Stour (Table S20 \& S21), however, in the River Dee, mitten crab DNA was detected $>10 \mathrm{~km}$ further downstream (D7) than a known site of occupation at Manley Hall (NBN 2015). Three sampling sites in the River Medway overlapped for both target species (M7, M10, M11) and similarly signal crayfish and mitten crabs were detected at two of the same sites in the River Dee (Figure 16, Table S22 and Table S23; D7 and D8). Despite having fewer sampling sites in the River Stour compared to the Dee and Medway catchments, there was an overlap in detection of both species in site ST3 (Table 11). Results from amplifying positive signal crayfish and mitten crab samples with HOT FIREPol ${ }^{\circledR}$ EvaGreen $^{\circledR}$ qPCR multiplex indicated that there was no A. astaci present in any of the three catchments. 


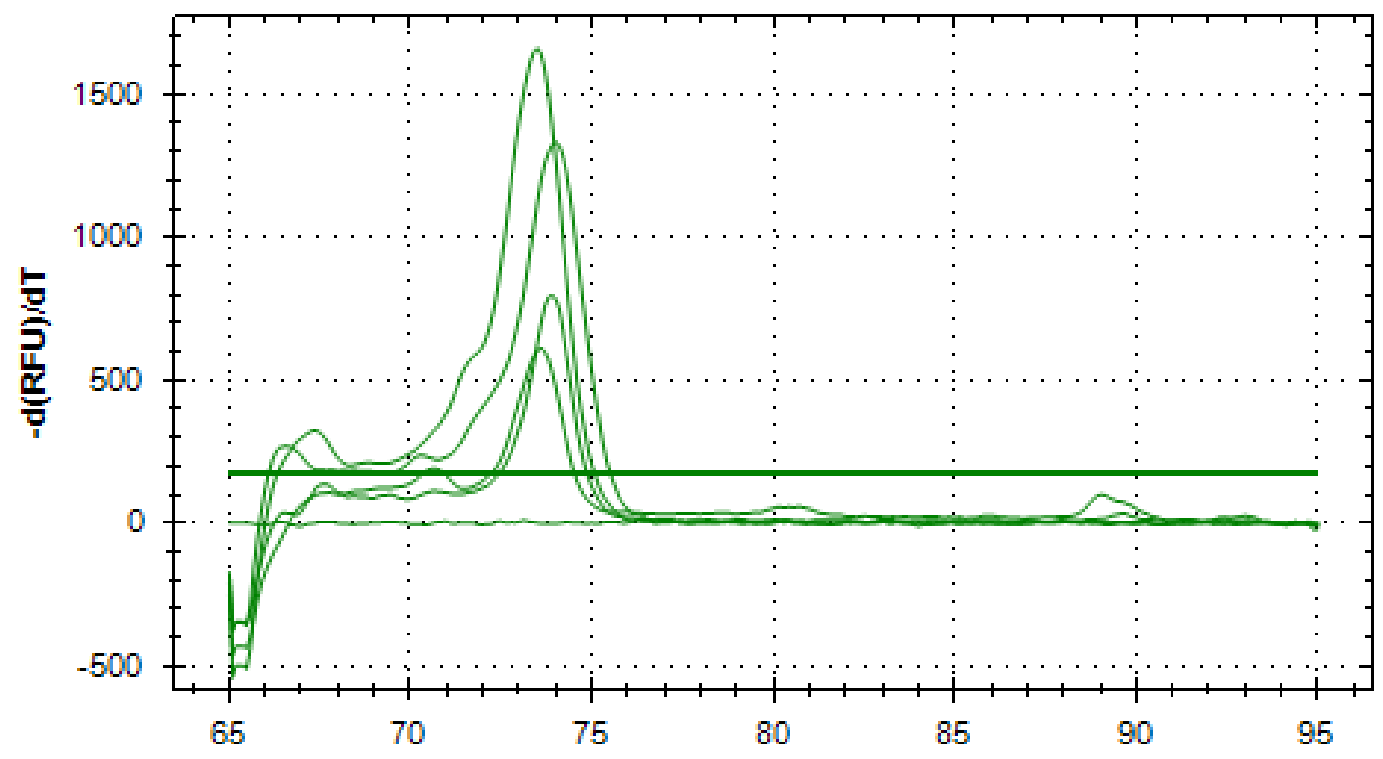

Figure 16. Melt peaks from SsoFast ${ }^{\mathrm{TM}}$ EvaGreen ${ }^{\circledR}$ water field samples in the River Dee positive for Pacifastacus leniusculus, and Eriocheir sinensis DNA. 
Table 11. Positive amplifications for signal crayfish (SC) and mitten crab (MC) in eDNA water (W) and sediment (S) samples across all sites for all three catchments (Medway, Dee and Stour) sampled in 2016. '+ positive amplification for target species in at least two out of three replicates in qPCR, '-' no amplifications for target species.

\begin{tabular}{|c|c|c|c|c|c|c|}
\hline & \multicolumn{6}{|c|}{ Sample } \\
\hline $\begin{array}{c}\text { Catchment/Site/Year/Sample } \\
\text { type }\end{array}$ & $\overline{\mathbf{A}}$ & $\mathbf{B}$ & $\mathbf{C}$ & $\mathbf{D}$ & $\mathbf{E}$ & $\mathbf{F}$ \\
\hline $\mathrm{M} / 1 / 2016 / \mathrm{W}$ & $+(\mathrm{SC})$ & - & $+(\mathrm{SC})$ & $+(\mathrm{SC})$ & - & $+(\mathrm{SC})$ \\
\hline $\mathrm{M} / 1 / 2016 / \mathrm{S}$ & N/A & N/A & N/A & N/A & N/A & N/A \\
\hline $\mathrm{M} / 2 / 2016 / \mathrm{W}$ & - & - & - & - & - & - \\
\hline $\mathrm{M} / 2 / 2016 / \mathrm{S}$ & N/A & N/A & N/A & N/A & N/A & N/A \\
\hline $\mathrm{M} / 3 / 2016 / \mathrm{W}$ & - & - & - & - & - & - \\
\hline $\mathrm{M} / 3 / 2016 / \mathrm{S}$ & - & - & - & - & - & - \\
\hline $\mathrm{M} / 4 / 2016 / \mathrm{W}$ & - & - & - & - & - & - \\
\hline $\mathrm{M} / 4 / 2016 / \mathrm{S}$ & N/A & N/A & N/A & N/A & N/A & N/A \\
\hline $\mathrm{M} / 5 / 2016 / \mathrm{W}$ & $+(\mathrm{SC})$ & $+(\mathrm{SC})$ & $+(\mathrm{SC})$ & $+(\mathrm{SC})$ & $+(\mathrm{SC})$ & $+(\mathrm{SC})$ \\
\hline $\mathrm{M} / 5 / 2016 / \mathrm{S}$ & N/A & N/A & N/A & N/A & N/A & N/A \\
\hline M/6/2016/W & - & - & - & - & - & - \\
\hline $\mathrm{M} / 6 / 2016 / \mathrm{S}$ & - & - & - & - & - & - \\
\hline $\mathrm{M} / 7 / 2016 / \mathrm{W}$ & $+(\mathrm{SC})$ & - & - & - & $+(\mathrm{SC})$ & $+(\mathrm{MC})$ \\
\hline $\mathrm{M} / 7 / 2016 / \mathrm{S}$ & - & $+(\mathrm{SC})$ & $+(\mathrm{SC})$ & - & $+(\mathrm{SC})$ & $+(\mathrm{SC})$ \\
\hline $\mathrm{M} / 8 / 2016 / \mathrm{W}$ & - & - & - & - & - & - \\
\hline $\mathrm{M} / 8 / 2016 / \mathrm{S}$ & $+(\mathrm{SC})$ & - & $+(\mathrm{SC})$ & $+(\mathrm{SC})$ & - & $+(\mathrm{SC})$ \\
\hline $\mathrm{M} / 9 / 2016 / \mathrm{W}$ & - & - & - & - & - & - \\
\hline M/9/2016/S & N/A & N/A & N/A & N/A & N/A & N/A \\
\hline $\mathrm{M} / 10 / 2016 / \mathrm{W}$ & $+(\mathrm{SC})$ & - & $+(\mathrm{MC})$ & $+(\mathrm{SC})$ & - & - \\
\hline $\mathrm{M} / 10 / 2016 / \mathrm{S}$ & N/A & N/A & N/A & N/A & N/A & N/A \\
\hline $\mathrm{M} / 11 / 2016 / \mathrm{W}$ & $+(\mathrm{MC})$ & $+(\mathrm{MC})$ & - & - & - & - \\
\hline $\mathrm{M} / 11 / 2016 / \mathrm{S}$ & $+(\mathrm{MC})$ & $+(\mathrm{MC})$ & $+(\mathrm{SC})$ & - & $+(\mathrm{SC})$ & - \\
\hline D/1/2016/W & - & - & - & $+(\mathrm{SC})$ & - & - \\
\hline $\mathrm{D} / 1 / 2016 / \mathrm{S}$ & $+(\mathrm{SC})$ & $+(\mathrm{SC})$ & $+(\mathrm{SC})$ & $+(\mathrm{SC})$ & $+(\mathrm{SC})$ & $+(\mathrm{SC})$ \\
\hline $\mathrm{D} / 2 / 2016 / \mathrm{W}$ & - & - & - & - & - & - \\
\hline $\mathrm{D} / 2 / 2016 / \mathrm{S}$ & - & - & - & - & - & - \\
\hline $\mathrm{D} / 3 / 2016 / \mathrm{W}$ & - & - & - & - & - & - \\
\hline $\mathrm{D} / 3 / 2016 / \mathrm{S}$ & - & - & - & - & - & - \\
\hline $\mathrm{D} / 4 / 2016 / \mathrm{W}$ & - & - & - & - & - & - \\
\hline
\end{tabular}




\begin{tabular}{ccccccc}
\hline $\mathrm{D} / 4 / 2016 / \mathrm{S}$ & - & - & - & - & - & - \\
$\mathrm{D} / 5 / 2016 / \mathrm{W}$ & - & - & - & - & - & - \\
$\mathrm{D} / 5 / 2016 / \mathrm{S}$ & - & - & - & - & - & - \\
$\mathrm{D} / 6 / 2016 / \mathrm{W}$ & - & - & - & - & - & - \\
$\mathrm{D} / 6 / 2016 / \mathrm{S}$ & - & - & - & - & - & - \\
$\mathrm{D} / 7 / 2016 / \mathrm{W}$ & - & - & - & - & $+(\mathrm{SC})$ & - \\
$\mathrm{D} / 7 / 2016 / \mathrm{S}$ & $+(\mathrm{MC})$ & - & $+(\mathrm{MC})$ & - & - & - \\
$\mathrm{D} / 8 / 2016 / \mathrm{W}$ & - & - & - & - & - & - \\
$\mathrm{D} / 8 / 2016 / \mathrm{S}$ & $+(\mathrm{MC})$ & $+(\mathrm{MC})$ & $+(\mathrm{SC})$ & $+(\mathrm{SC})$ & $+(\mathrm{MC})$ & $+(\mathrm{MC})$ \\
$\mathrm{D} / 9 / 2016 / \mathrm{W}$ & - & - & - & $+(\mathrm{MC})$ & - & - \\
$\mathrm{D} / 9 / 2016 / \mathrm{S}$ & - & - & - & - & - & - \\
$\mathrm{D} / 10 / 2016 / \mathrm{W}$ & - & - & - & - & - & - \\
$\mathrm{D} / 10 / 2016 / \mathrm{S}$ & - & - & - & - & - & - \\
$\mathrm{D} / 11 / 2016 / \mathrm{W}$ & - & - & - & - & - & - \\
$\mathrm{D} / 11 / 2016 / \mathrm{S}$ & - & - & - & - & - & - \\
$\mathrm{S} / 1 / 2016 / \mathrm{W}$ & - & - & - & - & - & - \\
$\mathrm{S} / 1 / 2016 / \mathrm{S}$ & $\mathrm{N} / \mathrm{A}$ & $\mathrm{N} / \mathrm{A}$ & $\mathrm{N} / \mathrm{A}$ & $\mathrm{N} / \mathrm{A}$ & $\mathrm{N} / \mathrm{A}$ & $\mathrm{N} / \mathrm{A}$ \\
$\mathrm{S} / 2 / 2016 / \mathrm{W}$ & - & - & - & - & - & - \\
$\mathrm{S} / 2 / 2016 / \mathrm{S}$ & $\mathrm{N} / \mathrm{A}$ & $\mathrm{N} / \mathrm{A}$ & $\mathrm{N} / \mathrm{A}$ & $\mathrm{N} / \mathrm{A}$ & $\mathrm{N} / \mathrm{A}$ & $\mathrm{N} / \mathrm{A}$ \\
$\mathrm{S} / 3 / 2016 / \mathrm{W}$ & $+(\mathrm{SC})$ & $+(\mathrm{MC})$ & - & - & - & - \\
$\mathrm{S} / 3 / 2016 / \mathrm{S}$ & - & $+(\mathrm{SC})$ & - & $+(\mathrm{SC})$ & $+(\mathrm{SC})$ & $+(\mathrm{SC})$ \\
\hline & & & & & &
\end{tabular}

$\mathrm{M}=$ River Medway, $\mathrm{D}=$ River Dee, $\mathrm{S}=$ River Stour, $+=$ positive amplification in at least two out of three replicates for target species for signal crayfish (SC) and mitten crab (MC).

\subsection{Detection success in relation to barriers}

Sites with the greatest number of positive samples for signal crayfish in the Medway catchment were clustered on the River Beult (M5 \& M7), which is a tributary that joins the main River Medway between the Teston Lock and Hampstead Lock. In comparison to the River Dee, the seven positive sites in the Medway catchment were distributed at regular intervals down the catchment, whereas positive sites in the Dee were located at very start of sample area (D1) and then clustered further downstream of three weirs (D7-D9). Despite presence of six locks within close proximity to one another in the upper Medway catchment (Figure 11; Table S13), and three weirs 
situated within $15 \mathrm{~km}$ in the River Dee (Figure 12; Table S13), signal crayfish DNA was detected above these barriers at M1 and D1 respectively.

Mitten crab DNA was also detected at site M7 in the Medway catchment, however a majority of the positive samples for this species were located further downstream at sites M10 and M11 (Table 11). Despite previous records of mitten crabs around Teston lock at M8, there was no DNA detected in either sediment or water samples from this site. However, there were positive detections of this target species directly upstream of Allington Lock at site M10, where mitten crabs were previously known to accumulate at lock gates as has been observed in other impounded catchments (Iwasaki 2004; Veldhuizen 2001). Mitten crab DNA in the River Dee was detected at three sites upstream of Chester Weir, a barrier which is known to be passable for this species, however mitten crab DNA was not detected any further upstream than site D7 (Table 11; Table S22 and Table S23).

In terms of sample type, water samples marginally outperformed sediment samples, with nine sites positive for one or both species versus 7 sites positive in sediment samples (Table 11). However, at sites positive for target species in sediment samples, there was a higher average number of positive samples for sediment (4 out of 6) compared to water ( 3 out of 6 ). For signal crayfish, there was no effect of barriers for positive detection of the species in water samples (deviance $=43.31$, df $=19, P=$ 0.091 ) or sediment samples (deviance $=50.663$, df $=13, P=0.254$ ). There was however an effect of river identity on positive detections of signal crayfish in water samples (deviance $=43.31, \mathrm{df}=19, P=0.020$ ), with a significantly higher detection success in the River Medway compared to the River Dee. Similarly, for mitten crab detection success did not depend on number of barriers upstream or downstream of sampling sites in sediment samples (deviance $=17.16$, df $=13, P=0.996$ ), but the number of barriers upstream of sampling site had a positive effect on detection success in water samples $($ deviance $=11.08, \mathrm{df}=20, P=0.011)$. 


\section{DISCUSSION}

In this study, I have demonstrated that it is possible to determine the influence of barriers on both signal crayfish and mitten crab distribution using eDNA. By utilising both water and sediment samples, I have been able to assess sites of individual and shared occupancy of both target species and investigate the consistency of positive detections between sample types.

Detections of DNA from target species at locations further upstream than previously reported, suggests that individuals have progressed further upstream (Deiner and Altermatt 2014; Roussel et al. 2015). Signal crayfish are known to migrate both up and downstream anything from 1 to $4 \mathrm{~km}$ upstream and 1.5 to $6 \mathrm{~km}$ downstream per year (Bubb et al. 2004), therefore it is likely that this species has expanded beyond its previously considered range (AquaInvaders 2016). The high proportion of positive sites in the Medway catchment suggests that signal crayfish has continued to persist and disperse from previously known locations in this River. Positive detections of signal crayfish further upstream than previously recorded in the River Dee, indicates upstream range expansion in this catchment (NBN 2009). Similarly, due to the catadromous nature of mitten crabs, juvenile crabs are known to migrate up to $750 \mathrm{~km}$ upstream as juveniles to mature (Herborg et al. 2007; Herborg et al. 2003), therefore the uppermost extent of DNA detection in a river is likely to be within close proximity to the true upstream extent of species occupation (Deiner and Altermatt 2014; Laramie et al. 2015; Pilliod et al. 2013; Spear et al. 2015). Similar to signal crayfish, within the Medway and Dee I detected mitten crabs further upstream than previously reported, again suggesting upstream range expansion of the species (Gilbey et al. 2008).

In both the Rivers Medway and Dee, multiple target species were detected in the same sampling site, both in sediment and water samples, in locations which mark the recorded downstream extent of signal crayfish and upstream extent of mitten crab (AquaInvaders 2016; NBN 2015); this could indicate that both species are occupying the same stretches of the Medway and Dee around these sites, which has already been observed in other catchments in the UK (Rosewarne et al. 2016). Overlapping zones 
between signal crayfish and mitten crabs are expected to result in negative impacts on local biota in comparison to single-species zones due to a combination of niche partitioning and predatory overlap (Rosewarne et al. 2016).

\subsection{Detection in relation to sample type and barriers}

Water and aquatic sediments are known sources of eDNA, and both sample types have been directly used in a range of non-invasive surveys and monitoring techniques (Ficetola et al. 2008; Kirshtein et al. 2007; Taberlet et al. 2012a; Turner et al. 2015). The observed increase in detection success within positive sites in sediment samples correlates with results from additional studies on DNA detection from sediment (Eichmiller et al. 2014; Honjo et al. 2012; Turner et al. 2015), and could be a result of the ecology of both target species (Treguier et al. 2014; Turner et al. 2015). Because both target species are benthic by nature, it was expected that eDNA would be more likely to be detected in the sediments as than in surface waters, as aqueous DNA from crabs and crayfish is most likely to originate from faeces, due to lack of mucus exuded in comparison to fish or amphibians (Caldwell et al. 2011; Eichmiller et al. 2014; Klymus et al. 2015; Roussel et al. 2015) which sinks rapidly into the substratum (Saba and Steinberg 2012). However, the nature of the aquatic sediment enables DNA to remain detectable for a longer period of time (at least 132 days for fish vs 25 days in water samples (Turner et al. 2015)), therefore the temporal persistence of DNA from sediment remains may be confounded by leaching of potentially older and unrepresentative DNA into lotic systems that can result in false positives (Goldberg et al. 2016; Roussel et al. 2015). The fact that there were more sites positive for target species in water samples compared to sediment samples could suggest that water samples are more effective than sediment at detecting target species in this study, however as sediment collection from all sites was not possible in the River Medway, this is not fully conclusive. There is little information regarding the longevity of invertebrate eDNA in sediments, however due to the cross-over in detection success between sediment and water samples, it is likely that detections in sediment for signal crayfish and mitten crabs represent more current-occupancy than past-occupancy (Treguier et al. 2014; Turner et al. 2015). 
One of the limitations of water eDNA sampling in flowing systems is that the source of the extracellular DNA cannot be easily determined (Deiner et al. 2016; Rees et al. 2015). Invertebrate eDNA has previously been successfully detected up to $12 \mathrm{~km}$ downstream from the DNA source (Deiner and Altermatt 2014) but the persistence of eDNA in riverine systems from source to sample site depends on numerous factors, including flow rate (Deiner and Altermatt 2014; Deiner et al. 2016; Nielsen et al. 2007).

There has been little previous consideration of the effects of water-retention barriers such as locks and flood gates on rate of eDNA detection. These barriers are considered to create 'mini-reservoirs' upstream of each obstacle (Collier et al. 1996), and therefore any eDNA is likely to build up at this site until the gates next open, which will result in a localised increased in concentration of eDNA and also overall slow the speed of downstream movement of DNA (Deiner and Altermatt 2014). The presence of a series of locks along a section of river, as seen in the River Medway, could result in DNA being 'held' in short-term reservoirs and then released as gates are opened for navigation, resulting in a sudden release of eDNA into the catchment. Significantly higher detection success for signal crayfish in the River Medway compared to the River Dee could be the result of a combination of the influence of barriers on eDNA longevity and additional factors including differences in local hydrological conditions and abundance (Ficetola et al. 2008; Light 2003; Rees et al. 2014; Thomsen et al. 2012). For signal crayfish, the lack of effect of barriers on DNA detection in the Medway is probably a result of downstream movement, as signal crayfish are able to undertake downstream movement through the lock systems to colonise areas further downstream (Bubb et al. 2004; Gherardi et al. 2011; Light 2003). Barriers however did appear to have an influence over the DNA detection of mitten crabs in the Medway. Detection likelihood of mitten crabs increases with the number of barriers upstream of the sampling site, which indicates that barriers in both the Medway and the Dee are restricting the upstream movement of this species (Schmidt et al. 2009). Mitten crabs are known to aggregate at barriers, especially when banks are too steep to navigate around barrier on land and the presence of large structures such as dams and flood 
gates are known to considerably slow down its upstream migration (Iwasaki 2004; Veldhuizen 2001). This congregation of individuals is likely to result in a stronger eDNA signal downstream of barriers, meaning greater eDNA detection, because density is known to be the major contributing factor to successful DNA detection in numerous aquatic species (Deiner and Altermatt 2014; Evans et al. 2016; Pilliod et al. 2013; Spear et al. 2015).

Overall, assessing the influence of barriers on invasive species presence and distribution is important for informing management strategies (Rahel and Olden 2008; Vander Zanden and Olden 2008). Long-term persistence of mitten crabs depends on the ability of juveniles to migrate upstream and colonise suitable freshwater habitats (Gilbey et al. 2008; Herborg et al. 2007; Rudnick et al. 2003), therefore river obstacles can have a great influence over colonisation success (Schmidt et al. 2009). Additionally, being able to detect sites of predicted range overlap between signal crayfish and mitten crabs using eDNA is important for informing management strategies of critical areas for invasive species control, particularly for species which experience complex trophic interactions and are potentially synergistic (Cowart et al. 2018; Dittel and Epifanio 2009; Parker et al. 1999; Rosewarne et al. 2016). 


\section{CHAPTER 4}

Development of a novel eDNA assay for monitoring the eradication of the highly invasive topmouth gudgeon

$$
\text { (Pseudorasbora parva })^{4}
$$

Pages $92-111$

Supporting information (pages $175-185$ )

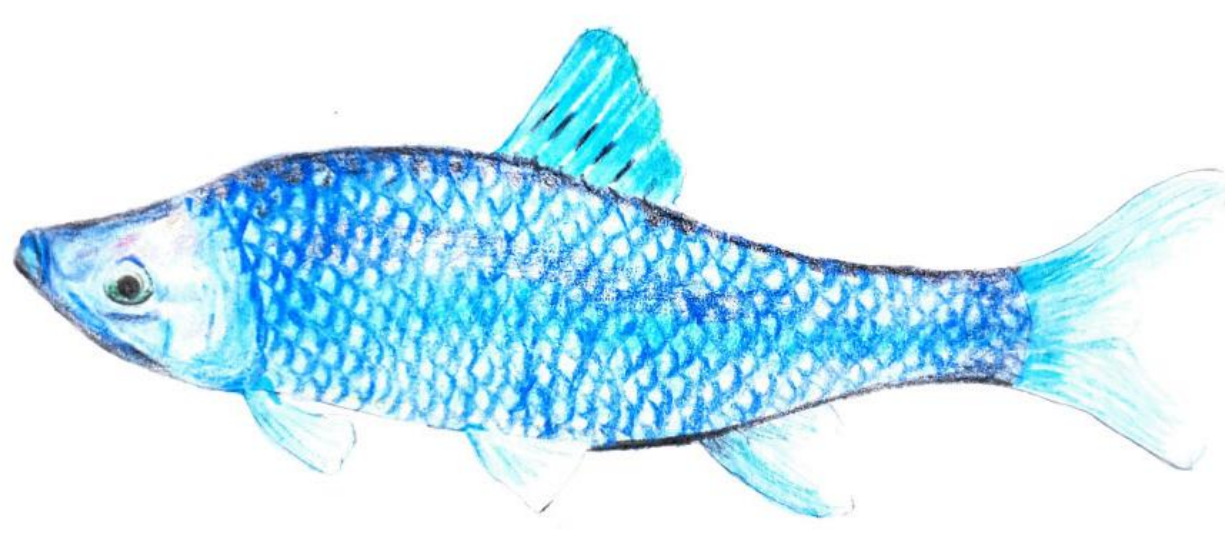

\footnotetext{
${ }^{4}$ This chapter is based on manuscript 'Robinson, C.V., Garcia de Leaniz, C., Rolla, M., Consuegra, S. Development of a novel eDNA assay for monitoring the eradication of the highly invasive topmouth gudgeon (Pseudorasbora parva). (In review: Biological Invasions).'
} 


\section{CHAPTER 4: INTRODUCTION}

Across Europe, fish are the most frequently introduced taxa to freshwater systems (García-Berthou et al. 2005) and topmouth gudgeon (Pseudorasbora parva) is one of the most invasive non-native fish species currently established in European countries (Britton et al. 2007; Copp et al. 2016). Originating from Asia, topmouth gudgeon is a small cyprinid fish which poses great risks to native biodiversity in freshwater systems (Britton et al. 2007; Pinder et al. 2005). In addition to physical disturbance and competition with native fish species for resources, this species is also a host of a highly infectious disease (Rosette-like Agent, closely related to Sphaerothecum destruens), which causes inflammation and mass organ failure of infected European cyprinids (Pinder et al. 2005; Spikmans et al. 2013). Traditional tools used to assess presence/absence of invasive fish such as topmouth gudgeon often include the use of seine nets, generic fish traps and also electrofishing (Jerde et al. 2011). Typically, these tools have proven to be unreliable in determining presence of low abundance species (Jerde et al. 2011; Magnuson et al. 1994), which is a problem when trying to assess the success of previous invasive fish eradication events (Britton et al. 2011b; Copp et al. 2010). Ineffective eradication can lead to survivors repopulating and subsequently dispersing to colonise new sites (Dunker et al. 2016). Topmouth gudgeon being a small ( $10 \mathrm{~cm}$ length) cyprinid fish, is often undetected by conventional sampling methods; a detection threshold of 0.5 fish per $\mathrm{m}^{2}$ in closed systems has been reported for both electrofishing and trapping techniques (Britton et al. 2011b). Despite being a species of great interest for removal with piscicide Rotenone (Allen et al. 2006), there are currently no effective and reliable traditional surveillance methods in place for monitoring the species (Britton et al. 2011b).

An alternative method to conventional sampling is the use of environmental DNA (eDNA) to detect DNA of invasive fish species in both still water and flowing systems (Rees et al. 2014). The application of eDNA to investigate success of fish eradications has previously been applied to Northern pike (Esox lucius (Dunker et al. 2016) and 
demonstrates higher sensitivity compared to traditional electrofishing or trapping methods. Previous eDNA methods adopted for analysing presence of topmouth gudgeon eDNA in eradicated ponds have focussed on end-point (i.e. conventional) PCR (Davison et al. 2017; Keskin 2014) with some success. Here I developed and tested a highly sensitive qPCR resolution melt curve (qPCR-HRM) assay to test the efficiency of an eradication programme in four ponds through species-specific diagnostic melt curve analyses and compared the results to traditional end-point PCR. I also assessed the effect of water volume on detection success by using two different protocols involving different water volumes.

\section{METHODS}

\subsection{Sample sites and eDNA collection}

Four ponds (Morolwg, Ashpits, Turbine and Dyfatty) were sampled at the Millennium Coastal Park (Llanelli, Wales) in August 2017. The presence of TMG at Ashpits pond had been confirmed by trapping and subsequent Rotenone treatment in 2011. Morolwg, Turbine and Dyfatty ponds were also treated with Rotenone in 2012, after confirmation of TMG presence by trapping and electrofishing. Visual confirmation of TMG in Ashpits pond in 2014 has led to concerns that TMG could have been reintroduced into Morolwg pond due to existing stream between these two ponds. There had been no records of TMG in Dyfatty or Turbine ponds since 2012 (Table 12; Figure 17).

A sample of $250 \mathrm{~mL}$ of pond water was collected in triplicate from the upper $30 \mathrm{~cm}$ of the water column using a sterile $1 \mathrm{~m}$ collection ladle before being pooled into a sterile 1L Nalgene bottle (final volume $750 \mathrm{~mL}$ ) at ten sampling points per pond. Filtration of $250 \mathrm{~mL}$ water volumes has been proven to be the recommended minimum volume of water to produce successful detection in a range of aquatic species (Dougherty et al. 2016; Goldberg et al. 2016; Olds et al. 2016; Hinlo et al. 2017). Sampling points were separated between 20 and $100 \mathrm{~m}$ per pond and samples were collected from the bank to avoid disturbing sediment in the unlikelihood any old TMG DNA is still present after five years (Turner et al. 2015; Chapter 3). An additional water sample of $15 \mathrm{~mL}$ was collected at each point per pond as in (Ficetola et al. 2008) to assess the sensitivity of the water volume to detect the target species in ponds. To each $15 \mathrm{~mL}$ 
sample, $33 \mathrm{~mL}$ of absolute ethanol and $1.5 \mathrm{~mL} 3 \mathrm{M}$ sodium acetate were added; tubes were kept upright on ice for transportation and subsequently stored at $-20{ }^{\circ} \mathrm{C}$ until DNA extraction. Ladles were decontaminated between ponds 1 and 2 (Ashpits and Morolwg) and 3 and 4 (Turbine and Dyfatty) by thorough spraying with 5\% Virkon® solution followed by rinsing three times with ultrapure water between study ponds to prevent potential DNA carryover, resulting in false positives (Szkuta et al. 2017). Virkon ${ }^{\circledR}$ was used as a non-toxic, non-bleaching alternative to decontaminating with sodium hypochlorite in the field (Stockton-Fiti \& Moffitt 2017; Szkuta et al. 2017). In between the two sampling days (i.e. between sampling ponds 2 and 3), ladles were autoclaved at $121{ }^{\circ} \mathrm{C}$.

Negative controls, consisting of ultrapure water in place of pond water, were taken at each pond for both methods and before sampling and after decontamination of each ladle before sampling a new pond. Environmental conditions, including water temperature, water depth and extent of cover were recorded at each site (Table 12). 
B
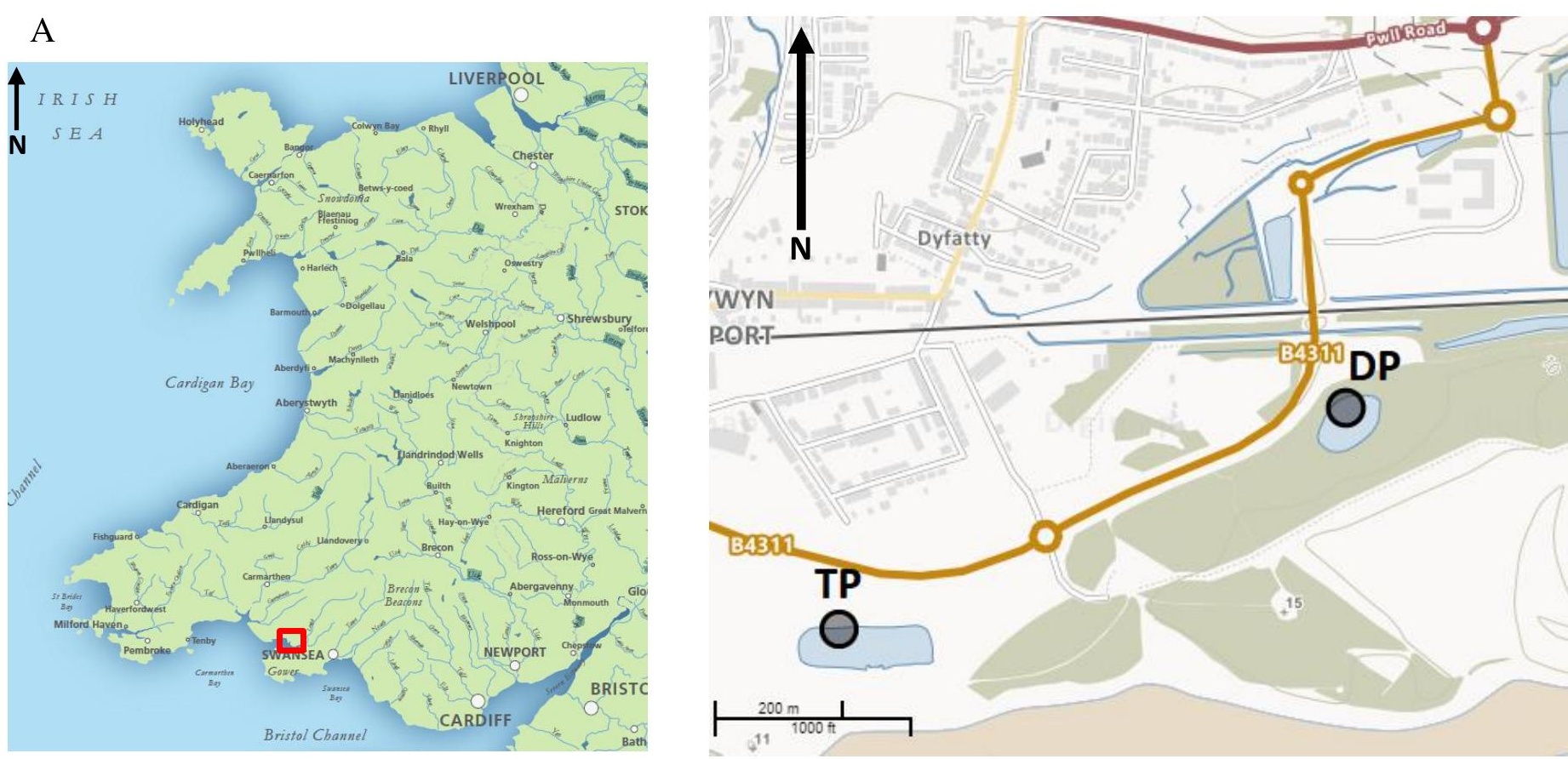

Figure 17. Location of study ponds. A) Location of the Millennium Coastal Park within relation to sampled for Pseudorasbora parva eDNA Millennium Coastal Park in Llanelli. At each pond (Morolw Pond, TP and Dyfatty Pond, DP) both ten $250 \mathrm{~mL}$ water samples were collected in triplicate (750 mL $\mathrm{mL}$ water sample were collected at each sampling point. Ordnance Survey (GB), Using: EDINA <http://digimap.edina.ac.uk/>, Created: July 2017. 
Table 12. Site information for the four ponds (1-4) and two reservoirs (5-6) sampled for presence of during August 2017 and October 2018.

\begin{tabular}{|c|c|c|c|c|c|c|}
\hline Site & Pond Name & Site GPS & $\begin{array}{c}\text { Pond } \\
\text { Volume } \\
\left(\mathbf{m}^{3}\right)\end{array}$ & $\begin{array}{c}\text { Average } \\
\text { Depth (m) }\end{array}$ & $\begin{array}{c}\text { Eradication } \\
\text { Attempt }\end{array}$ & $\begin{array}{c}\text { Current } \\
\text { Pseudorasbora } \\
\text { parva Status }\end{array}$ \\
\hline 1 & Morolwg & SN 4668001091 & 15,640 & 1.7 & Winter 2012 & Unknown \\
\hline 2 & Ashpits & SN 4659901150 & 89,538 & 1.5 & 2011 & Present \\
\hline 3 & Turbine & SN 4502100334 & 17,820 & 1.8 & Winter 2012 & Unknown \\
\hline 4 & Dyfatty & SN 4582900627 & 56,579 & 1.9 & Winter 2012 & Unknown \\
\hline 5 & Upper Lliedi & SN 5130804246 & Unknown & Unknown & N/A & Present \\
\hline 6 & Lower Lliedi & SN 5150604150 & Unknown & Unknown & N/A & Present \\
\hline
\end{tabular}




\subsection{Physical surveys for detection of TMG}

Trapping of TMG was attempted at four time points under permit EP/CW061-E546/11141/02 and EP/CW061-E-546/12754/01, using a range of trapping methods to maximise chance of successful detection. In July 2017, five standard minnow traps (20 $\mathrm{cm} \times 20 \mathrm{~cm}$ x $60 \mathrm{~cm}$ ) were placed by Natural Resources Wales at Ashpits pond at $1 \mathrm{~m}$ depth for seven days, concentrating on the eastern side of the pond where TMG had been previously seen. Traps were baited with fish pellets and checked daily. In February 2018 and June 2018, seine nets and ten standard minnow traps baited with fish pellets and algal-based bait were placed evenly around Ashpits (seine nets and traps) and Dyfatty Ponds (only traps) by Swansea University research staff at a depth of $1 \mathrm{~m}$ and checked after 3 hours (February) and 24 hours (June). Seine netting was also carried out in Ashpits, Morolwg and Dyfatty ponds in both February and June 2018. The final trapping time point was October 2018, where ten standard bottle minnow traps were placed around two ponds (east-end of Ashpits and Turbine) over a two-day period, baited with fresh mackerel and set at a depth of $1 \mathrm{~m}$ and checked after 24 hours. In addition, eight larvae $(<12 \mathrm{~mm})$ were collected by hand-netting from Ashpits $(n=5)$ and Morolwg $(n=3)$ and transported back to the university before being euthanised following Schedule 1 protocol of overdose of 2-Phenoxyethanol. DNA was extracted from a total of eight larvae from Ashpits $(n=5)$ and Morolwg $(n=3)$ ponds using Qiagen ${ }^{\circledR}$ DNeasy Blood and Tissue Kit (Qiagen, UK). Larvae DNA was eluted in $200 \mu \mathrm{l}$ and amplified using both end-point PCR and the new qPCR Pparva16S protocol. All amplified end-point PCR products were checked for the correct amplicon size using a 2\% agarose gel electrophoresis and were sequenced on an ABI Prism 377 sequencer to confirm species identity.

\subsection{Primer design and DNA extraction}

Species-specific qPCR primers (PparvaF 5'-CGAGCCCAAATAACAGAGGGT-3' and PparvaR 5'-CAGGCGAGGCTTATGTTTGC-3') were designed for TMG using NCBI Primer-BLAST to amplify a $147 \mathrm{bp}$ fragment of the 16S mtDNA gene and checked for cross-amplification using NCBI Primer-BLAST (Ye et al. 2006). Primers 
were tested in vitro for non-specific amplification against closely related species, including common carp (Cyprinus carpio), silver rudd (Scardinius erythrophthalmus), common bream (Abramis brama) and common roach (Rutilus rutilus), which are known to inhabit similar water systems (Davison et al. 2017). DNA from these species was assessed for amplification in triplicate using $\mathrm{qPCR}$ with a positive control consisting of $0.1 \mathrm{ng}$ of topmouth gudgeon DNA (Davison et al. 2017). All non-target species failed to amplify and no subsequent products were produced in HRM analysis. Primers were assessed in vitro using positive control tissue (caudal muscle) from 15 TMG caught locally in Wales during 2012/13. DNA was extracted using the Qiagen $®$ DNeasy Blood and Tissue Kit (Qiagen, UK), eluted in $200 \mu \mathrm{l}$, and amplified in endpoint PCR using the following Pparva16S protocol: $95{ }^{\circ} \mathrm{C}$ for $3 \mathrm{~min}$, followed by 40 cycles of $95{ }^{\circ} \mathrm{C}$ for $30 \mathrm{~s}, 61{ }^{\circ} \mathrm{C}$ for $30 \mathrm{~s}$ and $72{ }^{\circ} \mathrm{C}$ for $30 \mathrm{~s}$ with a final elongation step of $72{ }^{\circ} \mathrm{C}$ for $10 \mathrm{~min}$. All amplified PCR products were checked for the correct amplicon size using a $2 \%$ agarose gel electrophoresis.

15.4. $\quad$ qPCR optimisation

Specific in vitro testing of HRM-qPCR was performed for TMG to confirm the consistency of the qPCR product melting temperature. The annealing temperature of Pparva16S primers was optimised at $61{ }^{\circ} \mathrm{C}$ and yielded an efficiency of $91.1 \%, \mathrm{R} 2=$ 0.981 (Figure S10). For optimisation, the Pparva16S-qPCR was undertaken using SsoFast $^{\mathrm{TM}}$ EvaGreen ${ }^{\circledR}$ Supermix (Bio-Rad, UK) and the Pparva16S protocol. An additional HRM step was applied to the end of RT-qPCR reactions, ranging from 55 ${ }^{\circ} \mathrm{C}$ to $95{ }^{\circ} \mathrm{C}$ in $0.1{ }^{\circ} \mathrm{C}$ increments to assess the consistency of amplicon melt temperature (tm). The limit of detection (LOD) and limit of quantification (LOQ) were determined through running a dilution series ranging from $5 \mathrm{ng} / \mu \mathrm{l}$ to $5 \times 10-7 \mathrm{ng} / \mu 1$, using a TMG DNA pool (consisting of DNA from 15 individual TMG). HRM analysis was conducted on 15 individuals from three different populations to account for any degree of intraspecific variation in $\mathrm{qPCR}$ product melt temperature (tm).

15.5. Assay validation 
To validate the assay, I collected one $750 \mathrm{~mL}$ ( 3 x $250 \mathrm{~mL}$ ) sample from the Upper (high abundance of TMG) and one $750 \mathrm{~mL}(3 \times 250 \mathrm{~mL})$ sample from the Lower (low abundance of TMG) Lliedi reservoirs in October 2018, which confirmed for TMG from trapping attempts in June 2018 using standard minnow traps baited as above (permit: EP/CW061-E-546/12754/01; Table 12). Negative controls (ultrapure water) were collected as described previously for the Millennium Coastal Park and water samples were processed following the previously described filtration, extraction and Pparva16S-qPCR protocols. Subsequently, samples which displayed a melt peak consistent with TMG in at least one of three replicates in qPCR were re-amplified in end-point PCR using Pparva16S PCR protocol and sent for sequencing to confirm species identity.

\subsection{Analysis of eDNA field samples}

Samples of $750 \mathrm{~mL}$ of pooled water $(3 \times 250 \mathrm{~mL}$ at each sampling site) from each of the study ponds were filtered the same day of collection using the same filtration protocol as described previously for the Virkon® decontamination validation. DNA filtration and extraction took place in a designated eDNA area in a laboratory where no previous TMG DNA or tissue had been handled. Filters from water samples were stored in individual Eppendorfs at $-20{ }^{\circ} \mathrm{C}$ until subsequent DNA extraction. TMG DNA from filter papers was extracted using Qiagen® DNeasy Blood and Tissue Kit (Qiagen, UK), following the Qiagen Blood Spot extraction protocol with an adjustment to the elution volume (from 200 to $50 \mu \mathrm{l}$ ) to maximise DNA yield.

The $15 \mathrm{~mL}$ water samples were centrifuged at $6{ }^{\circ} \mathrm{C}$ for 45 minutes at $5000 \mathrm{~g}$ (Ficetola et al. 2008) and the supernatant was poured off to allow DNA extraction from the resulting pellet. DNA pellets were extracted using DNeasy PowerLyzer PowerSoil kit (Qiagen ${ }^{\circledR}, \mathrm{UK}$ ), which is known to produce higher yields of DNA for this method of eDNA capture (Hinlo et al., 2017), following a standard protocol with a reduction in elution volume (from 60 to $50 \mu \mathrm{l}$ ). All samples $(750 \mathrm{~mL}$ and $15 \mathrm{~mL}$ ) were amplified in triplicate in a Bio-Rad CFX96 Touch Real-Time PCR Detection System (Bio-Rad, $\mathrm{UK}$ ), in $10 \mu 1$ reactions consisting of $5 \mu 1$ SsoFast ${ }^{\mathrm{TM}}$ EvaGreen ${ }^{\circledR}$ Supermix (Bio-Rad, UK), $0.25 \mu 1$ each forward and reverse primer, $2.5 \mu 1$ HPLC water and $2 \mu 1$ of extracted 
DNA. Amplifications were carried out in triplicate using the standard Pparva16SqPCR protocol as described above and only samples which amplified consistently in one of three replicates at the target DNA product tm $\left(78.8^{\circ} \mathrm{C} \pm 0.3\right)$, with a melt rate above $200-\mathrm{d}(\mathrm{RFU}) / \mathrm{dT}$ were considered to be a positive result. qPCR reactions were carried out in a separate room from the eDNA extractions room under a PCR hood with laminar flow. I added a TMG positive control to each plate after all the eDNA samples had been loaded and sealed to prevent any false positives from manual contamination. As negative amplification controls I used ultrapure water which, along with extraction negative controls, were added to the same well location on each plate to test for eDNA contamination. Field samples were also amplified in triplicate in endpoint PCR with recently described species-specific primers (Davison et al. 2017), using the Pparva16S PCR protocol, and subsequent PCR products were checked for the correct amplicon size using a 2\% agarose gel. Any positive reactions for TMG DNA with both primer sets were sequenced on an ABI Prism 377 sequencer to confirm species identity.

\subsection{Statistical analysis}

I employed a generalized linear modelling approach in R v.3.4.3 (R Core Team, 2017) to model detection success (i.e. the proportion of sites that tested positive for topmouth gudgeon at each pond) as a function of assay type (three assays: conventional PCR on $750 \mathrm{ml}$ of water, qPCR on $15 \mathrm{~mL}$ of water, and qPCR on $750 \mathrm{~mL}$ of water) and pond identity (n: 4 ponds). I considered that topmouth gudgeon was present at a site if one of the three replicates tested positive for that site. A quasibinomial log-link was used to correct for overdispersion.

\section{RESULTS}

16.1. Assay validation in-situ

Results of qPCR confirmed a positive detection for TMG in one out of three replicates in both the upper (Ct: 36.6) and lower (Ct: 36.5) Lliedi reservoir samples (Table 13). All negative controls failed to amplify and TMG DNA control amplified in all three replicates (av. Ct: 24.5). Results of Sanger Sequencing confirmed TMG in both upper and lower reservoirs. 
Table 13. Mean Ct values of positive amplifications for Pseudorasbora parva in 750 $\mathrm{mL}$ and $15 \mathrm{~mL}$ water samples, amplified with designed Pparva16S primers from all four ponds (Morolwg Pond, MP; Ashpits Pond, AP; Turbine Pond, TP and Dyfatty Pond, DP) at each sampling point $(1-10)$ in optimised SsoFast ${ }^{\mathrm{TM}}$ EvaGreen ${ }^{\circledR}$ qPCR assay.

\begin{tabular}{cccccccccccc}
\hline Pond & $\begin{array}{c}\text { Water volume } \\
(\mathbf{m L})\end{array}$ & $\mathbf{1}$ & $\mathbf{2}$ & $\mathbf{3}$ & $\mathbf{4}$ & $\mathbf{5}$ & $\mathbf{6}$ & $\mathbf{7}$ & $\mathbf{8}$ & $\mathbf{9}$ & $\mathbf{1 0}$ \\
\hline MP & 750 & 33.6 & 35.3 & 29.1 & 38.8 & 28.8 & 36.1 & 35.3 & & & 35.4 \\
MP & 15 & & & & 37.8 & & & 34.5 & & & 36.7 \\
AP & 750 & 36.7 & 27.5 & 37.1 & 36.2 & 35.7 & 37.1 & 34.2 & 34.6 \\
AP & 15 & 37.9 & & 37.8 & 37.2 & & & & \\
TP & 750 & & 36.1 & 32.1 & 35.0 & 34.7 & & & 36.5 & 35.2 \\
TP & 15 & & 37.8 & & & & 36.8 & & & & \\
DP & 750 & 37.1 & 36.5 & 33.7 & 36.1 & 36.4 & & 37.2 & 27.1 & 38.5 \\
DP & 15 & & & & & & & & & & \\
\hline
\end{tabular}

16.2. Sensitivity and detection limits

The limit of detection (LOD) for TMG DNA was $0.005 \mathrm{ng} / \mu \mathrm{l}$, determined through a 10-fold dilution series in qPCR. The detection threshold for TMG DNA was 38 cycles and the product melt temperature (tm) was consistent throughout the dilution series (Table S24). In comparison, the newly designed Pparva16S primers amplified TMG DNA pools at $0.05 \mathrm{ng} / \mu \mathrm{l}$ and above, whereas the previously described COI primers (Davison et al. 2017) failed to amplify TMG DNA at $0.05 \mathrm{ng} / \mu 1$, highlighting the greater sensitivity of Pparva16S primers (Figure S11).

\subsection{Detection success}

No TMG were caught in any of the two trappings at Ashpits pond during July 2017 and February 2018. Despite this, larval DNA sequencing and qPCR profiles confirmed 
that two larvae caught from Ashpits pond matched 100\% with TMG on BLAST, despite lack of adult TMG being caught in traps and seine netting at trapping events. Remaining larvae failed to amplify and remained unidentified. Results of qPCR confirmed the presence of TMG DNA in all ponds, with melt temperatures of positive qPCR amplifications corresponding to TMG positive control melt temperature (78.8 ${ }^{\circ} \mathrm{C}$; Figure 18). Mean Ct values for positive $750 \mathrm{~mL}$ samples ranged from 28.8 to 38.8 in Morolwg, 27.5 to 36.7 in Ashpits, 32.1 to 36.5 in Turbine and 27.1 to 38.5 in Dyfatty (Table 13). Morolwg Pond (MP) yielded the highest proportion of sampling sites amplifying for TMG (8 out of 10 sites), whereas Turbine Pond (TP) had the lowest proportion of positive sampling sites (6/10; Table 14; Table S25). The $15 \mathrm{~mL}$ water samples successfully detected TMG in three out of the four ponds, with no TMG DNA being detected in Dyfatty Pond (Table 14; Table S26). Mean Ct values for positive 15 $\mathrm{mL}$ samples ranged from 34.5 to 37.8 in Morolwg, 37.2 to 37.9 in Ashpits and 36.8 to 37.8 in Turbine (Table 13). In comparison, results of end-point PCR with speciesspecific COI primers (Davison et al. 2017) failed to produce any positive amplification for TMG unless the PCR reaction was undertaken with 40 cycles. End-point PCR results also showed that TMG DNA was present in all four ponds, however most positive samples were only observed in one of the three triplicates and product bands were faint (Table 14; Figure 19). Sequencing of the 350bp (Davison et al. 2017) and $147 \mathrm{bp}$ products produced a $100 \%$ species match on BLAST (Ye et al. 2006), with target species (for both primer sets), confirming species presence in all positive amplifications. All negative controls sampled in the field and laboratory failed to amplify in both qPCR and end-point PCR, highlighting success of Virkon ${ }^{\circledR}$ decontamination and lack of DNA contamination throughout laboratory processing of samples.

Detection success varied significantly depending on eDNA assay (deviance $=31.32$, $\mathrm{df}=2, \mathrm{P}<0.001$ ) but not on pond identity (deviance $=3.36, \mathrm{df}=3, \mathrm{P}=0.5821$; Figure 20). My novel qPCR $750 \mathrm{~mL}$ eDNA assay detected the presence of TMG (31/40 or $77.5 \%)$ in a significantly higher proportion of sites $(\mathrm{t}=2.962, \mathrm{P}=0.016)$ than conventional PCR with the same water volume (14/40 or $35.0 \%)$ or qPCR with $15 \mathrm{~mL}$ of water $(8 / 40$ or $20.0 \%)$. The novel assay was 4.2 times more likely to detect TMG in 
an individual water sample than conventional end-point PCR, and 2.2 times more likely to detect its presence at a sampling site when multiple samples are collected (Table S27). 
Table 14. Positive amplifications for Pseudorasbora parva in filtered $750 \mathrm{~mL}$ water samples amplifie $750 \mathrm{~mL}$ water samples amplified in end-point PCR with Davison et al. (2017) primers and positives ar amplified with designed Pparva16S primers from all four ponds (Morolwg Pond, MP; Ashpits Pond, A DP) at each sampling point $(1-10)$ in optimised SsoFast ${ }^{\mathrm{TM}}$ EvaGreen ${ }^{\circledR}$ qPCR assay.

\begin{tabular}{|c|c|c|c|c|c|c|c|c|}
\hline & & & & & \multicolumn{4}{|c|}{ Sampling Point } \\
\hline Pond & $\begin{array}{c}\text { Assay/ } \\
\text { water } \\
\text { volume }\end{array}$ & 1 & 2 & 3 & 4 & 5 & 6 & 7 \\
\hline MP & $\begin{array}{c}16 \mathrm{~S} \text { qPCR/ } \\
750 \mathrm{~mL}\end{array}$ & $+(2)$ & $+(3)$ & $+(3)$ & $+(2)$ & $+(3)$ & $+(3)$ & $+(2)$ \\
\hline MP & $\begin{array}{c}\text { COI PCR/ } \\
750 \mathrm{~mL}\end{array}$ & & & & & $+(3)$ & & \\
\hline MP & $\begin{array}{c}16 \mathrm{~S} \text { qPCR/ } \\
15 \mathrm{~mL}\end{array}$ & & & & $+(2)$ & & & $+(1)$ \\
\hline $\mathrm{AP}$ & $\begin{array}{c}16 \mathrm{~S} \text { qPCR/ } \\
750 \mathrm{~mL}\end{array}$ & $+(1)$ & $+(3)$ & & $+(2)$ & & $+(3)$ & $+(2)$ \\
\hline $\mathrm{AP}$ & $\begin{array}{c}\text { COI PCR/ } \\
750 \mathrm{~mL}\end{array}$ & & $+(1)$ & & $+(1)$ & & & $+(1)$ \\
\hline
\end{tabular}




\begin{tabular}{|c|c|c|c|c|c|c|}
\hline$\overline{\mathrm{AP}}$ & $\begin{array}{c}16 \mathrm{~S} \mathrm{qPCR} / \\
15 \mathrm{~mL}\end{array}$ & $+(1)$ & & $+(2)$ & & $+(1)$ \\
\hline $\mathrm{TP}$ & $\begin{array}{c}16 \mathrm{~S} \mathrm{qPCR} / \\
750 \mathrm{~mL}\end{array}$ & & $+(2)$ & $+(3)$ & $+(3)$ & $+(3)$ \\
\hline $\mathrm{TP}$ & $\begin{array}{c}\text { COI PCR/ } \\
750 \mathrm{~mL}\end{array}$ & & $+(1)$ & $+(2)$ & $+(1)$ & $+(1)$ \\
\hline $\mathrm{TP}$ & $\begin{array}{c}\text { 16S qPCR/ } \\
15 \mathrm{~mL}\end{array}$ & & $+(2)$ & & & $+(2)$ \\
\hline DP & $\begin{array}{c}16 \mathrm{~S} \mathrm{qPCR} / \\
750 \mathrm{~mL}\end{array}$ & $+(2)$ & $+(3)$ & $+(2)$ & $+(2)$ & $+(2)$ \\
\hline DP & $\begin{array}{l}\text { COI PCR/ } \\
750 \mathrm{~mL}\end{array}$ & & & $+(1)$ & & \\
\hline DP & $\begin{array}{c}16 \mathrm{~S} \mathrm{qPCR} / \\
15 \mathrm{~mL}\end{array}$ & & & & & \\
\hline
\end{tabular}

$+(\#)=$ positive melt peak/positive band at $350 \mathrm{bp}$ for Pseudorasbora parva $(78.8 \mathrm{oC} \pm 0.3) ; \#=$ num 


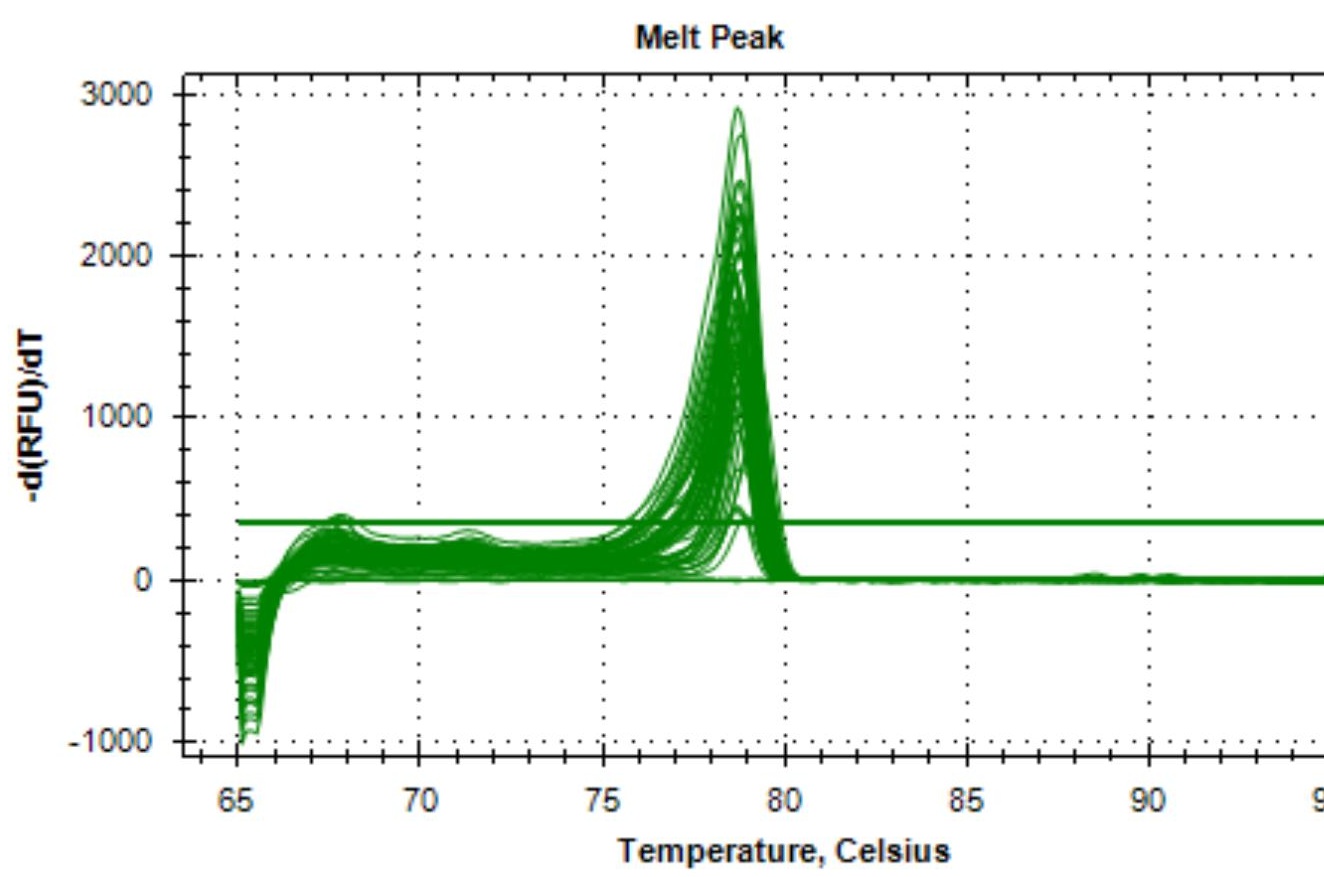

Figure 18. Melt curves from SsoFast ${ }^{\mathrm{TM}}$ EvaGreen ${ }^{\circledR}$ qPCR from positive field samples from pond AP; Turbine Pond, TP and Dyfatty Pond, DP) for Pseudorasbora parva. 
A

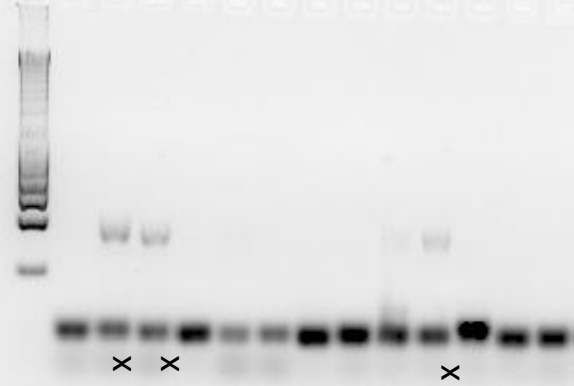

B

บั

Figure 19. Agarose gel from end-point PCR using Davison et al., 2017 primers on field eDNA samples in triplicate for Pseudorasbora parva. A) Field samples (x) with positive samples displaying a band at $350 \mathrm{bp}$ (200 bp ladder). B) Positive control tissue from topmouth gudgeon and negative controls.

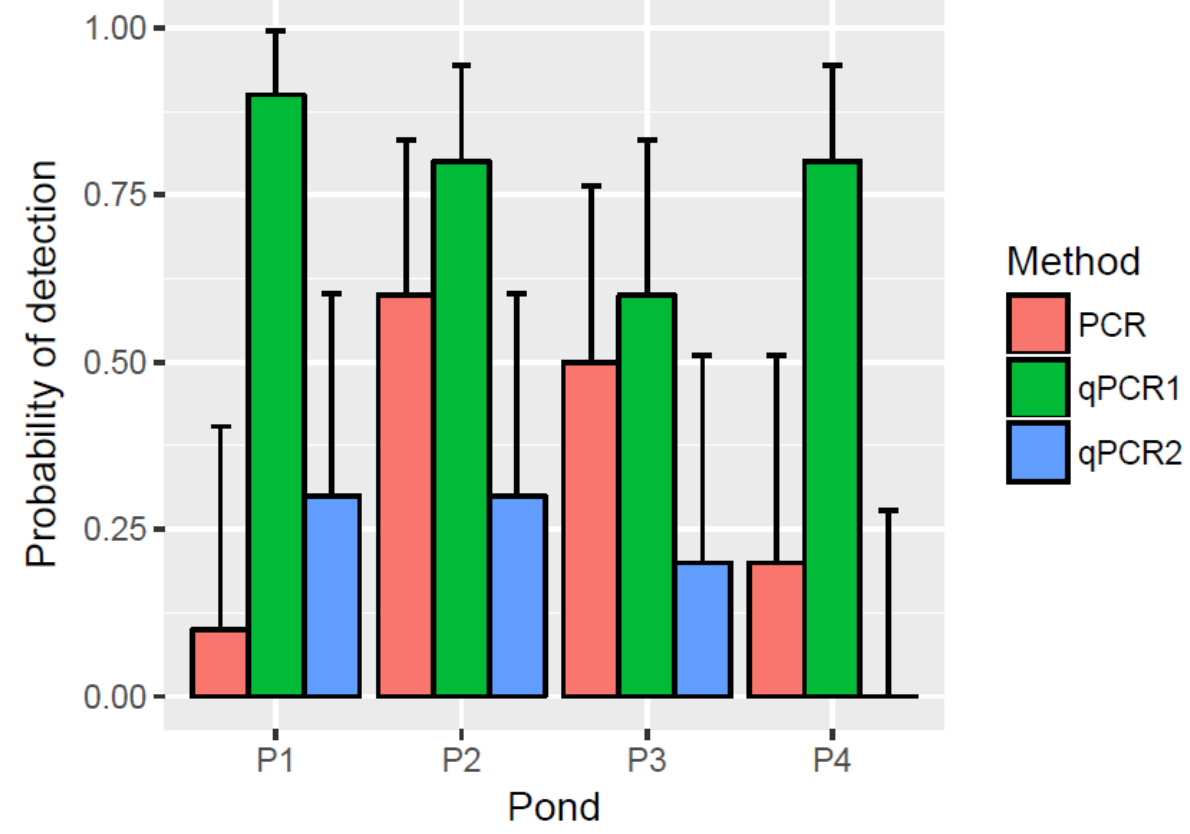

Figure 20. Probability of top mouth gudgeon (Pseudorasbora parva) DNA detection with deviation for each pond (Morolwg Pond, MP (P1); Ashpits Pond, AP (P2); Turbine Pond, TP (P3) and Dyfatty Pond, DP (P4)) for each amplification method (end point-PCR, qPCR with $750 \mathrm{~mL}$ water and qPCR with $15 \mathrm{~mL}$ water). 


\section{DISCUSSION}

The application of my novel qPCR TMG assay detected the presence of TMG DNA at sites where the species was thought to have been eradicated or had not been detected by trapping. This serves to highlight the difficulties of inferring species absences from traditional survey methods (Jerde et al., 2011; Ficetola et al., 2015) and the superior sensitivity of qPCR-based eDNA methods over traditional approaches. The assay was validated in-situ at a location where the species has been confirmed earlier this year. No evidence of PCR inhibition was detected compared to previously published endpoint PCR primers (Davison et al. 2017). The advantages of using an HRM-qPCR approach over end-point PCR include increased sensitivity and diagnostic nature of the melt peak analysis. With well-designed assays such as this, if DNA from target species is present in a sample, there will be a melt peak corresponding to that species, demonstrating that the DNA has successfully amplified (Héritier et al. 2017; Jaiswal et al. 2017; Robinson et al. 2018; Chapter 2 and 3). All HRM-qPCR assays are validated through sequencing, including positive field samples as in this study. In addition, the qPCR assay described here successfully amplified the target species in very small volumes of sample water $(15 \mathrm{~mL})$, albeit with lower sensitivity, which should greatly facilitate the collection of multiple replicated field samples, particularly in remote/inaccessible areas (Chapter 2 and 3).

The use of eDNA to detect and monitor invasive species at low densities has numerous advantages over traditional techniques, namely higher sensitivity and ease of collection (Evans et al. 2017; Jones 2013; Tucker et al. 2016). For example, eDNA from European weather loach (Misgurnus fossilis) and redfin perch (Perca fluviatilis) was detected at sites where fishing had previously failed to find these species (Bylemans et al. 2016; Sigsgaard et al. 2015). TMG has a small size, and trapping can on occasions be unsuccessful, particularly during the early life stages (Jerde et al. 2011; Magnuson et al. 1994). The detection threshold for TMG in closed systems using traditional methods (electrofishing and traps) is approximately 0.5 fish per $\mathrm{m}^{2}$, which could suggest low TMG densities in both Ashpits and Dyfatty ponds (Britton et al. 2011b). The existence of false-negatives poses a particular problem for the 
management of AIS because they tend to occur at low population abundance, particularly during the early stages of invasion (Fitzpatrick et al. 2009). My results show that high resolution melt curve analysis (HRM) based on species-specific melt curve profiles (Héritier et al. 2017; Jaiswal et al. 2017) offers even greater sensitivity and quicker results (Nathan et al. 2014; Wood et al. 2013) in comparison to traditional end-point PCR for the detection of TMG using eDNA.

Absence of adult TMG during the trapping events could be explained by low temperatures $\left(<10^{\circ} \mathrm{C}\right)$, short trapping time ( $<4$ hours), shallow deployment and belowthreshold densities, while size-selection biases can explain their absence during the 2016 surveys (Britton et al. 2011a). Post-eradication survey methods at the Millennium Coastal Park, including micromesh seine netting and trapping (plastic bottle and big mesh 'minnow' traps) is highly size-selective and it is possible that smaller colonising individuals $(<20 \mathrm{~mm})$ could have evaded nets and traps, resulting in false negatives and an incorrect indication of eradication success (Davies, Britton 2015). Even if eradication had been initially successful, it is possible that proximity to infected sites could have allowed fish to disperse through interconnecting streams (Britton et al., 2008; Copp et al., 2010; Pinder et al., 2005) and/or during flooding events, as reported for other AIS (Diez et al., 2012; Rahel and Olden, 2008; Scott et al., 2016). Inadvertent translocation of eggs and small larvae by local anglers across ponds is a possible pathway for re-introduction into the four ponds (Britton et al. 2007; Johansson et al. 2018; Pinder et al. 2005). The closest site of known TMG is the Lliedi reservoirs, which are over $5 \mathrm{~km}$ North-East of the ponds with no direct connection via a watercourse, rendering the Lliedi reservoirs as a TMG DNA source impossible (Balasingham et al. 2016). The lower Ct value of positive eDNA samples from the ponds (i.e. 28.8 in Morolwg and 27.1 in Dyfatty) in comparison to the $\mathrm{Ct}$ value of the DNA detected at the Lliedi reservoir (36.5 and 36.6) further supports the evidence that the reservoirs are not serving as a source of TMG DNA, due to short half-life of DNA and subsequent degradation which would occur between source and detection (Thomsen et al. 2012; Barnes \& Turner, 2015; Balasingham et al. 2016). 
The volume of environmental samples collected can greatly influence the rate of detection of eDNA from a range of aquatic species (Pilliod et al. 2013; Rees et al. 2014). There is a trade-off between sampling effort (number of samples collected and processed) and probability of species detection (Rees et al., 2014). In this study, the probability of detection by qPCR was c.4-6 times higher with a large water volume $(750 \mathrm{~mL})$ compared to a smaller volume $(15 \mathrm{~mL})$. This is not unexpected considering the predicted low abundance of target DNA, the 50x reduction in water volume and the large size of the ponds sampled. I take into consideration that if the $15 \mathrm{~mL}$ samples had been processed following the same laboratory and field protocols as the $750 \mathrm{~mL}$ samples, it is likely the resulting eDNA concentrations would have been considerably lower and would have likely resulted in fewer amplifications (Rees et al. 2014; Hinlo et al. 2017). Collecting smaller volumes of water with more replicates could offset the problem of sampling ponds and reservoirs without much additional effort (Goldberg et al. 2015; Rees et al. 2014) but my study shows that detection probabilities also depend on spatial scale, which will require careful planning.

In summary, routine monitoring with the assay developed here can provide valuable data regarding the expansion and dispersal of invasive TMG populations and, with further optimisation and calibration, could also be used to obtain relative estimates of species abundance. I have shown how the application of eDNA-qPCR methods can be used to monitor eradication programmes and help inform risk management strategies for TMG and other AIS under the Water Framework Directive. 


\section{CHAPTER 5}

When citizen science projects fail: lack of engagement with novel invasive species citizen science initiative

Pages $112-120$

Supporting information (pages 186 - 199)

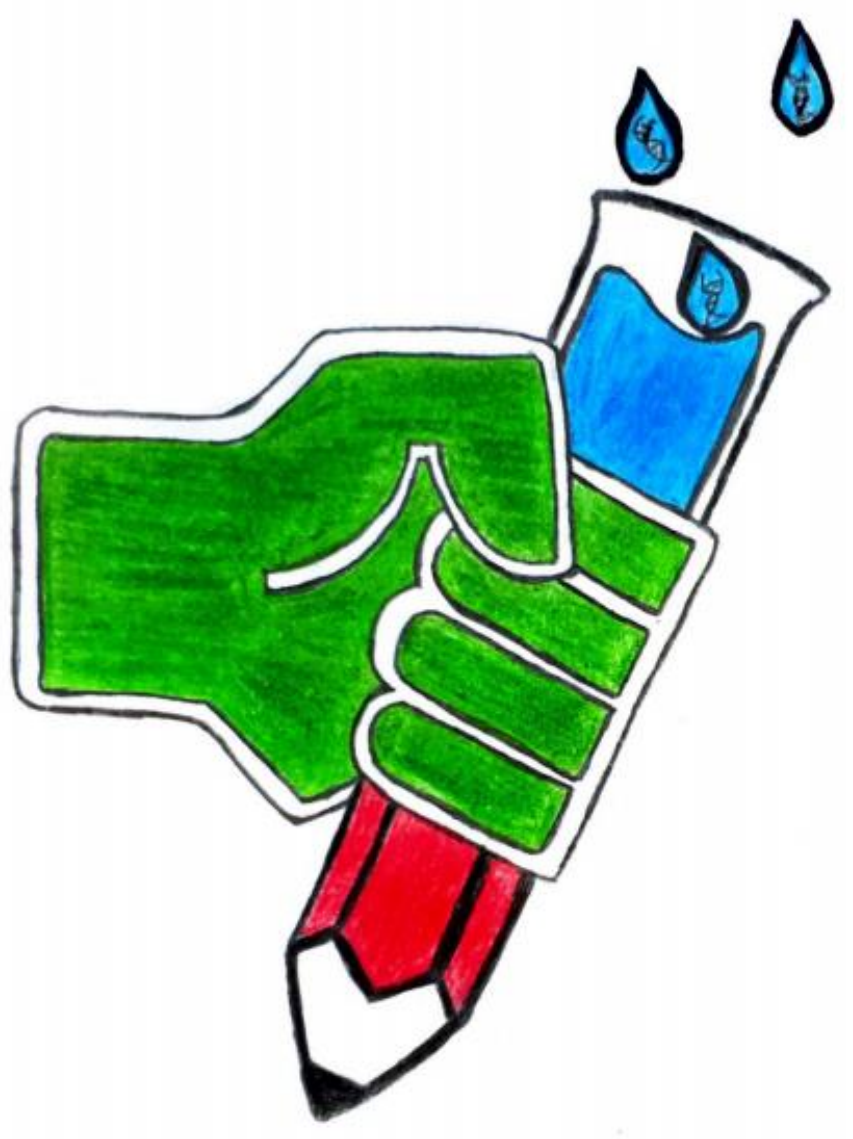




\section{CHAPTER 5: INTRODUCTION}

Public participation in biological data collection can play a crucial role in influencing ecological management and decision-making for resource management (Gura 2013, Pocock et al. 2015). This activity widely termed as 'citizen science', has been used globally as an ecological tool for both long-term and focussed short-term projects (Greenwood 2007, Dickinson et al. 2012, Biggs et al. 2015). Recent technological advances such as smartphone apps (e.g. AquaInvaders 2016), have increased the quality and reliability of citizen science data through the establishment of standardised data collection protocols and recruitment of nationwide administrators to screen and verify data (Bonter and Cooper 2012, Newman et al. 2012, Sullivan et al. 2014). Smartphone apps represent an important citizen science platform because they are widely available and increase accessibility, enabling projects to be more inclusive (Newman et al. 2012).

Understanding motivations of volunteers to participate in citizen science projects is important for ensuring data collection throughout duration of project and for the launch of new initiatives (Jordan et al. 2011). It is expected that knowledge gain (Jordan et al. 2011), incentives (Dickinson et al. 2012) and ease of accessibility, i.e. use of smartphones (Land-Zandstra et al. 2016) are fundamental drivers of public engagement with citizen science (Rotman et al. 2014). Duration of project and frequency of data collection required can also be determining factors for uptake and continuation of engagement (Rotman et al. 2014). Often, engagement in long- or shortterm projects is driven by independent motivations (e.g. social responsibility and time commitments) and different target groups (e.g. retired citizens versus students) often display interest towards either long- or short-term projects due to such motivations (Rotman et al. 2014).

18.1. Successful initiatives

To date there has been a number of successful citizen science initiatives which have focussed on collecting data for biological monitoring of a range of species (Table 15). 
Table 15. Summary of successful citizen science initiatives which include members of the public for a variety of aquatic and terrestrial species. Summaries of protocols used, number of sites samp volunteers engaged, the platform for data compiling and study reference are detailed below.

\begin{tabular}{|c|c|c|c|c|}
\hline Project name & $\begin{array}{c}\text { Target } \\
\text { taxa/species }\end{array}$ & Protocol(s) & $\begin{array}{c}\text { Number of sites } \\
\text { sampled }\end{array}$ & $\begin{array}{r}\text { Numbe } \\
\text { volunteers e } \\
\end{array}$ \\
\hline eBird & Birds & $\begin{array}{l}\text { Bird counting (travelling } \\
\text { count, stationary count, } \\
\text { area count and casual } \\
\text { observation) }\end{array}$ & 180,000 & 500,00 \\
\hline $\begin{array}{l}\text { Invaders of } \\
\text { Texas }\end{array}$ & $\begin{array}{l}\text { Invasive } \\
\text { plants }\end{array}$ & $\begin{array}{l}\text { Record occurrence of } \\
\text { invasive species } \\
\text { (location, abundance, } \\
\text { disturbance) }\end{array}$ & Unknown & 338 \\
\hline $\mathrm{n} / \mathrm{a}$ & $\begin{array}{c}\text { Great } \\
\text { crested newt }\end{array}$ & $\begin{array}{l}\text { eDNA water sampling, } \\
\text { torch counts, egg counts } \\
\text { and trapping }\end{array}$ & 35 & 50 \\
\hline $\begin{array}{l}\text { Neighborhood } \\
\text { Nestwatch }\end{array}$ & Birds & $\begin{array}{l}\text { Observe and report } \\
\text { nesting behaviour and } \\
\text { success of eight common } \\
\text { garden bird species }\end{array}$ & Unknown & 45 \\
\hline $\mathrm{n} / \mathrm{a}$ & $\begin{array}{c}\text { Invasive } \\
\text { Shore crab } \\
\text { and } \\
\text { Japanese } \\
\text { shore crab }\end{array}$ & $\begin{array}{c}\text { Systematic surveys } \\
\text { (quadrats) }\end{array}$ & 52 & 1000 \\
\hline
\end{tabular}




\begin{tabular}{ccccc}
\hline North Carolina & Loggerhead & Monitor beaches and & 30 miles of beach & 700 \\
Sea Turtle & sea turtles & collect data on sea turtle & \\
Project & & nests & \\
(NCSTP) & & & \\
\hline
\end{tabular}


These successful initiatives include either sole fieldwork (Delaney et al. 2008; Biggs et al. 2015) or a combination of fieldwork and online data sharing to compile records (Evans et al. 2005; Sullivan et al. 2009; Gallo and Waitt, 2011). These projects share common traits which have enabled success of the projects, including: 1) simple and standardised protocols and 2) use of exisiting volunteer and professional networks to promote the project and increase participation (e.g. volunteer beach organisations (VBOs; Cornwell and Campbell, 2012) and Lady Bird Johnson Wildflower Center, US Forest Service Forest Health Protection, the Texas Forest Service, the Texas Master Naturalists, and the Texas Parks and Wildlife Department; Gallo and Waitt, 2011). To ensure quality of data collected, these projects often had professionals overseeing data collection (Delaney et al. 2008; Biggs et al. 2014) and all data observations were verified by specialist editors before being published online.

\subsection{Crayfish Count: New citizen science initiative}

Citizen scienists are being utilised more frequently for biomonitoring of invasive species (Delaney et al. 2008, Crall et al. 2010; Biggs et al. 2015; Chapters 2 and 3), Quality of invasive species data has been increased through implementation of smartphone apps, such as 'AquaInvaders', 'That's Invasive!' and 'Plant Tracker', however quantity of data (i.e. number of records), particularly for aquatic invasive species remains low (179 (AquaInvaders 2018)).

The 'Crayfish Count' project was designed to enable members of the public to detect and monitor signal crayfish. This initiative consisted of a combination of smartphone app recording and active biological sampling (abdomen swabs and eDNA) to contribute towards nationwide distribution databases for signal crayfish and to identify locations where crayfish plague is prevalent or absent. For this initiative, two sampling kits were designed; the first comprised of a sampling protocol for recording and swabbing the crayfish, a guide to an invasive species recording app developed by an app company Natural Apptitude (AquaInvaders; www.natural-apptitude.co.uk), a crayfish ID guide, a biosecurity guide, sterile swab and self-addressed stamped envelope (Figure S12-S22). The second kit for eDNA sampling consisted of Falcon 
tubes pre-filled with $33 \mathrm{~mL}$ absolute ethanol and $1.5 \mathrm{~mL} 3 \mathrm{M}$ sodium acetate, sample collection tubes, ultrapure water, sampling protocol, gloves and record sheet. Blank samples were collected to test for contamination between sites, as a measure of sample collection quality. eDNA water samples were collected by anglers at pre-determined locations in the River Taff and subsequently collected by myself and taken back to Swansea University to be stored at -20 until DNA extraction and analysis.

After the project timeline had come to an end, an online anonymous survey was sent to MTAC and AVAC members, which consisted of a set of closed questions aimed at addressing drivers for participation and also barriers/demotivating factors leading to no participation (questions asked detailed in supporting information pages 197-198). An incentive of $£ 10$ Amazon gift card prize draw was incorporated into the survey to encourage feedback.

18.3. Crayfish Count: Project outcome

Two angling clubs showed initial interest in the Crayfish Count initiative (Merthyr Tydfil Angling Club; hereafter MTAC and Afan Valley Angling Club), however a total of two people collected eDNA samples and one person collected a swab. No new recordings of signal crayfish were recorded on the AquaInvaders app or website throughout the crayfish season or six months after the season had ended. Analysis of eDNA water samples collected by MTAC indicated that water blanks were $100 \%$ contamination-free, which suggests correct steps were followed to prevent DNA carryover from water samples to the blank samples. Signal crayfish DNA was detected in one of the seven sites sampled (see Chapter 2) demonstrating that it is highly likely that MTAC adhered to protocol, maximising likelihood to successful DNA detection. Furthermore, only eight people responded to the post-project questionnaire and given the small sample size $(n=8)$ it was not possible to draw any meaningful conclusions from the responses.

18.4. When citizen science fails: Lessons learned 
Despite the best intentions when designing this project, the 'Crayfish Count' failed to establish as a citizen science initiative. For this project, I had already established the anglers had a vested interest in monitoring signal crayfish and had previous experience in removal of signal crayfish with local community groups (Crawford et al. 2006, Holdich et al. 2014). However, in hindsight, there were numerous shortcomings with the design of the project which are likely to have contributed to the fate of the project.

Protocol complexity is known to be a key determining factor as to whether members of the public will engage with new citizen science initiatives (Bonney et al. 2009, Parsons et al. 2011). The higher the effort input required for biological sampling, the greater the likelihood that citizens will fail to engage with the project (Bonney et al. 2009, Parsons et al. 2011). In this instance, the crayfish search and swab protocol was considered simple, however I failed to perceive the project as a non-scientist and in fact the sampling protocol for this project is longer and more specialised than many other biological monitoring citizen science initiatives (e.g. eBird (Sullivan et al. 2014)). Despite using a memorable slogan ('Record, Swab, Post'), which has been utilised in many other citizen science initiatives to aid sample collection (Silvertown, 2009), it is likely that the protocol was too complex, which is likely to have discouraged participation (Bonney et al. 2009). Future biological monitoring citizen science initiatives should consider the protocol design carefully to ensure that the required sampling is simple, easily understood by non-specialists and still address the goals of the initiative (Bonter and Cooper 2012, Newman et al. 2012, Sullivan et al. 2014). Trialling protocols with feedback from members of the public could be an effective way of ensuring protocols meet the necessary requirements to allow new projects to be successful (Parsons et al. 2011).

In addition, the passive approach (online at own leisure) of questionnaire completion likely was the cause of low numbers of returned questionnaires, despite this working on other initiatives (e.g. BeeWatch; van der Wal et al. 2016). A better approach would have been to organise a number of dissemination events in areas local to the anglers and present individuals with paper questionnaires in addition to online surveys (Huyser de Bernardo and Curtis, 2012). This would have likely resulted in a greater number of 
questionnaires returned, which then could have indicated with more power as to what the anglers deemed was their main motivations or barriers to participating in the project.

The main positive result from the Crayfish Count was the lack of contamination from eDNA in the River Taff. In comparison to the search and swab protocol, the eDNA protocol has been previously designed with non-specialists such as members of the public as end-users in mind (see Chapter 2) and similar protocols have been used in eDNA citizen science initiatives with great success (e.g. Biggs et al. 2015). This demonstrates that despite eDNA sampling being considered as a sensitive, specialist type of biological sampling (Rees et al. 2014), it is possible to utilise members of the public in citizen science initiatives as an alternative to field biologists, to collect valuable data on presence and absence of aquatic invasive species, without compromising quality of the data collected (Biggs et al. 2015; Robinson et al. 2018; Chapter 2).

\subsection{Conclusions}

This study has highlighted the difficulty in designing new initiatives effectively to ensure sufficient take up for engagement and therefore meaningful data collection (Conrad and Hilchey 2011, Dickinson et al. 2012, Roy et al. 2012). The main downfalls of this project design include both protocol complexity and unsuitable approach of generating feedback from members of the public, in comparison to other successful initiatives (Bonney et al. 2009; Sullivan et al. 2009). However, the Crayfish Count does highlight the ease of incorporating eDNA monitoring into the field of citizen science and the ability of citizens to collect data on aquatic invasive species current distribution. For future citizen science initiatives, 1) implementing simple protocols and 2) linking new citizen science projects with existing platforms such as OPAL (www.opalexplorenature.org) can increase visibility, accessibility and reputability of the project, resulting in higher levels of interest and engagement and therefore greater likelihood of project success. 
GENERAL DISCUSSION 
This thesis demonstrates how the application of molecular tools (microsatellites and eDNA) can contribute to understanding invasion success, determining current distributions and enabling early detection of target aquatic invasive species. Additionally, this thesis highlights the difficulty of ensuring success of citizen science initiatives concerning invasive species monitoring. Research outcomes of this thesis have been addressed throughout the chapters and summarised below.

18.6. Using population genetics to investigate invasion success The application of population genetics for generating a better understanding of invasive species biology is a relatively recent approach (Le Roux and Wieczorek 2008). Use of molecular markers, such as microsatellites allow for questions to be addressed, such as dispersal routes and key vectors, admixture rates, evidence of introgression, adaptation, genetic fitness and the role of genetic variation for facilitating invasion success (Reed and Frankham, 2003; Le Roux and Wieczorek 2008; Zalewski et al. 2010; Torres and Álvarez 2012). The biggest challenge for invasion genetics is understanding the link between genetic variation within a population and fitness of an individual and what this means for population expansion (Allendorf et al. 2010). Through assessment of genetic diversity, population structuring and evidence of admixture, I have determined that invasion success for several signal crayfish populations in Great Britain is likely to have occured through a combination of numerous introductions, human-facilitated dispersal and co-invasion with Aphanomyces astaci. Population genetics has enabled the factors influencing invasion success (i.e. number of introductions and available genetic diversity) to be determined for these populations of signal crayfish. Linking this information with the known ecological traits of signal crayfish (i.e. dispersal mechanisms), can enable the success of any future introductions of this species to be predicted. In addition, I have determined that repeated removal effort of signal crayfish (i.e. in the Bachowey) can reduce the genetic diversity of the remaining crayfish population, which could render heavily trapped populations genetically compromised long-term and therefore could influence their length of persistence at that location. There are however limitations to the wider application of population genetic results, particularly when only a small subset of existing populations have been sampled (Bossart and Prowell 1998; Taberlet 
et al. 1999). In addition, lack of a baseline on population genetics of signal crayfish across the native range makes it difficult to assess the role of genetic diversity in its success in non-native areas (Purcell et al. 2015; Smouse et al. 2011). Overall, this study has enabled a better understanding of how genetic diversity could have influenced the invasion success for this species through assessment of population structure and diversity across Great Britain. Results from this genetic analysis has complemented previous studies concerning genetic diversity of signal crayfish across Europe (Petrusek et al. 2017) and the most likely colonisation scenario of numerous simultaneous introductions has been identified for this species in Great Britain. This information is particulaly important for predicting success of future invasions and vital for informing control and management of this species (Peay 2009; Handley et al., 2011; Lennox et al. 2015).

18.7. Environmental DNA assays for monitoring of target aquatic invasive species

Unlike population genetic studies, which are applied to determine genetic parameters post-invasion, the application of eDNA techniques can provide information on presence, absence and abundance of invasive species from the early stages of invasion (Darling and Blum 2007; Jerde et al. 2011; Nathan et al. 2014). The single-species approach of previous eDNA assays for signal crayfish have provided sufficient information on current distribution of this species within target catchments across Great Britain, however lack relevant information in terms of spatial occupation of signal crayfish in relation to the previously widespread native white-clawed crayfish, and/or A. astaci infection status of detected signal crayfish. I have utilised recent advancements in qPCR technology and chemistry to develop a multiplex to simultaneously assess site occupation of both invasive and native crayfish with relation to $A$. astaci presence/absence, which is particularly important for determining potential sites for white-clawed crayfish reintroductions and/or sites of coexistence in absence of A. astaci (Lodge et al. 2012; Peters and Lodge 2013). Confirmed cases of coexistence of signal crayfish and white-clawed crayfish has not been reported before in Great Britain, despite this being possible in the absence of A. astaci (Schrimpf et al. 2013). This multiplex assay could be used as a routine screening tool for detecting new 
outbreaks of $A$. astaci infections and/or introduction of infected signal crayfish individuals, which can inform safe guarding of remnant white-clawed crayfish populations. The design of this assay could also be applied to other aquatic invasive species which co-invade with novel pathogens (i.e. topmouth gudgeon and Sphaerothecum destruens; Spikmans et al. 2013), as a management tool for early detection and disease prevalence. This eDNA methodology was designed for use in a citizen science project, therefore this assay can be utilised in future nationwide monitoring programs, having being previously validated in numerous studies, including the Crayfish Count project (Chapters 2, 3 and 5). Multiplexes for simultaneous detection of multiple species compared to single-species assays provide more information per PCR reaction, which reduces costs of eDNA screening whilst maintaining the diagnostic nature of qPCR, despite some evidence of reduced detectability (Liu et al. 2018; Wozney and Wilson 2017).

Problems with low detection rates of eDNA is a well-documented limitation of using eDNA assays to infer invertebrate species presence particularly in freshwater systems (Treguier et al. 2014). Despite advances in DNA extraction kits which now enable higher eDNA yields than previously possible, environmental parameters such as temperature, $\mathrm{pH}$, flow rate and organic inhibitors still pose a problem for the reliability and reproducibility of eDNA assays (Deiner and Altermatt 2014). In this thesis, I have demonstrated how higher eDNA detection rates can be achieved when considering the ecology of the target species, with improved fine-scale detection of both signal crayfish and mitten crabs being possible by collecting a combination of surface sediment and water eDNA samples. Using eDNA to understand how these two invasive species respond to river fragmentation is important for estimating how successful any future invasions of these species will be in catchments with differing fragmentation status (Gilbey et al. 2008; Herborg et al. 2007; Rudnick et al. 2003; Schmidt et al. 2009). Being able to assess the relative effect of barriers on dispersal of signal crayfish and mitten crabs without requiring visual confirmation of the species highlights the benefits of using eDNA methodologies, particularly for AIS which can naturally exist as sparse, low-density populations in new environments or are particularly good at evading capture by traditional methods, such as topmouth gudgeon 
(Britton et al. 2008; Britton et al. 2007). In addition, it is possible that this assay can be used to identify population segregation of target species due to the presence of impassible barriers, which could identify populations which may not persist long-term due to being genetically compromised in terms of gene flow (Hitchings and Beebee 1997). This thesis also details how effective eDNA assays can be for monitoring eradication of invasive fish, particularly in comparison to seine netting and trapping. Chapter 4 highlights the benefits of using qPCR technology in comparison to endpoint PCR techniques for improved sensitivity and avoidance of false negatives, particularly when analysing DNA from low-volume $(<1 \mathrm{~L})$ water samples.

18.8. Strengths and weaknesses of a novel citizen science initiative Previously, eDNA studies have been successfully streamlined and integrated into citizen science initiatives for monitoring rare native species of high interest (Biggs et al. 2015), however there have been few examples of using citizen science as a platform for collecting data on invasive species presence (Crall et al. 2011; Delaney et al. 2008; Silvertown 2009). The novel citizen science initiative I designed was unsuccessful and lack of feedback from the anglers meant evaluation of reasons for limited participation was not possible. Factors including protocol complexity and inappropriate questionnaire design were likely the reason Crayfish Count did not succeed. This project did however highlight the suitability of eDNA methodologies for citizen science programs, as previously utilised throughout this thesis (chapters 2 and 3) and in other studies (i.e. Biggs et al. 2015) with success. Effort required from members of the public for taking part in biological monitoring initiavties should be considered before initiating new citizen science monitoring programmes, because there is high effort and monetary input involved with setting up and maintaining such programmes and without identifying factors influencing engagement success, projects are unlikely to be successful (Druschke and Seltzer 2012).

Overall, in this thesis, I have shown that by using a combination of population genetics, eDNA and (potentially) citizen science, it is possible to better understand the establishment success, site occupation and dispersal of target aquatic invasive species. 


\section{CONCLUSIONS}

- Multiple source populations and possibly high genetic diversity at time of invasion are likely to have facilitated the successful invasion of signal crayfish in Great Britain.

- A novel eDNA multiplex assay was developed which can provide information on the localized distribution of both signal and white-clawed crayfish and can identify areas of coexistence between these species at sites with free of $A$. astaci infection.

- The influence of river barriers on the distribution of signal crayfish and mitten crab can be determined through use of the eDNA assay, which can then be used to predict extent of dispersal in novel catchments with high levels of fragmentation.

- Artificial barriers influence the eDNA detection success of mitten crabs downstream of barriers, however there is no effect of river barriers on detection of signal crayfish, as identified using the eDNA assay.

- Eradication of invasive topmouth gudgeon can be monitored through applying a species-specific eDNA assay to qPCR technology, which eliminates the problem of false negatives of traditional trapping and netting methods.

- Topmouth gudgeon appears to persist in ponds where it had previously been eradicated, despite no visual signs of the species being present using the designed species-specific eDNA assay.

- 'Crayfish Count' citizen science initiative has not been an effective tool for monitoring signal crayfish and demonstrates how design and implementation of protocols needs to be simple and suitable for target groups. 


\section{SUPPORTING INFORMATION}

Table S1. Information on the microsatellites used in analysis (Froufe et al. 2015), including $n$ fluorescent dyes, concentration of primer in PCR reaction $(\mu \mathrm{m})$ and allele size range covered by eac

\begin{tabular}{cccc}
\hline \multicolumn{1}{c}{ Locus } & Primer Sequence (5'-3') & $\begin{array}{c}\text { Fluorescent } \\
\text { dye }\end{array}$ & $\begin{array}{c}\text { Prim } \\
\text { concentrat }\end{array}$ \\
\hline Multiplex 1 & F: TGTCGGATCATAGTCGTCGT & VIC & \\
R: GGCTCTCAGTAACCTACCAGG & F: AAATAAGACCCGACAAAGCG & FAM & \\
LPL40 & F: CAGTCGATATTTCTTTATATCCCTTCA & PET & \\
& R: CTGGTTCCAGATAGCAGCGT & & 0.6 \\
Multiplex 2 & F: TGTCGGATCATAGTCGTCGT & PET \\
LPL15 & R: AGGCTCTCAGTAACCTACCAGG & & \\
LPL32 & F: AAAGCGGACAACATGGAAGT & FAM & \\
& R: GCCGCAAGTGTAAGCTGAA & & \\
LPL45 & F: TCTAGAAACAGACTGGTCTCATGG & FAM & \\
\hline
\end{tabular}


R: CACCTACGGGCTATTCATGC

Multiplex 3

Scop1

F: GCCCTCTGCTTACTTTCTCAC

NED

0.4

R: CTCATGGAGTACGAGTCCAGA

Scop9

F: GCTGAAATGGAGGGATGA

FAM

R: TGTGCCTTTTCTAAGCTGT

Scop31

F: GATCTGGACGTCGACGTCTT

R: CCCTGTACCATTCATGATTG 
Table S2. Pairwise $F_{\mathrm{ST}}$ values (below diagonal) and significance (above diagonal) for all pop sampled with 'null' microsatellites (Scop1, Scop9, Scop31 and LPL45) removed.

\begin{tabular}{lccccccc}
\hline & Sirhowy & Lugg & Dderw & Lea & Bachowey & Mochdre & Gavenny \\
\hline Sirhowy & 0.000 & $*$ & $*$ & $*$ & $*$ & $*$ & $*$ \\
Lugg & 0.261 & 0.000 & $*$ & $*$ & $*$ & $*$ & $*$ \\
Dderw & 0.350 & 0.126 & 0.000 & $*$ & $*$ & $*$ & $*$ \\
Lea & 0.207 & 0.041 & 0.137 & 0.000 & $*$ & $*$ & - \\
Bachowey & 0.222 & 0.064 & 0.160 & 0.064 & 0.000 & $*$ & $*$ \\
Mochdre & 0.184 & 0.057 & 0.199 & 0.032 & 0.035 & 0.000 & - \\
Gavenny & 0.207 & 0.050 & 0.168 & 0.015 & 0.054 & 0.010 & 0.000 \\
Pant-y-Llyn & 0.228 & 0.031 & 0.083 & 0.027 & 0.020 & 0.040 & 0.028 \\
Oregon & 0.392 & 0.441 & 0.545 & 0.362 & 0.371 & 0.330 & 0.334 \\
\hline
\end{tabular}

$* P<0.0013$ 
Table S3. Genetic diversity values of nine Pacifastacus leniusculus populations for nine microsate Number of effective alleles; $H_{\mathrm{O}}$ Observed heterozygosity; $H_{\mathrm{E}}$ Expected heterozygosity; $H W P$-valu equilibrium; $F_{I S}$ Fixation index (positive value indicates homozygosity excess); N Number of sampl HW after Bonferroni correction $(P<0.000617)$ are indicated in bold.

\begin{tabular}{llrrrrrr}
\hline & & & \multicolumn{5}{c}{ Microsatellite } \\
\hline Population & & LPL15 & LPL26 & LPL32 & LPL40 & LPL45 & LPL6 \\
1 (Sirhowy) & $N_{\mathrm{A}}$ & 5 & 3 & 3 & 3 & 2 & 3 \\
& $N_{\mathrm{E}}$ & 2.961 & 2.582 & 2.052 & 2.187 & 1.399 & 2.799 \\
& $H_{\mathrm{O}}$ & 0.567 & 0.700 & 0.433 & 0.633 & 0.138 & 0.533 \\
& $H_{\mathrm{E}}$ & 0.662 & 0.613 & 0.513 & 0.543 & 0.285 & 0.643 \\
& $H W$ & $\mathbf{0 . 0 0 0}$ & 0.567 & 0.571 & 0.195 & 0.005 & 0.548 \\
& $F_{\mathrm{IS}}$ & 0.144 & -0.142 & 0.155 & -0.167 & 0.517 & 0.170 \\
& $N_{\mathrm{A}}$ & 12 & 1 & 1 & 4 & 4 & 10 \\
& $N_{\mathrm{E}}$ & 8.145 & 1.000 & 1.000 & 3.035 & 1.418 & 7.627 \\
& $H_{\mathrm{O}}$ & 0.867 & 0.000 & 0.000 & 0.600 & 0.067 & 0.833 \\
& $H_{\mathrm{E}}$ & 0.877 & 0.000 & 0.000 & 0.671 & 0.295 & 0.869 \\
& $H_{W}$ & 0.764 & N/A & N/A & $\mathbf{0 . 0 0 0}$ & $\mathbf{0 . 0 0 0}$ & 0.740 \\
& $F_{\mathrm{IS}}$ & 0.012 & N/A & N/A & 0.105 & 0.774 & 0.041 \\
& $N_{\mathrm{A}}$ & 8 & 1 & 2 & 2 & 5 & 5 \\
\hline
\end{tabular}




\begin{tabular}{|c|c|c|c|c|c|c|c|}
\hline & $N_{\mathrm{E}}$ & 3.673 & 1.000 & 1.034 & 1.684 & 2.539 & 2.050 \\
\hline & $H_{\mathrm{O}}$ & 0.767 & 0.000 & 0.033 & 0.367 & 0.133 & 0.433 \\
\hline & $H_{\mathrm{E}}$ & 0.728 & 0.000 & 0.033 & 0.406 & 0.606 & 0.512 \\
\hline & $H W$ & 0.415 & N/A & 0.926 & 0.595 & 0.000 & 0.862 \\
\hline & $F_{\mathrm{IS}}$ & -0.053 & N/A & -0.017 & 0.097 & 0.780 & 0.154 \\
\hline \multirow[t]{6}{*}{4 (Lea) } & $N_{\mathrm{A}}$ & 11 & 4 & 4 & 5 & 4 & 10 \\
\hline & $N_{\mathrm{E}}$ & 6.294 & 1.578 & 1.360 & 2.903 & 1.250 & 5.764 \\
\hline & $H_{\mathrm{O}}$ & 0.865 & 0.216 & 0.189 & 0.730 & 0.108 & 0.811 \\
\hline & $H_{\mathrm{E}}$ & 0.841 & 0.366 & 0.265 & 0.656 & 0.200 & 0.827 \\
\hline & $H W$ & 0.997 & 0.000 & 0.000 & 0.482 & 0.000 & 0.992 \\
\hline & $F_{\text {IS }}$ & -0.028 & 0.410 & 0.286 & -0.113 & 0.459 & 0.019 \\
\hline \multirow[t]{6}{*}{5 (Bachowey) } & $N_{\mathrm{A}}$ & 8 & 3 & 3 & 4 & 3 & 7 \\
\hline & $N_{\mathrm{E}}$ & 5.049 & 1.375 & 1.667 & 3.267 & 1.241 & 4.878 \\
\hline & $H_{\mathrm{O}}$ & 0.842 & 0.211 & 0.421 & 0.263 & 0.105 & 0.737 \\
\hline & $H_{\mathrm{E}}$ & 0.802 & 0.273 & 0.400 & 0.694 & 0.194 & 0.795 \\
\hline & $H W$ & 0.598 & 0.591 & 0.945 & 0.000 & 0.000 & 0.500 \\
\hline & $F_{\text {IS }}$ & -0.050 & 0.228 & -0.052 & 0.621 & 0.457 & 0.073 \\
\hline \multirow[t]{2}{*}{6 (Mochdre) } & $N_{\mathrm{A}}$ & 12 & 4 & 5 & 3 & 3 & 12 \\
\hline & $N_{\mathrm{E}}$ & 7.293 & 1.473 & 1.774 & 2.533 & 1.667 & 6.685 \\
\hline
\end{tabular}




\begin{tabular}{|c|c|c|c|c|c|c|c|}
\hline & $H_{\mathrm{O}}$ & 0.947 & 0.158 & 0.368 & 0.579 & 0.105 & 0.895 \\
\hline & $H_{\mathrm{E}}$ & 0.863 & 0.321 & 0.436 & 0.605 & 0.400 & 0.850 \\
\hline & $H W$ & 0.986 & 0.017 & 0.322 & 0.157 & 0.003 & 0.951 \\
\hline & $F_{\text {IS }}$ & -0.098 & 0.509 & 0.156 & 0.043 & 0.737 & -0.052 \\
\hline \multirow[t]{6}{*}{7 (Gavenny) } & $N_{\mathrm{A}}$ & 11 & 5 & 4 & 6 & 4 & 11 \\
\hline & $N_{\mathrm{E}}$ & 7.577 & 1.756 & 1.436 & 2.735 & 2.683 & 8.087 \\
\hline & $H_{\mathrm{O}}$ & 0.724 & 0.345 & 0.207 & 0.621 & 0.241 & 0.793 \\
\hline & $H_{\mathrm{E}}$ & 0.868 & 0.430 & 0.304 & 0.634 & 0.627 & 0.876 \\
\hline & $H W$ & 0.004 & 0.325 & 0.015 & 0.868 & 0.000 & 0.132 \\
\hline & $F_{\text {IS }}$ & 0.166 & 0.199 & 0.319 & 0.022 & 0.615 & 0.095 \\
\hline \multirow[t]{6}{*}{8 (Oregon) } & $N_{\mathrm{A}}$ & 13 & 3 & 3 & 5 & 2 & 13 \\
\hline & $N_{\mathrm{E}}$ & 7.848 & 1.174 & 1.112 & 2.473 & 1.670 & 7.848 \\
\hline & $H_{\mathrm{O}}$ & 0.842 & 0.053 & 0.105 & 0.474 & 0.000 & 0.842 \\
\hline & $H_{\mathrm{E}}$ & 0.873 & 0.148 & 0.101 & 0.596 & 0.401 & 0.873 \\
\hline & $H W$ & 0.673 & 0.000 & 0.996 & 0.017 & 0.000 & 0.673 \\
\hline & $F_{\text {IS }}$ & 0.035 & 0.645 & -0.041 & 0.205 & 1.000 & 0.035 \\
\hline \multirow[t]{3}{*}{9 (Pant-y-Llyn) } & $N_{\mathrm{A}}$ & 11 & 3 & 4 & 3 & 3 & 8 \\
\hline & $N_{\mathrm{E}}$ & 7.237 & 1.336 & 1.296 & 2.288 & 1.300 & 6.169 \\
\hline & $H_{\mathrm{O}}$ & 0.813 & 0.219 & 0.125 & 0.375 & 0.000 & 0.719 \\
\hline
\end{tabular}




\begin{tabular}{rlrrrrrr}
\hline & $H_{\mathrm{E}}$ & 0.862 & 0.251 & 0.229 & 0.563 & 0.231 & 0.838 \\
& $H W$ & 0.249 & 0.236 & $\mathbf{0 . 0 0 0}$ & 0.056 & $\mathbf{0 . 0 0 0}$ & 0.335 \\
& $F_{\mathrm{IS}}$ & 0.057 & 0.130 & 0.453 & 0.334 & 1.000 & 0.142 \\
& & & & & & & \\
& $N_{\mathrm{A}}$ & 10 & 3 & 3 & 4 & 3 & 9 \\
& $N_{\mathrm{E}}$ & 6.231 & 1.475 & 1.415 & 2.567 & 1.685 & 5.767 \\
& $H_{\mathrm{O}}$ & 0.804 & 0.211 & 0.209 & 0.516 & 0.100 & 0.733 \\
& $H_{\mathrm{E}}$ & 0.820 & 0.267 & 0.253 & 0.596 & 0.360 & 0.787 \\
& $F_{\mathrm{IS}}$ & 0.021 & 0.283 & 0.157 & 0.127 & 0.704 & 0.075 \\
& $N$ & 27.2 & 27.2 & 27.2 & 27.2 & 26.9 & 27.2 \\
\hline
\end{tabular}


Table S4. Results of ABC analyses for estimated posterior parameters. Means, medians, modes and qu population size $\left(N_{\mathrm{e}}\right)$ of Sirhowy; N2 $=N_{\mathrm{e}}$ of Lugg; N3 $=N_{\mathrm{e}}$ of Dderw; N4 $=N_{\mathrm{e}}$ of pooled populations $N_{\mathrm{e}}$ of Bachowey; N6 = $N_{\mathrm{e}}$ of Pant-y-Llyn; $\mathrm{t}=$ time of divergence in generations; Â $\mu$ mic $11=$ mean repeat motifs added/removed from microsatellites in each mutation step and snimic_1 = single insert

\begin{tabular}{lrrrrrrr}
\hline Parameter & mean & \multicolumn{1}{l}{ median } & mode & $\mathbf{q 0 2 5}$ & q050 & q250 & q \\
\hline N1 & 251 & 219 & 189 & 103 & 116 & 168 \\
N2 & 486 & 382 & 281 & 130 & 156 & 264 \\
N3 & 1370 & 1330 & 1240 & 529 & 619 & 1000 \\
N4 & 1270 & 1220 & 1010 & 476 & 564 & 909 \\
N5 & 2460 & 2470 & 2500 & 2370 & 2400 & 2450 \\
N6 & 1050 & 963 & 757 & 327 & 396 & 672 \\
t & 517 & 471 & 417 & 220 & 249 & 368 \\
Âmic_1 & 0.000925 & 0.000946 & 0.001 & 0.000734 & 0.000774 & 0.000882 \\
pmic_1 & 0.270 & 0.283 & 0.300 & 0.166 & 0.188 & 0.255 \\
snimic_1 & 0.00000782 & 0.00000958 & 0.00001 & 0.000000583 & 0.00000117 & 0.00000627 \\
\hline
\end{tabular}


Table S5. Posterior probabilities for all three scenarios estimated with a maximum of $1 \%$ of simulate datasets closest to the observed using the logistic approach.

\begin{tabular}{cccccccc}
\hline Scenario & \multicolumn{7}{c}{$\mathbf{n}$} \\
\hline & 3000 & 6000 & 9000 & 12000 & 15000 & 18000 & 21000 \\
\hline 1 & 0.7405 & 0.7903 & 0.8127 & 0.8176 & 0.8179 & 0.8160 & 0.8160 \\
& $(0.4876-$ & $(0.6409-$ & $(0.7026-$ & $(0.7250-$ & $(0.7358-$ & $(0.7408-$ & $(0.7465-$ \\
& $0.9933)$ & $0.9396)$ & $0.9229)$ & $0.9102)$ & $0.9001)$ & $0.8913)$ & $0.08854)$ \\
2 & 0.0711 & 0.0633 & 0.0650 & 0.0700 & 0.0746 & 0.0795 & 0.0817 \\
& $(0.0000-$ & $(0.0077-$ & $(0.0176-$ & $(0.0256-$ & $(0.0323-$ & $(0.0385-$ & $(0.0428-$ \\
& $0.1597)$ & $0.1189)$ & $0.1123)$ & $0.1144)$ & $0.1169)$ & $0.1206)$ & $0.1206)$ \\
3 & 0.1884 & 0.1464 & 0.1223 & 0.1124 & 0.1075 & 0.1044 & 0.1024 \\
& $(0.0000-$ & $(0.0221-$ & $(0.0363-$ & $(0.0438-$ & $(0.0490-$ & $(0.0528-$ & $(0.0556-$ \\
& $0.4095)$ & $0.2707)$ & $0.2083)$ & $0.1810)$ & $0.1660)$ & $0.1561)$ & $0.1491)$ \\
\hline
\end{tabular}


Table S6. StructureSelector output table using the Puechmaille Method to infer the true K (4) from the British Pacifastacus leniusculus populations analysed using four alternative statistics (MedMed, MedMean, MaxMed and MaxMean).

\begin{tabular}{|c|c|c|c|c|c|}
\hline $\mathbf{K}$ & MedMed & MedMean & MaxMed & MaxMean & Reps \\
\hline 1 & 1 & 1 & 1 & 1 & 20 \\
\hline 2 & 2 & 2 & 2 & 2 & 20 \\
\hline 3 & 3 & 3 & 3 & 3 & 20 \\
\hline 4 & 4 & 4 & 4 & 4 & 20 \\
\hline 5 & 4 & 4 & 4 & 4 & 20 \\
\hline 6 & 4 & 4 & 4 & 4 & 20 \\
\hline 7 & 4 & 3 & 4 & 3 & 20 \\
\hline \multirow[t]{2}{*}{8} & 3 & 3 & 4 & 3 & 21 \\
\hline & MedMedK & MedMeaK & MaxMedK & MaxMeaK & \\
\hline ALL & 4 & 4 & 4 & 4 & \\
\hline
\end{tabular}


Table S7. StructureSelector output table using the Puechmaille Method to infer the true K (5) from the all Pacifastacus leniusculus populations analysed using four alternative statistics (MedMed, MedMean, MaxMed and MaxMean).

\begin{tabular}{|c|c|c|c|c|c|}
\hline $\mathbf{K}$ & MedMed & MedMean & MaxMed & MaxMean & Reps \\
\hline 2 & 2 & 2 & 2 & 2 & 20 \\
\hline 3 & 3 & 3 & 3 & 3 & 20 \\
\hline 4 & 4 & 4 & 4 & 4 & 20 \\
\hline 5 & 5 & 5 & 5 & 5 & 20 \\
\hline 6 & 4 & 4 & 5 & 5 & 20 \\
\hline 7 & 4 & 4 & 4 & 4 & 20 \\
\hline 8 & 4 & 4 & 4 & 4 & 20 \\
\hline \multirow[t]{2}{*}{9} & 4 & 4 & 4 & 4 & 21 \\
\hline & MedMedK & MedMeaK & MaxMedK & MaxMeaK & \\
\hline ALL & 5 & 5 & 5 & 5 & \\
\hline
\end{tabular}




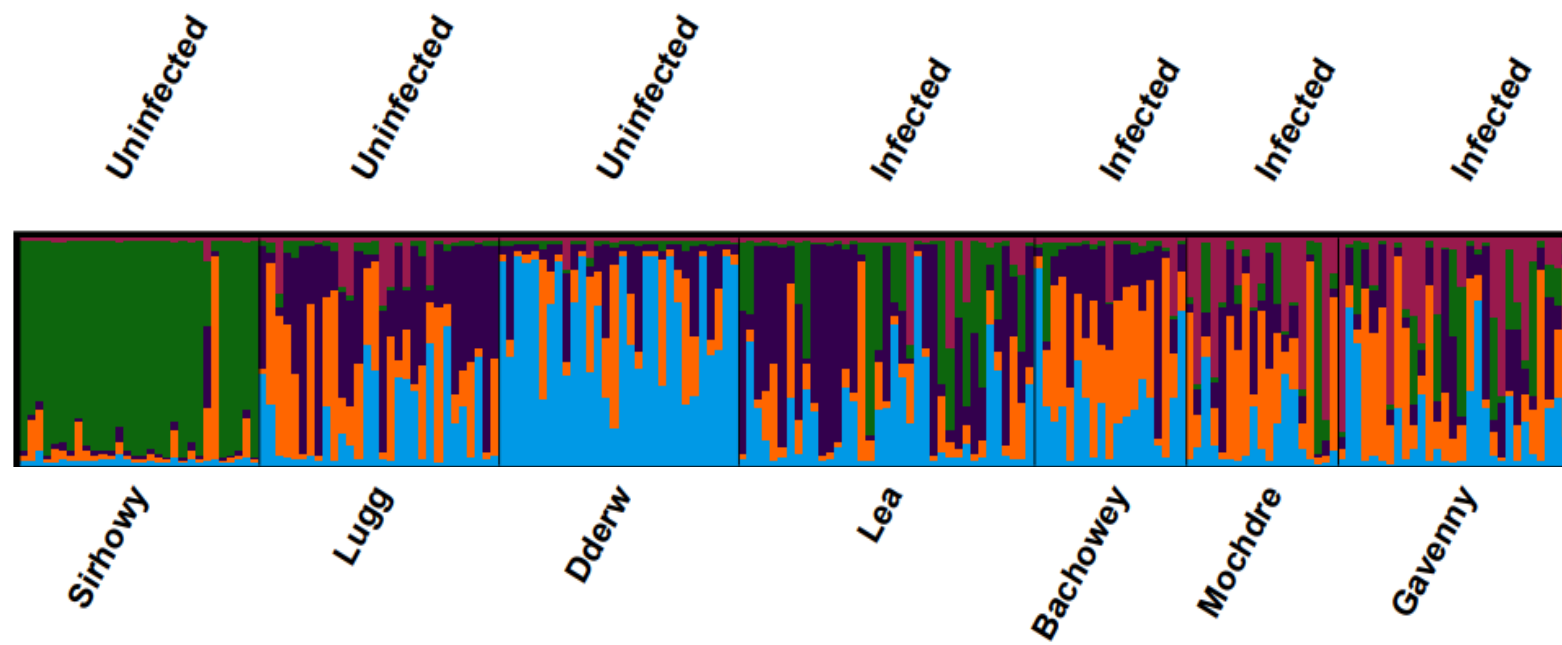

Figure S1. STRUCTURE analysis for Pacifastacus leniusculus populations with 'null' microsatellite removed at $\mathrm{K}=5$ clusters; each bar represents an individual crayfish, the different colours represent di the proportion of each crayfish attributable to each cluster. Infection status is stated above the output stated below for each population. 

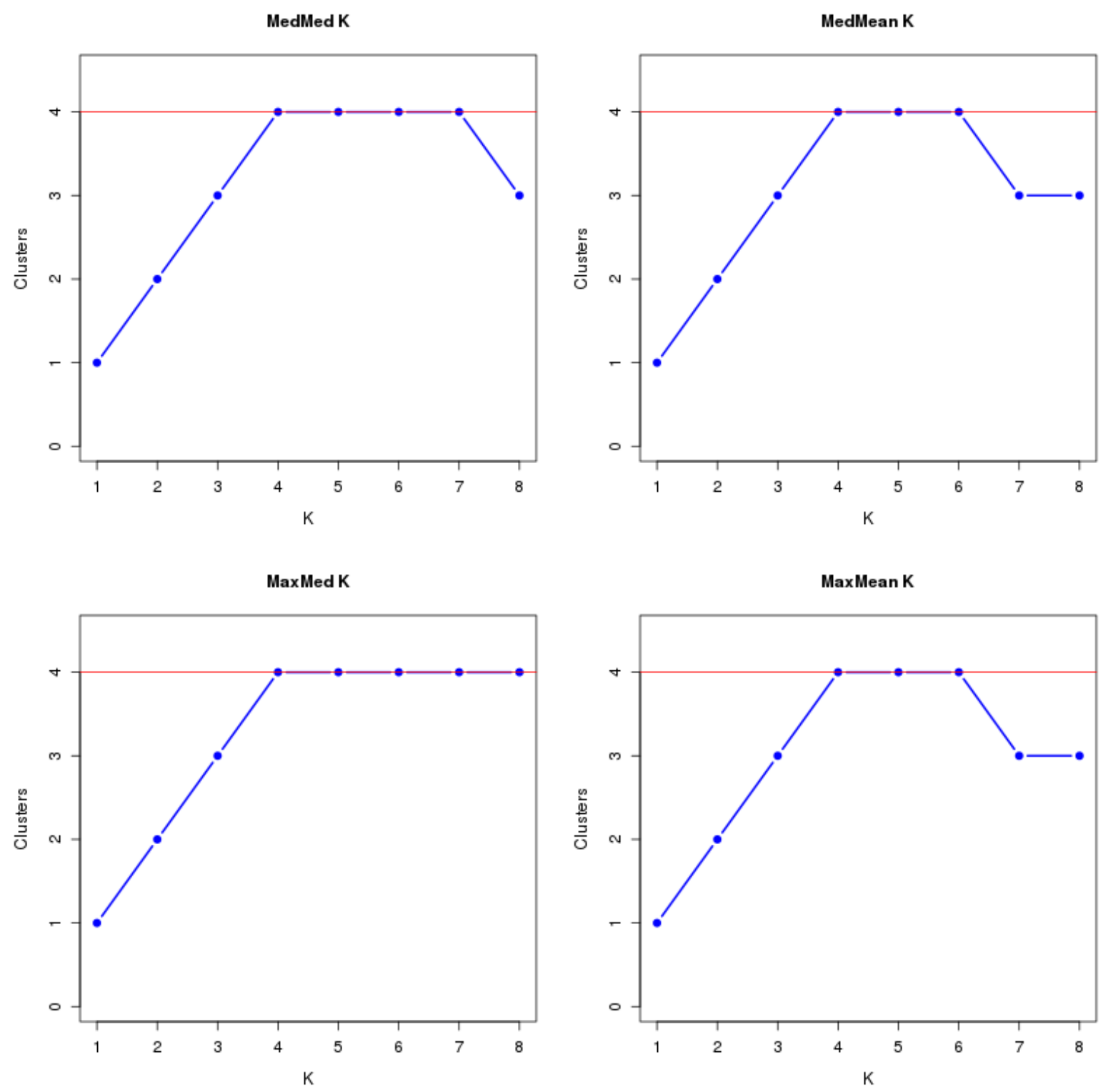

Figure S2. Most likely $\mathrm{K}$ for all British populations studied (excluding Oregon), determined using MedMedK, MedMeanK, MaxMedK and MaxMeanK statistics in StructureSelector. 

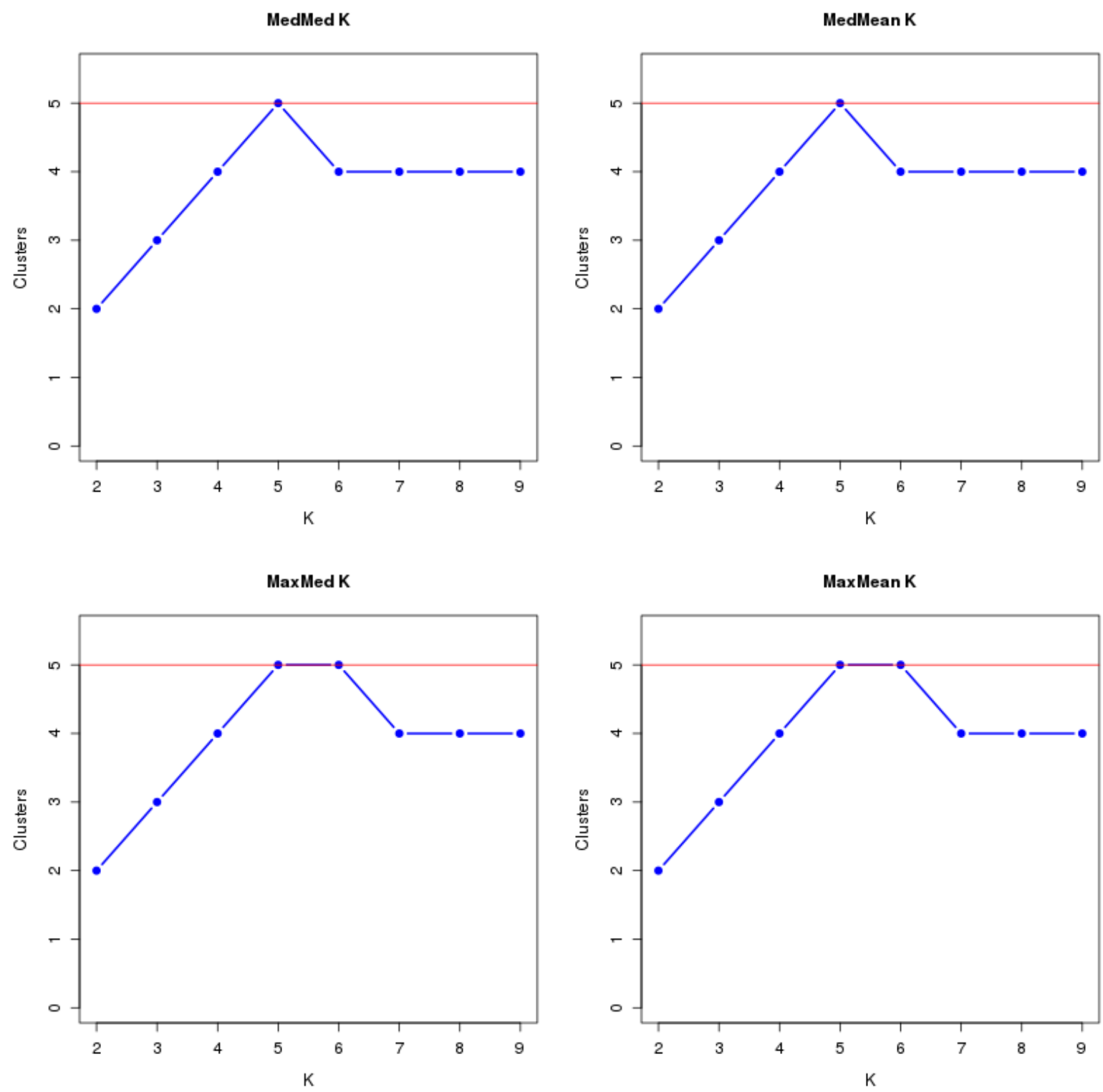

Figure S3. Most likely $\mathrm{K}$ for all nine populations studied (including Oregon) determined using MedMedK, MedMeanK, MaxMedK and MaxMeanK statistics in StructureSelector. 


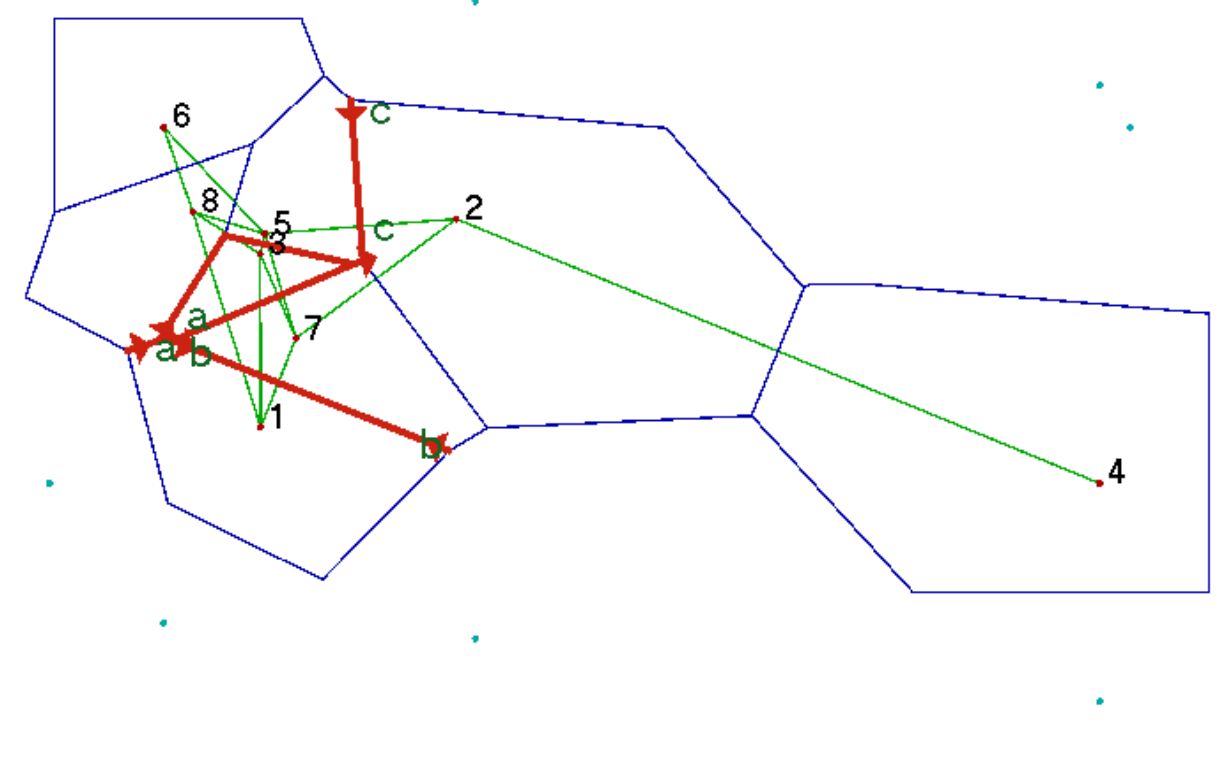

Figure S4. Output from BARRIER, highlighting the main breaks in genetic continuity (red lines); the green line corresponds to the Delaunay triangulation between populations (red dots) and Voronoï tessellation used to calculate position of the barriers (blue line). Populations: 1=Sirhowy, 2=Lugg, 3=Dderw, 4=Lea, 5=Bachowey, 6=Mochdre, 7=Gavenny, 8=Pant-y-Llyn. Barriers: $\mathrm{a}=$ isolates population 3, $\mathrm{b}=$ isolates population $1, \mathrm{c}=$ between population 2 and 5 . 

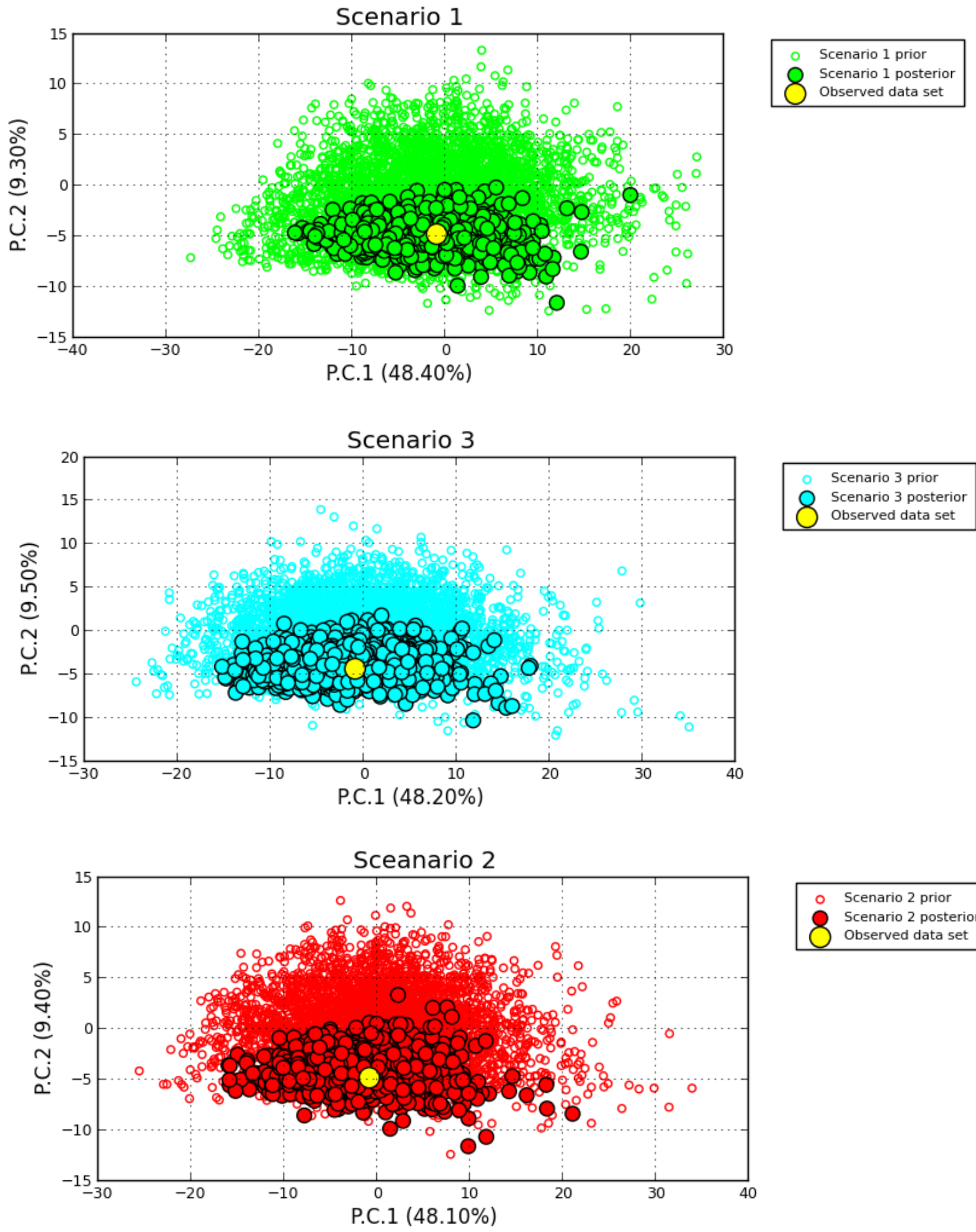

Scenario 2 prior
Scenario 2 posterio Observed data set

Figure S5. Principal component analysis (PCA) showing the fit of posterior distributions for all three scenarios tested, displaying 10000 prior plots per scenario. 
Figure. S6. Alignment of DNA fragments from eDNA samples for both Pacifastacus leniusculus ApalPlen16S forward (A) and reverse (B) primers against reference sequences. Seq_A.pal = positi eDNA fragment; Seq_P. len = positive in-situ Pacifastacus leniusculus eDNA fragment. A 340 350 360

A. pallipes KP866114.1 A-AGAAGGTTAAGTTACTTTAGGGATAACAGCGTAAT P. leniusculus JX077952.1 GT.A. .A.C. . . . . . . . Seq A. pal Seq P. len Apalplen16S F

GT.A. .A. C.

B

A. pallipes KP866114.1 AAGAGAGTTTGCGACCTCGATGTTGAATTAAAAGTTC P. leniusculus JX077952.1 Seq_A. pal Seq P. len Apalplen $16 \mathrm{~S} \mathrm{R}$ 

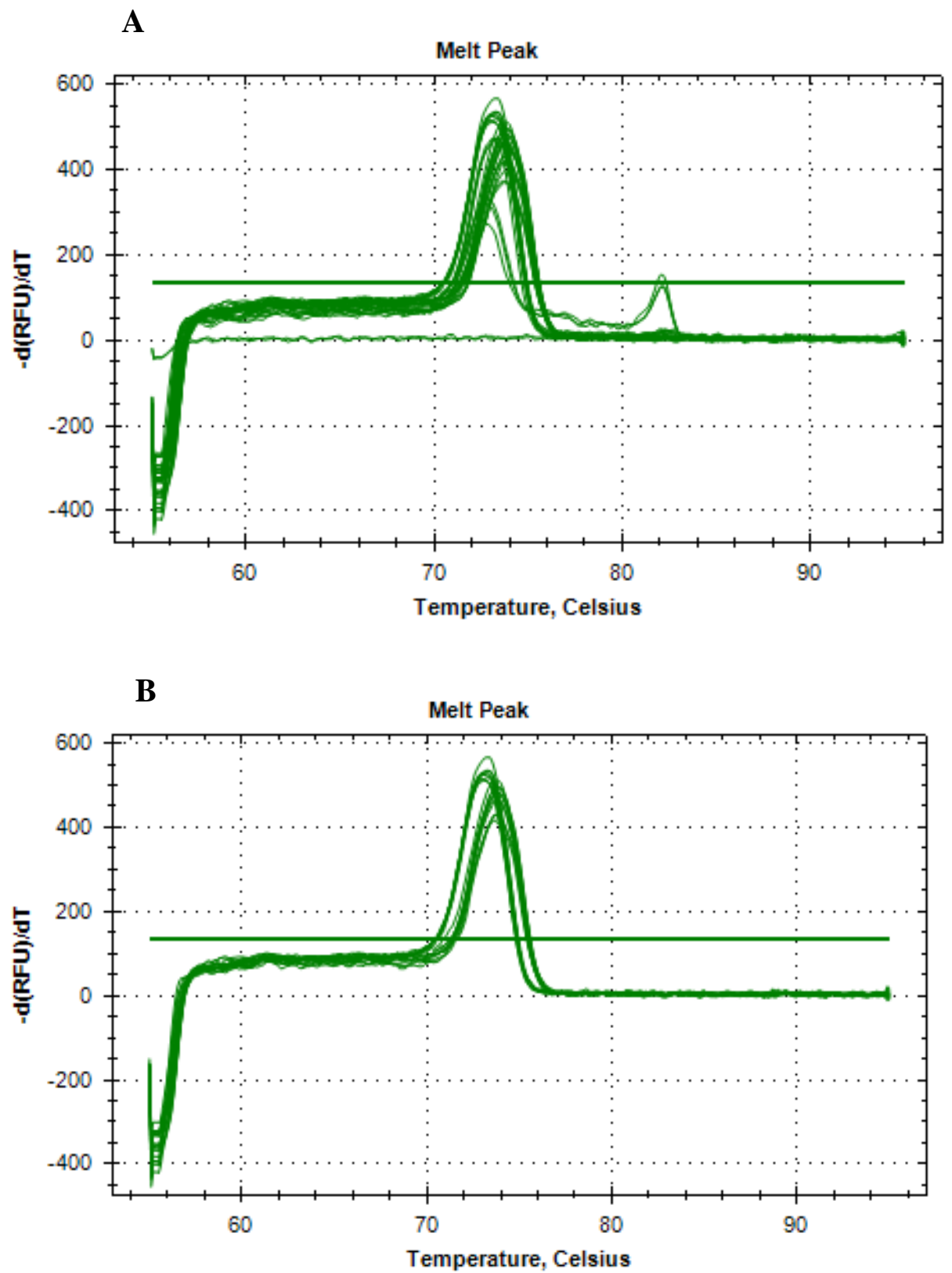

Figure. S7. Melt peaks from SYBR ${ }^{\mathrm{TM}}$ Green dilution series (A) and from SsoFast ${ }^{\mathrm{TM}}$ EvaGreen ${ }^{\circledR}$ dilution series (B) for Pacifastacus leniusculus and Austropotamobius pallipes DNA pools. 
A

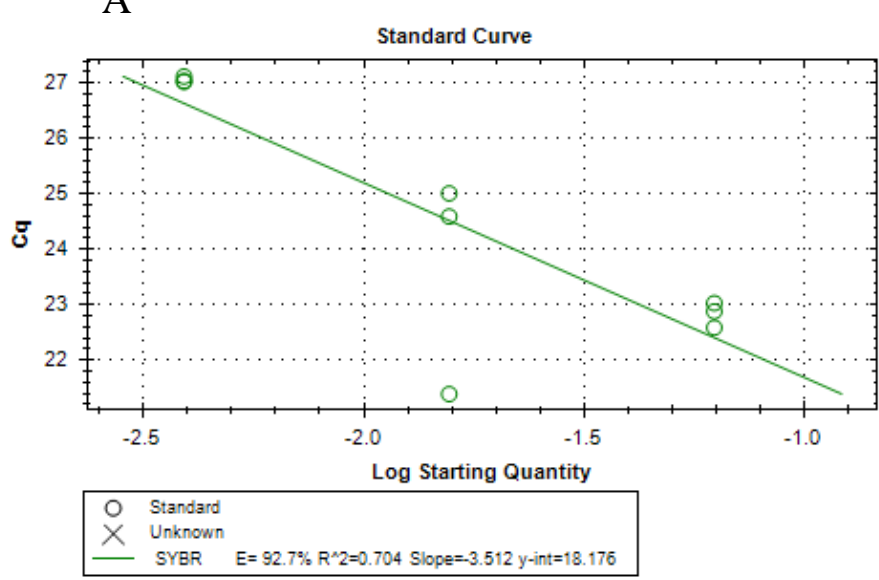

$\mathrm{C}$

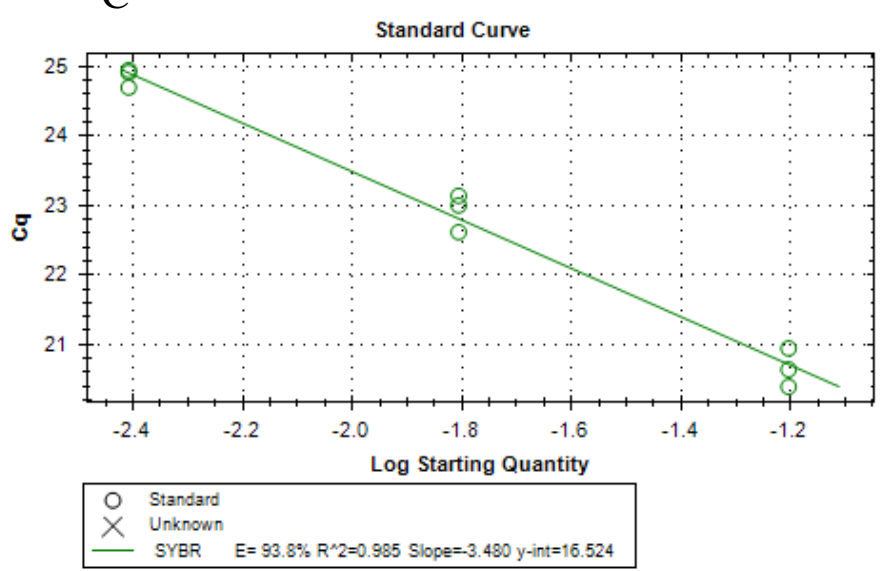

B

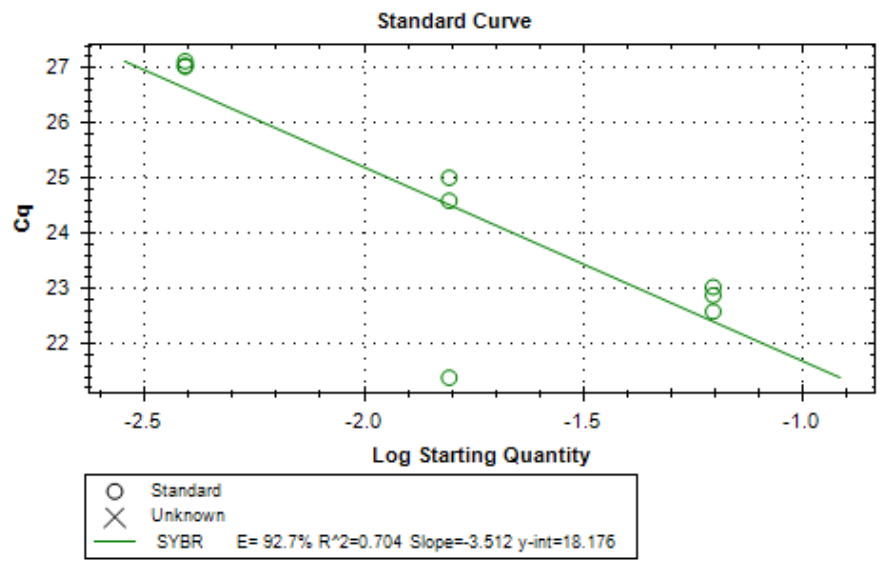

$\mathrm{D}$

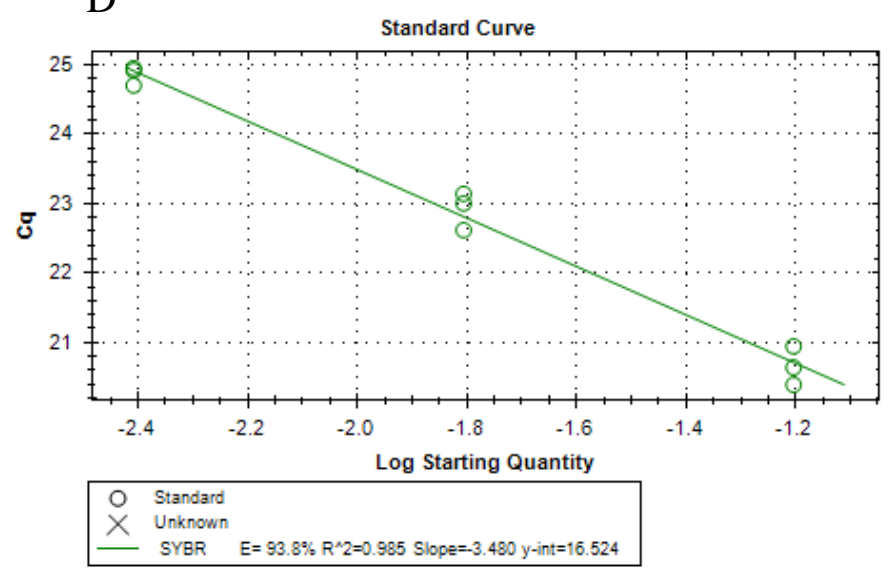

Figure S8. Efficiency outputs from SYBR ${ }^{\mathrm{TM}}$ Green dilution series for Pacifastacus leniusculus (A) and Austropotamobius pallipes (B); efficiency outputs from SsoFast ${ }^{\mathrm{TM}}$ EvaGreen ${ }^{\circledR}$ dilution series for (B) for Pacifastacus leniusculus (C) and Austropotamobius pallipes (D). 


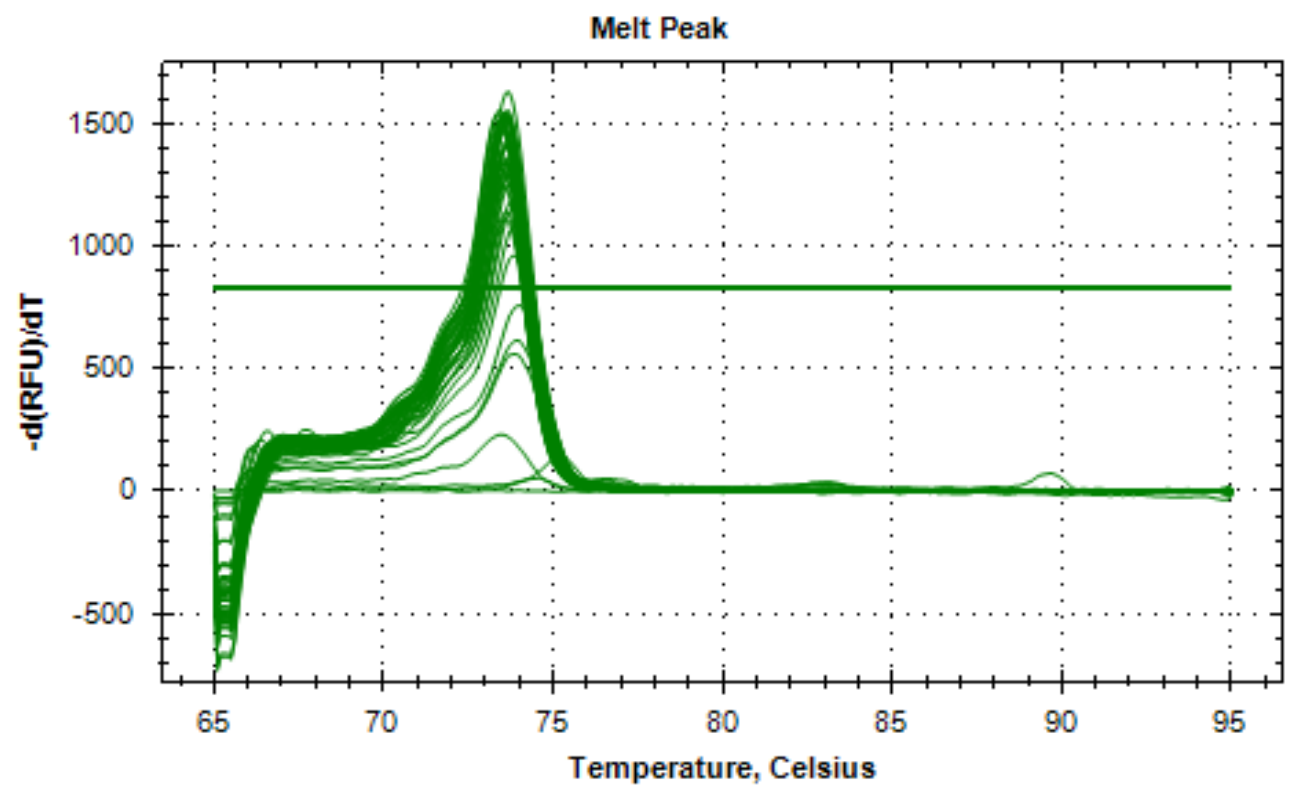

Figure S9. Melt peaks from SsoFast ${ }^{\mathrm{TM}}$ EvaGreen ${ }^{\circledR}$ ex-situ Pacifastacus leniusculus eDNA qPCR amplifications. 
Table S8. Melt peak data from SYBR ${ }^{\mathrm{TM}}$ Green and SsoFast ${ }^{\mathrm{TM}}$ EvaGreen ${ }^{\circledR}$ dilution series for Pacifastacus leniusculus (s_pool) and Austropotamobius pallipes (n_pool).

\begin{tabular}{|c|c|c|c|}
\hline Mastermix & Sample ID & Concentration (ng/ $\mu \mathrm{l})$ & Melt Temperature $\left({ }^{\circ} \mathrm{C}\right)$ \\
\hline SYBR $^{\text {TM }}$ Green & s_pool & 5 & 72.50 \\
\hline SYBR ${ }^{\mathrm{TM}}$ Green & s_pool & 5 & 72.80 \\
\hline SYBRTM Green & s_pool & 5 & 72.80 \\
\hline SYBR $^{\text {TM }}$ Green & n_pool & 5 & 73.70 \\
\hline SYBR $^{\text {TM }}$ Green & n_pool & 5 & 73.70 \\
\hline SYBRTM Green & n_pool & 5 & 73.70 \\
\hline SYBRTM Green & s_pool & 0.5 & 73.10 \\
\hline SYBRTM Green & s_pool & 0.5 & 73.40 \\
\hline SYBR $^{\mathrm{TM}}$ Green & s_pool & 0.5 & 73.30 \\
\hline SYBRTM Green & n_pool & 0.5 & 73.70 \\
\hline SYBRTM Green & n_pool & 0.5 & 73.70 \\
\hline SYBR ${ }^{\mathrm{TM}}$ Green & n_pool & 0.5 & 73.70 \\
\hline SYBRTM Green & s_pool & 0.05 & 73.40 \\
\hline SYBR $^{\text {TM }}$ Green & s_pool & 0.05 & 73.40 \\
\hline SYBR ${ }^{\mathrm{TM}}$ Green & s_pool & 0.05 & 73.30 \\
\hline SYBR $^{\text {TM }}$ Green & n_pool & 0.05 & 73.80 \\
\hline SYBR ${ }^{\mathrm{TM}}$ Green & n_pool & 0.05 & 73.70 \\
\hline SYBR $^{\mathrm{TM}}$ Green & n_pool & 0.05 & 73.60 \\
\hline SYBR ${ }^{\mathrm{TM}}$ Green & s_pool & 0.005 & 73.70 \\
\hline SYBR ${ }^{\mathrm{TM}}$ Green & s_pool & 0.005 & 73.30 \\
\hline SYBR $^{\mathrm{TM}}$ Green & s_pool & 0.005 & 73.20 \\
\hline SYBR $^{\mathrm{TM}}$ Green & n_pool & 0.005 & 73.70 \\
\hline SYBR $^{\mathrm{TM}}$ Green & n_pool & 0.005 & 73.70 \\
\hline SYBR $^{\mathrm{TM}}$ Green & n_pool & 0.005 & 73.80 \\
\hline SYBR $^{\mathrm{TM}}$ Green & s_pool & 0.0005 & 72.90 \\
\hline SYBR $^{\mathrm{TM}}$ Green & s_pool & 0.0005 & 73.00 \\
\hline SYBR $^{\mathrm{TM}}$ Green & s_pool & 0.0005 & 73.00 \\
\hline SYBR $^{\mathrm{TM}}$ Green & n_pool & 0.0005 & 73.80 \\
\hline SYBR $^{\mathrm{TM}}$ Green & n_pool & 0.0005 & 73.70 \\
\hline
\end{tabular}




\begin{tabular}{|c|c|c|c|}
\hline SYBR $^{\mathrm{TM}}$ Green & n_pool & 0.0005 & 73.70 \\
\hline SYBR $^{\mathrm{TM}}$ Green & MB & N/A & None \\
\hline SYBR $^{\mathrm{TM}}$ Green & MB & N/A & None \\
\hline SYBR $^{\mathrm{TM}}$ Green & MB & N/A & None \\
\hline SsoFast $^{\mathrm{TM}}$ EvaGreen ${ }^{\circledR}$ & s_pool & 5 & 82.10 \\
\hline SsoFast $^{\mathrm{TM}}$ EvaGreen ${ }^{\circledR}$ & s_pool & 5 & 72.50 \\
\hline SsoFast $^{\mathrm{TM}}$ EvaGreen ${ }^{\circledR}$ & s_pool & 5 & 72.80 \\
\hline SsoFast $^{\mathrm{TM}}$ EvaGreen ${ }^{\circledR}$ & s_pool & 5 & 72.80 \\
\hline SsoFast $^{\mathrm{TM}}$ EvaGreen ${ }^{\circledR}$ & n_pool & 5 & 73.70 \\
\hline SsoFast $^{\mathrm{TM}}$ EvaGreen ${ }^{\circledR}$ & n_pool & 5 & 73.70 \\
\hline SsoFast $^{\mathrm{TM}}$ EvaGreen ${ }^{\circledR}$ & n_pool & 5 & 73.70 \\
\hline SsoFast $^{\mathrm{TM}}$ EvaGreen ${ }^{\circledR}$ & s_pool & 0.5 & 73.10 \\
\hline SsoFast $^{\mathrm{TM}}$ EvaGreen ${ }^{\circledR}$ & s_pool & 0.5 & 73.40 \\
\hline SsoFast $^{\mathrm{TM}}$ EvaGreen ${ }^{\circledR}$ & s_pool & 0.5 & 73.30 \\
\hline SsoFast $^{\mathrm{TM}}$ EvaGreen ${ }^{\circledR}$ & n_pool & 0.5 & 73.70 \\
\hline SsoFast $^{\mathrm{TM}}$ EvaGreen ${ }^{\circledR}$ & n_pool & 0.5 & 73.70 \\
\hline SsoFast $^{\mathrm{TM}}$ EvaGreen ${ }^{\circledR}$ & n_pool & 0.5 & 73.70 \\
\hline SsoFast $^{\mathrm{TM}}$ EvaGreen ${ }^{\circledR}$ & s_pool & 0.05 & 73.70 \\
\hline SsoFast $^{\mathrm{TM}}$ EvaGreen ${ }^{\circledR}$ & s_pool & 0.05 & 73.70 \\
\hline SsoFast $^{\mathrm{TM}}$ EvaGreen ${ }^{\circledR}$ & s_pool & 0.05 & 73.70 \\
\hline SsoFast $^{\mathrm{TM}}$ EvaGreen ${ }^{\circledR}$ & n_pool & 0.05 & 73.80 \\
\hline SsoFast $^{\mathrm{TM}}$ EvaGreen ${ }^{\circledR}$ & n_pool & 0.05 & 73.70 \\
\hline SsoFast $^{\mathrm{TM}}$ EvaGreen ${ }^{\circledR}$ & n_pool & 0.05 & 73.70 \\
\hline SsoFast $^{\mathrm{TM}}$ EvaGreen ${ }^{\circledR}$ & s_pool & 0.005 & 73.70 \\
\hline SsoFast $^{\mathrm{TM}}$ EvaGreen ${ }^{\circledR}$ & s_pool & 0.005 & 73.70 \\
\hline SsoFast $^{\mathrm{TM}}$ EvaGreen ${ }^{\circledR}$ & s_pool & 0.005 & 73.60 \\
\hline SsoFast $^{\mathrm{TM}}$ EvaGreen ${ }^{\circledR}$ & n_pool & 0.005 & 73.70 \\
\hline SsoFast $^{\mathrm{TM}}$ EvaGreen ${ }^{\circledR}$ & n_pool & 0.005 & 73.70 \\
\hline SsoFast $^{\mathrm{TM}}$ EvaGreen ${ }^{\circledR}$ & n_pool & 0.005 & 73.80 \\
\hline
\end{tabular}

Sample ID: PC_SC Signal crayfish positive DNA control, PC_NC Native crayfish positive DNA control, n_pool Native crayfish DNA pool, s_pool Signal crayfish DNA pool, MB Amplification negative control 
Table S9. Melt curve data from SsoFast ${ }^{\mathrm{TM}}$ EvaGreen ${ }^{\circledR}$ mixed DNA ratios of crayfish species (Pacifastacus leniusculus and Austropotamobius pallipes) qPCR amplifications.

\begin{tabular}{|c|c|c|}
\hline Mastermix & Sample ID & Melt Temperature $\left({ }^{\circ} \mathrm{C}\right)$ \\
\hline SsoFast $^{\mathrm{TM}}$ EvaGreen ${ }^{\circledR}$ & 10:90 S:N & 74.20 \\
\hline SssoFast $^{\mathrm{TM}}$ EvaGreen ${ }^{\circledR}$ & 10:90 S:N & 74.10 \\
\hline SsoFast ${ }^{\mathrm{TM}}$ EvaGreen ${ }^{\circledR}$ & 10:90 S:N & 74.20 \\
\hline SssoFast $^{\mathrm{TM}}$ EvaGreen ${ }^{\circledR}$ & 90:10 S:N & 74.80 \\
\hline SssoFast $^{\mathrm{TM}}$ EvaGreen ${ }^{\circledR}$ & 90:10 S:N & 74.90 \\
\hline SsoFast ${ }^{\mathrm{TM}}$ EvaGreen ${ }^{\circledR}$ & 90:10 S:N & 74.90 \\
\hline SssoFast $^{\mathrm{TM}}$ EvaGreen ${ }^{\circledR}$ & 20:80 S:N & 74.30 \\
\hline SsoFast ${ }^{\mathrm{TM}}$ EvaGreen ${ }^{\circledR}$ & 20:80 S:N & 74.30 \\
\hline SsoFast $^{\mathrm{TM}}$ EvaGreen ${ }^{\circledR}$ & 20:80 S:N & 74.30 \\
\hline SsoFast $^{\mathrm{TM}}$ EvaGreen ${ }^{\circledR}$ & 30:70 S:N & 74.30 \\
\hline SsoFast ${ }^{\mathrm{TM}}$ EvaGreen ${ }^{\circledR}$ & 30:70 S:N & 74.40 \\
\hline SssoFast $^{\mathrm{TM}}$ EvaGreen ${ }^{\circledR}$ & 30:70 S:N & 68.30 \\
\hline SsoFast ${ }^{\mathrm{TM}}$ EvaGreen ${ }^{\circledR}$ & 30:70 S:N & 74.40 \\
\hline SsoFast ${ }^{\mathrm{TM}}$ EvaGreen ${ }^{\circledR}$ & 40:60 S:N & 74.70 \\
\hline SssoFast $^{\mathrm{TM}}$ EvaGreen ${ }^{\circledR}$ & 40:60 S:N & 74.70 \\
\hline SssoFast $^{\mathrm{TM}}$ EvaGreen ${ }^{\circledR}$ & 40:60 S:N & 74.60 \\
\hline SssoFast $^{\mathrm{TM}}$ EvaGreen ${ }^{\circledR}$ & 50:50 S:N & 74.70 \\
\hline SsoFast $^{\mathrm{TM}}$ EvaGreen ${ }^{\circledR}$ & 50:50 S:N & 74.70 \\
\hline SsoFast $^{\mathrm{TM}}$ EvaGreen ${ }^{\circledR}$ & $50: 50 \mathrm{~S}: \mathrm{N}$ & 74.70 \\
\hline SsoFast ${ }^{\mathrm{TM}}$ EvaGreen ${ }^{\circledR}$ & 60:40 S:N & 74.70 \\
\hline SssoFast $^{\mathrm{TM}}$ EvaGreen ${ }^{\circledR}$ & 60:40 S:N & 74.70 \\
\hline SssoFast $^{\mathrm{TM}}$ EvaGreen ${ }^{\circledR}$ & 60:40 S:N & 74.70 \\
\hline SsoFast ${ }^{\mathrm{TM}}$ EvaGreen ${ }^{\circledR}$ & $70: 30 \mathrm{~S}: \mathrm{N}$ & 74.80 \\
\hline SssoFast $^{\mathrm{TM}}$ EvaGreen ${ }^{\circledR}$ & $70: 30 \mathrm{~S}: \mathrm{N}$ & 74.80 \\
\hline SsoFast ${ }^{\mathrm{TM}}$ EvaGreen ${ }^{\circledR}$ & $70: 30 \mathrm{~S}: \mathrm{N}$ & 74.70 \\
\hline
\end{tabular}




\begin{tabular}{|c|c|c|}
\hline SsoFast $^{\mathrm{TM}}$ EvaGreen ${ }^{\circledR}$ & $80: 20 \mathrm{~S}: \mathrm{N}$ & 74.80 \\
\hline SssoFast $^{\mathrm{TM}}$ EvaGreen ${ }^{\circledR}$ & $80: 20 \mathrm{~S}: \mathrm{N}$ & 74.70 \\
\hline SsoFast $^{\mathrm{TM}}$ EvaGreen ${ }^{\circledR}$ & $80: 20 \mathrm{~S}: \mathrm{N}$ & 74.70 \\
\hline SsoFast $^{\mathrm{TM}}$ EvaGreen ${ }^{\circledR}$ & PC_SC & 74.00 \\
\hline SssoFast $^{\mathrm{TM}}$ EvaGreen ${ }^{\circledR}$ & PC_SC & 74.10 \\
\hline SssoFast $^{\mathrm{TM}}$ EvaGreen ${ }^{\circledR}$ & PC_SC & 74.10 \\
\hline SssoFast $^{\mathrm{TM}}$ EvaGreen ${ }^{\circledR}$ & PC_NC & 74.80 \\
\hline SsoFast $^{\mathrm{TM}}$ EvaGreen ${ }^{\circledR}$ & PC_NC & 74.80 \\
\hline SsoFast $^{\mathrm{TM}}$ EvaGreen ${ }^{\circledR}$ & PC_NC & 74.90 \\
\hline SsoFast $^{\mathrm{TM}}$ EvaGreen ${ }^{\circledR}$ & MB & None \\
\hline SsoFast $^{\mathrm{TM}}$ EvaGreen ${ }^{\circledR}$ & MB & None \\
\hline SsoFast $^{\mathrm{TM}}$ EvaGreen ${ }^{\circledR}$ & MB & None \\
\hline SssoFast $^{\mathrm{TM}}$ EvaGreen ${ }^{\circledR}$ & MB & None \\
\hline SsoFast $^{\mathrm{TM}}$ EvaGreen ${ }^{\circledR}$ & MB & None \\
\hline SsoFast $^{\mathrm{TM}}$ EvaGreen ${ }^{\circledR}$ & MB & None \\
\hline
\end{tabular}

Sample ID: PC_SC Signal crayfish positive DNA control, PC_NC Native crayfish positive DNA control, N Native crayfish, S Signal crayfish, MB Amplification negative control 
Table S10. Melt peak data from HOT FIREPol ${ }^{\circledR}$ EvaGreen ${ }^{\circledR}$ eDNA qPCR amplifications from the Medway and Itchen catchments, at sites where both Pacifastacus leniusculus and Austropotamobius pallipes DNA was detected in the same site.

\begin{tabular}{|c|c|c|c|c|}
\hline Mastermix & Catchment & Year & Sample ID & Melt Temperature $\left({ }^{\circ} \mathrm{C}\right)$ \\
\hline HOT FIREPol $^{\circledR}$ EvaGreen $^{\circledR}$ & Medway & 2016 & M5A & 76.90 \\
\hline HOT FIREPol ${ }^{\circledR}$ EvaGreen $^{\circledR}$ & Medway & 2016 & M5A & 76.00 \\
\hline HOT FIREPol $^{\circledR}$ EvaGreen $^{\circledR}$ & Medway & 2016 & M5A & 76.00 \\
\hline HOT FIREPol $^{\circledR}$ EvaGreen $^{\circledR}$ & Medway & 2016 & M5B & 76.00 \\
\hline HOT FIREPol $^{\circledR}$ EvaGreen $^{\circledR}$ & Medway & 2016 & M5B & 76.00 \\
\hline HOT FIREPol ${ }^{\circledR}$ EvaGreen $^{\circledR}$ & Medway & 2016 & M5B & 75.90 \\
\hline HOT FIREPol $^{\circledR}$ EvaGreen $^{\circledR}$ & Medway & 2016 & M5C & None \\
\hline HOT FIREPol $^{\circledR}$ EvaGreen $^{\circledR}$ & Medway & 2016 & M5C & 75.90 \\
\hline HOT FIREPol $^{\circledR}$ EvaGreen $^{\circledR}$ & Medway & 2016 & M5C & 75.90 \\
\hline HOT FIREPol $^{\circledR}$ EvaGreen $^{\circledR}$ & Medway & 2016 & M5D & 75.90 \\
\hline HOT FIREPol $^{\circledR}$ EvaGreen $^{\circledR}$ & Medway & 2016 & M5D & None \\
\hline HOT FIREPol $^{\circledR}$ EvaGreen $^{\circledR}$ & Medway & 2016 & M5D & 75.90 \\
\hline HOT FIREPol $^{\circledR}$ EvaGreen $^{\circledR}$ & Medway & 2016 & M5E & 75.80 \\
\hline HOT FIREPol $^{\circledR}$ EvaGreen $^{\circledR}$ & Medway & 2016 & M5E & None \\
\hline HOT FIREPol $^{\circledR}$ EvaGreen $^{\circledR}$ & Medway & 2016 & M5E & None \\
\hline HOT FIREPol $^{\circledR}$ EvaGreen $^{\circledR}$ & Medway & 2016 & M5F & 75.90 \\
\hline HOT FIREPol $^{\circledR}$ EvaGreen $^{\circledR}$ & Medway & 2016 & M5F & 75.90 \\
\hline HOT FIREPol $^{\circledR}$ EvaGreen $^{\circledR}$ & Medway & 2016 & M5F & 75.80 \\
\hline HOT FIREPol $^{\circledR}$ EvaGreen $^{\circledR}$ & Medway & 2017 & M5C & 75.90 \\
\hline HOT FIREPol $^{\circledR}$ EvaGreen $^{\circledR}$ & Medway & 2017 & M5C & 75.90 \\
\hline HOT FIREPol $^{\circledR}$ EvaGreen $^{\circledR}$ & Medway & 2017 & M5C & 76.90 \\
\hline HOT FIREPol $^{\circledR}$ EvaGreen $^{\circledR}$ & Itchen & 2017 & $\mathrm{I} 8 \mathrm{C}$ & 74.80 \\
\hline HOT FIREPol $^{\circledR}$ EvaGreen $^{\circledR}$ & Itchen & 2017 & $\mathrm{I} 8 \mathrm{C}$ & 74.90 \\
\hline HOT FIREPol $^{\circledR}$ EvaGreen $^{\circledR}$ & Itchen & 2017 & $\mathrm{I} 8 \mathrm{C}$ & 74.70 \\
\hline HOT FIREPol $^{\circledR}$ EvaGreen $^{\circledR}$ & Itchen & 2017 & $\mathrm{I} 8 \mathrm{~F}$ & 73.60 \\
\hline HOT FIREPol $^{\circledR}$ EvaGreen $^{\circledR}$ & Itchen & 2017 & $\mathrm{I} 8 \mathrm{~F}$ & 74.00 \\
\hline HOT FIREPol ${ }^{\circledR}$ EvaGreen $^{\circledR}$ & Itchen & 2017 & $\mathrm{I} 8 \mathrm{~F}$ & None \\
\hline HOT FIREPol $^{\circledR}$ EvaGreen $^{\circledR}$ & N/A & N/A & PC_SC & 75.90 \\
\hline
\end{tabular}




\begin{tabular}{lllll}
\hline HOT FIREPol $^{\circledR}$ EvaGreen $^{\circledR}$ & N/A & N/A & PC_SC & 76.00 \\
HOT FIREPol $^{\circledR}$ EvaGreen $^{\circledR}$ & N/A & N/A & PC_SC & 75.90 \\
HOT FIREPol $^{\circledR}$ EvaGreen $^{\circledR}$ & N/A & N/A & PC_AA & 82.90 \\
HOT FIREPol $^{\circledR}$ EvaGreen $^{\circledR}$ & N/A & N/A & PC_AA & 82.90 \\
HOT FIREPol $^{\circledR}$ EvaGreen $^{\circledR}$ & N/A & N/A & PC_AA & 82.90 \\
HOT FIREPol $^{\circledR}$ EvaGreen $^{\circledR}$ & N/A & N/A & MB & None \\
HOT FIREPol $^{\circledR}$ EvaGreen $^{\circledR}$ & N/A & N/A & MB & None \\
HOT FIREPol $^{\circledR}$ EvaGreen $^{\circledR}$ & N/A & N/A & MB & None \\
\hline
\end{tabular}

Sample ID: M\# Medway catchment sample with corresponding subsample letter, I\# Itchen catchment sample with corresponding subsample letter, PC_SC Signal crayfish positive DNA control, PC_NC Native crayfish positive DNA control, PC_AA Crayfish plague positive DNA control, MB Amplification negative control 
Table S11. Melt peak data from SsoFast ${ }^{\mathrm{TM}}$ EvaGreen ${ }^{\circledR}$ eDNA qPCR amplifications from the River Itchen at for samples positive for Pacifastacus leniusculus and Austropotamobius pallipes DNA.

\begin{tabular}{|c|c|c|c|}
\hline Mastermix & Catchment & Sample & Melt Temperature $\left({ }^{\circ} \mathrm{C}\right)$ \\
\hline SsoFast $^{\text {TM }}$ EvaGreen ${ }^{\circledR}$ & Itchen & I1_A & 74.60 \\
\hline SsoFast $^{\mathrm{TM}}$ EvaGreen ${ }^{\circledR}$ & Itchen & I1_A & 74.60 \\
\hline SsoFast $^{\mathrm{TM}}$ EvaGreen ${ }^{\circledR}$ & Itchen & I1_C & 74.80 \\
\hline SsoFast $^{\text {TM }}$ EvaGreen ${ }^{\circledR}$ & Itchen & I1_C & 74.70 \\
\hline SsoFast $^{\text {TM }}$ EvaGreen ${ }^{\circledR}$ & Itchen & I5_C & 73.80 \\
\hline SsoFast $^{\text {TM }}$ EvaGreen ${ }^{\circledR}$ & Itchen & I5_C & 73.70 \\
\hline SsoFast $^{\mathrm{TM}}$ EvaGreen ${ }^{\circledR}$ & Itchen & I7_E & 74.10 \\
\hline SsoFast $^{\mathrm{TM}}$ EvaGreen ${ }^{\circledR}$ & Itchen & I8_A & 73.70 \\
\hline SsoFast $^{\mathrm{TM}}$ EvaGreen ${ }^{\circledR}$ & Itchen & I8_C & 74.80 \\
\hline SsoFast ${ }^{\mathrm{TM}}$ EvaGreen ${ }^{\circledR}$ & Itchen & I8_C & 74.90 \\
\hline SsoFast $^{\mathrm{TM}}$ EvaGreen ${ }^{\circledR}$ & Itchen & I8_C & 74.70 \\
\hline SsoFast ${ }^{\mathrm{TM}}$ EvaGreen ${ }^{\circledR}$ & Itchen & I8_F & 73.60 \\
\hline SsoFast $^{\mathrm{TM}}$ EvaGreen ${ }^{\circledR}$ & Itchen & I8_F & 74.00 \\
\hline SsoFast $^{\text {TM }}$ EvaGreen ${ }^{\circledR}$ & Itchen & I10_A & 73.60 \\
\hline SsoFast ${ }^{\mathrm{TM}}$ EvaGreen ${ }^{\circledR}$ & Itchen & I10_A & 73.70 \\
\hline SsoFast ${ }^{\mathrm{TM}}$ EvaGreen ${ }^{\circledR}$ & Itchen & I10_A & 73.80 \\
\hline SsoFast $^{\text {TM }}$ EvaGreen ${ }^{\circledR}$ & Itchen & I10_B & 73.70 \\
\hline SsoFast $^{\mathrm{TM}}$ EvaGreen ${ }^{\circledR}$ & Itchen & I12_B & 74.00 \\
\hline SsoFast $^{\mathrm{TM}}$ EvaGreen ${ }^{\circledR}$ & Itchen & I12_B & 74.00 \\
\hline SsoFast $^{\mathrm{TM}}$ EvaGreen ${ }^{\circledR}$ & Itchen & I12_B & 74.00 \\
\hline SsoFast $^{\mathrm{TM}}$ EvaGreen ${ }^{\circledR}$ & Itchen & I15_B & 74.00 \\
\hline SsoFast $^{\mathrm{TM}}$ EvaGreen ${ }^{\circledR}$ & Itchen & I15_B & 73.90 \\
\hline SsoFast ${ }^{\mathrm{TM}}$ EvaGreen ${ }^{\circledR}$ & Itchen & I15_B & 73.80 \\
\hline SsoFast $^{\mathrm{TM}}$ EvaGreen ${ }^{\circledR}$ & Itchen & I15_D & 73.90 \\
\hline SsoFast $^{\mathrm{TM}}$ EvaGreen ${ }^{\circledR}$ & Itchen & I15_F & 73.90 \\
\hline SsoFast $^{\mathrm{TM}}$ EvaGreen ${ }^{\circledR}$ & Itchen & I16_A & 73.70 \\
\hline SsoFast $^{\mathrm{TM}}$ EvaGreen ${ }^{\circledR}$ & Itchen & I16_A & 73.60 \\
\hline SsoFast $^{\text {TM }}$ EvaGreen ${ }^{\circledR}$ & Itchen & I16_F & 73.60 \\
\hline SsoFast $^{\text {TM }}$ EvaGreen ${ }^{\circledR}$ & Itchen & PC_NC & 74.40 \\
\hline SsoFast $^{\text {TM }}$ EvaGreen $\AA$ & Itchen & PC_NC & 74.50 \\
\hline SsoFast $^{\mathrm{TM}}$ EvaGreen ${ }^{\circledR}$ & Itchen & PC_NC & 74.80 \\
\hline SsoFast $^{\text {TM }}$ EvaGreen ${ }^{\circledR}$ & Itchen & PC_SC & 73.80 \\
\hline SsoFast $^{\mathrm{TM}}$ EvaGreen ${ }^{\circledR}$ & Itchen & PC_SC & 73.80 \\
\hline SsoFast ${ }^{\mathrm{TM}}$ EvaGreen ${ }^{\circledR}$ & Itchen & PC_SC & 73.90 \\
\hline
\end{tabular}


Sample ID: I\# Itchen catchment sample with corresponding subsample letter, PC_SC Signal crayfish positive DNA control, PC_NC Native crayfish positive DNA control, MB Amplification negative control 
Table S12. Location of major barriers present upstream to downstream of the sampling area of the Stour, including type of obstruction, GPS coordinates and distance to nearest upstream and d information provided by Environment Agency and Natural Resources Wales (EA, 2017).

\begin{tabular}{lcccc}
\hline River & Obstruction Name & $\begin{array}{c}\text { Obstruction } \\
\text { Type }\end{array}$ & Obstruction GPS & $\begin{array}{c}\text { Distance upstrea) } \\
\text { barrier (k) }\end{array}$ \\
\hline Medway & Leigh Barrier Control & Flood Gate & TQ 56386 46116 & N/A \\
& Structure & & & 3.5 \\
Medway & Town Lock & Lock & TQ 59356 46478 & 2.2 \\
Medway & Eldridges Lock & Lock & TQ 61191 47173 & 1.4 \\
Medway & Porters Lock & Lock & TQ 62488 47088 \\
Medway & East Lock & Lock & TQ 64202 47298 & 1.9 \\
Medway & Oak Weir Lock & Lock & TQ 65354 47202 & 1.2 \\
Medway & Sluice Weir Lock & Lock & TQ 66919 47947 & 2.0 \\
Medway & Hampstead Lock & Lock & TQ 68686 50345 & 4.6 \\
Medway & Teston Lock & Lock & TQ 70840 53052 & 4.7 \\
Medway & East Farleigh Lock & Lock & TQ 73521 53572 & 3.2 \\
Medway & Allington Lock & Lock & TQ 74833 58153 & 3.7 \\
Medway & Tidal gate 2 & Flood Gate & TQ 72961 58962 & 2.3 \\
\hline
\end{tabular}




\begin{tabular}{ccccr}
\hline Medway & Tidal gate 4 & Flood Gate & TQ 72751 58847 & 0.2 \\
Medway & Tidal gate 6 & Flood Gate & TQ 71750 58994 & 1.0 \\
Dee & Horseshoe falls & Weir & SJ 19540 43330 & N/A \\
Dee & Weir on the Dee & Weir & SJ 34841 41469 & 23.8 \\
Dee & Erbistock Mill Weir & Weir & SJ 35423 42107 \\
Dee & Chester Weir & Weir & SJ 40757 65819 & 5.0 \\
\hline
\end{tabular}

Table S13. Upstream and downstream proximity of each sampling site in relation to the nearest Medway and River Dee.

\begin{tabular}{cccc}
\hline River & Site & $\begin{array}{c}\text { Distance upstream to next barrier } \\
(\mathbf{k m})\end{array}$ & $\begin{array}{r}\text { Distance downstrea } \\
(\mathbf{k n}\end{array}$ \\
\hline Medway & M1 & 3.3 & 0.3 \\
Medway & M2 & 2.0 & 4.0 \\
Medway & M3 & N/A \\
Medway & M4 & 3.4 & 0.6 \\
Medway & M5 & N/A \\
Medway & M6 & N/A & 5.9 \\
Medway & M7 & N/A & 13. \\
Medway & M8 & 0.2 & 8.6 \\
\hline
\end{tabular}




\begin{tabular}{cccc}
\hline Medway & M9 & 3.3 & 0.0 \\
Medway & M10 & 3.3 & 0.2 \\
Medway & M11 & 7.5 & 5.0 \\
Dee & D1 & N/A & 42. \\
Dee & D2 & N/A & 30. \\
Dee & D3 & N/A & 30 \\
Dee & D4 & 1.1 & 26. \\
Dee & D5 & 16.4 & 7.3 \\
Dee & D6 & 2.5 & 49. \\
Dee & D7 & 16.6 & 32. \\
Dee & D8 & 24.1 & 20. \\
Dee & D9 & 36.6 & 11. \\
Dee & D10 & 44.2 & 5.4 \\
Dee & D11 & 48.7 & 1.1
\end{tabular}


Table S14. Melt peak data from SsoFast ${ }^{\mathrm{TM}}$ EvaGreen ${ }^{\circledR}$ dilution series for Pacifastacus leniusculus (SC_pool), Austropotamobius pallipes (NC_pool) and Eriocheir sinensis (MC_pool).

\begin{tabular}{lcc}
\hline Sample & Fluorophore & Melt Temperature $\left({ }^{\circ} \mathbf{C}\right)$ \\
\hline MC_pool & SYBR & 73.5 \\
MC_pool & SYBR & 73.4 \\
MC_pool & SYBR & 73.4 \\
MC_pool & SYBR & 73.4 \\
MC_pool & SYBR & 73.4 \\
MC_pool & SYBR & 73.3 \\
MC_pool & SYBR & 73.3 \\
MC_pool & SYBR & 73.3 \\
MC_pool & SYBR & 73.2 \\
MC_pool & SYBR & 73.1 \\
MC_pool & SYBR & 73.4 \\
MC_pool & SYBR & 73.4 \\
SC_pool & SYBR & 73.7 \\
SC_pool & SYBR & 73.6 \\
SC_pool & SYBR & 73.6 \\
SC_pool & SYBR & 73.6 \\
SC_pool & SYBR & 73.7 \\
SC_pool & SYBR & 73.7 \\
SC_pool & SYBR & 73.6 \\
SC_pool & SYBR & 73.6 \\
SC_pool & SYBR & 73.7 \\
SC_pool & SYBR & 73.6 \\
SC_pool & SYBR & 73.7 \\
SC_pool & SYBR & 73.7 \\
\hline
\end{tabular}




\begin{tabular}{lll}
\hline NC_pool & SYBR & 74.5 \\
NC_pool & SYBR & 74.6 \\
NC_pool & SYBR & 74.5 \\
NC_pool & SYBR & 74.6 \\
NC_pool & SYBR & 74.6 \\
NC_pool & SYBR & 74.4 \\
NC_pool & SYBR & 74.6 \\
NC_pool & SYBR & 74.6 \\
NC_pool & SYBR & 74.6 \\
NC_pool & SYBR & 74.6 \\
NC_pool & SYBR & 74.6 \\
\hline
\end{tabular}

Sample ID: PC_SC Signal crayfish positive DNA control, PC_NC Native crayfish positive DNA control, PC_MC Mitten crab positive DNA control 
Table S15. Melt peak data from SsoFast ${ }^{\mathrm{TM}}$ EvaGreen ${ }^{\circledR}$ dilution series for Pacifastacus leniusculus (SC), Austropotamobius pallipes (NC) and Eriocheir sinensis (MC) mixed proportions

\begin{tabular}{|c|c|c|}
\hline Sample & Fluorophore & Melt Temperature $\left({ }^{\circ} \mathrm{C}\right)$ \\
\hline $2: 2: 2$ & SYBR & 74.4 \\
\hline $2: 2: 2$ & SYBR & 74.4 \\
\hline $2: 2: 2$ & SYBR & 74.4 \\
\hline $1: 2: 2$ & SYBR & 74.4 \\
\hline $1: 2: 2$ & SYBR & 74.4 \\
\hline $1: 2: 2$ & SYBR & 74.4 \\
\hline $2: 1: 2$ & SYBR & 74.4 \\
\hline $2: 1: 2$ & SYBR & 74.4 \\
\hline $2: 1: 2$ & SYBR & 74.4 \\
\hline $2: 2: 1$ & SYBR & 73.7 \\
\hline $2: 2: 1$ & SYBR & 73.6 \\
\hline $2: 2: 1$ & SYBR & 73.6 \\
\hline PC_SC & SYBR & 73.7 \\
\hline PC_SC & SYBR & 73.6 \\
\hline PC_SC & SYBR & 73.6 \\
\hline PC_NC & SYBR & 74.5 \\
\hline PC_NC & SYBR & 74.5 \\
\hline PC_NC & SYBR & 74.5 \\
\hline PC_MC & SYBR & 73.4 \\
\hline PC_MC & SYBR & 73.3 \\
\hline PC_MC & SYBR & 73.4 \\
\hline MB & SYBR & None \\
\hline MB & SYBR & None \\
\hline MB & SYBR & None \\
\hline
\end{tabular}

Sample ID: PC_SC Signal crayfish positive DNA control, PC_NC Native crayfish positive DNA control, PC_MC Mitten crab positive DNA control, MB amplification blank 
Table S16. Melt peak data from SsoFast ${ }^{\mathrm{TM}}$ EvaGreen ${ }^{\circledR}$ dilution series for Pacifastacus leniusculus (SC), and Eriocheir sinensis (MC) mixed proportions.

\begin{tabular}{|c|c|c|}
\hline Sample & Fluorophore & Melt Temperature $\left({ }^{\circ} \mathrm{C}\right)$ \\
\hline $9: 1$ & SYBR & 73.7 \\
\hline $9: 1$ & SYBR & 73.7 \\
\hline $9: 1$ & SYBR & 73.7 \\
\hline $8: 2$ & SYBR & 73.6 \\
\hline $8: 2$ & SYBR & 736. \\
\hline $8: 2$ & SYBR & 73.6 \\
\hline $7: 3$ & SYBR & 73.6 \\
\hline $7: 3$ & SYBR & 73.6 \\
\hline $7: 3$ & SYBR & 73.6 \\
\hline $6: 4$ & SYBR & 73.4 \\
\hline $6: 4$ & SYBR & 73.4 \\
\hline $6: 4$ & SYBR & 73.4 \\
\hline $5: 5$ & SYBR & 73.4 \\
\hline $5: 5$ & SYBR & 73.4 \\
\hline $5: 5$ & SYBR & 73.4 \\
\hline $4: 6$ & SYBR & 73.4 \\
\hline $4: 6$ & SYBR & 73.4 \\
\hline $4: 6$ & SYBR & 73.4 \\
\hline $3: 7$ & SYBR & 73.4 \\
\hline $3: 7$ & SYBR & 73.4 \\
\hline $3: 7$ & SYBR & 73.4 \\
\hline $2: 8$ & SYBR & 73.4 \\
\hline $2: 8$ & SYBR & 73.4 \\
\hline $2: 8$ & SYBR & 73.4 \\
\hline $1: 9$ & SYBR & 73.4 \\
\hline $1: 9$ & SYBR & 73.4 \\
\hline $1: 9$ & SYBR & 73.4 \\
\hline PC_SC & SYBR & 73.7 \\
\hline
\end{tabular}




\begin{tabular}{ccc}
\hline PC_SC & SYBR & 73.7 \\
PC_SC & SYBR & 73.7 \\
PC_MC & SYBR & 73.3 \\
PC_MC & SYBR & 73.4 \\
PC_MC & SYBR & 73.3 \\
MB & SYBR & None \\
MB & SYBR & None \\
MB & SYBR & None \\
\hline
\end{tabular}

Sample ID: PC_SC Signal crayfish positive DNA control, PC_MC Mitten crab positive DNA control, MB amplification blank 
Table S17. Number of water and sediment samples collected, positive sites for both water and sedin crayfish (SC) and mitten crab (MC)) and total number of positive sites for each sample type.

$\begin{array}{ccccc}\text { Catchment } & \begin{array}{c}\text { Total Water } \\ \text { Sample Sites }\end{array} & \begin{array}{c}\text { Total Sediment } \\ \text { Sample Sites }\end{array} & \begin{array}{c}\text { No. Positive SC } \\ \text { sites (Water) }\end{array} & \begin{array}{c}\text { No. Positive SC } \\ \text { sites (Sediment) }\end{array}\end{array}$

\begin{tabular}{ccccc}
\hline Medway & 11 & 5 & 4 & 3 \\
Dee & 11 & 11 & 1 & 2 \\
Stour & 3 & 1 & 1 & 1 \\
Total & 25 & 17 & 6 & 6 \\
\hline
\end{tabular}


Table S18. Melt peak data from SsoFast ${ }^{\mathrm{TM}}$ EvaGreen ${ }^{\circledR}$ water field samples in the River Medway positive for Pacifastacus leniusculus (SC), and Eriocheir sinensis (MC) DNA.

\begin{tabular}{|c|c|c|}
\hline Fluorophore & Sample & Melt Temperature $\left({ }^{\circ} \mathrm{C}\right)$ \\
\hline SYBR & M_1A & 73.9 \\
\hline SYBR & M_1A & 73.8 \\
\hline SYBR & M_1A & 73.7 \\
\hline SYBR & M_1C & 73.8 \\
\hline SYBR & M_1C & 73.7 \\
\hline SYBR & M_1C & 73.7 \\
\hline SYBR & M_1D & 73.7 \\
\hline SYBR & M_1D & 73.6 \\
\hline SYBR & M_1D & 73.6 \\
\hline SYBR & M_1F & 73.7 \\
\hline SYBR & M_1F & 73.6 \\
\hline SYBR & M_1F & 73.6 \\
\hline SYBR & M_5A & 74.0 \\
\hline SYBR & M_5A & 74.1 \\
\hline SYBR & M_5A & 74.1 \\
\hline SYBR & M_5B & 74.0 \\
\hline SYBR & M_5B & 74.0 \\
\hline SYBR & M_5C & 74.1 \\
\hline SYBR & M_5C & 74.1 \\
\hline SYBR & M_5D & 74.1 \\
\hline SYBR & M_5D & 74.0 \\
\hline SYBR & M_5D & 74.1 \\
\hline SYBR & M_5E & 74.0 \\
\hline SYBR & M_5E & 73.8 \\
\hline SYBR & M_5E & 73.8 \\
\hline SYBR & M_5F & 73.8 \\
\hline
\end{tabular}




\begin{tabular}{|c|c|c|}
\hline SYBR & M_5F & 73.8 \\
\hline SYBR & M_5F & 74.1 \\
\hline SYBR & M_7A & 73.9 \\
\hline SYBR & M_7A & 72.9 \\
\hline SYBR & M_7E & 73.6 \\
\hline SYBR & M_7E & 73.6 \\
\hline SYBR & M_7F & 73.3 \\
\hline SYBR & M_7F & 73.4 \\
\hline SYBR & M_7F & 73.3 \\
\hline SYBR & M_10A & 73.9 \\
\hline SYBR & M_10A & 73.6 \\
\hline SYBR & M_10A & 73.7 \\
\hline SYBR & M_10C & 73.3 \\
\hline SYBR & M_10C & 73.3 \\
\hline SYBR & M_10D & 73.6 \\
\hline SYBR & M_10D & 73.7 \\
\hline SYBR & M_11A & 73.5 \\
\hline SYBR & M_11A & 73.5 \\
\hline SYBR & M_11B & 73.4 \\
\hline SYBR & M_11B & 73.4 \\
\hline SYBR & M_1BL & None \\
\hline SYBR & M_1BL & None \\
\hline SYBR & M_1BL & None \\
\hline SYBR & M_2BL & None \\
\hline SYBR & M_2BL & None \\
\hline SYBR & M_2BL & None \\
\hline SYBR & M_3BL & None \\
\hline SYBR & M_3BL & None \\
\hline SYBR & M_3BL & None \\
\hline SYBR & M_4BL & None \\
\hline SYBR & M_4BL & None \\
\hline
\end{tabular}




\begin{tabular}{|c|c|c|}
\hline SYBR & M_4BL & None \\
\hline SYBR & M_5BL & None \\
\hline SYBR & M_5BL & None \\
\hline SYBR & M_5BL & None \\
\hline SYBR & M_6BL & None \\
\hline SYBR & M_6BL & None \\
\hline SYBR & M_6BL & None \\
\hline SYBR & M_7BL & None \\
\hline SYBR & M_7BL & None \\
\hline SYBR & M_7BL & None \\
\hline SYBR & M_8BL & None \\
\hline SYBR & M_8BL & None \\
\hline SYBR & M_8BL & None \\
\hline SYBR & M_9BL & None \\
\hline SYBR & M_9BL & None \\
\hline SYBR & M_9BL & None \\
\hline SYBR & M_10BL & None \\
\hline SYBR & M_10BL & None \\
\hline SYBR & M_10BL & None \\
\hline SYBR & M_11BL & None \\
\hline SYBR & M_11BL & None \\
\hline SYBR & M_11BL & None \\
\hline SYBR & EB1 & None \\
\hline SYBR & EB1 & None \\
\hline SYBR & EB1 & None \\
\hline SYBR & $\mathrm{EB} 2$ & None \\
\hline SYBR & EB2 & None \\
\hline SYBR & EB2 & None \\
\hline SYBR & EB3 & None \\
\hline SYBR & EB3 & None \\
\hline SYBR & EB3 & None \\
\hline
\end{tabular}




\begin{tabular}{lcl}
\hline SYBR & MB & None \\
SYBR & MB & None \\
SYBR & MB & None \\
SYBR & PC_MC & 73.3 \\
SYBR & PC_MC & 73.3 \\
SYBR & PC_SC & 73.7 \\
SYBR & PC_SC & 73.7
\end{tabular}

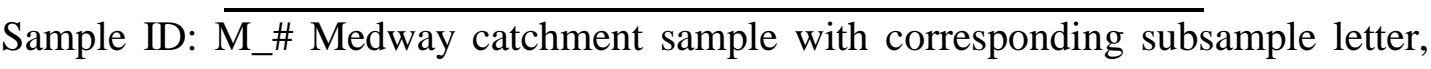
PC_SC Signal crayfish positive DNA control, PC_MC Mitten crab positive DNA control, EB\# extraction blank, M_\#BL site blank, MB amplification blank 
Table S19. Melt peak data from SsoFast ${ }^{\mathrm{TM}}$ EvaGreen ${ }^{\circledR}$ sediment field samples in the River Medway positive for Pacifastacus leniusculus (SC), and Eriocheir sinensis (MC) DNA.

\begin{tabular}{|c|c|c|}
\hline Fluorophore & Sample & Melt Temperature $\left({ }^{\circ} \mathrm{C}\right)$ \\
\hline SYBR & M_S7_B & 73.7 \\
\hline SYBR & M_S7_B & 73.7 \\
\hline SYBR & M_S7_B & 73.7 \\
\hline SYBR & M_S7_C & 73.8 \\
\hline SYBR & M_S7_C & 74.0 \\
\hline SYBR & M_S7_C & 73.8 \\
\hline SYBR & M_S7_E & 73.9 \\
\hline SYBR & M_S7_E & 73.8 \\
\hline SYBR & M_S7_E & 73.6 \\
\hline SYBR & M_S7_F & 73.6 \\
\hline SYBR & M_S7_F & 73.6 \\
\hline SYBR & M_S7_F & 73.9 \\
\hline SYBR & M_S8_A & 73.9 \\
\hline SYBR & M_S8_A & 74.0 \\
\hline SYBR & M_S8_A & 74.0 \\
\hline SYBR & M_S8_C & 73.6 \\
\hline SYBR & M_S8_C & 73.8 \\
\hline SYBR & M_S8_D & 73.9 \\
\hline SYBR & M_S8_D & 73.9 \\
\hline SYBR & M_S8_D & 73.9 \\
\hline SYBR & M_S8_F & 73.6 \\
\hline SYBR & M_S8_F & 73.7 \\
\hline SYBR & M_S11_A & 73.3 \\
\hline SYBR & M_S11_A & 73.3 \\
\hline SYBR & M_S11_A & 73.3 \\
\hline SYBR & M_S11_B & 73.3 \\
\hline SYBR & M_S11_B & 73.4 \\
\hline SYBR & M_S11_B & 73.4 \\
\hline SYBR & M_S11_C & 73.1 \\
\hline
\end{tabular}




\begin{tabular}{lll}
\hline SYBR & M_S11_C & 73.2 \\
SYBR & M_S11_C & 75.3 \\
SYBR & M_S11_E & 73.6 \\
SYBR & M_S11_E & 73.7 \\
SYBR & M_S1BL & None \\
SYBR & M_S1BL & None \\
SYBR & M_S1BL & None \\
SYBR & M_S2BL & None \\
SYBR & M_S2BL & None \\
SYBR & M_S2BL & None \\
SYBR & M_S3BL & None \\
SYBR & M_S3BL & None \\
SYBR & M_S3BL & None \\
SYBR & M_S4BL & None \\
SYBR & M_S4BL & None \\
SYBR & M_S4BL & None \\
SYBR & M_S5BL & None \\
SYBR & M_S5BL & None \\
SYBR & M_S5BL & None \\
SYBR & PC_SC & 73.9 \\
SYBR & PC_SC & 73.9 \\
SYBR & PC_SC & 74 \\
SYBR & PC_MC & 73.3 \\
SYBR & PC_MC & 73.4 \\
SYBR & PC_MC & 73.3 \\
SYBR & MB & None \\
SYBR & MB & None \\
SYBR & MB & M \\
\hline
\end{tabular}

Sample ID: M_S\# Medway catchment sample with corresponding subsample letter, PC_SC Signal crayfish positive DNA control, PC_MC Mitten crab positive DNA control, EB extraction blank, M_S\#BL site blank, MB amplification blank 
Table S20. Melt peak data from SsoFast ${ }^{\mathrm{TM}}$ EvaGreen ${ }^{\circledR}$ water field samples in the River Stour positive for Pacifastacus leniusculus (SC), and Eriocheir sinensis (MC) DNA.

\begin{tabular}{|c|c|c|}
\hline Fluorophore & Sample & Melt Temperature $\left({ }^{\circ} \mathrm{C}\right)$ \\
\hline SYBR & S_3A & 73.8 \\
\hline SYBR & $\mathrm{S} \_3 \mathrm{~A}$ & 73.6 \\
\hline SYBR & S_3A & 73.8 \\
\hline SYBR & S_3B & 73.4 \\
\hline SYBR & $S \_3 B$ & 73.4 \\
\hline SYBR & S_3B & 73.3 \\
\hline SYBR & S_1BL & None \\
\hline SYBR & S_1BL & None \\
\hline SYBR & S_1BL & None \\
\hline SYBR & S_2BL & None \\
\hline SYBR & S_2BL & None \\
\hline SYBR & S_2BL & None \\
\hline SYBR & S_3BL & None \\
\hline SYBR & S_3BL & None \\
\hline SYBR & S_3BL & None \\
\hline SYBR & PC_MC & 73.4 \\
\hline SYBR & PC_MC & 73.3 \\
\hline SYBR & PC_MC & 73.3 \\
\hline SYBR & PC_SC & 73.7 \\
\hline SYBR & PC_SC & 73.7 \\
\hline SYBR & PC_SC & 74.0 \\
\hline SYBR & MB & None \\
\hline SYBR & $\mathrm{MB}$ & None \\
\hline SYBR & MB & None \\
\hline
\end{tabular}

Sample ID: S_\# Stour catchment sample with corresponding subsample letter, PC_SC Signal crayfish positive DNA control, PC_MC Mitten crab positive DNA control, EB extraction blank, MB amplification blank 
Table S21. Melt peak data from SsoFast ${ }^{\mathrm{TM}}$ EvaGreen $^{\circledR}$ sediment field samples in the River Stour positive for Pacifastacus leniusculus (SC), and Eriocheir sinensis (MC) DNA.

\begin{tabular}{ccc}
\hline Fluorophore & Sample & Melt Temperature $\left({ }^{\circ}\right.$ C) \\
\hline SYBR & S_S_3B & 73.6 \\
SYBR & S_S_3B & 73.6 \\
SYBR & S_S_3D & 73.7 \\
SYBR & S_S_3D & 73.7 \\
SYBR & S_S_3E & 73.6 \\
SYBR & S_S_3E & 73.7 \\
SYBR & S_S_3E & 74.0 \\
SYBR & S_S_3F & 73.6 \\
SYBR & S_S_3F & 73.6 \\
SYBR & MB & None \\
SYBR & MB & None \\
SYBR & MB & None \\
SYBR & PC_MC & 73.4 \\
SYBR & PC_MC & 73.3 \\
SYBR & PC_MC & 73.3 \\
SYBR & PC_SC & 73.9 \\
SYBR & PC_SC & 74.0 \\
SYBR & PC_SC & 74.0
\end{tabular}

Sample ID: S_S_\# Stour catchment sample with corresponding subsample letter, PC_SC Signal crayfish positive DNA control, PC_MC Mitten crab positive DNA control, EB extraction blank, MB amplification blank 
Table S22. Melt peak data from SsoFast ${ }^{\mathrm{TM}}$ EvaGreen ${ }^{\circledR}$ water field samples in the River Dee positive for Pacifastacus leniusculus (SC), and Eriocheir sinensis (MC) DNA.

\begin{tabular}{|c|c|c|}
\hline Fluorophore & Sample & Melt Temperature $\left({ }^{\circ} \mathrm{C}\right)$ \\
\hline SYBR & D_1D & 73.9 \\
\hline SYBR & D_1D & 73.6 \\
\hline SYBR & D_7E & 73.9 \\
\hline SYBR & D_7E & 73.8 \\
\hline SYBR & D_9D & 73.5 \\
\hline SYBR & D_9D & 73.4 \\
\hline SYBR & D_9D & 73.3 \\
\hline SYBR & D_1BL & None \\
\hline SYBR & D_1BL & None \\
\hline SYBR & D_1BL & None \\
\hline SYBR & D_2BL & None \\
\hline SYBR & D_2BL & None \\
\hline SYBR & D_2BL & None \\
\hline SYBR & D_3BL & None \\
\hline SYBR & D_3BL & None \\
\hline SYBR & D_3BL & None \\
\hline SYBR & D_4BL & None \\
\hline SYBR & D_4BL & None \\
\hline SYBR & D_4BL & None \\
\hline SYBR & D_5BL & None \\
\hline SYBR & D_5BL & None \\
\hline SYBR & D_5BL & None \\
\hline SYBR & D_6BL & None \\
\hline SYBR & D_6BL & None \\
\hline SYBR & D_6BL & None \\
\hline SYBR & D_7BL & None \\
\hline SYBR & D_7BL & None \\
\hline SYBR & D_7BL & None \\
\hline SYBR & D_8BL & None \\
\hline SYBR & D_8BL & None \\
\hline
\end{tabular}




\begin{tabular}{|c|c|c|}
\hline SYBR & D_8BL & None \\
\hline SYBR & D_9BL & None \\
\hline SYBR & D_9BL & None \\
\hline SYBR & D_9BL & None \\
\hline SYBR & D_10BL & None \\
\hline SYBR & D_10BL & None \\
\hline SYBR & D_10BL & None \\
\hline SYBR & D_11BL & None \\
\hline SYBR & D_11BL & None \\
\hline SYBR & D_11BL & None \\
\hline SYBR & EB4 & None \\
\hline SYBR & EB4 & None \\
\hline SYBR & EB4 & None \\
\hline SYBR & EB5 & None \\
\hline SYBR & EB5 & None \\
\hline SYBR & EB5 & None \\
\hline SYBR & EB6 & None \\
\hline SYBR & EB6 & None \\
\hline SYBR & EB6 & None \\
\hline SYBR & MB & None \\
\hline SYBR & MB & None \\
\hline SYBR & MB & None \\
\hline SYBR & PC_MC & 73.5 \\
\hline SYBR & PC_MC & 73.5 \\
\hline SYBR & PC_MC & 73.5 \\
\hline SYBR & PC_SC & 73.7 \\
\hline SYBR & PC_SC & 73.7 \\
\hline SYBR & PC_SC & 74.0 \\
\hline
\end{tabular}

Sample ID: D_\# Dee catchment sample with corresponding subsample letter, PC_SC Signal crayfish positive DNA control, PC_MC Mitten crab positive DNA control, EB extraction blank, D_\#BL Dee site blank, EB\# extraction blank, MB amplification blank 
Table S23. Melt peak data from SsoFast ${ }^{\mathrm{TM}}$ EvaGreen ${ }^{\circledR}$ sediment field samples in the River Dee positive for Pacifastacus leniusculus (SC), and Eriocheir sinensis (MC) DNA.

\begin{tabular}{|c|c|c|}
\hline Fluorophore & Sample & Melt Temperature $\left({ }^{\circ} \mathrm{C}\right)$ \\
\hline SYBR & $\overline{D 1}$ 1_S_A & 73.9 \\
\hline SYBR & D1_S_A & 73.9 \\
\hline SYBR & D1_S_A & 73.9 \\
\hline SYBR & D1_S_B & 73.9 \\
\hline SYBR & D1_S_B & 73.8 \\
\hline SYBR & D1_S_B & 73.9 \\
\hline SYBR & D1_S_C & 73.7 \\
\hline SYBR & D1_S_C & 73.7 \\
\hline SYBR & D1_S_D & 73.7 \\
\hline SYBR & D1_S_D & 73.9 \\
\hline SYBR & D1_S_E & 74.0 \\
\hline SYBR & D1_S_E & 73.7 \\
\hline SYBR & D1_S_F & 74.0 \\
\hline SYBR & D1_S_F & 73.6 \\
\hline SYBR & D7_S_A & 73.2 \\
\hline SYBR & D7_S_A & 73.2 \\
\hline SYBR & D7_S_A & 73.3 \\
\hline SYBR & D7_S_C & 73.4 \\
\hline SYBR & D7_S_C & 73.4 \\
\hline SYBR & D8_S_A & 73.2 \\
\hline SYBR & D8_S_A & 73.4 \\
\hline SYBR & D8_S_B & 73.2 \\
\hline SYBR & D8_S_B & 73.2 \\
\hline SYBR & D8_S_B & 73.2 \\
\hline SYBR & D8_S_C & 73.8 \\
\hline SYBR & D8_S_C & 73.9 \\
\hline SYBR & D8_S_D & 73.6 \\
\hline
\end{tabular}




\begin{tabular}{|c|c|c|}
\hline SYBR & D8_S_D & 73.6 \\
\hline SYBR & D8_S_E & 73.3 \\
\hline SYBR & D8_S_E & 73.4 \\
\hline SYBR & D8_S_F & 73.7 \\
\hline SYBR & D8_S_F & 73.7 \\
\hline SYBR & D_BL1 & None \\
\hline SYBR & D_BL1 & None \\
\hline SYBR & D_BL1 & None \\
\hline SYBR & D_BL2 & None \\
\hline SYBR & D_BL2 & None \\
\hline SYBR & D_BL2 & None \\
\hline SYBR & D_BL3 & None \\
\hline SYBR & D_BL3 & None \\
\hline SYBR & D_BL3 & None \\
\hline SYBR & D_BL4 & None \\
\hline SYBR & D_BL4 & None \\
\hline SYBR & D_BL4 & None \\
\hline SYBR & MB & None \\
\hline SYBR & $\mathrm{MB}$ & None \\
\hline SYBR & MB & None \\
\hline SYBR & PC_MC & 73.4 \\
\hline SYBR & PC_MC & 73.4 \\
\hline SYBR & PC_MC & 73.5 \\
\hline SYBR & PC_SC & 73.7 \\
\hline SYBR & PC_SC & 73.8 \\
\hline SYBR & PC_SC & 73.8 \\
\hline
\end{tabular}

Sample ID: D\#_S Dee catchment sample with corresponding subsample letter, PC_SC Signal crayfish positive DNA control, PC_MC Mitten crab positive DNA control, EB extraction blank, D_BL\# Dee site blank, EB\# extraction blank, MB amplification blank 


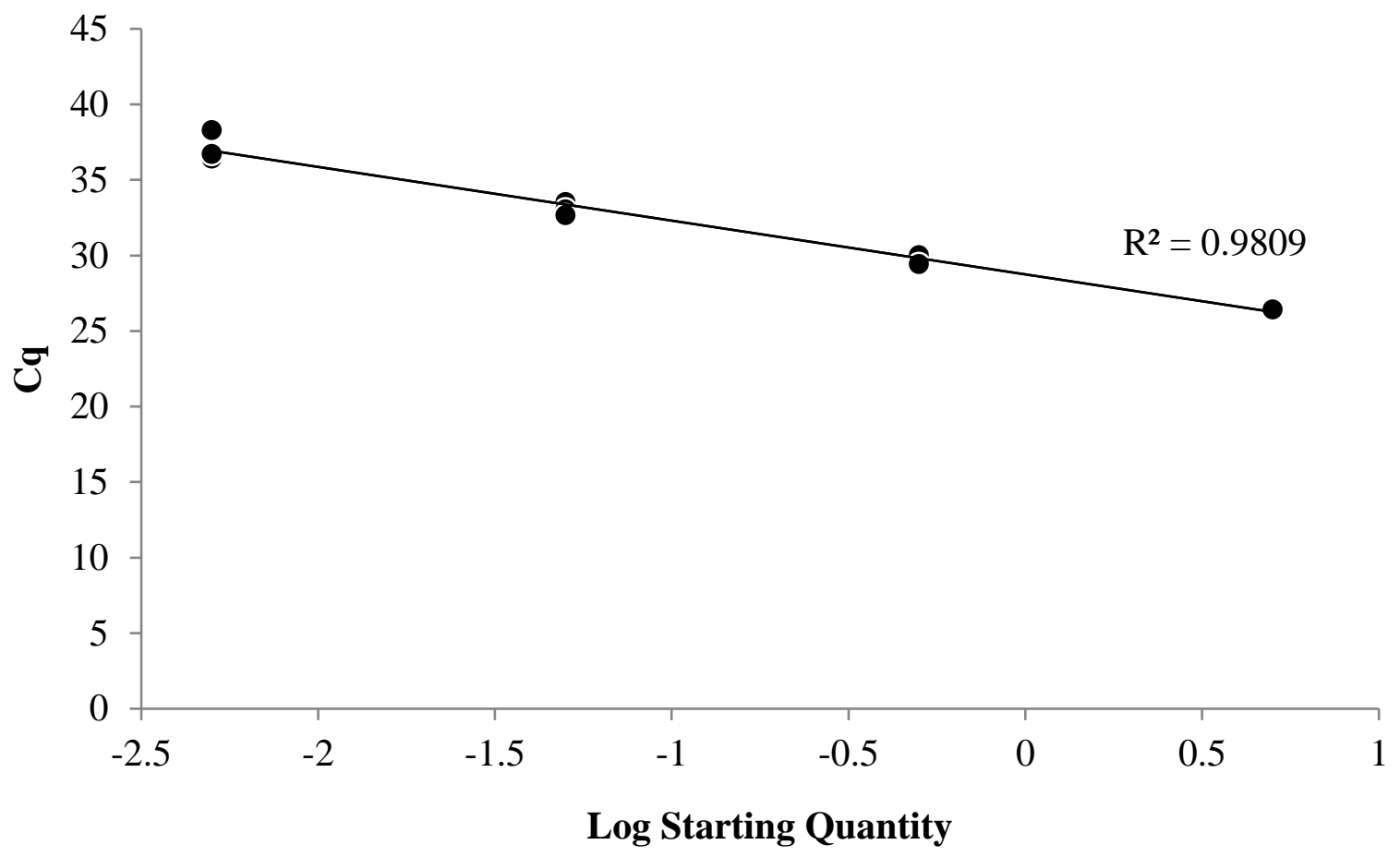

Figure S10. Efficiency curve from SsoFast ${ }^{\mathrm{TM}}$ EvaGreen ${ }^{\circledR}$ dilution series for Pseudorasbora parva DNA pool, starting at $5 \mathrm{ng} / \mu \mathrm{l}$ DNA concentration to $5 \times 10^{-7}$ $\mathrm{ng} / \mu \mathrm{l}$. 


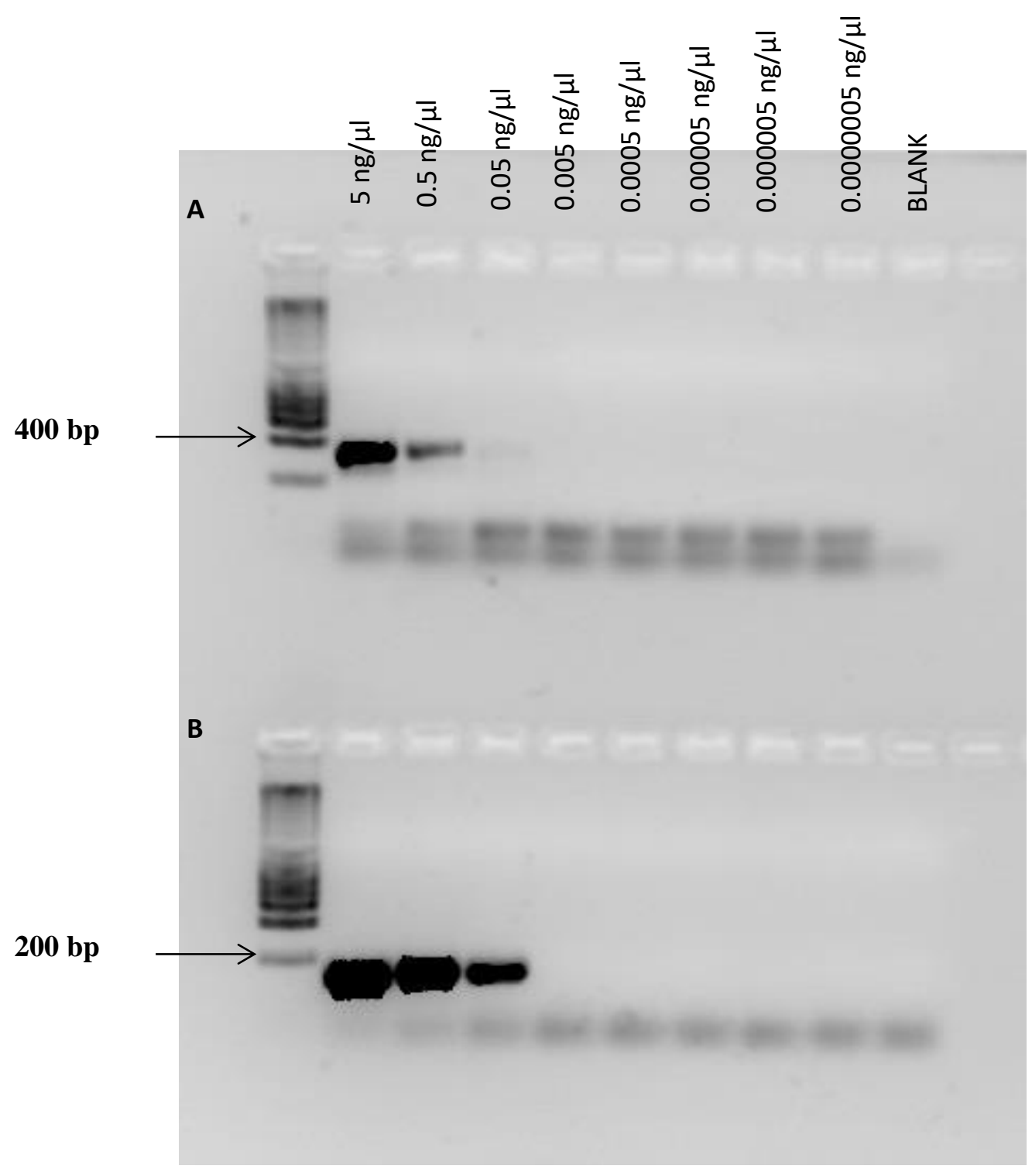

Figure S11. Gel electrophoresis output for end-point PCR 10-fold dilution series with COI primers (Davison et al., 2017; A) and designed Pparva16S primers (B). 
Table S24. Amplification data from SsoFast ${ }^{\mathrm{TM}}$ EvaGreen ${ }^{\circledR}$ dilution series for Pseudorasbora parva DNA pool.

\begin{tabular}{|c|c|c|c|c|c|c|c|}
\hline Fluor & Content & Concentration $(\mathrm{ng} / \mu \mathrm{l})$ & Sample & $\mathbf{C q}$ & $\begin{array}{l}\text { Cq } \\
\text { Mean }\end{array}$ & $\begin{array}{l}\text { Cq } \\
\text { Dev }\end{array}$ & Std. \\
\hline SYBR & Std-1 & 5 & TMG_pool & N/A & 0 & & 0 \\
\hline SYBR & Std-1 & 5 & TMG_pool & 26.36 & 26.32 & & 0.05 \\
\hline SYBR & Std-1 & 5 & TMG_pool & 26.28 & 26.32 & & 0.05 \\
\hline SYBR & Std-2 & 0.5 & TMG_pool & 29.67 & 29.6 & & 0.284 \\
\hline SYBR & Std-2 & 0.5 & TMG_pool & 29.85 & 29.6 & & 0.284 \\
\hline SYBR & Std-2 & 0.5 & TMG_pool & 29.29 & 29.6 & & 0.284 \\
\hline SYBR & Std-3 & 0.05 & TMG_pool & 33.38 & 32.93 & & 0.429 \\
\hline SYBR & Std-3 & 0.05 & TMG_pool & 32.88 & 32.93 & & 0.429 \\
\hline SYBR & Std-3 & 0.05 & TMG_pool & 32.53 & 32.93 & & 0.429 \\
\hline SYBR & Std-4 & 0.005 & TMG_pool & 38.16 & 37 & & 1.014 \\
\hline SYBR & Std-4 & 0.005 & TMG_pool & 36.28 & 37 & & 1.014 \\
\hline SYBR & Std-4 & 0.005 & TMG_pool & 36.56 & 37 & & 1.014 \\
\hline
\end{tabular}

Table S25. Melt curve data from SsoFast ${ }^{\mathrm{TM}}$ EvaGreen ${ }^{\circledR}$ qPCR amplifications of positive $750 \mathrm{~mL}$ field samples from Morolwg Pond, MP; Ashpits Pond, AP; Turbine Pond, TP and Dyfatty Pond, DP at each sampling point (P) for Pseudorasbora parva.

\begin{tabular}{ccccc}
\hline Sample & Melt Temperature & Peak Height & Begin Temperature & End Temperature \\
\hline MPP1 & None & None & None & None \\
MPP1 & 78.8 & 1382.24 & 74.1 & 80.4 \\
MPP1 & 78.8 & 1564.81 & 75.6 & 80.3 \\
MPP2 & 78.8 & 686.29 & 74.6 & 80.7 \\
MPP2 & 78.7 & 1458.3 & 75.6 & 80.8 \\
MPP2 & 78.7 & 1334.47 & 75.2 & 80.8 \\
MPP3 & 78.8 & 2263.07 & 73.3 & 80.7 \\
MPP3 & 78.7 & 2455.5 & 73.5 & 80.9 \\
MPP3 & 78.7 & 2916.66 & 73.3 & 80.4 \\
MPP4 & 78.7 & 457.99 & 77.2 & 80 \\
MPP4 & None & None & None & None \\
MPP4 & 79.4 & 419.18 & 79.1 & 80.7 \\
\hline
\end{tabular}




\begin{tabular}{|c|c|c|c|c|}
\hline MPP5 & 79 & 1844.79 & 73.7 & 81 \\
\hline MPP5 & 78.8 & 1980.32 & 73.8 & 80.5 \\
\hline MPP5 & 78.8 & 1948.93 & 74.1 & 80.5 \\
\hline MPP6 & 78.7 & 1009.06 & 76.2 & 80.4 \\
\hline MPP6 & 78.6 & 1450.87 & 75.1 & 80.1 \\
\hline MPP6 & 78.6 & 1567.75 & 74.1 & 80.1 \\
\hline MPP7 & 78.6 & 1270.03 & 74.7 & 80.5 \\
\hline MPP7 & 78.5 & 1760.27 & 74.3 & 80.4 \\
\hline MPP7 & 78.5 & 1951.74 & 74.8 & 80.1 \\
\hline MPP8 & None & None & None & None \\
\hline MPP8 & 78.5 & 1590.32 & 75.2 & 80.1 \\
\hline MPP8 & None & None & None & None \\
\hline MPP9 & None & None & None & None \\
\hline MPP9 & None & None & None & None \\
\hline MPP9 & None & None & None & None \\
\hline MPP10 & 78.7 & 1144.19 & 75.2 & 80.1 \\
\hline MPP10 & 78.7 & 1641.57 & 75.2 & 80.7 \\
\hline MPP10 & 78.6 & 1467.49 & 74.3 & 80.4 \\
\hline APP1 & None & None & None & None \\
\hline APP1 & None & None & None & None \\
\hline APP1 & 78.7 & 922.13 & 77.1 & 80 \\
\hline APP2 & 78.8 & 2016.6 & 73.7 & 80.5 \\
\hline APP2 & 78.8 & 2098.51 & 76.2 & 80.5 \\
\hline APP2 & 78.8 & 2348.39 & 74.3 & 80.5 \\
\hline APP3 & None & None & None & None \\
\hline APP3 & None & None & None & None \\
\hline APP3 & None & None & None & None \\
\hline APP4 & 78.7 & 1087.3 & 75.7 & 80.1 \\
\hline APP4 & 78.6 & 1405.5 & 75.4 & 80.5 \\
\hline APP4 & None & None & None & None \\
\hline APP5 & None & None & None & None \\
\hline APP5 & None & None & None & None \\
\hline APP5 & None & None & None & None \\
\hline APP6 & 78.7 & 1238.33 & 77.1 & 80.2 \\
\hline APP6 & 78.7 & 1119.73 & 74.7 & 80.6 \\
\hline APP6 & 79.1 & 1117.57 & 75.9 & 80.5 \\
\hline APP7 & None & None & None & None \\
\hline APP7 & 79 & 1526.71 & 74.5 & 81.2 \\
\hline
\end{tabular}




\begin{tabular}{|c|c|c|c|c|}
\hline APP7 & 79.1 & 1631.21 & 75.6 & 80.8 \\
\hline APP8 & None & None & None & None \\
\hline APP8 & None & None & None & None \\
\hline APP8 & 78.7 & 1230.85 & 76.1 & 80.4 \\
\hline APP9 & 78.7 & 1858.93 & 74.7 & 80.5 \\
\hline APP9 & 78.8 & 1911.83 & 74.7 & 80.4 \\
\hline APP9 & 78.6 & 1905.34 & 75.1 & 80.6 \\
\hline APP10 & 78.7 & 1626.21 & 75.2 & 80.3 \\
\hline APP10 & 78.7 & 1424.01 & 74.6 & 81.2 \\
\hline APP10 & 78.6 & 1728.19 & 74.7 & 80.4 \\
\hline ТPP1 & None & None & None & None \\
\hline TPP1 & None & None & None & None \\
\hline TPP1 & None & None & None & None \\
\hline TPP2 & 78.7 & 444.78 & 75.4 & 80.2 \\
\hline TPP2 & None & None & None & None \\
\hline TPP2 & 78.8 & 1706.65 & 74.6 & 80.5 \\
\hline TPP3 & None & None & None & None \\
\hline TPP3 & None & None & None & None \\
\hline TPP3 & None & None & None & None \\
\hline TPP4 & 78.7 & 2239.13 & 74.6 & 80.6 \\
\hline TPP4 & 78.7 & 2239.2 & 74.2 & 80.8 \\
\hline TPP4 & 78.7 & 2113.4 & 74.1 & 80.8 \\
\hline TPP5 & 78.6 & 1875.08 & 74.4 & 80.7 \\
\hline TPP5 & 78.7 & 2318.02 & 74.8 & 80.6 \\
\hline TPP5 & 78.8 & 2029.71 & 75.3 & 80.3 \\
\hline TPP6 & 78.8 & 1744.25 & 74.1 & 80.5 \\
\hline TPP6 & 78.7 & 2178.47 & 74.1 & 80.6 \\
\hline TPP6 & 78.7 & 1404.07 & 75.2 & 80.4 \\
\hline TPP7 & None & None & None & None \\
\hline TPP7 & None & None & None & None \\
\hline TPP7 & None & None & None & None \\
\hline TPP8 & None & None & None & None \\
\hline TPP8 & None & None & None & None \\
\hline TPP8 & None & None & None & None \\
\hline ТРP9 & 79.1 & 830.62 & 77.1 & 80.4 \\
\hline ТРP9 & 78.7 & 1065.52 & 75.1 & 80.5 \\
\hline ТРP9 & None & None & None & None \\
\hline ТPP10 & 78.8 & 1163.54 & 74.9 & 80.7 \\
\hline
\end{tabular}




\begin{tabular}{|c|c|c|c|c|}
\hline TPP10 & 78.7 & 1344.09 & 74.6 & 80.7 \\
\hline TPP10 & 78.8 & 1023.41 & 74.4 & 80.7 \\
\hline DPP1 & None & None & None & None \\
\hline DPP1 & 79.1 & 1186.12 & 76.3 & 80.7 \\
\hline DPP1 & 78.8 & 1143.57 & 75.7 & 80.1 \\
\hline DPP2 & 78.8 & 1235.97 & 75.1 & 80.1 \\
\hline DPP2 & 79 & 1300.56 & 76.5 & 80.6 \\
\hline DPP2 & 78.8 & 1365.41 & 75.1 & 80.7 \\
\hline DPP3 & None & None & None & None \\
\hline DPP3 & None & None & None & None \\
\hline DPP3 & None & None & None & None \\
\hline DPP4 & 78.7 & 2327.73 & 73.7 & 80.5 \\
\hline DPP4 & 78.8 & 2039.45 & 74.5 & 80.9 \\
\hline DPP4 & 79.5 & 1190.27 & 75.3 & 80.7 \\
\hline DPP5 & None & None & None & None \\
\hline DPP5 & 78.7 & 1305.95 & 75.7 & 80 \\
\hline DPP5 & 79.1 & 888.61 & 76.7 & 80.6 \\
\hline DPP6 & 78.8 & 2016.19 & 74.8 & 80.5 \\
\hline DPP6 & 79 & 396.32 & 77.4 & 80.1 \\
\hline DPP6 & None & None & None & None \\
\hline DPP7 & None & None & None & None \\
\hline DPP7 & None & None & None & None \\
\hline DPP7 & None & None & None & None \\
\hline DPP8 & 78.8 & 1325.54 & 74.6 & 80.7 \\
\hline DPP8 & 78.7 & 876.47 & 75.4 & 80.6 \\
\hline DPP8 & 79.1 & 1417.68 & 74.3 & 80.7 \\
\hline DPP9 & 79.1 & 1275.43 & 74.2 & 81.2 \\
\hline DPP9 & 79.1 & 1280.49 & 74.4 & 80.9 \\
\hline DPP9 & 79.1 & 1457.15 & 73.8 & 81.4 \\
\hline DPP10 & 78.9 & 729.93 & 76.1 & 80.3 \\
\hline DPP10 & 78.6 & 1031.94 & 74.7 & 80.6 \\
\hline DPP10 & 78.5 & 797.48 & 75.5 & 80 \\
\hline MPB0 & None & None & None & None \\
\hline МРB0 & None & None & None & None \\
\hline MPB0 & None & None & None & None \\
\hline MPBL1 & None & None & None & None \\
\hline MPBL1 & None & None & None & None \\
\hline MPBL1 & None & None & None & None \\
\hline
\end{tabular}




\begin{tabular}{|c|c|c|c|c|}
\hline APBL1 & None & None & None & None \\
\hline APBL1 & None & None & None & None \\
\hline APBL1 & None & None & None & None \\
\hline TPBL1 & None & None & None & None \\
\hline TPBL1 & None & None & None & None \\
\hline TPBL1 & None & None & None & None \\
\hline DPBL1 & None & None & None & None \\
\hline DPBL1 & None & None & None & None \\
\hline DPBL1 & None & None & None & None \\
\hline FB1 & None & None & None & None \\
\hline FB1 & None & None & None & None \\
\hline FB2 & None & None & None & None \\
\hline FB2 & None & None & None & None \\
\hline FB2 & None & None & None & None \\
\hline EB & None & None & None & None \\
\hline EB & None & None & None & None \\
\hline EB & None & None & None & None \\
\hline $\mathrm{AB}$ & None & None & None & None \\
\hline $\mathrm{AB}$ & None & None & None & None \\
\hline $\mathrm{AB}$ & None & None & None & None \\
\hline PC_TMG & 79 & 1605.57 & 74.5 & 80.8 \\
\hline PC_TMG & 78.9 & 1595.56 & 74.8 & 81 \\
\hline PC_TMG & 78.9 & 1552.06 & 74.6 & 81 \\
\hline
\end{tabular}

FB: filter blank, EB: extraction blank, AB: amplification blank, PC: positive control

Table S26. Melt curve data from SsoFast ${ }^{\mathrm{TM}}$ EvaGreen ${ }^{\circledR}$ qPCR amplifications of $15 \mathrm{~mL}$ field samples from Morolwg Pond, MP; Ashpits Pond, AP; Turbine Pond, TP and Dyfatty Pond, DP at each sampling point (P) for Pseudorasbora parva.

\begin{tabular}{ccccc}
\hline Sample & Melt Temperature & Peak Height & Begin Temperature & End Temperature \\
\hline MPP1 & None & None & None & None \\
MPP1 & None & None & None & None \\
MPP1 & None & None & None & None \\
MPP2 & None & None & None & None \\
MPP2 & None & None & None & None \\
MPP2 & None & None & None & None \\
\hline
\end{tabular}




\begin{tabular}{|c|c|c|c|c|}
\hline MPP3 & None & None & None & None \\
\hline MPP3 & None & None & None & None \\
\hline MPP3 & None & None & None & None \\
\hline MPP4 & None & None & None & None \\
\hline MPP4 & 78.5 & 1514.93 & 74.8 & 80.5 \\
\hline MPP4 & 78.7 & 1033.39 & 76.4 & 80.2 \\
\hline MPP5 & None & None & None & None \\
\hline MPP5 & None & None & None & None \\
\hline MPP5 & None & None & None & None \\
\hline MPP6 & None & None & None & None \\
\hline MPP6 & None & None & None & None \\
\hline MPP6 & None & None & None & None \\
\hline MPP7 & 78.7 & 1316.49 & 74.5 & 80.3 \\
\hline MPP7 & None & None & None & None \\
\hline MPP7 & None & None & None & None \\
\hline MPP8 & None & None & None & None \\
\hline MPP8 & None & None & None & None \\
\hline MPP8 & None & None & None & None \\
\hline MPP9 & None & None & None & None \\
\hline MPP9 & None & None & None & None \\
\hline MPP9 & None & None & None & None \\
\hline MPP10 & None & None & None & None \\
\hline MPP10 & 78.8 & 940.45 & 74 & 81.1 \\
\hline MPP10 & None & None & None & None \\
\hline APP1 & None & None & None & None \\
\hline APP1 & 78.6 & 1050.41 & 76.4 & 80.4 \\
\hline APP1 & None & None & None & None \\
\hline APP2 & None & None & None & None \\
\hline APP2 & None & None & None & None \\
\hline APP2 & None & None & None & None \\
\hline APP3 & None & None & None & None \\
\hline APP3 & None & None & None & None \\
\hline APP3 & None & None & None & None \\
\hline APP4 & None & None & None & None \\
\hline APP4 & 78.6 & 1085.79 & 75.6 & 80.2 \\
\hline APP4 & 78.6 & 1155.02 & 75.5 & 80.2 \\
\hline APP5 & None & None & None & None \\
\hline APP5 & None & None & None & None \\
\hline
\end{tabular}




\begin{tabular}{|c|c|c|c|c|}
\hline APP5 & None & None & None & None \\
\hline APP6 & None & None & None & None \\
\hline APP6 & 78.5 & 1132.17 & 75.4 & 80.1 \\
\hline APP6 & None & None & None & None \\
\hline APP7 & None & None & None & None \\
\hline APP7 & None & None & None & None \\
\hline APP7 & None & None & None & None \\
\hline APP8 & None & None & None & None \\
\hline APP8 & None & None & None & None \\
\hline APP8 & None & None & None & None \\
\hline APP9 & None & None & None & None \\
\hline APP9 & None & None & None & None \\
\hline APP9 & None & None & None & None \\
\hline APP10 & None & None & None & None \\
\hline APP10 & None & None & None & None \\
\hline APP10 & None & None & None & None \\
\hline TPP1 & None & None & None & None \\
\hline TPP1 & None & None & None & None \\
\hline TPP1 & None & None & None & None \\
\hline TPP2 & 78.6 & 1371.57 & 75.3 & 80.6 \\
\hline TPP2 & 78.6 & 731.96 & 76.5 & 80.1 \\
\hline TPP2 & None & None & None & None \\
\hline TPP3 & None & None & None & None \\
\hline ТРP3 & None & None & None & None \\
\hline ТРP3 & None & None & None & None \\
\hline TPP4 & None & None & None & None \\
\hline TPP4 & None & None & None & None \\
\hline TPP4 & None & None & None & None \\
\hline TPP5 & None & None & None & None \\
\hline TPP5 & None & None & None & None \\
\hline TPP5 & None & None & None & None \\
\hline TPP6 & None & None & None & None \\
\hline TPP6 & 78.5 & 1446.08 & 74.8 & 80.1 \\
\hline TPP6 & 78.6 & 1316.45 & 75.3 & 80.2 \\
\hline TPP7 & None & None & None & None \\
\hline TPP7 & None & None & None & None \\
\hline TPP7 & None & None & None & None \\
\hline ТРP8 & None & None & None & None \\
\hline
\end{tabular}




\begin{tabular}{|c|c|c|c|c|}
\hline TPP8 & None & None & None & None \\
\hline TPP8 & None & None & None & None \\
\hline ТPP9 & None & None & None & None \\
\hline ТPР9 & None & None & None & None \\
\hline ТРP9 & None & None & None & None \\
\hline ТPP10 & None & None & None & None \\
\hline ТРP10 & None & None & None & None \\
\hline ТРP10 & None & None & None & None \\
\hline DPP1 & None & None & None & None \\
\hline DPP1 & None & None & None & None \\
\hline DPP1 & None & None & None & None \\
\hline DPP2 & None & None & None & None \\
\hline DPP2 & None & None & None & None \\
\hline DPP2 & None & None & None & None \\
\hline DPP3 & None & None & None & None \\
\hline DPP3 & None & None & None & None \\
\hline DPP3 & None & None & None & None \\
\hline DPP4 & None & None & None & None \\
\hline DPP4 & None & None & None & None \\
\hline DPP4 & None & None & None & None \\
\hline DPP5 & None & None & None & None \\
\hline DPP5 & None & None & None & None \\
\hline DPP5 & None & None & None & None \\
\hline DPP6 & None & None & None & None \\
\hline DPP6 & None & None & None & None \\
\hline DPP6 & None & None & None & None \\
\hline DPP7 & None & None & None & None \\
\hline DPP7 & None & None & None & None \\
\hline DPP7 & None & None & None & None \\
\hline DPP8 & None & None & None & None \\
\hline DPP8 & None & None & None & None \\
\hline DPP8 & None & None & None & None \\
\hline DPP9 & None & None & None & None \\
\hline DPP9 & None & None & None & None \\
\hline DPP9 & None & None & None & None \\
\hline DPP10 & None & None & None & None \\
\hline DPP10 & None & None & None & None \\
\hline DPP10 & None & None & None & None \\
\hline
\end{tabular}




\begin{tabular}{ccccc}
\hline PC_TMG & 79.1 & 1991.82 & 74.5 & 80.8 \\
PC_TMG & 79 & 1825.98 & 74.5 & 80.7 \\
PC_TMG & 79.1 & 1851.12 & 75.3 & 80.8 \\
AB & None & None & None & None \\
AB & None & None & None & None \\
AB & None & None & None & None
\end{tabular}

$\overline{\text { FB: filter blank, EB: extraction blank, AB: amplification blank, PC: positive control }}$

Table S27. Probability of detection (binomial proportions, $95 \mathrm{CI}$ ) of topmouth gudgeon (Pseudorasbora parva) at different spatial scales using a traditional PCR method and the novel qPCR assay with different volumes of water.

\begin{tabular}{|c|c|c|c|c|}
\hline \multirow[b]{2}{*}{ Method } & \multirow{2}{*}{$\begin{array}{r}\text { Water } \\
\text { volume } \\
(\mathbf{m L})\end{array}$} & \multicolumn{3}{|c|}{ Probability of detection } \\
\hline & & $\begin{array}{l}\text { Pond } \\
\text { (n:4) }\end{array}$ & $\begin{array}{c}\text { Site } \\
(n: 40)\end{array}$ & $\begin{array}{l}\text { Sample } \\
\text { (n:120) }\end{array}$ \\
\hline qPCR & 750 & $1.00(0.40-1.00)$ & $\begin{array}{c}0.78(0.62- \\
0.89)\end{array}$ & $0.63(0.54-0.72)$ \\
\hline PCR & 750 & $1.00(0.40-1.00)$ & $\begin{array}{c}0.35(0.21- \\
0.52)\end{array}$ & $0.15(0.09-0.23)$ \\
\hline qPCR & 15 & $0.75(0.20-0.99)$ & $\begin{array}{c}0.20(0.09- \\
0.36)\end{array}$ & $0.10(0.05-0.17)$ \\
\hline
\end{tabular}




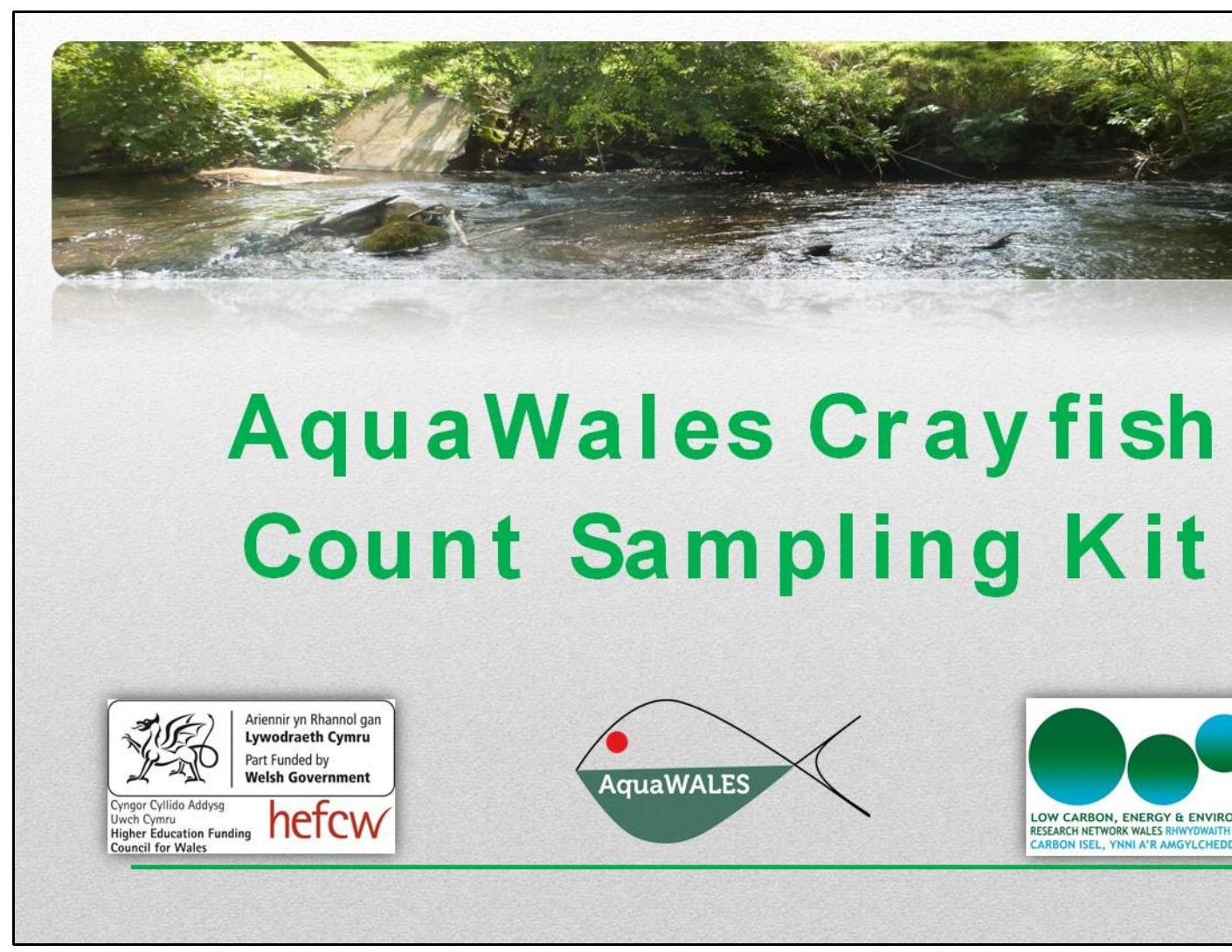

Figure S12. Cover page for Crayfish Count kit. 


\section{CONTENTS}

Page 2: Sampling protocol

Page 3: Spot guide \& marking sheet

Page 4: Signal crayfish ID features

Page 5: Signal crayfish \& White-clawed crayfish ID

Page 6: Sightings recording sheet

Page 7: Aqualnvaders smartphone app guide

Page 8: Aqualnvaders website guide

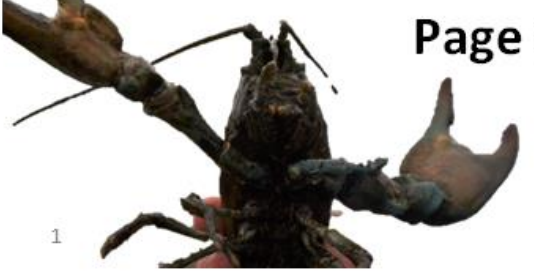

Page 9: Participation sheet

Figure S13. Contents page for crayfish count kit. 


\section{Sampling Protocol}

Field Sampling:

1. Begin rock turning (gently) to search for crayfish - please return rocks wher

2. If any crayfish are seen, then carefully remove crayfish and take photograp guide on page 7) or via camera and upload to computer to submit (page 8) distinguishing areas in the photograph (red underside of claws/pale blue $\mathrm{c}$ guide page $4 \& 5$

3. Assess the crayfish for dark spots (particularly abdomen); note number (if paper form overleaf (page 3 ) and take a swab of these patches

\section{After sampling:}

4. Submit any sightings via app if using the app, ensuring all data is included a possible and also record required information down onto form attached ( $p$

5. Return swabs to return address along with this information pack

6. Remember to disinfect and dry footwear on leaving the river to prevent $\mathrm{sp}$ diseases being carried by signal crayfish to our native crayfish populations

NOTE: IF you find a NATIVE white clawed crayfish, return to the water $\mathrm{i}$ guide)

Figure S14. Sampling protocol detailing instructions for field sampling and handling of samples. 


\section{Spot Mark Sheet \& Guide}

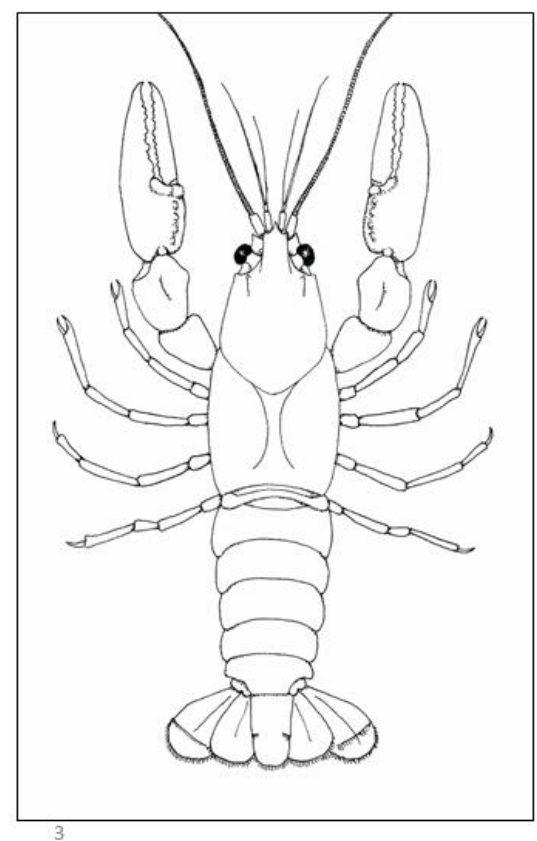

1. Observe top-side and under-side of crayfish-especially abdomen

2. Record any presence of spots and number overleaf

3. Mark on any dark spots you observe on the crayfish (top-side or under-side) on these diagrams

4. Use the space below to add

additional information/comments

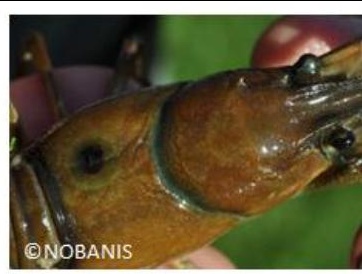

Notes:

Figure S15. Recording sheet for marking dark spots on crayfish found, complete with protocol and 


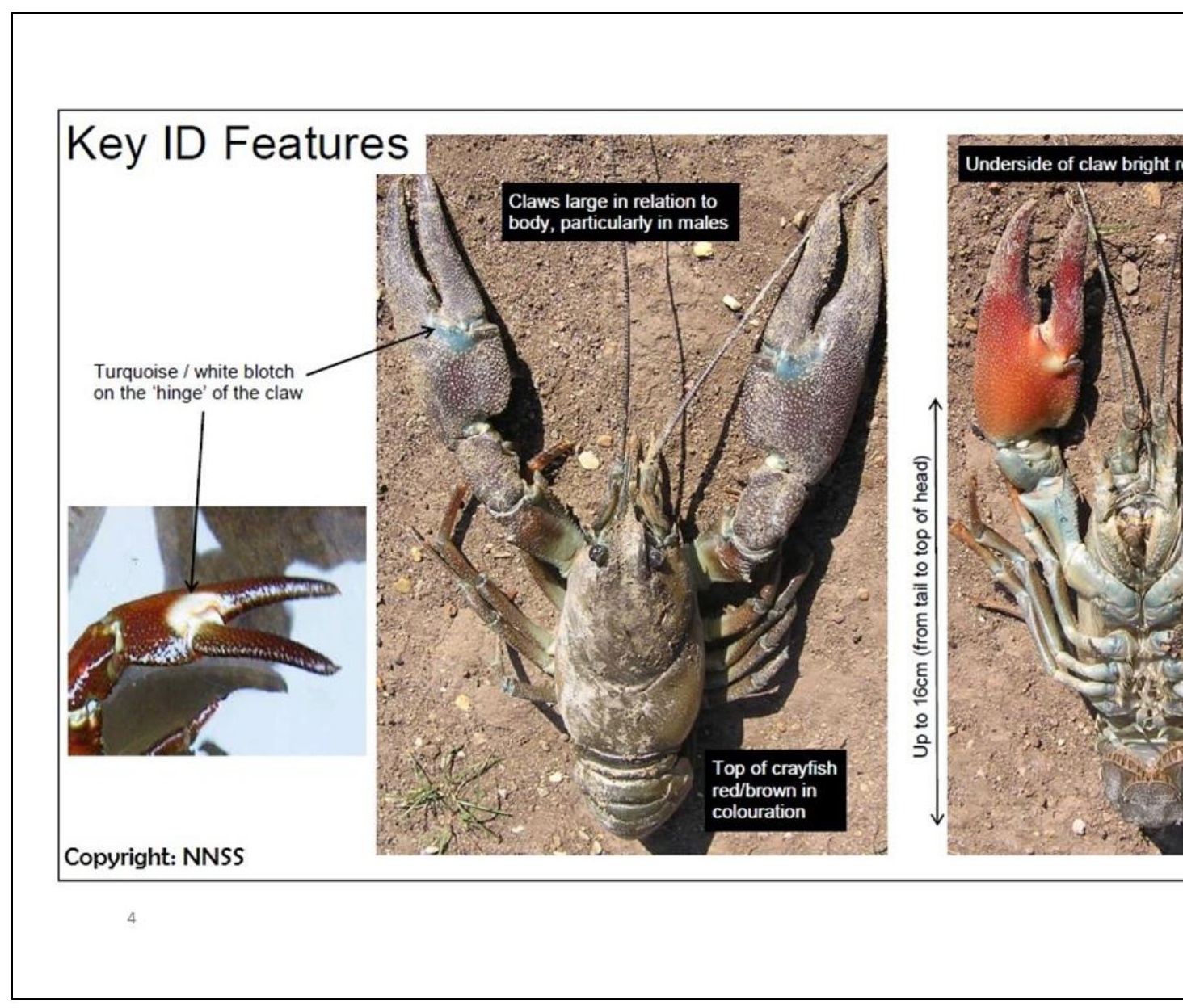

Figure S16. Key identification features for signal crayfish, including claw colour, size and general c carapace (CNNSS). 


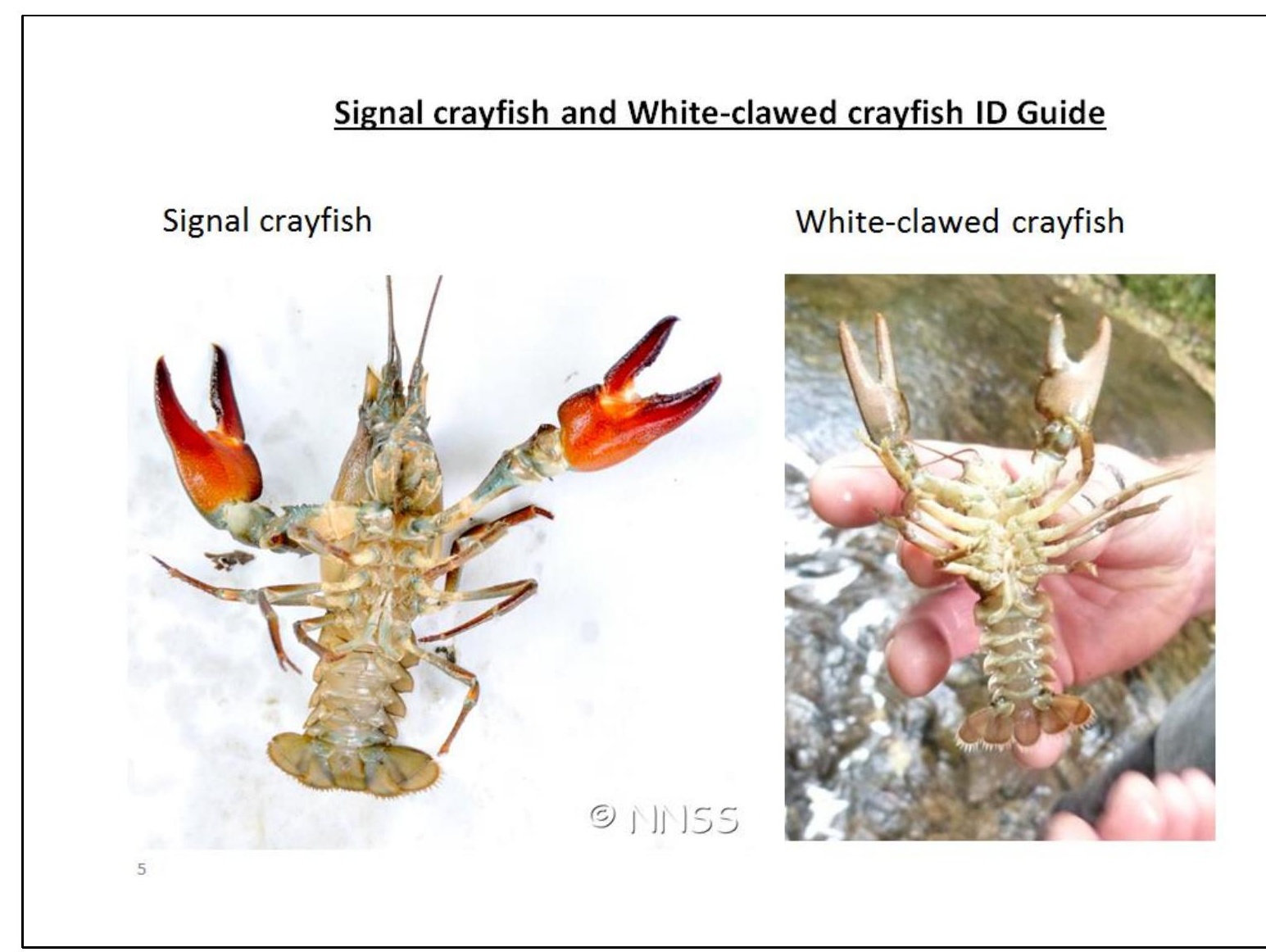

Figure S17. Key identification features of the underside of signal crayfish and white-clawed crayfist and to avoid endangered white-clawed crayfish being sampled. 


\section{Recording sheet}

1. General information

\begin{tabular}{|c|c|c|c|c|c|c|}
\hline \multirow{2}{*}{ EXAMPLE } & $\begin{array}{c}\text { Survey Group } \\
\text { Size }\end{array}$ & Date & Location & GPS Location & Time (GMT) \\
\cline { 2 - 7 } & Chloe Robinson & 2 & 21.01 .17 & River Edu & S0 09876 67453 & $11: 59$ AM \\
\hline & & & & & \\
\hline & & & & & \\
\hline
\end{tabular}

\section{Sighting information}

\begin{tabular}{|c|c|c|c|c|c|c|c|}
\hline \multicolumn{3}{|c|}{ Species Found (please tick) } & \multicolumn{3}{|c|}{ Certainty (please tick) } & \multirow[b]{2}{*}{$\begin{array}{l}\text { Number of } \\
\text { individuals }\end{array}$} & \multirow[b]{2}{*}{$\begin{array}{c}\text { Photo taken } \\
(\mathrm{Y} / \mathrm{N})\end{array}$} \\
\hline $\begin{array}{c}\text { Signal } \\
\text { crayfish }\end{array}$ & $\begin{array}{c}\text { White-clawed } \\
\text { crayfish }\end{array}$ & $\begin{array}{c}\text { Other } \\
\text { crayfish }\end{array}$ & $<50 \%$ & $50-100 \%$ & $100 \%$ & & \\
\hline$x$ & & & & & $x$ & 1 & $Y$ \\
\hline & & & & & & & \\
\hline & & & & & & & \\
\hline
\end{tabular}

3. Swab ID and Effort Time

\begin{tabular}{|c|c|c|c|c|c|}
\hline \multirow[b]{2}{*}{ Swab ID } & \multicolumn{4}{|c|}{$\begin{array}{c}\text { Effort time (in minutes - please } \\
\text { tick) }\end{array}$} & \multirow[b]{2}{*}{ Comments/Extra Information } \\
\hline & $<5$ & 5 to 10 & 20 to 30 & $30+$ & \\
\hline CR21.01.16 & & $\mathrm{x}$ & & & Crayfish missing one claw \\
\hline & & & & & \\
\hline & & & & & \\
\hline
\end{tabular}

Notes:

Survey group If alone $=1$, if with others state how many

Certainty How certain you are that it is the species you state it to be

Dark spots How many (if any) dark spots are on crayfish

Effort time How long survey has been at time of sighting/how long you have been in the water before you sight a crayfish

Swab ID Your initials followed by the date - i.e. CR16.03.17

Comments Any extra info-e.g. crayfish behaviour, associated species ets

6

Figure S18. Recording sheet for signal crayfish sightings including example recording (in red). 


\section{Guide to using aquainvaders smartphone app}

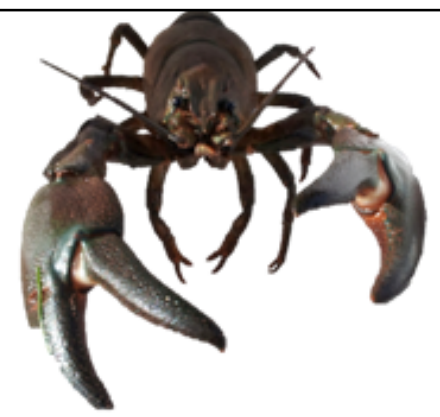

1. Download the app for free from Google Play (for androids) or the App Store (for iPhone)

2. Register with the app - it's simple! Click on 'create an account' at the bottom of the screen -You just need to add your name, email and create a password

3. Once signed up you are ready to record! When recording a sighting, scroll down until you see the species you want to record and click on it

4. Click on 'Photo Evidence' to add your photo of the suspected invasive species to the recording

5. Click on 'Location' to log where you have spotted the species (most phones automatically find your location with GPS, but you can alternatively add a location yourself via map/text)

6. Click on 'Site name' and add a site name for your location

7. Click on 'Number' and select the number of individuals of the species you have seen

8. You can also add any notes/extra information about the sighting by clicking on 'Add a note'

9. Finally, check all of the information is entered and is correct and click on 'Submit sighting'

Note: There is an ID guide integrated within the app - if you are unsure about a sighting, click the 'ID Guide' in the top right hand corner to help you determine the species
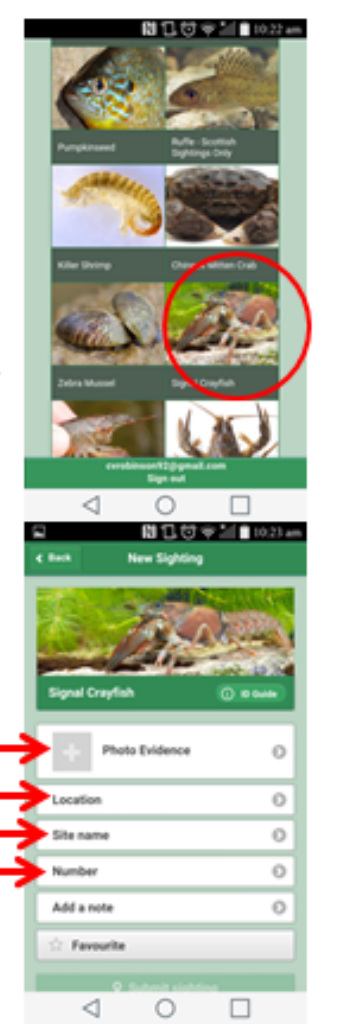

Figure S19. Guide for use of Aquainvaders smartphone app, including step-by-step guide on submitting recordings and screenshots to help assist with navigating the app. 


\section{Guide to using aquainvaders website}

Similarly to the app, you can record sightings of invasive species via the aquainvaders website

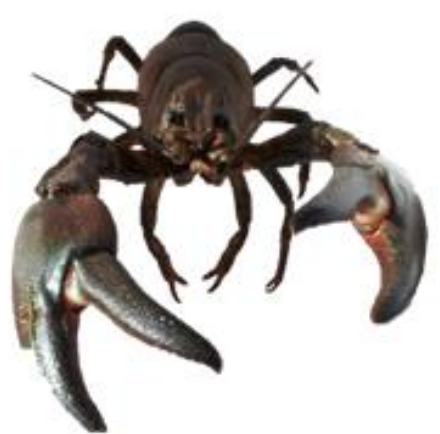

1. Visit the aquainvaders webpage: $w w w$ wbrc.ac.uk/aquainvaders/home

2. Click on 'add record' at the top of the page

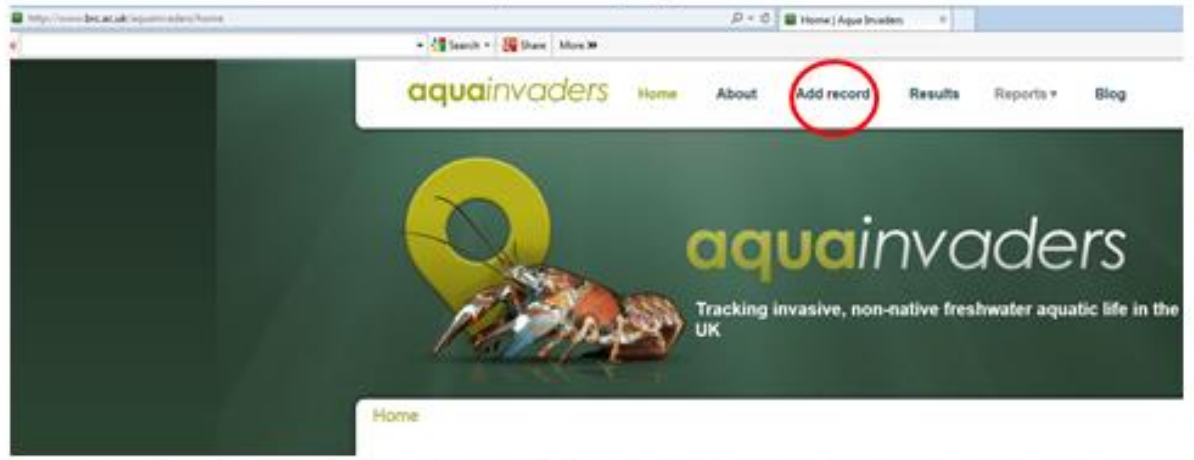

3. Write the date in the top box and then start typing the species you saw under the heading 'Species'

4. Next, select the number of individuals and add any comments/extra info

$$
\text { aquainvaders Home About Addrecord Results Reports * Blog }
$$
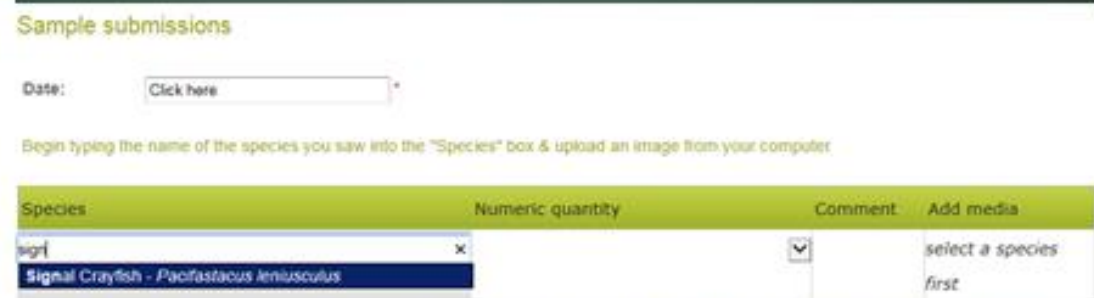

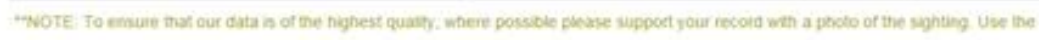

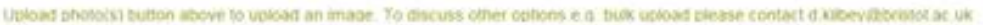

5. Add photos you have taken of the invasive species in the 'Add media' column

6. Finally, select on the map where you had the sighting (or enter spatial ref. manually), add your name and email and click on 'Submit'

Figure S20. Guide for use of Aquainvaders website, including step-by-step guide on submitting recordings and screenshots to help assist with navigating the website. 


\section{Participation sheet}

Q1. Name (N/A if wish to remain anonymous):

Q2. Contact email number (N/A if wish to remain anonymous):

Q3. Age (please tick category):

$\begin{array}{ccccc}\square & \square & \square & \square & \square \\ 18 \text { or under } & 18-30 & \square 1-50 & 51-60 & 61+\end{array}$

Q4. Education level (please tick category):

$$
\begin{gathered}
\text { Secondary school } \\
\text { (GCSE/O-level) }
\end{gathered}
$$

Q5. Occupation (N/A if wish to remain anonymous):

Q6. Are you an angler? (Please tick) If NO, please proceed to Q8.

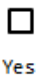

$\square$

No

Q7. How often do you fish? (Please tick category)

Less than on month

Every 2 weeks

Q8. Would you be interested in getting involved with other citizen science projects? (Pleas

Figure S21. Participation sheet to be filled out by individuals which have collected samples to $g$ fishing frequency and interest towards future citizen science project. 


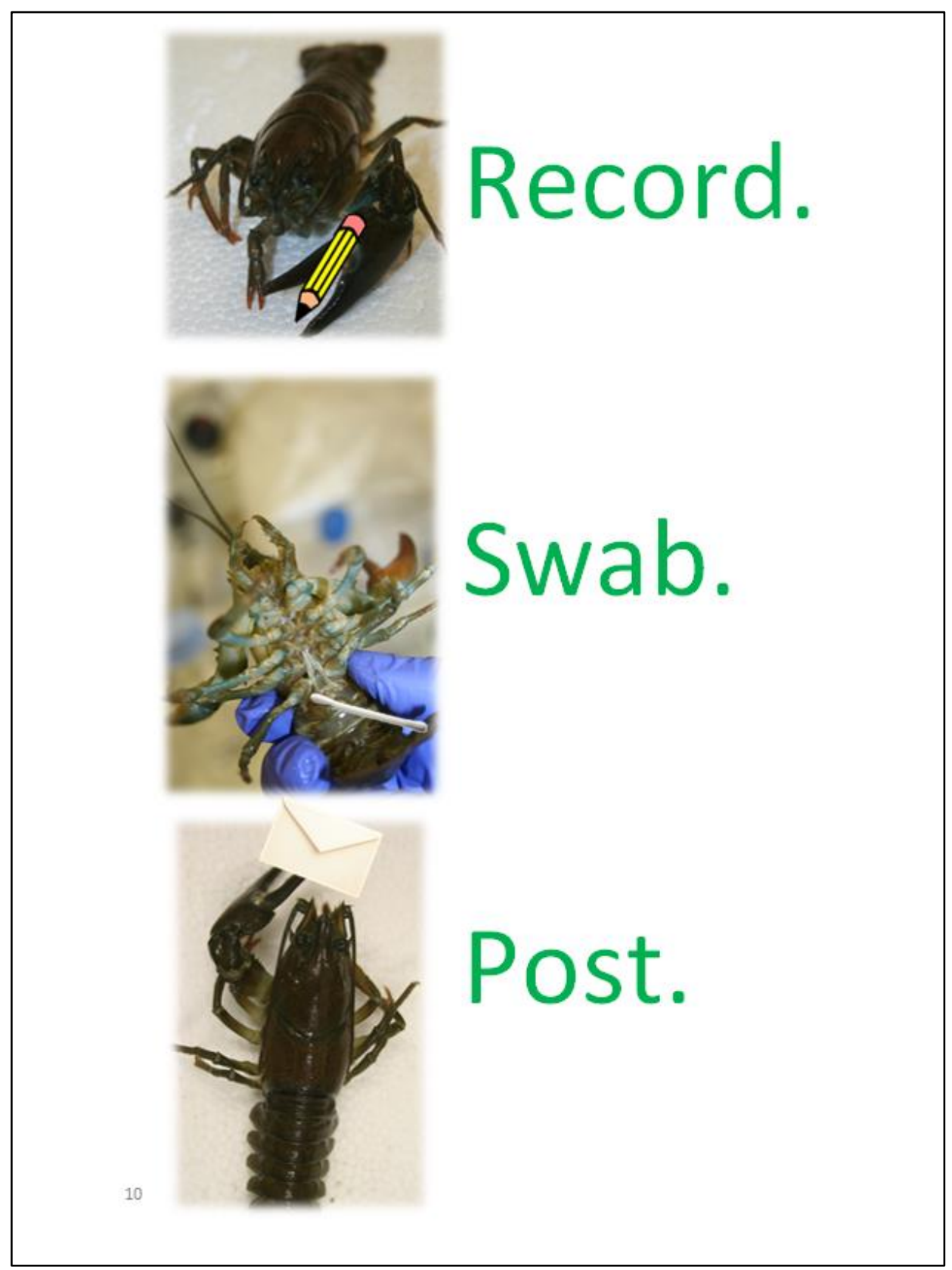

Figure S22. Short phrase 'Swab. Record. Post' with pictures on back page of Crayfish Count kit. 
Motivation for Participation in Crayfish Count Project

Q1. Did you attend an event which included a presentation on the 'Crayfish Count' in 2016?

Possible answers: Yes or No

Q2. Did you receive/collect a 'Crayfish Count' sampling kit?

Possible answers: Yes or No

Q3. Did you participate in the 'Crayfish Count' (recording and swabbing crayfish)?

Possible answers: Yes or No

Q4. If yes, please select the boxes which best describe what motivated you to participate.

Possible answers: Educational gain (knowledge/skill), Social gain (socialising/expanding personal network), benefit to environment (find where signal crayfish are/contribute to environmental science), N/A, Other (please specify)

Q5. If no, please select the boxes which best describe why you did not participate.

Possible answers: Availability (lack of time to participate), protocol appeal (too long/too difficult), lack of obvious benefit to self (knowledge/skill gain), N/A, Other (please specify) 
Q6. Did you participate in environmental DNA (eDNA) water collection in the Taff?

Possible answers: Yes or No

Q7. If yes, please select the boxes which best describe what motivated you to participate.

Possible answers: Educational gain (knowledge/skill), Social gain

(socialising/expanding personal network), benefit to environment (find where signal crayfish are/contribute to environmental science), N/A, Other (please specify)

Q8. If no, please select the boxes which best describe why you did not participate.

Possible answers: Availability (lack of time to participate), protocol appeal (too long/too difficult), lack of obvious benefit to self (knowledge/skill gain), N/A, Other (please specify)

\section{Q9. Please select your age category}

Possible answers: Under 18/18-24/25-34/35-44/45-54/55-64/65+

Q10. Would you like to be included in a prize draw for a $£ 10$ Amazon gift card?

Possible answers: Yes (please insert email address below)/No 
Database references:

Robinson, C.V., Uren Webster, T.M., Consuegra, S., 2018. Data on optimisation of a multiplex HRM-qPCR assay for native and invasive crayfish as well as the crayfish plague in four river catchment. Data in Brief 19, 1092-1109.

https://doi.org/10.1016/j.biocon.2018.04.009 


\section{ETHICS STATEMENTS AND PERMITS}

\section{BIOSCIENCES STUDENT PROJECT ETHICS CHECK-LIST v.5}

1. Have you read the Departmental Statement on use of animals in research (see student handbook)?<smiles>C1CC1</smiles>

Yes. Go to 2

No. Read them. You cannot begin your project without reading them

2. Does your study involve humans as the focus of research, or make use of data collected from human subjects?

Yes. Submit application to CoS Ethics Committee

No. Go to 3.

3. Does your study involve any species protected by UK, EU or international law, or work in protected areas including Special Areas of Conservation (SACs)s, Sites of importance for Nature Conservation (SINCS), Sites of Special Scientific Interest (SSSIs), Marine Reserves in the UK or abroad?

$\square$ Yes. Ensure that you have permission from local authorities. Go to 4

No. Go to 4.

4. Does your study involve work on any animal protected under the Animals (Scientific Procedures) Act 1986, namely any living vertebrate, other than man, and any living cephalopod. Fish and amphibians are protected once they can feed independently and cephalopods at the point when they hatch. Embryonic and foetal forms of mammals, birds and reptiles are protected during the last third of their gestation or incubation period.

Yes. Go to 5

No. You can now begin your project

5. Does your study involve a regulated procedure (i.e. carried out on a protected animal that may cause a level of pain, suffering, distress or lasting harm equivalent to, or higher than, that caused by inserting a hypodermic needle according to good veterinary practice)?

Yes. You cannot begin your project without a formal assessment by the University AWERP group. stop

No. You can now begin your project

Student: CHWOEV ROB WSON

Signed:

Supervisor:

Date: $01102 / 16$ Signed:

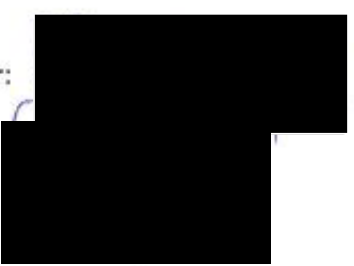

Swansea University adheres to the ARRIVE guidelines for reporting animal research www.nc 3 rs.orR. Uk/ARRIVEuniversities 


\section{College of Science Intranet}

HOME $>$ ETHICAL REVIEWS $>$ FORM

\section{APPLICATION FOR ETHICAL APPROVAL OF PROJECTS INVOLVING ENVIRONMENTAL RISKS}

RESEARCH CANNOT COMMENCE UNTIL ETHICAL APPROVAL HAS BEEN OBTAINED

Pleose note form is opened os read-only.

Reference No: STAFF_BIOL_57954_180717135327_1

Status: Approved Proposal :College Ethics Committee DECISION Details

Submitted By: Carlos Garcia De Leaniz

Submitted Date: 15 Sep 2017

1. Title of Research Project:

AMBER - respirometry and suiming experiments

2. Staff/students undertaking research:

Peter Jones

3. Primary staff contact detail (Name, E-mail, Phone):

4. Please provide details of the proposed work, potential risks and how those risks will be managed (Please refer to the University Research Ethics and Governance Framework document, Section F. Policy on Managing Environmenta Risks of Research).

The project involvez the collection of a range of aquatic invertebratez (see below for speciez and numbers) for use in suiming and respirometry experiments in the aquatic research facilities at CSAR, Singleton Campus. Depending on the species, organiems will either be collected from wild populations (uith appropriate consents and licencez from regulatory bodiez - EA and WRW), or be obtained from captive bred atockz at other hatchery facilities.

The study organisms will include both native and non-native species. Some of the study species are knoun to be invasive and have negative environmental impacts when liberated to non-native habitats. For instance many species compete aggrezsively for space and food with indigenouz organiams, while othera (e.g. aignal crayfiah) can carry

A number of ateps will be taken to limit the biosecurity risk presented by the use of invasive speciez in this study:

- When collecting organisms from wild populations, standard biosecurity protocols will be followed to prevent the spread of invazive apeciez. A11 equipment coning into contact with the vater will be checked, dried and cleaned before and after collectiona at each zite, including the use of a broad apectrum disinfectant auch a Virkon.

All organisma will be kept in appropriate containera to prevent their eacape during transportation.

I certify that the answers to the questions given above are true and accurate to the best of my knowledge and belief and I take full responsibility for it. I also confirm that I have read the University's Policy Framework on Research Ethics $\&$ Governance and will abide by its ethical guidelines, as well as the ethical principles underlying good practice appropriate to my discipline. 


\section{College of Science Intranet}

\section{HOME $>$ EIHICAL REVIEWS $>$ FORM}

\section{Initial Proposal to AWERB Group}

Reference No: STAFF_BIOL_57954_180717143234_2

Status: Approved Proposal :AWERB Group DECISION Details

Submitted By: Peter Jones

Submitted Date: 18 Sep 2017

Pleose note form is opened os read-only.

Please provide the information requested in sections 1-8 below. Use lay terms where possible and avoid confidential material.

1. Title of research project/teaching activity:

AMBER - suiming/respirometry experiments

2. College:

Seience

3. Staff Contact:

\section{Summary of project/activity:}

This proposal is to investigate the suimming behaviour and metabolic rate of a range of freshuater fish (see speciez and numberz below), to assesz how they are likely to respond to the presence of velocity barrierz in
riverz and atreams. Experiments will be undertaken within the aquatic research facilities at CSAR, Singleton Campus.

The study species will either be sourced from wild populations or from captive stocks. Fish will only be collected from the wild where population abundance is sufficient that removal is likely to have a negligible affect on population status. Collection sites will be selected in conzultation with NRil and/or Ea, and all include electro-fishing, netting and trapping. In all cases, best practice techniques will be followed, and the

5. Location(s) at which the proposed project/activity is to be undertaken:

6. External approvals required for the proposed project/activity:

FR2 consentz for the use of electric fishing and netting equipment to capture fish (to be obtained for each collection site in advance from Environment Agency and Natural Resources Walez)

Licence to keep live fish (Fish Health Inspectorate)

7. Does the proposed project/activity involve a Schedule 1 method (as defined by ASPA 1986) being corried out by members of this University's staff or by it's student? If yes, please list the incividuals involved:

Peter Jones

Carlos Garcia de Leani

Luca Borger

Edward Pope 
Authorisation to fish using instruments (other than rod and line) under section 27A Salmon and Freshwater Fisheries Act 1975.

Permit Reference NT/CW081-B-797/3888/02 Date of Issue 29 September 2016

\section{Authorisation Holder}

Name Chloe Robinson

Enterprise N/A

Position N/A

Address

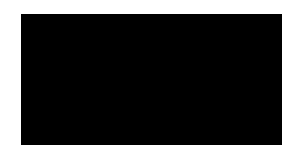

Post code

2. Fishing Instruments

Authorisation has been granted to the above named authorisation holder to use the following fishing instruments:

\begin{tabular}{|l|l|l|}
\hline Instrument & Number & Additional Notes \\
\hline Crayfish Trap & & \\
\hline
\end{tabular}

\section{Species for Removal}

It is a condition of this authorisation that only the following fish species may be removed:

- Crayfish, Signal (PCL: Pacifastacus leniusculus)

At: River Wye Tributaries (CW081-B-797)

Upstream Limit: S011154141

Downstream Limit: SO03894649

From: 21 September 2015

To: $\quad 31$ May 2017

\section{Conditions}

Subject to the following condition(s):

- All other species of fish or eels caught in the trap, shall be returned to the water as soon as is practicable and with as little damage as possible.

- No trap shall exceed the following dimensions: $600 \mathrm{~mm}$ in length and $350 \mathrm{~mm}$ width at its widest point. The mesh size shall not exceed $30 \mathrm{~mm}$ at its widest point.

- All traps where the entrance to the trap is greater than $95 \mathrm{~mm}$ internal diameter must be fitted with an otter guard.

- Any traps that are discovered lost, stolen, or not retrievable upon the last inspection should be reported to the Environment Agency as soon as practicable.

- Each individual crayfish trap must have an Environment Agency issued tag attached when in use. 


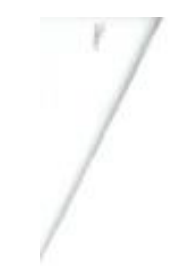

Cyfoeth

Naturiol

Cymru

Natural

Resources

Wales

Authorisation to fish using instruments (other than rod and line) under section 27A Salmon and Freshwater Fisheries Act 1975.

Permit Reference EP/CW061-E-546/11141/01 Date of Issue 15 November 2017

1. Authorisation Holder

Name Mr Peter Jones

Enterprise N/A

Position N/A

Address

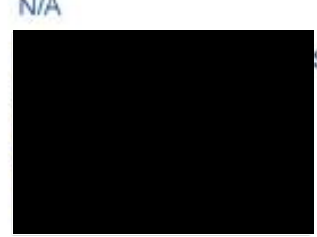

Science, Post code

2. Fishing Instruments

Authorisation has been granted to the above named authorisation holder to use the following fishing instruments:

\begin{tabular}{|l|l|l|}
\hline Instrument & Number & Additional Notes \\
\hline Fyke Net <1m opening & & \\
\hline Other & & Micro Mesh \\
\hline Minnow Trap & & \\
\hline Seine Net & & \\
\hline Back Pack & & HT2000 Backpack \\
\hline
\end{tabular}

3. Species for Removal

It is a condition of this authorisation that only the following fish species may be removed:

- Topmouth Gudgeon

At: Ashpits Local Nature Reserve (CW061-E-546); LLANELLI; SN46200100

From: 15 November 2017

To: $\quad 04$ January 2018

\section{Conditions}

Subject to the following condition(s):

- All other species of fish or eels caught in nets or traps shall be returned to the water as soon as is practicable and with as little damage as possible

- If any Otters or Water Voles are trapped the traps must be removed immediately and Natural Resources Wales notified as soon as practicable. 
Authorisation to fish using instruments (other than rod and line) under section 27A Salmon and Freshwater Fisheries Act 1975.

Permit Reference EP/CW061-E-546/11141/02 Date of Issue O6 February 2018

1. Authorisation Holder

Name Mr Peter Jones

Enterprise N/A

Position N/A

Address

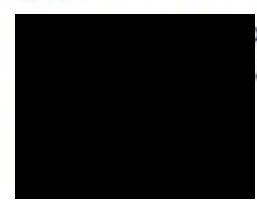

gical Science, Post code

2. Fishing Instruments

Authorisation has been granted to the above named authorisation holder to use the following fishing instruments:

\begin{tabular}{|l|l|l|}
\hline Instrument & Number & Additional Notes \\
\hline Fyke Net <1m opening & & \\
\hline Other & & Micro Mesh \\
\hline Minnow Trap & & \\
\hline Seine Net & & \\
\hline Back Pack & & \\
\hline
\end{tabular}

i. Species for Removal

It is a condition of this authorisation that only the following fish species may be removed:

- Topmouth Gudgeon

At: Ashpits Local Nature Reserve (CW061-E-546); LLANELLI; SN46200100

From: 15 November 2017

To: $\quad 04$ March 2018

4. Conditions

Subject to the following condition(s):

- All other species of fish or eels caught in nets or traps shall be returned to the water as soon as is practicable and with as little damage as possible.

- If any Otters or Water Voles are trapped the traps must be removed immediately and Natural Resources Wales notified as soon as practicable. 


\section{Authorisation to fish using instruments (other than rod and line)} under section 27A Salmon and Freshwater Fisheries Act 1975.

\section{Permit Reference EP/CW061-E-546/12720/02 Date of Issue 15 June 2018}

\section{Authorisation Holder}

Name Dr Peter Jones

Enterprise CSAR - Salmon Lab Room 28

Position Research Technician

Address

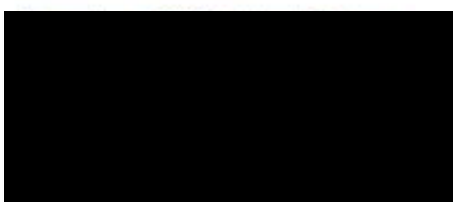

Post code

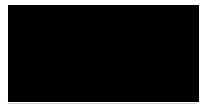

2. Fishing Instruments

Authorisation has been granted to the above named authorisation holder to use the following fishing instruments:

\begin{tabular}{|l|l|l|}
\hline Instrument & Number & Additional Notes \\
\hline Minnow Trap & & \\
\hline Seine Net & & \\
\hline Back Pack & & \\
\hline
\end{tabular}

3. Species for Removal

It is a condition of this authorisation that only the following fish species may be removed:

- Topmouth Gudgeon

At: Ashpits Local Nature Reserve (CW061-E-546); LLANELLI; SN46200100

From: 16 June 2018

To: $\quad 31$ August 2018

4. Conditions

Subject to the following condition(s):

5. Contact Details

If you wish to discuss your authorisation please contact Natural Resources Wales on 03000653000. 


\section{GLOSSARY}

Admixture

Allelic frequencies

Bonferroni correction

Carapace

Catadromous

Dissemination

DNA amplification

Effective population size

Electrofishing

Founder effects

$\mathrm{F}_{\text {ST }}$

Genetic diversity

Haplotype

Hardy-Weinberg

equilibrium
Interbreeding between two or more previously isolated populations.

Relative frequency of an allele (variant of a gene) at a particular locus in a population, expressed as a fraction or percentage.

An adjustment made to $P$ values when several dependent or independent statistical tests are being performed simultaneously on a single data set.

Hard-upper shell of a tortoise, crustacean, or arachnid.

The act of migrating down rivers to the sea to spawn.

The act of spreading something, especially information, widely; circulation.

Production of multiple copies of a sequence of DNA.

Number of individuals in a population who contribute offspring to the next generation.

Fish (a stretch of water) using electrocution or a weak electric field.

The reduced genetic diversity which results when a population is descended from a small number of colonizing ancestors.

Measure of population differentiation due to genetic structure.

Total number of genetic characteristics in the genetic makeup of a species.

Set of genetic determinants located on a single chromosome.

A fundamental principle of population genetics: population gene frequencies and genotype frequencies remain constant from generation to generation if mating 
is random and if mutation, selection, immigration, and emigration do not occur.

Heterozygosity

Having different alleles at one or more corresponding chromosomal loci.

Homozygosity by locus

When an individual has two identical genes at a locus.

Hybridisation

The process of an animal or plant breeding with an individual of another species or variety.

In silico

Conducted or produced by means of computer modelling or computer simulation.

Limit of detection

Lowest quantity or concentration of a component that can be reliably detected with a given analytical method.

Limit of quantification Lowest concentration at which the analyte can not only be reliably detected but at which some predefined goals for bias and imprecision are met.

Linkage disequilibrium Occurrence in members of a population of combinations of linked genes in non-random proportions.

Metabarcoding Method of DNA barcoding that uses universal PCR primers to identify DNA from a mixture of organisms.

Microsatellite A set of short repeated DNA sequences at a particular locus on a chromosome, which vary in number in different individuals and so can be used for genetic fingerprinting.

Null alleles

An allele which has the same phenotype when homozygous as when heterozygous with a deficiency that disrupts the locus in question.

Overdispersion Presence of greater variability (statistical dispersion) in a data set than would be expected based on a given statistical model.

PCR inhibition

Any factor which prevent the amplification of nucleic acids through the polymerase chain reaction. 
Phenotypic plasticity

Polymorphism

Primer

Propagule pressure

Supernatant
Some of the changes in an organism's behaviour, morphology and physiology in response to a unique environment.

Presence of genetic variation within a population, upon which natural selection can operate

Short strand of RNA or DNA that serves as a starting point for DNA synthesis.

Composite measure of the number of individuals of a species released into a region to which they are not native. It incorporates estimates of the absolute number of individuals involved in any one release event (propagule size) and the number of discrete release events (propagule number).

Liquid lying above a solid residue after crystallization, precipitation, centrifugation, or other process. 


\section{REFERENCES}

Abdelkrim, J., Pascal, M., Samadi, S., 2007. Establishing causes of eradication failure based on genetics: case study of ship rat eradication in St. Anne Archipelago. Conservation Biology 21, 719-730.

Agersnap, S., Larsen, W., Knudsen, S., Strand, D.A., Thomsen, P.F., Hesselsøe, M., Mortensen, P.B., Vrålstad, T., Møller, P.R., 2017. Monitoring of noble, signal and narrow-clawed crayfish using environmental DNA from freshwater samples. PLoS ONE 12, e0179261.

Alderman, D., Holdich, D., Reeve, I., 1990. Signal crayfish as vectors in crayfish plague in Britain. Aquaculture 86, 3-6.

Alderman, D.J., Wickins, J.F., 1996. Crayfish culture; laboratory leaflet number 76, ed. F.D. Laboratory. Ministry of Agriculture, Fisheries and Food Directorate of Fisheries Research, Lowestoft.

Allen, Y., Kirby, S., Copp, G., Brazier, M., 2006. Toxicity of rotenone to topmouth gudgeon Pseudorasbora parva for eradication of this non-native species from a tarn in Cumbria, England. Fisheries Management and Ecology 13, 337-340.

Allendorf, F.W., Hohenlohe, P.A., Luikart, G., 2010. Genomics and the future of conservation genetics. Nature Reviews Genetics 11, 697-709.

Allendorf, F.W., Lundquist, L.L., 2003. Introduction: population biology, evolution, and control of invasive species. Conservation Biology 17, 24-30.

Andreou, D., Arkush, K., Guégan, J., Gozlan, R., 2012. Introduced pathogens and native freshwater biodiversity: a case study of Sphaerothecum destruens. PLOS ONE 7, e36998.

Aparicio, J.M., Ortego, J., Cordero, P.J., 2006. What should we weigh to estimate heterozygosity, alleles or loci? Molecular Ecology 15, 4659-4665.

AquaInvaders, 2016. Pacifastacus leniusculus records.

Arismendi, I., Soto, D., Penaluna, B., Jara, C., Leal, C., Leon-Munoz, J., 2009. Aquaculture, non-native salmonid invasions and associated declines of native fishes in Northern Patagonian lakes. Freshwater Biology 54, 1135-1147. 
Azuma, N., Usio, N., Korenaga, T., Koizum, I., Takamura, N., 2011. Genetic population structure of the invasive signal crayfish Pacifastacus leniusculus in Japan inferred from newly developed microsatellite markers. Plankton \& Benthos Research 6, 187-194.

Banha, F., Anastácio, P., 2014. Desiccation survival capacities of two invasive crayfish species. Knowledge and Management of Aquatic Ecosystems 413, 1-5.

Banks, N.C., Paini, D.R., Bayliss, K.L., Hodda, M., 2015. The role of global trade and transport network topology in the human-mediated dispersal of alien species. Ecology Letters 18, 188-199.

Barnes, M., Turner, C., 2015. The ecology of environmental DNA and implications for conservation genetics Conservation Genetics 17, 1-17.

Barnes, M.A., Turner, C.R., Jerde, C.L., Renshaw, M.A., Chadderton, W.L., Lodge, D.M., 2014. Environmental conditions influence eDNA persistence in aquatic systems. Environmental Science \& Technology 48, 1819-1827.

Becking T., Mrugała, A., Delaunay, C., Svoboda, J., Raimond, M., Viljamaa-Dirks, S., Petrusek, A., Grandjean, F., C., B.-V., 2015. Effect of experimental exposure to differently virulent Aphanomyces astaci strains on the immune response of the noble crayfish Astacus astacus. Journal of Invertebrate Pathology 132, 115-124.

Behrens-Chapuis, S., Malewski, T., Suchecka, E., Geiger, M.F., Herder, F., Bogdanowicz, W., 2018. Discriminating European cyprinid specimens by barcode high-resolution melting analysis (Bar-HRM) - A cost efficient and faster way for specimen assignment? Fisheries Research 204, 61-73.

Belfiore, N., May, B., 2000. Variable microsatellite loci in red swamp crayfish, Procambarus clarkii, and their characterization in other crayfish taxa. Molecular Ecology 9, 2155-2234.

Beyer, K., 2004. Escapees of potentially invasive fishes from an ornamental aquaculture facility: the case of topmouth gudgeon Pseudorasbora parva. Journal of Fish Biology 65, 326-327.

Beyer, K., Copp, G., Gozlan, R., 2007. Microhabitat use and interspecific associations of introduced topmouth gudgeon Pseudorasbora parva and native fishes in a small stream. Journal of Fish Biology 71, 224-238. 
Biggs, J., Ewald, N., Valentini, A., Gaboriaud, C., Dejean, T., Griffiths, R.A., Foster, J., Wilkinson, J.W., Arnell, A., Brotherton, P., Williams, P., Dunn, F., 2015. Using eDNA to develop a national citizen science-based monitoring programme for the great crested newt (Triturus cristatus). Biological Conservation 183, 19-28.

Bills, T.D., Marking, L.L., 2011. Control of nuisance populations of crayfish with traps and toxicants. The Progressive Fish-Culturist 50, 103-106.

Blanchet, S., Rey, O., Etienne, R., Lek, S., Loot, G., 2009. Species-specific responses to landscape fragmentation: implications for management strategies. Evolutionary Applications 3, 291-304.

Bohmann, K., Evans, A., Gilbert, M.T.P., Carvalho, G.R., Creer, S., Knapp, M., Douglas, W.Y., de Bruyn, M., 2014. Environmental DNA for wildlife biology and biodiversity monitoring. Trends in Ecology \& Evolution 29, 358-367.

Bonney, R., Cooper, C.B., Dickinson, J.L., Kelling, S., Phillips, T., Rosenberg, K.V., Shirk, J., 2009. Citizen Science: a developing tool for expanding science knowledge and scientific literacy. BioScience 59, 977-984.

Bonter, D.N., Cooper, C.B., 2012. Data validation in citizen science: a case study from Project FeederWatch. Frontiers in Ecology and the Environment 10, 305-307.

Bossart, J.L., Prowell, D.P., 1998. Genetic estimates of population structure and gene flow: Limitations, lessons and new directions. Trends in Ecology and Evolution 13, 202-206.

Brancatelli, G.I.E., Zalba, S.M., 2018. Vector analysis: a tool for preventing the introduction of invasive alien species into protected areas. Nature Conservation 24, 43-63.

Brazier, M., 2015. EA progress in eradicating the deadly topmouth gudgeon, In Centre for Environment, Fisheries and Aquaculture Science. Gov.uk, Marine Science

Britton, J., Davies, G., Brazier, M., 2008. Contrasting life history traits of invasive topmouth gudgeon (Pseudorasbora parva) in adjacent ponds in England. Journal of Applied Ichthyology 24, 694-698.

Britton, J., Davies, G., Brazier, M., 2010. Towards the successful control of the invasive Pseudorasbora parva in the UK. Biological Invasions 12, 125-131. 
Britton, J., Davies, G., Brazier, M., Pinder, A., 2007. A case study on the population ecology of a topmouth gudgeon (Pseudorasbora parva) population in the UK and the implications for native fish communities. Aquatic Conservation 17, 749-759.

Britton, J., Gozlan, R., Copp, G., 2011a. Managing non-native fish in the environment. Fish and Fisheries 12, 256-274.

Britton, J.R., Pegg, J., Gozlan, R.E., 2011b. Quantifying imperfect detection in an invasive pest fish and the implications for conservation management. Biological Conservation 144, 2177-2181.

Brodin, T., Drotz, M.K., 2014. Individual variation in dispersal associated behavioral traits of the invasive Chinese mitten crab (Eriocheir sinensis, H. Milne Edwards, 1854) during initial invasion of Lake Vänern, Sweden Current Zoology 60, 410-416.

Bruyere, B., Rappe, S., 2007. Identifying the motivations of environmental volunteers. Journal of Environmental Planning and Management 50, 503-516.

Bubb, D.H., Thom, T.J., Lucas, M.C., 2004. Movement and dispersal of the invasive signal crayfish Pacifastacus leniusculus in upland rivers. Freshwater Biology 49, 357-368.

Bubb, D.H., Thom, T.J., Lucas, M.C., 2005. The within-catchment invasion of the non-indigenous signal crayfish Pacifastacus leniusculus (Dana), in upland rivers. KMAE 376, 665-673.

Bubb, D.H., Thom, T.J., Lucas, M.C., 2006. Movement, dispersal and refuge use of co-occurring introduced and native crayfish. Freshwater Biology 51, 13591368.

Buxton, A.S., Groombridge, J.J., Griffiths, R.A., 2018. Seasonal variation in environmental DNA detection in sediment and water samples. PLoS ONE 13, e0191737.

Bylemans, J., Furlan, E.M., Pearce, L., Daly, T., Gleeson, D.M., 2016. Improving the containment of a freshwater invader using environmental DNA (eDNA) based monitoring. Biological Invasions 18, 3081-3089. 
Cai, W., Ma, Z., Yang, C., Wang, C.M., Wang, L., Wang, W., Zhao, G., Geng, Y., Yu, D.W., 2017. Using eDNA to detect the distribution and density of invasive crayfish in the Honghe-Hani rice terrace World Heritage site. PLoS ONE 12.

Caldwell, J., Payment, P., Villemur, R., 2011. Mitochondrial DNA as source tracking markers of fecal contamination. Springer, New York.

CanalPlan, 2015. River Medway Non-Tidal Section.

Carlsson, J.E.L., Egan, D., Collins, P.C., Farrell, E.D., Igoe, F., Carlsson, J., 2017. A qPCR MGB probe based eDNA assay for European freshwater pearl mussel (Margaritifera margaritifera L.). Aquatic Conservation 27, 1341-1344.

Casimiro, A.C.R., Garcia, D.A.Z., Costa, A.D.A., Britton, J.R., Orsi, M.L., 2017. Impoundments facilitate a biological invasion: Dispersal and establishment of non-native armoured catfish Loricariichthys platymetopon (Isbrückler \& Nijssen, 1979) in a neotropical river. Limnologica - Ecology and Management of Inland Waters 62, 34-37.

Charise, A.C., Morris, T.J., Wilson, C.C., Freeland, J.R., 2018. Validation of environmental DNA (eDNA) as a detection tool for at-risk freshwater pearly mussel species (Bivalvia: Unionidae). Aquatic Conservation: Marine and Freshwater Ecosystems 17.

Coleman, R.A., Pavlova, B.G.A., Beheregaray, L.B., Kearns, J., Lyon, J., Sasaki, M., Leblois, R., Sgro, C., Sunnucks, P., 2018. Artificial barriers prevent genetic recovery of small isolated populations of a low-mobility freshwater fish. Heredity $120,515-532$.

Collier, M., Webb, R.H., Schmidt, J.C., 1996. Dams and rivers: a primer on the downstream effects of dams. U.S. Geological Survey, Denver, Colorado.

Conrad, C.C., Hilchey, K.G., 2011. A review of citizen science and community-based environmental monitoring: issues and opportunities. Environmental Monitoring and Assessment 176, 273-291.

Consuegra, S., Phillips, N., Gajardo, G., Garcia de Leaniz, C., 2011. Winning the invasion roulette: escapes from fish farms increase admixture and facilitate establishment of non-native rainbow trout. Evolutionary Applications 4, 660671. 
Cooper, J., 2011. Anesthesia, analgesia and euthanasia of invertebrates. ILAR 52, 196 $-204$.

Copp, G., Wesley, K., Verreycken, H., Russell, I., 2007. When an 'invasive' fish species fails to invade! Example of the topmouth gudgeon Pseudorasbora parva. Aquatic Invasions 2, 107-112.

Copp, G.H., Godard, M.J., Russell, I.C., Peeler, E.J., Gherardi, F., Tricarico, E., Miossec, L., Goulletquer, P., Almeida, D., Britton, J.R., Vilizzi, L., Mumford, J., Williams, C., Reading, A., Rees, E.M.A., Merino-Aguirre, R., 2016. A preliminary evaluation of the European Non-native Species in Aquaculture Risk Assessment Scheme applied to species listed on Annex IV of the EU Alien Species Regulation. Fisheries Management and Ecology 23, 12-20.

Copp, G.H., Vilizzi, L., Gozlan, R.E., 2010. Fish movements: the introduction pathway for topmouth gudgeon Pseudorasbora parva and other non-native fishes in the UK. Aquatic Conservation 20, 269-273.

Cornuet, J.M., Pudlo, P., Veyssier, J., Dehne-Garcia, A., Gautier, M., Leblois, R., Marin, J.M., Estoup, A., 2014. DIYABC v2.0: a software to make Approximate Bayesian Computation inferences about population history using Single Nucleotide Polymorphism, DNA sequence and microsatellite data. Bioinformatics 30, 1187-1189.

Cornwell, M.L., Campbell, L.M., 2011. Co-producing conservation and knowledge: Citizen-based sea turtle monitoring in North Carolina, USA. Social Studies of Science 42, 101-120.

Cowart, D.A., Breedveld, K.G.H., Ellis, M.J., Hull, J.M., Larson, E.R., 2018. Environmental DNA (eDNA) applications for the conservation of imperiled crayfish (Decapoda: Astacidea) through monitoring of invasive species barriers and relocated populations. Journal of Crustacean Biology 38, 257-266.

Crawford, L., Yeomans, W.E., Adams, C.E., 2006. The impact of introduced signal crayfish Pacifastacus leniusculus on stream invertebrate communities. Aquatic Conservation 16, 611-621.

Crowl, T.A., Crist, T.O., Parmenter, R.R., Belovsky, G., Lugo, A.E., 2008. The spread of invasive species and infectious disease as drivers of ecosystem change. Frontiers in Ecology and the Environment 6, 238-246. 
Darling, J.A., Mahon, A.R., 2011. From molecules to management: adopting DNAbased methods for monitoring biological invasions in aquatic environments. Environmental Research 111, 978-988.

Davies, G., Britton, J., 2015. Assessing the efficacy and ecology of biocontrol and biomanipulation for managing invasive pest fish. Journal of Applied Ecology $52,1264-1273$.

Davison, P., Copp, G., Créach, V., Vilizzi, L., Britton, J., 2017. Application of environmental DNA analysis to inform invasive fish eradication operations. Science of Nature 104, 1-7.

Davy, C., Kidd, A., Wilson, C., 2015. Development and Validation of Environmental DNA (eDNA) Markers for Detection of Freshwater Turtles. PLoS ONE 10, $\mathrm{e} 0130965$.

De Silva, S.S., Nguyen, T.T., Turchini, G.M., Amarasinghe, U.S., Abery, N.W., 2009. Alien species in aquaculture and biodiversity: a paradox in food production. AMBIO 38, 24-28.

de Vos, E., Edwards, S.J., McDonald, I., Wray, D.S., Carey, P.J., 2002. A baseline survey of the distribution and origin of platinum group elements in contemporary fluvial sediments of the Kentish Stour, England. Applied Geochemistry 17, 1115-1121.

DEFRA, 2015. Common standards monitoring guidance for freshwater fauna, ed. JNCC.

Deiner, K., Altermatt, F., 2014. Transport distance of invertebrate environmental DNA in a natural river. PLoS ONE 9, e88786.

Deiner, K., Fronhofer, E.A., Mächler, E., Walser, J.-C., Altermatt, F., 2016. Environmental DNA reveals that rivers are conveyer belts of biodiversity information. Nature Communications 7, 1-9.

Dejean, T., Valentini, A., Duparc, A., Pellier-Cuit, S., Pompanon, F., Taberlet, P., Miaud, C., 2011. Persistence of Environmental DNA in Freshwater Ecosystems. PLoS ONE 6, e23398.

Dejean, T., Valentini, A., Miquel, C., Taberlet, P., Bellemain, E., Miaud, C., 2012. Improved detection of an alien invasive species through environmental DNA 
barcoding: the example of the American bullfrog Lithobates catesbeianus. Journal of Applied Ecology 49, 953-959.

Delaney, D.G., Sperling, C.D., Adams, C.S., Leung, B., 2008. Marine invasive species: validation of citizen science and implications for national monitoring networks. Biological Invasions 10, 117-128.

Dettmers, J.M., Boisvert, B.A., Barkley, T., Sparks, R.E., 2005. Potential impact of steel-hulled barges on movement of fish across an electric barrier to prevent the entry of invasive carp into Lake Michigan, In US Fish and Wildlife Service. pp. 1-12.

Devictor, V., Whittaker, R.J., Beltrame, C., 2010. Beyond scarcity: citizen science programmes as useful tools for conservation biogeography. Diversity and Distributions 16, 354-362.

Dickinson, J.L., Bonney, R., 2012. Citizen Science: Public participation in environmental research. Cornell University Press, Cornell, USA.

Dickinson, J.L., Shirk, J., Bonter, D., Bonney, R., Crain, R.L., Martin, J., Phillips, T., Purcell, K., 2012. The current state of citizen science as a tool for ecological research and public engagement. Frontiers in Ecology and the Environment 10, 291-297.

Dickinson, J.L., Zuckerberg, B., Bonter, D., 2010. Citizen Science as an ecological research tool: challenges and benefits. Annual Review of Ecology, Evolution and Systematics 41, 149-172.

Didham, R.K., Tylianakis, J.M., Hutchison, M.A., Ewers, R.M., Gemmell, N.J., 2005. Are invasive species the drivers of ecological change? Trends in Ecology \& Evolution 20, 470-474.

Diéguez-Uribeondo, J., 2006. The dispersion of the Aphanomyces astaci carrier Pacifastacus leniusculus by humans represents the main cause of disappearance of the indigenous crayfish Austropotamobius pallipes in Navarra. Bulletin Français de la Pêche et de la Pisciculture 380, 1303-1312.

Diéguez-Uribeondo, J., Huang, T., Cerenius, L., Söderhäll, K., 1995. Physiological adaptation of an Aphanomyces astaci strain isolated from the freshwater crayfish Procambarus clarkii. Mycological Research 99, 574-578. 
Dittel, A., Epifanio, C., 2009. Invasion biology of the Chinese mitten crab Eriochier sinensis: A brief review. Journal of Experimental Marine Biology and Ecology 374, 79-82.

Dlugosch, K.M., Parker, I.M., 2008. Founding effects in species invasions: genetic variation, adaptive evolution, and the role of multiple introductions. Molecular Ecology 17, 431-449.

Do, C., Waples, R., Peel, D., Macbeth, G., Tillet, B., Overden, J., 2013. NeEstimator V2: re-implementation of software for the estimation of contemporary effective population size ( $\mathrm{Ne}$ ) from genetic data. Molecular Ecology Resources $14,209-214$.

Doi, H., Inui, R., Akamatsu, Y., Kanno, K., Yamanaka, H., Takahara, T., Minamoto, T., 2017. Environmental DNA analysis for estimating the abundance and biomass of stream fish. Freshwater Biology 62, 30-39.

Doi, H., Takahara, T., Minamoto, T., Matsuhashi, S., Uchii, K., Yamanaka, H., 2015. Droplet Digital Polymerase Chain Reaction (PCR) outperforms real-time PCR in the detection of environmental DNA from an invasive fish species. Environmental Science \& Technology 49, 5601-5608.

Dougherty, M., Larson, E., Renshaw, M., Gantz, C., Egan, S., Erickson, D., Lodge, D., 2016. Environmental DNA (eDNA) detects the invasive rustycrayfish Orconectes rusticus at low abundances. Journal of Applied Ecology 53, 722732.

Druschke, C.G., Seltzer, C.E., 2012. Failures of engagement: lessons learned from a citizen science pilot study. Applied Environmental Education \& Communication 11, 178-188.

Dunker, K.J., Sepulveda, A.J., Massengill, R.L., Olsen, J.B., Russ, O.L., Wenburg, J.K., Antonovich, A., 2016. Potential of Environmental DNA to Evaluate Northern Pike (Esox lucius) Eradication Efforts: An Experimental Test and Case Study. PLoS ONE 11, e0162277.

Dunn, A.M., Torchin, M.E., Hatcher, M.J., Kotanen, P.M., Blumenthal, D.M., Byers, J.E., Coon, C.A.C., Frankel, V.M., Holt, R.D., Hufbauer, R.A., Kanarek, A.R., Schierenbeck, K.A., Wolfe, L.M., Perkins, S.E., 2012. Indirect effects of parasites in invasions. Functional Ecology 26, 1262-1274. 
Dunn, J., McClymont, H., Christmas, M., Dunn, A., 2009. Competition and parasitism in the native White Clawed Crayfish Austropotamobius pallipes and the invasive Signal Crayfish Pacifastacus leniusculus in the UK. Biological Invasions 11, 315-324.

Edgerton, B.F., Henttonen, P., Jussila, J., Mannonen, A., Paasonen, P., Taugbøl, T., Edsman, L., Souty-Grosset, C., 2004. Understanding the causes of disease in European freshwater crayfish. Conservation Biology, 1466-1474.

Eichmiller, J., Best, S., Sorensen, P., 2016. Effects of temperature and trophic state on degradation of environmental DNA in lake water. Environmental Science \& Technology 50, 1859-1867.

Eichmiller, J.J., Bajer, P.G., Sorensen, P.W., 2014. The relationship between the distribution of common carp and their environmental DNA in a small lake. PLoS ONE 9, e112611.

Estoup, A., Jarne, P., Cornuet, J.-M., 2002. Homoplasy and mutation model at microsatellite loci and their consequences for population genetics analysis. Molecular Ecology 11, 1591-1604.

EU, 2014. Regulation (EU) No 1143/2014 of the European Parliament and of the Council of 22 October 2014 on the prevention and management of the introduction and spread of invasive alien species, ed. T.E.P.a.t.C.o.t.E. Union, pp. 35-55. Official Journal of the European Union, Strasbourg.

Evans, C., Abrams, E., Reitsma, R., Roux, K., Salmonsen, L., Marra, P.P., 2005. The Neighborhood Nestwatch Program: participant outcomes of a citizen-science ecological research project. Conservation Biology 19, 589-594.

Evans, N.T., Olds, B.P., Renshaw, M.A., Turner, C.R., Li, Y., Jerde, C.L., Mahon, A.R., Pfrender, M.E., Lamberti, G.A., Lodge, D.M., 2016. Quantification of mesocosm fish and amphibian species diversity via environmental DNA metabarcoding. Molecular Ecology Resources 16, 29-41.

Evans, N.T., Shirey, P.D., Wieringa, J.G., Mahon, A.R., Lamberti, G.A., 2017. Comparative cost and effort of fish distribution detection via environmental DNA analysis and electrofishing. Fisheries 42, 90-99. 
Excoffier, L., Laval, G., Schneider, S., 2005. Arlequin (ver. 3.0): An integrated software package for population genetics data analysis. Evolutionary Bioinformatics 1, 47 - 50 .

Fagan, W., 2002. Connectivity, fragmentation and extinction risk in dendritic metapopulations. Ecological Society of America 83, 3243-3249.

Fausch, K.D., Rieman, B.E., Dunham, J.B., Young, M.K., Peterson, D.P., 2009. Invasion versus isolation: Trade-Offs in managing native salmonids with barriers to upstream movement. Conservation Biology 23, 859-870.

Fialho, C., Banha, F., Anastácio, P., 2016. Factors determining active dispersal capacity of adult Chinese mitten crab Eriocheir sinensis (Decapoda, Varunidae). Hydrobiologia 767, 321-331.

Ficetola, G.F., Miaud, C., Pompanon, F., Taberlet, P., 2008. Species detection using environmental DNA from water samples. Biology Letters 4, 423-425.

Ficetola, G.F., Pansu, J., Bonin, A., Coissac, E., Giguet-Covex, C., De Barba, M., Gielly, L., Lopes, C.M., Boyer, F., Pompanon, F., Rayé, G., Taberlet, P., 2015. Replication levels, false presences and the estimation of the presence/absence from eDNA metabarcoding data. Molecular Ecology Resources 15, 543-556.

Ficetola, G.F., Taberlet, P., Coissac, E., 2016. How to limit false positives in environmental DNA and metabarcoding? Molecular Ecology Resources 16, 604-607.

Figiel, C.R., Bohn, S., 2015. Laboratory experiments for the detection of environmental DNA of crayfish: examining the potential. Freshwater Crayfish 21, 159-163.

Filipová, L., Grandjean, F., Lieb, D., Petrusek, A., 2011. Haplotype variation in the spiny-cheek crayfish Orconectes limosus: colonization of Europe and genetic diversity of native stocks. Journal of North American Benthological Society 30, 871-881.

Filipová, L., Petrusek, A., Matasová, K., Delaunay, C., Grandjean, F., 2013. Prevalence of the crayfish plague pathogen Aphanomyces astaci in populations of the signal crayfish Pacifastacus leniusculus in France: Evaluating the Threat to Native Crayfish. PLoS ONE 8, 1-10. 
Fischer, M.L., Salgado, I., Beninde, J., Klein, R., Frantz, A.C., Heddergott, M., Cullingham, C.I., Kyle, C.J., Hochkirch, A., 2017. Multiple founder effects are followed by range expansion and admixture during the invasion process of the raccoon (Procyon lotor) in Europe. Diversity and Distributions 23, 409-420.

Fitzpatrick, M.C., Preisser, E.L., Ellison, A.M., Elkinton, J.S., 2009. Observer bias and the detection of low-density populations. Ecological Applications 19, 16731679.

Forstmeier, W., Schielzeth, H., Mueller, J., Ellegren, H., Kempenaers, B., 2012. Heterozygosity-fitness correlations in zebra finches: microsatellite markers can be better than their reputation. Molecular Ecology 21, 3237-3249.

Freeman, M., Turnball, J., Yeomans, W., Bean, C., 2010. Prospects for management strategies of invasive crayfish populations with an emphasis on biological control. Aquatic Conservation: Marine and Freshwater Ecosystems 20, 211223.

Freire, M., Genzano, G.N., Neumann-Leitao, S., Perez, C.D., 2014. The nonindigenous medusa Blackfordia virginica (Hydrozoa, Leptothecata) in tropical Brazil: 50 years of unnoticed presence. . Biological Invasions 16, 1-5.

Frings, R.M., Vaeßen, S.C.K., Groß, H., Roger, S., Schüttrumpf, H., 2012. A fishpassable barrier to stop the invasion of non-indigenous crayfish. Biological Conservation 159, 521-529.

Froufe, E., Varandas, S., Teixeira, A., Sousa, R., Filipov á, L., Petrusek, A., Edsman, L., Lopes-Lima, M., 2015. First results on the genetic diversity of the invasive signal crayfish Pacifastacus leniusculus (Dana, 1852) in Europe using novel microsatellite loci. Journal of Applied Genetics 56, 375-380.

Furlan, E.M., Gleeson, D.M., C.M., H., Duncan, R.P., 2016. A framework for estimating the sensitivity of eDNA surveys. Molecular Ecology Resources 16, 641-654.

Gallardo, B., Aldridge, D.C., 2013. The ‘dirty dozen’: socio-economic factors amplify the invasion potential of 12 high-risk aquatic invasive species in Great Britain and Ireland. Journal of Applied Ecology 50, 757-766.

Gallo, T., Waitt, D., 2011. Creating a successful citizen science model to detect and report invasive species. BioScience 61, 459-465. 
Ganoza, C.A., Matthias, M.A., Collins-Richards, D., Brouwer, K.C., Cunningham, C.B., Segura, E.R., Gilman, R.H., Gotuzzo, E., Vinetz, J.M., 2006. Determining risk for severe Leptospirosis by molecular analysis of environmental surface waters for pathogenic Leptospira. PLOS Medicine 3, e308.

García-Berthou, E., Alcaraz, C., Pou-Rovira, Q., Zamora, L., Coenders, G., Feo, C., 2005. Introduction pathways and establishment rates of invasive aquatic species in Europe. Canadian Journal of Fisheries and Aquatic Sciences 62, 453463.

Geerts, A.N., Boets, P., Van den Heede, S., Goethals, P., Van der heyden, C., 2018. A search for standardized protocols to detect alien invasive crayfish based on environmental DNA (eDNA): A lab and field evaluation. Ecological Indicators 84, 564-572.

Gherardi, F., Aquiloni, L., Die'guez-Uribeondo, J., Tricarico, E., 2011. Managing invasive crayfish: is there a hope? Aquatic Sciences 73, 185-200.

Gilbey, V., Attrill, M., Coleman, R., 2008. Juvenile Chinese mitten crabs (Eriocheir sinensis) in the Thames estuary: distribution, movement and possible interactions with the native crab Carcinus maenas. Biological Invasions 10, 67-77.

Giguet-Covex, C., Pansu, J., Arnaud, F., Rey, P-J., Griggo, C., Gielly, L., Domaizon, I., Coissac, E., David, F., Choler, P., Poulenard, J., Taberlet, P., 2014. Long livestock farming history and human landscape shaping revealed by lake sediment DNA. Nature Communications 5, 3211.

Goldberg, C., Strickler, K., Pilliod, D., 2015. Moving environmental DNA methods from concept to practice for monitoring aquatic macroorganisms. Biological Conservation 183, 1-3.

Goldberg, C.S., Turner, C.R., Deiner, K., Klymus, K.E., Thomsen, P.F., Murphy, M.A., Spear, S.F., McKee, A., Oyler-McCance, S.J., Cornman, R.S., 2016. Critical considerations for the application of environmental DNA methods to detect aquatic species. Methods in Ecology and Evolution 7, 1299-1307. 
Gollasch, S., 2010. The Importance of Ship Hull Fouling as a Vector of Species Introductions into the North Sea. The Journal of Bioadhesion and Biofilm Research 18, 105-121.

Goudet, J., 1995. FSTAT (Version 1.2): a computer program to calculate F-statistics. Journal of Heredity 86, 485-486.

Gouin, N., Grandjean, F., Souty-Grosset, C., 2006. Population genetic structure of the endangered crayfish Austropotamobius pallipes in France based on microsatellite variation: biogeographical inferences and conservation implications. Freshwater Biology 51, 1369-1387.

Gozlan, R.E., 2017. Interference of non-native Species with fisheries and aquaculture. Impact of Biological Invasions on Ecosystem Services 12, 119-137.

Gozlan, R.E., St-Hilaire, S., Feist, S.W., Martin, P., Kent, M.L., 2005. Biodiversity: Disease threat to European fish. Nature 435, 1046.

Grason, E.W., McDonald, P.S., Adams, J., Litle, K., Apple, J.K., Pleus, A., 2018. Citizen science program detects range expansion of the globally invasive European green crab in Washington State (USA) Management of Biological Invasions 9, 39-47.

Greenwood, J.J.D., 2007. Citizens, science and bird conservation. Journal of Ornithology 148, 77-124.

Griffiths, S.W., Collen, P., Armstrong, J.D., 2004. Competition for shelter among over-wintering signal crayfish and juvenile Atlantic salmon., In Journal of Fish Biology. pp. 436-447.

Guan, R.-Z., Wiles, P.R., 1999. Growth and reproduction of the introduced crayfish Pacifastacus leniusculus in a British lowland river. Fisheries Research 42, 245 259.

Gurnell, A.M., Downward, S.R., Jones, R., 1994. Channel planform change on the river dee meanders, 1876-1992. River Research and Applications 9, 187-204.

Guy, R.A., Payment, P., Krull, U.J., Horgen, P.A., 2003. Real-time PCR for quantification of Giardia and Cryptosporidium in environmental water samples and sewage. Applied and Environmental Microbiology 69, 5178-5185.

Haddaway, N.R., Wilcox, R.H., Heptonstall, R.E.A., Griffiths, H.M., Mortimer, R.J.G., Christmas, M., Dunn, A.M., 2012. Predatory functional response and 
prey choice identify predation differences between native/invasive and parasitised/unparasitised crayfish. PLOS ONE 7, e32229.

Handley, L.-J.L., Estoup, A., Evans, D.M., Thomas, C.E., Lombaert, E., Facon, B., Aebi, A., Roy, H.E., 2011. Ecological genetics of invasive alien species. BioControl 56, 409-428.

Harper, K.J., Anucha, N.P., Turnbull, J.F., Bean, C.W., Leaver, M.J., 2018. Searching for a signal: Environmental DNA (eDNA) for the detection of invasive signal crayfish, Pacifastacus leniusculus (Dana, 1852). Management of Biological Invasions 9, 137-148.

Havel, J.E., Kovalenko, K.E., Thomaz, S.M., Amalfitano, S., Kats, L.B., 2015. Aquatic invasive species: challenges for the future. Hydrobiologia 750, 147170.

Hayes, K.R., Cannon, R., Neil, K., Inglis, G., 2005. Sensitivity and cost considerations for the detection and eradication of marine pests in ports. Marine Pollution Bulletin 50, 823-834.

Hein, C.L., Roth, B.M., Ives, A.R., Vander Zanden, M.J., 2006. Fish predation and trapping for rusty crayfish (Orconectes rusticus) control: a whole-lake experiment. Canadian Journal of Fisheries and Aquatic Sciences 63, 383-393.

Hein, C.L., Vander Zanden, M.J., Magnuson, J.J., 2007. Intensive trapping and increased fish predation cause massive population decline of an invasive crayfish. Freshwater Biology 52, 1134-1146.

Herborg, L.-M., Rudnick, D.A., Siliang, Y., Lodge, D.M., MacIsaac, H.J., 2007. Predicting the range of Chinese mitten crabs in Europe. Conservation Biology 21, 1316-1323.

Herborg, L.-M., Rushton, S., Clare, A., Bentley, M., 2005. The Invasion of the Chinese Mitten Crab (Eriocheir sinensis) in the United Kingdom and Its Comparison to Continental Europe. Biological Invasions 7, 959-968.

Herborg, L.-M., Rushton, S.P., Clare, A.S., Bentley, M.G., 2003. Spread of the Chinese mitten crab (Eriocheir sinensis, H. Milne Edwards) in continental Europe: analysis of a historical data set. Hydrobiologia 503, 21-28. 
Héritier, L., Verneau, O., Breuil, G., Meistertzheim, A.-L., 2017. The high resolution melting analysis (HRM) as a molecular tool for monitoring parasites of the wildlife. Parasitology 144, 563-570.

Hinlo, R., Gleeson, D., Lintermans, M., Furlan, E., 2017. Methods to maximise recovery of environmental DNA from water samples. PLoS ONE 12, $\mathrm{e} 0179251$.

Hirsch, J.E., 2005. An index to quantify an individual's scientific research output. Proceedings of the National Academy of Sciences of the United States of America 102, 16569-16572.

Hitchings, S.P., Beebee, T.J.C., 1997. Genetic substructuring as a result of barriers to gene flow in urban Rana temporaria (common frog) populations: implications for biodiversity conservation. Heredity 79, 117-127.

Hobbs, H.H., Jass, J.P., Huner, J.V., 1989. A review of global crayfish introductions with particular emphasis on two North American species (Decapoda, Cambaridae). Crustaceana 56, 299-316.

Holdich, D.M., James, J., Jackson, C., Peay, S., 2014. The North American signal crayfish, with particular reference to its success as an invasive species in Great Britain. Ethology, Ecology \& Conservation 26, 232-262.

Holdich, D.M., Lowery, R.S., 1988. Freshwater crayfish: biology, management and exploitation. Croom Helm, London.

Holdich, D.M., Reynolds, J.D., Souty-Grosset, C., Sibley, P.J., 2009. A review of the ever increasing threat to European crayfish from non-indigenous crayfish species. Knowledgement and Management of Aquatic Ecosystems 11, 394395.

Holdich, D.M., Sibley, P.J., Peay, S., 2004. The white-clawed crayfish - a decade on. British Wildlife 15, 153-164.

Honjo, M.N., Minamoto, T., Kawabata, Z., 2012. Reservoirs of Cyprinid herpesvirus 3 (CyHV-3) DNA in sediments of natural lakes and ponds. Veterinary Microbiology 155, 183-190.

Hudina, S., Gali ć, N., Roessink, I., Hock, K., 2011. Competitive interactions between co-occurring invaders: identifying asymmetries between two invasive crayfish species. Biological Invasions 13, 1791-1803. 
Hutchins, P.R., Sepulveda, A.J., Martin, R.M., Hopper, L.R., 2017. A probe-based quantitative PCR assay for detecting Tetracapsuloides bryosalmonae in fish tissue and environmental DNA water samples. Conservation Genetic Resources 1, 1-3.

Huver, J.R., Koprivnikar, J., Johnson, P.T., Whyard, S., 2014. Development and application of an eDNA method to detect and quantify a pathogenic parasite in aquatic ecosystems. Ecological Applications 25, 991-1002.

Huyser de Bernardo, D., Curtis, A., 2012. Using online and paper surveys: the effectiveness of mixed-mode methodology for populations over 50. Research on Aging 35, 220-240.

Ikeda, K., Doi, H., Tanaka, K., Kawai, T., Negishi, J., 2016. Using environmental DNA to detect an endangered crayfish Cambaroides japonicus in streams. Conservation Genetic Resources 8, 231-234.

IUCN, 2017. IUCN Red List of Threatened Species: Austropotamobius pallipes.

Iwasaki, K., 2004. Human-mediated introduction of marine organisms in Japan: a review In Assessment and Control of Biological Invasion Risks. eds F. Koike, M.N. Clout, M. Kawamichi, M.D. Poorter, K. Iwaysuki, pp. 104-112. World Conservation Union (IUCN), Gland, Switzerland.

Jackson, M., Myrholm, C., Shaw, C., Ramsfield, T., 2017. Using nested PCR to improve detection of earthworm eDNA in Canada. Soil Biology and Biochemistry 113, 215-218.

Jaiswal, N., Tripathi, R., Malhotra, S.K., 2017. Accentuated molecular detection technique to segregate and identify helminths of fish through High Resolution Melting (HRM) Single Cell Biology 6, 1-5.

James, J., Nutbeam-Tuffs, S., Cable, J., Mrugała, A., Viñuela-Rodriguez, N., Petrusek, A., Oidtmann, B., 2017. The prevalence of Aphanomyces astaci in invasive signal crayfish from the UK and implications for native crayfish conservation. Parasitology 144, 1-8.

James, J., Slater, F., Cable, J., 2014a. A.L.I.E.N. Databases: Addressing the lack in establishment of non-natives databases. Crustaceana 87, 1192-1199. 
James, J., Slater, F., Vaughan, I., Young, K., Cable, J., 2014b. Comparing the ecological impacts of native and invasive crayfish: could native species' translocation do more harm than good? Oecologia 178, 309-316.

Jane, S.F., Wilcox, T.M., McKelvey, K.S., Young, M.K., Schwartz, M.K., Lowe, W.H., Letcher, B.H., Whiteley, A.R., 2015. Distance, flow and PCR inhibition: eDNA dynamics in two headwater streams. Molecular Ecology Resources 15, 216-227.

Jerde, C.L., Mahon, A.R., Chadderton, W.L., Lodge, D.M., 2011. "Sight-unseen" detection of rare aquatic species using environmental DNA. Conservation Letters 4, 150-157.

Johansson, M.L., Dufour, B.A., Wellband, K.W., Corkum, L.D., MacIsaac, H.J., Heath, D.D., 2018. Human-mediated and natural dispersal of an invasive fish in the eastern Great Lakes. Heredity 120, 533-546.

Johnson, L., Ricciardi, A., Carlton, J., 2001. Overland dispersal of aquatic invasive species: a risk assessment of transient recreational boating. Ecological Applications 11, 1789-1799.

Johnson, P., Olden, J., Vander Zanden, M., 2008. Dam invaders: impoundments facilitate biological invasions into freshwaters. Frontiers in Ecology and the Environment 6, 357-363.

Jones, M., 2013. Environmental DNA: Genetics steps forward when traditional ecological surveys fall short. Fisheries 38, 332-333.

Jordan, R.C., Gray, S.A., Howe, D.V., Brooks, W.R., Ehrenfeld, J.G., 2011. Knowledge gain and behavioral change in citizen science programs. Conservation Biology 25, 1148-1154.

Kerby, J., Riley, S., Kats, L., Wilson, P., 2005. Barriers and flow as limiting factors in the spread of an invasive crayfish (Procambarus clarkii) in southern California streams. Biological Conservation 126, 402-409.

Kirjavainen, J., Sipponen, M., 2004. Environmental benefit of different crayfish management strategies in Finland. Fisheries Management and Ecology 11, 213-218. 
Kirjavainen, J., Westman, K., 1999. Natural history and development of the introduced signal crayfish, Pacifastacus leniusculus, in a small, isolated Finnish lake, from 1968 to 1993. Aquatic Living Resources 12, 387-401.

Kirshtein, J.D., Anderson, C.W., Wood, J.S., Longcore, J.E., Voytek, M.A., 2007. Quantitative PCR detection of Batrachochytrium dendrobatidis DNA from sediments and water. Diseases of Aquatic Organisms 77, 11-15.

Klymus, K., Marshall, N., Stepien, C., 2017. Environmental DNA (eDNA) metabarcoding assays to detect invasive invertebrate species in the Great Lakes. PLoS ONE 12, e0177643.

Klymus, K.E., Richter, C.A., Chapman, D.C., Paukert, C., 2015. Quantification of eDNA shedding rates from invasive bighead carp Hypophthalmichthys nobilis and silver carp Hypophthalmichthys molitrix. Biological Conservation 183, 7784.

Kolar, C.S., Lodge, D.M., 2001. Progress in invasion biology: predicting invaders. Trends in Ecology \& Evolution 16, 199-204.

Kolbe, J.J., Glor, R.E., Rodriguez Schettino, L., Lara, A.C., Larson, A., Losos, J.B., 2004. Genetic variation increases during biological invasion by a Cuban lizard. Nature 431, 177-181.

Kouper, I., 2010. Science blogs and public engagement with science: practices, challenges, and opportunities. Journal of Science Communication 9, 1-10.

Kozubíková, E., Filipová, L., Kozák, P., Ďuriš, Z., Martín, M.P., Diéguez-Urbibeondo, J., Oidtmann, B., Petrusek, A., 2008. Prevalence of crayfish plague pathogen Aphanomyces astaci in invasive American crayfishes in the Czech Republic. Conservation Biology 23, 1204-1213.

Land-Zandstra, A.M., Devilee, J.L.A., Snik, F., Buurmeijer, F., van den Broek, J.M., 2016. Citizen science on a smartphone: participants' motivations and learning. Public Understanding of Science 25, 45-60.

Laramie, M.B., Pilliod, D.S., Goldberg, C.S., 2015. Characterizing the distribution of an endangered salmonid using environmental DNA analysis. Biological Conservation 183, 29-37.

Larson, E., Renshaw, M., Gantz, C., Umek, J., Chandra, S., Lodge, D., Egan, S., 2017. Environmental DNA (eDNA) detects the invasive crayfishes Orconectes 
rusticus and Pacifastacus leniusculus in large lakes of North America. Hydrobiologia 800, 173-185.

Laverty, C., Green, K.D., Dick, J.T.A., Barrios-O'Neill, D., Mensink, P.J., Médoc, V., Spataro, T., Caffrey, J.M., Lucy, F.E., Boets, P., Britton, J.R., Pegg, J., Gallagher, C., 2017. Assessing the ecological impacts of invasive species based on their functional responses and abundances. Biological Invasions 19, 1653-1665.

Leff, L., McArthur, J., Shimkets, L., 1992. Information spiraling: movement of bacteria and their genes in streams. Microbial Ecology 24, 11-24.

Le Roux, J., Wieczorek, A.M., 2008. Molecular systematics and population genetics of biological invasions: towards a better understanding of invasive species management. Annals in Applied Biology 154, 1-17.

Levy-Booth, D.J., Campbell, R.G., Gulden, R.H., Hart, M.M., Powell, J.R., Klironomos, J.N., Pauls, K.P., Swanton, C.J., Trevors, J.T., Dunfield, K.E., 2007. Cycling of extracellular DNA in the soil environment. Soil Biology and Biochemistry 39, 2977-2991.

Lee, C.E., 2002. Evolutionary genetics of invasive species. Trends in Ecology \& Evolution 17, 386-391.

Lee, S.-R., Jo, Y.-S., Park, C.-H., Friedman, J.M., Olson, M.S., 2018. Population genomic analysis suggests strong influence of river network on spatial distribution of genetic variation in invasive saltcedar across the southwestern United States. Molecular Ecology 27, 636-646.

Lemmens, P., Mergeay, J., Vanhove, T., Meester, L., Declerck, S., 2014. Suppression of invasive topmouth gudgeon Pseudorasbora parva by native pike Esox lucius in ponds. Aquatic Conservation: Marine and Freshwater Ecosystems 25, $41-48$

Lennox, R., Choi, K., Harrison, P.M., Paterson, J.E., Peat, T.B., Ward, T.D., Cooke, S.J., 2015. Improving science-based invasive species management with physiological knowledge, concepts, and tools. Biological Invasions 17, 22132227.

Lewis, M.A., Petrovskii, S.V., Potts, J.R., 2016. Stochasticity and invasion dynamics. The mathematics behind biological invasions 44, 211-232. 
Li, Y.-L., Liu, J.-X., 2017. StructureSelector: A web-based software to select and visualize the optimal number of clusters using multiple methods. Molecular Ecology Resources 18, 176-177.

Light, T., 2003. Success and failure in a lotic crayfish invasion: the roles of hydrologic variability and habitat alteration. Freshwater Biology 48, 1886-1897.

Ling, N., 2003. Rotenone - a review of its toxicity and use for fisheries management. Science for Conservation 211, 1-9.

Lintermans, M., 2000. Recolonization by the mountain galaxias Galaxias olidus of a montane stream after the eradication of rainbow trout Oncorhynchus mykiss. Marine and Freshwater Research 51, 799-804.

Liu, Y., Singh, P., Mustapha, A., 2018. Multiplex high resolution melt-curve real-time PCR assay for reliable detection of Salmonella. Food Control 91, 225-230.

Lodge, D.M., Deines, A., Gherardi, F., Yeo, D.C., Arcella, T., Baldridge, A.K., Barnes, M.A., Chadderton, W.L., Feder, J.L., Gantz, C.A., 2012. Global introductions of crayfishes: evaluating the impact of species invasions on ecosystem services. Annual Review of Ecology, Evolution, and Systematics 43, 449-472.

Lodge, D.M., Taylor, C.A., Holdich, D.M., Skurdal, J., 2000. Nonindigenous crayfishes threaten North American freshwater biodiversity: lessons from Europe. Fisheries 25, 7-20.

Lye, G.C., Osbourne, J.L., Park, K.J., Goulson, D., 2012. Using citizen science to monitor Bombus populations in the UK: nesting ecology and relative abundance in the urban environment. Journal of Insect Conservation 16, 697707.

Lymbery, A.J., Morine, M., Kanani, H.G., Beatty, S.J., Morgan, D.L., 2014. Coinvaders: The effects of alien parasites on native hosts. International Journal for Parasitology: Parasites and Wildlife 3, 171-177.

Magnuson, J.J., Benson, B.J., McLain, A.S., 1994. Insights on species richness and turnover from long-term ecological research: fishes in North temperate lakes. American Zoologist 34, 437-451. 
Manni, F., Guérard, E., Heyer, E., 2004. Geographic patterns of (genetic, morphologic, linguistic) variation: how barriers can be detected by "Monmonier's algorithm". Human Biology 76, 173-190.

Marques, M., Banha, F., Aquas, M., Anastácio, P., 2015. Environmental cues during overland dispersal by three freshwater invaders: Eriocheir sinensis, Pacifastacus leniusculus, and Procambarus clarkii (Crustacea, Decapoda). Hydrobiologia 742, 81-93.

Martinou, A., Mancuso, T., Rossi, A.M., 2010. Application of High-Resolution Melting to Large-Scale, High-Throughput SNP Genotyping: A Comparison with the TaqMan® Method. Journal of Biomolecular Screening 15, 623-629.

Marvier, M., Kareiva, P., Neubert, M.G., 2004. Habitat destruction, fragmentation, and disturbance promote invasion by habitat generalists in a multispecies metapopulation. Risk Analysis 24, 869-878.

Mauvisseau, Q., Coignet, A., Delaunay, C., Pinet, F., Bouchon, D., Souty-Grosset, C., 2018. Environmental DNA as an efficient tool for detecting invasive crayfishes in freshwater ponds. Hydrobiologia 805, 163-175.

McMahon, R.F., 2002. Evolutionary and physiological adaptations of aquatic invasive animals: $r$ selection versus resistance. Canadian Journal of Fisheries and Aquatic Sciences 59, 1235-1244.

Miaud, C., Dejean, T., Savard, K., Millery-Vigues, A., Valentini, A., Gaudin, N.C.G., Garner, T.W., 2016. Invasive North American bullfrogs transmit lethal fungus Batrachochytrium dendrobatidis. Biological Invasions 18, 2299-2308.

Minchin, D., 2007. Aquaculture and transport in a changing environment: Overlap and links in the spread of alien biota. Marine Pollution Bulletin 55, 302-313.

Miralles, L., Dopico, E., Delvo-Delva, F., Garcia-Vazquez, E., 2016. Controlling populations of invasive pygmy mussel (Xenostrobus securis) through citizen science and environmental DNA. Marine Pollution Bulletin 110, 127-132.

Mizumoto, H., Urabe, H., Kanbe, T., Fukushima, M., Araki, H., 2018. Establishing an environmental DNA method to detect and estimate the biomass of Sakhalin taimen, a critically endangered Asian salmonid. Limnology 19, 219-227.

Monmonier, M.S., 1973. Maximum-difference barriers: an alternative numerical regionalisation method. Geographical Analysis 5, 245-261. 
Moorhouse, T.P., Macdonald, D.W., 2010. Immigration rates of signal crayfish (Pacifastacus leniusculus) in response to manual control measures.. Freshwater Biology 56, 993-1001.

Moyer, G., D1'az-Ferguson, E., Hill, J., Shea, C., 2014. Assessing Environmental DNA Detection in Controlled Lentic Systems. PLOS ONE 9, 1-9.

Nathan, L.M., Simmons, M., Wegleitner, B.J., Jerde, C.L., Mahon, A.R., 2014. Quantifying environmental DNA signals for aquatic invasive species across multiple detection platforms. Environmental Science \& Technology 48, 12800-12806.

Naue, J., Hansmann, T., Schmidt, U., 2014. High-Resolution Melting of 12S rRNA and Cytochrome b DNA sequences for discrimination of species within distinct European animal families. PLoS ONE 9, e115575.

NBN, 2009. Crayfish (Crustacea; Astacura) data for Britain and Ireland to 2003, Oxfordshire.

NBN, 2015. RISC And ALERT Marine Non-Native Species (Chinese Mitten Crab, Wakame And Carpet Sea Squirt) Records.

Nielsen, K.M., Johnsen, P.J., Bensasson, D., Daffonchio, D., 2007. Release and persistence of extracellular DNA in the environment. Environmental Biosafety Research 6, 37-53.

Nov, O., Arazy, O., Anderson, D., 2011. Technology-mediated citizen science participation: a motivational model Proceedings of the Fifth International AAAI Conference on Weblogd and Social Media 1, 249-256.

O'Hanley, J., Wright, J., Diebel, M., Fedora, M.A., Soucy, C.L., 2013. Restoring stream habitat connectivity: A proposed method for prioritizing the removal of resident fish passage barriers. Journal of Environmental Management 125, 1927.

Olds, B.P., Jerde, C.L., Renshaw, M.A., Li, Y., Evans, N.T., Turner, C.R., Deiner, K., Mahon, A.R., Brueseke, M.A., Shirey, P.D., Pfrender, M.E., Lodge, D.M., Lamberti, G.A., 2016. Estimating species richness using environmental DNA. Ecology and Evolution 6, 4214-4226.

Oidtmann, B., Heitz, E., Rogers, D., Hoffman, R.W., 2002. Transmission of crayfish plague. Diseases of Aquatic Organisms 52, 159-167. 
Olson, Z.H., Briggler, J.T., Williams, R.N., 2012. An eDNA approach to detect eastern hellbenders (Cryptobranchus a. alleganiensis) using samples of water. Wildlife Research 39, 629-636.

Parker, I.M., Simberloff, D., Lonsdale, W., Goodwell, K., Wonham, M., Kareiva, P., Williamson, M.H., Von Holle, B., Moyle, P.B., Byers, J.E., Goldwasser, L., 1999. Impact: toward a framework for understanding the ecological effects of invaders. Biological Invasions 1, 3-19.

Parsons, J., Lukyanenko, R., Wiersma, Y., 2011. Easier citizen science is better. Nature 471, 37.

Peakall, R., Smouse, P., 2006. Genalex 6: genetic analysis in Excel. Population genetic software for teaching and research. Molecular Ecology Notes 6, 288-295.

Peay, S., 2009. Invasive non-indigenous crayfish species in Europe: Recommendations on managing them. Knowledge and Management of Aquatic Ecosystems 3, 394-395.

Peay, S., Hiley, P.D., 2004. A review of crayfish and angling, Unpublished report, Environment Agency, Thames Region, Hatfield.

Peiró, D.F., Almerão, M.P., Delaunay, C., Jussila, J., Makkonen, J., Bouchon, D., Araujo, P.B., Souty-Grosset, C., 2016. First detection of the crayfish plague pathogen Aphanomyces astaci in South America: a high potential risk to native crayfish. Hydrobiologia 781, 181-190.

Peters, J.A., Lodge, D.M., 2013. Habitat, predation, and coexistence between invasive and native crayfishes: prioritizing lakes for invasion prevention. Biological Invasions 15, 2489-2502.

Petrusek, A., Filipová, L., Kozubíková-Balcarová, E., Grandjean, F., 2017. High genetic variation of invasive signal crayfish in Europe reflects multiple introductions and secondary translocations. Freshwater Science 36, 838-850.

Pietramellara, G., Ascher, J., Borgogni, F., Ceccherini, M., Guerri, G., Nannipieri, P., 2009. Extracellular DNA in soil and sediment: fate and ecological relevance. Biology and Fertility of Soils 45, 219-235.

Pilliod, D.S., Goldberg, C.S., Arkle, R.S., Waits, L.P., 2013. Estimating occupancy and abundance of stream amphibians using environmental DNA from filtered 
water samples. Canadian Journal of Fisheries and Aquatic Sciences 70, 11231130.

Pilliod, D.S., Goldberg, C.S., Arkle, R.S., Waits, L.P., 2014. Factors influencing detection of eDNA from a stream-dwelling amphibian. Molecular Ecology Resources 14, 109-116.

Pinder, A., Gozlan, R., Britton, J., 2005. Dispersal of the invasive topmouth gudgeon, Pseudorasbora parva in the UK: a vector for an emergent infectious disease. Fisheries Management and Ecology 12, 411-414.

Pintor, L.M., Sih, A., Bauer, M.L., 2008. Differences in aggression, activity and boldness between native and introduced populations of an invasive crayfish. Oikos 117, 1629-1636.

Pochon, X., Bott, N.J., Smith, K.F., Wood, S.A., 2013. Evaluating detection limits of next-generation sequencing for the surveillance and monitoring of international marine pests. PLOS ONE 8, e73935.

Pocock, M.J.O., Roy, H.E., Preston, C.D., Roy, D.B., 2015. The Biological Records Centre: a pioneer of citizen science. Biological Journal of the Linnean Society $115,475-493$.

Pratt, T., O'Connor, L., Hallett, A., McLaughlin, R., Katopodis, C., Hayes, D., Bergstedt, R., 2009. Balancing aquatic habitat fragmentation and control of invasive species: enhancing selective fish passage at sea lamprey control barriers. Transactions of the American Fisheries Society 138, 652-665.

Prenter, J., Macneil, C., Dick, J.T., Dunn, A.M., 2004. Roles of parasites in animal invasions. Trends in Ecology \& Evolution 19, 385-390.

Prentis, P.J., Wilson, J.R.U., Dormontt, E.E., Richardson, D.M., Lowe, A.J., 2008. Adaptive evolution in invasive species. Trends in Plant Science 13, 299-294.

Price, A.L., Peterson, J.T., 2010. Estimation and modelling of electrofishing capture efficiency for fishes in wadeable warm water streams. North American Journal of Fisheries 30, 481-498.

Pritchard, J.K., Stephens, M., Donnelly, P., 2000. Inference of Population Structure Using Multilocus Genotype Data. Genetics 155, 945-959.

Purcell, C.M., Chabot, C.L., Craig, M.T., Martinez-Takeshita, N., Allen, L.G., Hyde, J.R., 2015. Developing a genetic baseline for the yellowtail amberjack species 
complex, Seriola lalandi sensu lato, to assess and preserve variation in wild populations of these globally important aquaculture species. Conservation Genetics 16, 1475-1488.

Rahel, F., 2013. Intentional Fragmentation as a Management Strategy in Aquatic Systems BioScience 63, 362-372.

Rahel, F., Olden, J., 2008. Assessing the Effects of Climate Change on Aquatic Invasive Species. Conservation Biology 22, 521-533.

Ramalho, R., Anastácio, P., 2015. Factors inducing overland movement of invasive crayfish (Procambarus clarkii) in a ricefield habitat. Hydrobiologia 746, 135146.

Ramón-Laca, A., Gleeson, D., Yockney, I., Perry, M., Nugent, G., Forsyth, D.M., 2014. Reliable discrimination of 10 ungulate species using High Resolution Melting analysis of faecal DNA. PLoS ONE 9, e92043.

Reed, D.H., Frankham, R., 2003. Correlation between fitness and genetic diversity. Conservation Biology 17, 230-237.

Reed, G.H., Kent, J.O., Wittwer, C.T., 2007. High-resolution DNA melting analysis for simple and efficient molecular diagnostics. Pharmacogenomics 8, 597-608.

Rees, H., Maddison, B., Middleditch, D., Patmore, J., Gough, K., 2014. The detection of aquatic animal species using environmental DNA - a review of eDNA as a survey tool in ecology. Journal of Applied Ecology 51, 1450-1459.

Rees, H.C., Gough, K.C., Middleditch, D.J., Patmore, J.R.M., Maddison, B.C., 2015. Applications and limitations of measuring environmental DNA as indicators of the presence of aquatic animals. Journal of Applied Ecology 52, 827-831.

Rhodes, C.P., Holdich, D.M., 1982. Observations on the fecundity of the freshwater crayfish, Austropotamobius pallipes (Lereboullet) in the British Isles. Hydrobiologia 89, 231-236.

Rice, C.J., Larson, E.R., Taylor, C.A., 2018. Environmental DNA detects a rare large river crayfish but with little relation to local abundance. Freshwater Biology $63,443-455$.

Rius, M., Darling, J.A., 2014. How important is intraspecific genetic admixture to the success of colonising populations? Trends in Ecology \& Evolution 29, 233242. 
Robinson, C.V., Uren Webster, T.M., Cable, J., James, J., Consuegra, S., 2018. Simultaneous detection of invasive signal crayfish, endangered whiteclawed crayfish and the crayfish plague pathogen using environmental DNA. Biological Conservation 222, 241-252.

Rödel, M.O., Ernst, R., 2004. Measuring and monitoring amphibian diversity in tropical forests. An evaluation of methods with recommendations for standardisation. Ecotropica 10, 1-14.

Roman, J., Darling, J.A., 2007. Paradox lost: genetic diversity and the success of aquatic invasions. Trends in Ecology \& Evolution 22, 454-464.

Rosewarne, P., Piper, A., Wright, R., Dunn, A., 2013. Do low-head riverine structures hinder the spread of invasive crayfish? Case study of signal crayfish (Pacifastacus leniusculus) movements at a flow gauging weir Management of Biological Invasions 4, 273-282.

Rosewarne, P.J., Mortimer, R.J.G., Newton, R.J., Grocock, C., Wing, C.D., Dunn, A.M., 2016. Feeding behaviour, predatory functional responses and trophic interactions of the invasive Chinese mitten crab (Eriocheir sinensis) and signal crayfish (Pacifastacus leniusculus). Freshwater Biology 61, 426-443.

Rotman, D., Hammock, J., Preece, J., Hansen, D., Boston, C., Bowser, A., He, Y., 2014. Motivations affecting initial and long-term participation in citizen science projects in three countries. iConference 2014, 110-124.

Roussel, J.M., Paillisson, J.M., Tréguier, A., Petit, E., 2015. The downside of eDNA as a survey tool in water bodies. Journal of Applied Ecology 52, 823-826.

Rousset, F., 2008. GENEPOP/'007: a complete re-implementation of the GENEPOP software for Windows and Linux. Mol Ecol Resour 8, 103-106.

Rout, T.M., Thompson, C.J., McCarthy, M.A., 2009. Robust decisions for declaring eradication of invasive species. Journal of Applied Ecology 46, 782-786.

Roy, H.E., Pocock, M.J.O., Preston, C.D., Roy, D.B., Savage, J., 2012. Understanding citizen science and environmental monitoring. Final Report on behalf of UKEOF., eds J.C. Tweddle, L.D. Robinson, pp. 1-170. NERC Centre for Ecology \& Hydrology and Natural History Museum, London, UK. 
Rudnick, D.A., Hieb, K., Grimmer, K.F., Resh, V.H., 2003. Patterns and processes of biological invasion: The Chinese mitten crab in San Francisco Bay. Basic and Applied Ecology 4, 249-262.

Ruesink, J.L., Leniham, H.S., Trimble, A.C., Heiman, K.W., Byers, M.F., Kay, M.C., 2005. Introduction of non-native oysters: ecosystem effects and restoration implications. Annual Review of Ecology, Evolution and Systematics 36, 643689.

Rushbrook, B., 2014. Crayfish Conservation in Hampshire's Chalk Streams.

Ryan, R.L., Kaplan, R., Grese, R.E., 2001. Predicting volunteer commitment in environmental stewardship programmes. Journal of Environmental Planning and Management 44, 629-648.

Saba, G.K., Steinberg, D.K., 2012. Abundance, composition, and sinking rates of fish fecal pellets in the Santa Barbara Channel. Scientific Reports 2, 715-716.

Sandodden, R., Johnsen, S., 2010. Eradication of introduced signal crayfish Pacifastacus leniusculus using the pharmaceutical BETAMAX VET.®. Aquatic Invasions 5, 75-81.

Sansom, B.J., Sassoubre, L.M., 2017. Environmental DNA (eDNA) shedding and decay rates to model freshwater mussel eDNA transport in a river. Environmental Science \& Technology 51, 14244-14253.

Sassoubre, L.M., Yamahara, K.M., Gardner, L.D., Block, B.A., Boehm, A.B., 2016. Quantification of environmental DNA (eDNA) shedding and decay rates for three marine fish. . Environmental Science \& Technology 50, 10456-10464.

Savini, D., Occhipinti-Ambrogi, A., Marchini, A., Tricarico, E., Gherardi, F., Olenin, S., Gollasch, S., 2010. The top 27 animal alien species introduced into Europe for aquaculture and related activities. Journal of Applied Ichthyology 26, 1-7.

Schmidt, R.E., Daniels, R.A., Swift, E.L., Shadis, I.B., 2009. Inferences on the biology of juvenile Chinese mitten crab (Eriocheir sinensis) from exuviae in a Hudson River tributary, New York, USA. Aquatic Invasions 4, 613-617.

Schrimpf, A., Pârvulescu, L., Copilas-Ciocianu, D., Petrusek, A., Schulz, R., 2012. Crayfish plague pathogen detected in the Danube Delta- a potential threat to freshwater biodiversity in southeastern Europe. Aquatic Invasions 7, 503-510. 
Schrimpf, A., Schmidt, T., Schulz, R., 2014. Invasive Chinese mitten crab (Eriocheir sinensis) transmits crayfish plague pathogen (Aphanomyces astaci) Aquatic Invasions 9, 203-209.

Shogren, A.J., Tank, J.L., Andruszkiewicz, E., Olds, B., Mahon, A.R., Jerde, C.L., Bolster, D., 2017. Controls on eDNA movement in streams: Transport, Retention, and Resuspension. Scientific Reports 7.

Sigsgaard, E.E., Carl, H., Møller, P.R., Thomsen, P.F., 2015. Monitoring the nearextinct European weather loach in Denmark based on environmental DNA from water samples. Biological Conservation 183, 46-52.

Silvertown, J., 2009. A new dawn for citizen science. Trends in Ecology \& Evolution 24, 467-471.

Simberloff, D., Gibbons, L., 2004. Now you see them, now you don't! - population crashes of established introduced species. Biological Invasions 6, 161-172.

Simberloff, D., Martin, J.-L., Genovesi, P., Maris, V., Wardle, D.A., Aronson, J., Courchamp, F., Galil, B., García-Berthou, E., Pascal, M., Pyšek, P., Sousa, R., Tabacchi, E., Vilà, M., 2013. Impacts of biological invasions: what's what and the way forward. Trends in Ecology \& Evolution 28, 58-66.

Smart, A., Tingley, R., Weeks, A., van Rooyen, A., McCarthy, M., 2015. Environmental DNA sampling is more sensitive than a traditional survey technique for detecting an aquatic invader. Ecological Applications 25, 19441952.

Smart, A.S., Weeks, A.R., Van Rooyen, A.R., Moore, A., McCarthy, M.A., Tingley, R., 2016. Assessing the cost-efficiency of environmental DNA sampling. Methods in Ecology and Evolution 7, 1291-1298.

Smouse, P.E., Waples, R.S., Tworek, J.A., 2011. A genetic mixture analysis for use with incomplete source population data. Canadian Journal of Fisheries and Aquatic Sciences 47, 620-634.

Spear, S.F., Groves, J.D., Williams, L.A., Waits, L.P., 2015. Using environmental DNA methods to improve detectability in a hellbender (Cryptobranchus alleganiensis) monitoring program. Biological Conservation 183, 38-45. 
Spencer, K.L., Cundy, A.B., Croudace, I.W., 2003. Heavy metal distribution and earlydiagenesis in salt marsh sediments from the Medway Estuary, Kent, UK. Estuarine, Costal and Shelf Science 57, 43-54.

Spikmans, F., van Tongeren, T., van Alen, T.A., van der Velde, G., Op den Camp, H.J.M., 2013. High prevalence of the parasite Sphaerothecum destruens in the invasive topmouth gudgeon Pseudorasbora parva in the Netherlands, a potential threat to native freshwater fish Aquatic Invasions 8, 355-360.

Stockton-Fiti, K.A., Moffitt, C.M., 2017. Safety and efficacy of Virkon® aquatic as a control tool for invasive Molluscs in aquaculture. Aquaculture 480, 71-76.

Szkuta, B., Oorschot, R.A.H.V., Ballantyne, K.N., 2017. DNA decontamination of fingerprint brushes. Forensic Science International 277, 41-50.

Strand, D.A., Jussila, J., Johnsen, S.I., Viljamaa-Dirks, S., Edsman, L., Wiik-Nielsen, J., Viljugrein, H., Engdahl, F., Vrålstad, T., 2014. Detection of crayfish plague spores in large freshwater systems. Journal of Applied Ecology 51, 544-553.

Strauss, A., White, A., Boots, M., 2012. Invading with biological weapons: the importance of disease-mediated invasions. Functional Ecology 26, 1249-1261.

Sullivan, B.L., Aycrigg, J.L., Barry, J.H., Bonney, R.E., Bruns, N., Cooper, C.B., Damoulas, T., Dhondt, A.A., Dietterich, T., Farmsworth, A., Fink, D., Fitzpatrick, J.W., Fredericks, T., Gerbracht, J., Gomes, C., Hochachka, W.M., Iliff, M.J., Lagoze, C., La Sorte, F.A., Merrifield, M., Morris, W., Phillips, T.B., Reynolds, M., Rodewald, A.D., Rosenberg, K.V., Trautmann, N.M., Wiggins, A., Winkler, D.W., Wong, W.-K., Wood, C.L., Yu, J., Kelling, S., 2014. The eBird enterprise: An integrated approach to development and application of citizen science. Biological Conservation 169, 31-40.

Svoboda, J., Strand, D.A., Vrålstad, T., Grandjean, F., Edsman, L., Koz ák, P., Kouba, A., Fristad, R.F., Koca, A.B., Petrusek, A., 2014. The crayfish plague pathogen can infect freshwater-inhabiting crabs. Freshwater Biology 59, 918-929.

Szücs, M., Melbourne, B.A., Tuff, T., Weiss-Lehman, C., Hufbauer, R.A., 2017. Genetic and demographic founder effects have long-term fitness consequences for colonising populations. Ecology Letters 20, 436-444.

Taberlet, P., Bonin, A., Zinger, L., Coissac, E., 2018. Workflow in eDNA studies and main methods used. Oxford University Press, Oxford, UK. 
Taberlet, P., Coissac, E., Hajibabaei, M., Rieseberg, L.H., 2012a. Environmental DNA. Molecular Ecology 21, 1789-1793.

Taberlet, P., Coissac, E., Pompanon, F., Brochmann, C., Willerslev, E., 2012b. Towards next-generation biodiversity assessment using DNA metabarcoding. Molecular Ecology 21, 2045-2050.

Taberlet, P., Waits, L.P., Luikart, G., 1999. Noninvasive genetic sampling: look before you leap. Trends in Ecology \& Evolution 14, 323-327.

Takahara, T., Minamoto, T., Doi, H., 2013. Using Environmental DNA to estimate the distribution of an invasive fish species in ponds. PLoS ONE 8, e56584.

Taylor, A.T., Papeş, M., Long, J.M., 2018. Incorporating fragmentation and nonnative species into distribution models to inform fluvial fish conservation. Conservation Biology 32, 171-182.

Thomsen, P., Kielgast, J., Iversen, L.L., Wiuf, C., Rasmussen, M., Gilbert, M.T.P., Orlando, L., Willerslev, E., 2012. Monitoring endangered freshwater biodiversity using environmental DNA. Molecular Ecology 21, 2565-2573.

Thomsen, P.F., Willerslev, E., 2015. Environmental DNA - An emerging tool in conservation for monitoring past and present biodiversity. Biological Conservation 183, 4-18.

Tillotson, M.D., Kelly, R.P., Duda, J.J., Hoy, M., Kralj, J., Quinn, T.P., 2018. Concentrations of environmental DNA (eDNA) reflect spawning salmon abundance at fine spatial and temporal scales. Biological Conservation 220, 111.

Tilmans, M., Mrugała, A., Svoboda, J., Engelsma, M.Y., Petie, M., Soes, D.M., Nutbeam-Tuffs, S., Oidtmann, B., Roessink, I., Petrusek, A., 2014. Survey of the crayfish plague pathogen presence in the Netherlands reveals a new Aphanomyces astaci carrier. Journal of Invertebrate Pathology 120, 74-79.

Torres, E., Álvarez, F., 2012. Genetic variation in native and introduced populations of the red swamp crayfish Procambarus clarkii (Girard, 1852) (Crustacea, Decapoda, Cambaridae) in Mexico and Costa Rica. REABIC 7, 235-241.

Townsend, C., Crowl, T., 1991. Fragmented Population Structure in a Native New Zealand Fish: An Effect of Introduced Brown Trout? Oikos 61, 347-354. 
Trebitz, A.S., Hoffman, J.C., Darling, J.A., Pilgrim, E.M., Kelly, J.R., Brown, E.A., Chadderton, W.L., Egan, S.P., Grey, E.K., Hashsham, S.A., Klymus, K.E., Mahon, A.R., Ram, J.L., Schultz, M.T., Stepien, C.A., Schardt, J.C., 2017. Early detection monitoring for aquatic non-indigenous species: Optimizing surveillance, incorporating advanced technologies, and identifying research needs. Journal of Environmental Management 202, 229-310.

Tréguier, A., Paillisson, J.-M., Dejean, T., Valentini, A., Schlaepfer, M., Roussel, J.M., 2014. Environmental DNA surveillance for invertebratespecies: advantages and technical limitations todetect invasive crayfish Procambarus clarkii infreshwater ponds. Journal of Applied Ecology 51, 871-879.

Treguier, A., Paillisson, J.M., Dejean, T., Valentini, A., Schlaepfer, M.A., Roussel, J.M., 2014. Environmental DNA surveillance for invertebrate species: advantages and technical limitations to detect invasive crayfish Procambarus clarkii in freshwater ponds. Journal of Applied Ecology 51, 871-879.

Trombulak, S., Frissell, C., 2000. Review of Ecological Effects of Roads on Terrestrial and Aquatic Communities. Conservation Biology 14, 18-30.

Tucker, A.J., Chadderton, L., Jerde, C.L., Renshaw, M.A., Uy, K.L., Gantz, C.A., Mahon, A.R., Bowen, A., Strakosh, T., Bossenbroek, J.M., Sieracki, J.L., Beletsky, D., Bergner, J., Lodge, D.M., 2016. A sensitive environmental DNA (eDNA) assay leads to new insights on Ruffe (Gymnocephalus cernua) spread in North America. Biological Invasions 18, 3205-3222.

Tulloch, A.I.T., Possingham, H.P., Joseph, L.N., Szabo, J., Martin, T.G., 2013. Realising the full potential of citizen science monitoring programs. Biological Conservation $165,128-138$.

Turner, C., Uy, K., Everhart, R., 2015. Fish environmental DNA is more concentrated in aquatic sediments than surface water. Biological Conservation 183, 93-102.

Turner, M.J., Schaeffer, J.M., 1989. Mode of action of Ivermectin. Springer-Verlag, Berlin.

Uller, T., Leimu, R., 2011. Founder events predict changes in genetic diversity during human-mediated range expansions. Global Change Biology 17, 3478-3485.

Unestam, T., 1966. Studies on the crayfish plague fungus Aphanomyces astaci. Physiologia Plantarum 19, 1110-1119. 
van der Velde, T., Milton, D.A., Lawson, T.J., Wilcox, C., Lansdell, M., Davis, G., Perkins, G., Hardesty, B.D., 2017. Comparison of marine debris data collected by researchers and citizen scientists: Is citizen science data worth the effort? Biological Conservation 208, 127-138.

van der Wal, R., Sharma, N., Mellish, C., Robinson, A., Siddharthan, A., 2016. The role of automated feedback in training and retaining biological recorders for citizen science. Conservation Biology 30, 550-561.

Van Leeuwen, C., Huig, N., Van der Velde, G., Van Allen, T., Wagemaker, C., Sherman, C., Klaassen, M., Figuerola, J., 2013. How did this snail get here? Several dispersal vectors inferred for an aquatic invasive species. Freshwater Biology 58, 88-99.

Van Oosterhout, C., Hutchinson, W.F., Wills, D.P.M., Shipley, P., 2004. MICROCHECKER: software for identifying and correcting genotyping errors in microsatellite data. Molecular Ecology Notes 4, 535-538.

Vander Zanden, M.J., Hansen, G.J., Higgins, S.N., Kornis, M.S., 2010. A pound of prevention, plus a pound of cure: early detection and eradication of invasive species in the Laurentian Great Lakes. Journal of Great Lakes Research 36, 199-205.

Vander Zanden, M.J., Olden, J.D., 2008. A management framework for preventing the secondary spread of aquatic invasive species. Canadian Journal of Fisheries and Aquatic Sciences 65, 1512-1522.

Vanschoenwinkel, B., Gielen, S., Vandewaerde, H., Seaman, M., Brendonck, L., 2008. Relative importance of different dispersal vectors for small aquatic invertebrates in a rock pool metacommunity. Ecography: Pattern and Process in Ecology 31, 567-577.

Veldhuizen, T.C., 2001. Life History, distribution, and impacts of the Chinese mitten crab, Eriochelr sinensis. . Aquatic Invaders 12, 24410-24427.

Vilà, M., Basnou, C., Pyšek, P., Josefsson, M., Genovesi, P., Gollasch, S., Nentwig, W., Olenin, S., Roques, A., Roy, D., Hulme, P., 2010. How well do we understand the impacts of alien species on ecosystem services? A panEuropean, cross-taxa assessment. Frontiers in Ecology and the Environment 8, 135-144. 
Vilcinskas, A., 2015. Pathogens as biological weapons of invasive species. PLOS Pathogens 11, e1004714.

Vossen, R.H.A.M., Aten, E., Roos, A., den Dunnen, J.T., 2009. High-Resolution Melting Analysis (HRMA)-More than just sequence variant screening. Human Mutation 30, 860-866.

Vrålstad, T., Knutsen, A., Tengs, T., Holst-Jensen, A., 2009. A quantitative TaqMan MGB real-time polymerase chain reaction based assay for detection of the causative agent of crayfish plague Aphanomyces astaci. Veterinary Microbiology 137, 146-155.

Walker, D.M., Leys, J.E., Dunham, K.E., Oliver, J.C., Schiller, E.E., Stephenson, K.S., Kimrey, J.T., Wooten, J., Rogers, M.W., 2017. Methodological considerations for detection of terrestrial small-body salamander eDNA and implications for biodiversity conservation. Molecular Ecology Resources 17, 1223-1230.

Westman, K., Savolainen, R., Julkunen, M., 2002. Replacement of the native crayfish Astacus astacus by the introduced species Pacifastacus leniusculus in a small, enclosed Finnish lake: a 30-year study. Ecography 25, 53-73.

Willerslev, E., Hansen, A.J., Binladen, J., Brand, T.B., Gilbert, M.T.P., Shapiro, B., Bunce, M., Wiuf, C., Gilichinsky, D.A., Cooper, A., 2003. Diverse plant and animal genetic records from Holocene and Pleistocene sediments. Science 300, 791-795.

Wilson, C.C., Wozney, K.M., Smith, C.M., 2016. Recognizing false positives: synthetic oligonucleotide controls for environmental DNA surveillance. Methods in Ecology and Evolution 7, 23-29.

Winfield, I., Fletcher, J., James, J., 2011. Invasive fish species in the largest lakes of Scotland, Northern Ireland, Wales and England: the collective UK experience. Hydrobiologia 660, 93-103.

Wittwer, C., Stoll, S., Strand, D., Vrålstad, T., Nowak, C., Thines, M., 2018. eDNAbased crayfish plague monitoring is superior to conventional trap-based assessments in year-round detection probability. Hydrobiologia 807, 87-97.

Wittwer, C.T., 2009. High-resolution DNA melting analysis: advancements and limitations. Human Mutation 30, 857-859. 
Wood, S.A., Smith, K.F., Banks, J.C., Tremblay, L.A., Rhodes, L., Mountfort, D., Cary, S.C., Pochon, X., 2013. Molecular genetic tools for environmental monitoring of New Zealand's aquatic habitats, past, present and the future. New Zealand Journal of Marine and Freshwater Research 47, 90-119.

Wozney, K.M., Wilson, C.C., 2017. Quantitative PCR multiplexes for simultaneous multispecies detection of Asian carp eDNA. Journal of Great Lakes Research 43, 771-776.

Wright, D.R., Underhill, L.G., Keene, M., Knight, A.T., 2015. Understanding the motivations and satisfactions of volunteers to improve the effectiveness of citizen science programs. Society \& Natural Resources 28, 1013-1029.

Wye \& Usk Foundation, 2012. The Tubney Charitable Trust.

Yang, S., Ramachandran, P., Rothman, R., Hsieh, Y.-H., Hardick, A., Won, H., Kecojevic, A., Jackman, J., Gaydos, C., 2009. Rapid identification of biothreat and other clinically relevant bacterial species by use of Universal PCR coupled with High-Resolution Melting Analysis. Journal of Clinical Microbiology 47, 2252-2255.

Ye, J., McGinnis, S., Madden, T.L., 2006. BLAST: improvements for better sequence analysis. Nucleic Acids Research 34, 6-9.

Yue, G.H., Li, J., Bai, Z., Wang, C.M., Feng, F., 2010. Genetic diversity and population structure of the invasive alien red swamp crayfish. Biological Invasions 12, 2697-2706.

Zaiko, A., Minchin, D., Olenin, S., 2014. " The day after tomorrow": anatomy of an 'r'strategist aquatic invasion. Aquatic Invasions 9, 145-155.

Zalewski, A., Michalska-Parda, A., Bartoszewicz, M., Kozakiewicz, M., Brzezi ński, M., 2010. Multiple introductions determine the genetic structure of an invasive species population: American mink Neovison vison in Poland. Biological Conservation 143, 1355-1363.

Zenetos, A., Koutsogiannopoulos, D., Ovalis, P., Poursanidis, D., 2013. The role played by citizen scientists in monitoring marine alien species in Greece. Cahiers de Biologie Marine 54, 419-426. 